\title{
WestVirginiaUniversity
}

THE RESEARCH REPOSITORY @ WVU

Graduate Theses, Dissertations, and Problem Reports

2020

\section{Avian and salamander response to young forest management in West Virginia}

\author{
Eric L. Margenau \\ West Virginia University
}

Follow this and additional works at: https://researchrepository.wvu.edu/etd

Part of the Forest Management Commons, Other Ecology and Evolutionary Biology Commons, and the Terrestrial and Aquatic Ecology Commons

\section{Recommended Citation}

Margenau, Eric L., "Avian and salamander response to young forest management in West Virginia" (2020). Graduate Theses, Dissertations, and Problem Reports. 7945.

https://researchrepository.wvu.edu/etd/7945

This Dissertation is protected by copyright and/or related rights. It has been brought to you by the The Research Repository @ WVU with permission from the rights-holder(s). You are free to use this Dissertation in any way that is permitted by the copyright and related rights legislation that applies to your use. For other uses you must obtain permission from the rights-holder(s) directly, unless additional rights are indicated by a Creative Commons license in the record and/ or on the work itself. This Dissertation has been accepted for inclusion in WVU Graduate Theses, Dissertations, and Problem Reports collection by an authorized administrator of The Research Repository @ WVU.

For more information, please contact researchrepository@mail.wvu.edu. 


\title{
AVIAN AND SALAMANDER RESPONSE TO YOUNG FOREST MANAGEMENT IN WEST VIRGINIA
}

\author{
Eric L. Margenau
}

\begin{abstract}
Dissertation submitted
to the Davis College of Agriculture, Natural Resources, and Design

at West Virginia University

in partial fulfillment of the requirements for the degree of

Doctor of Philosophy in

Natural Resource Science
\end{abstract}

Petra B. Wood, Ph.D., Chair

Donald J. Brown, Ph.D.

Christopher T. Rota, Ph.D.

Christopher W. Ryan, Ph.D.

Michael P. Strager, Ph.D.

Division of Forestry and Natural Resources,

Wildlife and Fisheries Resources Program

Morgantown, West Virginia

2020

Keywords: young forest management, energy corridors, wildlife openings, intact forest, avian community, salamander community

Copyright 2020 Eric L. Margenau 


\title{
ABSTRACT \\ Avian and salamander response to young forest management in West Virginia
}

\author{
Eric L. Margenau
}

This dissertation focuses on the effects of various young forest habitat management techniques on the avian and salamander community in West Virginia. Wildlife species associated with the nascent stage of forest succession are experiencing precipitous population declines throughout much of the eastern United States due to decreases in the amount of young forest area which have been brought on by changes in disturbance regimes over the past century. As a result, the need to find novel approaches for creating young forest habitats to sustain young forest wildlife populations is necessary. However, young forest habitat creation often negatively affects species that are considered disturbance-avoidant. As a result, I assessed the tradeoffs between creating young forest habitat for disturbance-associated species with the potential negative effects of reducing habitat suitability for disturbance-avoidant species throughout this dissertation. In Chapter 1, I summarize how historical land use practices in West Virginia have created current young forest conditions and the effects that these conditions have had on wildlife species that are specialized in exploiting young forest areas. I also introduce the study sites where this research was conducted and provide chapter objectives and topics of this dissertation.

The recent proliferation of linear energy infrastructure throughout the central Appalachian region has prompted managers to explore ways of managing the young forest bird community in association with these long, linear openings but little empirical data exist. At the same time, forest interior songbirds and woodland salamanders are often negatively affected by energy infrastructure within forest dominated landscapes and any young forest management in these landscapes may further degrade habitats for forest interior species. In chapter 2 we studied how harvest size $(15 \mathrm{~m}, 30 \mathrm{~m}$, and $45 \mathrm{~m}$ wide $)$ and intensity $\left(14 \mathrm{~m}^{2} / \mathrm{ha}\right.$ and $4.5 \mathrm{~m}^{2} /$ ha residual basal area) of cut-back borders, which are linear tree cuttings adjacent to gas/oil pipeline and utility powerline rights-of-way (ROWs) or wildlife openings, influenced habitat suitability along ROWs and wildlife openings for the young forest and forest interior communities. The objectives of this chapter were to examine whether the implementation of cut-back borders increased habitat suitability for wildlife species and which cut-back border treatments optimized the tradeoff between maximizing positive responses of disturbance-dependent species (i.e., young forest species) while minimizing negative responses of disturbance-avoidant species (i.e., forest interior species). We found that young forest species' abundances and species richness increased one-year and two-years after treatment, particularly in the 15-m wide borders, likely due to the increase of young forest habitat in conjunction with existing habitat in ROW corridors or wildlife openings. Additionally, we found that forest interior songbirds and woodland salamander, groups that are often negatively affected by ROWs in forested landscapes, did not decrease in cut-back borders following treatment likely because the retention of canopy trees in combination with adjacent mature forests retained suitable habitat conditions. These results suggest that cut-back 
borders along abrupt forest edges of ROWs and wildlife openings create suitable habitat conditions for young forest avifauna without negatively affecting forest interior avifauna. Cutback borders, particularly those 15-m in width, appear to be a viable management option for managing forest bird communities in ROW and wildlife opening landscapes.

Due to the prominence of commercial logging as a means to create young forest habitat, forests of low- or poor-quality stocking are often overlooked and thus limit options for management and conservation of young forest wildlife species. In order to promote habitat for young forest wildlife species, more opportunities for creating young forest habitat via forest management are greatly needed. In chapter 3 we assessed three non-commercial young forest management treatments (clearcut-and-leave [CL], clearcut-and-windrow [CW], and hack-and-spray [HS]) for promoting young forest habitat. Similar to Chapter 2, the objectives of this chapter were to examine whether the non-commercial young forest management treatments increased habitat suitability for young forest wildlife species and to determine which treatments optimized the tradeoff between maximizing positive responses of disturbance-dependent species and minimizing negative responses of disturbance-avoidant species. Additionally, we included a cost-benefit analysis to quantify the tradeoffs between maximizing songbird richness (cavity nesting guild, forest gap habitat guild, forest interior habitat guild, and young forest habitat guild) and minimizing cost of forest management. Implementation of regeneration treatments induced a dichotomous response from the avian community. Young forest songbird species responded positively to the CL treatment and negatively to the HS treatment, while forest interior songbirds responded positively to the HS treatment and negatively to the CL treatment. Eastern red-backed salamander (Plethodon cinereus), a terrestrial salamander most suited to forest interiors, responded positively to the HS treatment immediately following treatment. Based on our cost-benefit analysis, the CL treatment was the optimum treatment for maximizing songbird species richness and minimizing cost of habitat management followed by the control, the HS treatment, and the $\mathrm{CW}$ treatment. These results suggest that non-commercial forest management can provide suitable habitat conditions for young forest songbirds but can negatively affect forest interior songbirds, while other treatments retain suitable habitat conditions for forest interior species but do not provide immediate suitable habitat for young forest species.

Land managers must be able to assess the influence of habitat features across multiple spatial scales when developing management plans. Stand-level habitat management measures are often thought to have the most profound effect on species presence, but broader spatial habitat features may limit the effectiveness of local-level management if not fully considered. In chapter 4, we assessed the influence of local- (100-m radius surrounding point counts) and landscape-level (500-m radius) habitat features on the forest songbird community in cut-back borders along rights-of-way (ROWs) and wildlife openings. We examined four local-level variables (standlevel canopy cover, proportion of maintained early-successional habitat, proportion of young forest/shrubland habitat, and ROW/wildlife opening width) and five landscape-level variables (proportion of young forest/shrubland, core forest, and mature forest and distance to and size of 
nearest young forest/shrubland patch) to determine which variables had the strongest influence on species abundances and guild richness in cut-back borders. Landscape-level variables had the strongest influence on abundances and richness of young forest, forest gap, forest interior, and conservation priority species. Distance to nearest young forest/shrubland patch negatively influenced abundances of Carolina wren, eastern towhee, and hooded warbler (i.e., abundance increased with decreasing distance to nearest young forest/shrubland patch), and positively influenced abundance of ovenbird. Size of nearest young forest/shrubland patch positively influenced common yellowthroat abundance, and negatively influenced black-and-white warbler and indigo bunting abundances. Proportion of young forest/shrubland habitat at the landscapelevel positively influenced mature forest-associated species black-and-white warbler, cerulean warbler, and hooded warbler as well as the species of conservation priority guild. No local-level variables strongly influenced abundance or richness in cut-back borders. These results indicate that within forest dominated landscapes, cut-back borders located closer to pre-existing young forest/shrubland patches benefit young forest species while size of nearest young forest/shrubland patch is likely species-specific. For mature forest species, presence of young forest/shrubland area at the landscape level appears to increase abundances in cut-back borders.

The focus of this dissertation has been on implementing novel young forest management techniques and evaluating their effects on the forest fauna. Our results indicate that young forest management techniques generally benefitted young forest birds but their effects on forest interior songbirds and woodland salamanders varied. Future implementation of young forest management should consider the tradeoffs between maximizing positive responses of the young forest community while minimizing negative responses of the forest interior community in order to develop broad ecosystem-based management strategies for wildlife communities. 


\section{ACKNOWLEDGEMENTS}

There are many people that have helped make this project a success and guided me along my journey. I would first and foremost like to thank my advisor, Dr. Petra Wood. Petra has been a source of guidance and wisdom throughout my time at WVU. She has provided me with the freedom and independence to pursue my interests as they related to this project and has been invaluable in my growth as a researcher. I would also like to thank Dr. Donald Brown, Dr. Chris Rota, Dr. Chris Ryan, and Dr. Mike Strager for agreeing to serve on my graduate advisory committee, their help and expertise throughout this project, and helpful feedback on my dissertation.

Funding for the bird portion of this project was provided through the Pittman-Robertson Wildlife Restoration Act Grant 48-R. I would like to thank the West Virginia Division of Natural Resources for funding and housing, and the many personnel that assisted in logistics, data collection, or anything else that was needed during this project. I would like to thank Gary Foster, Dr. Chris Ryan, Keith Krantz, and Mike Peters for coordinating this project. Much praise should go to DNR biologists and wildlife managers for their help coordinating field visits, assisting with data collection, knowledge of study sites, and general help; they include Holly Morris, Rich Rogers, Steve Rauch, Todd Dowdy, Alan Shipley, Craig McDougal, Delbert Vandevander, Jordan Stackpole, Josh Vance, Justin Philips, Larry Hines, Lee Strawn, Mark Richardson, Michael McKewen, Thomas Pratt, Tom Hardman, and Tom Stark. Other DNR and related field personnel who assisted with breeding songbird surveys include Rich Bailey, Katie Loucks, Steve Wilson, Tiffany Beachy, and Jesse Reese. DNR foresters played a vital role in timber cruising field sites for preparation prior to contractors and includes Josh Simons, Steve Stasny, and Tyler Nutter.

Wildlife Management Institute personnel Pat Ruble and Mark Banker assisted with coordinating site visits and managing bid packages for logging companies. Lumber for coverboards used in salamander sampling was provided by Dennis Phillips Sawmill. Non-field personnel were vital in helping with this project; from assisting with hiring technicians, providing GIS data and infield resources; they include Becky Nestor (WVU Cooperative Research Unit), Tammie Thompson (WVDNR), Chris George (WVDNR), and Jeremy Rowan (WVDNR). Additional WVU personnel who helped on a variety of topics include Dr. David DeVallance, Dr. Greg Dahle, Dr. Pat Mazik, and Dr. Stuart Welsh. I would also like to thank my fellow Wood lab members Dr. Gretchen Nareff, Hannah Clipp, Dr. Jim Sheehan, Dr. Laura Farwell, Lincoln Oliver, Dr. Mack Frantz, and Sara Crayton for their help and support.

I would like to thank the many field technicians that endured inclement weather, and steep and muddy terrain to assist me with my dissertation research. They were vital for this project helping with data collection, data entry, and generally keeping me sane during the field season, these data would not have been possible without their help. They include Allison Melcher, Bethany Darby, Bill Pence, Claudia Winters, Devin Hoffer, Erin Smith, Haley Snyder, Jeffrey Roth, Jennifer 
Janes, Katelyn Horn, Lauren Stollings, Lydia Stiffler, Matt Hardy, Meredith Lewis, Saahirah Cue, Sara Crayton, and Stuart Robertson. 


\section{TABLE OF CONTENTS}

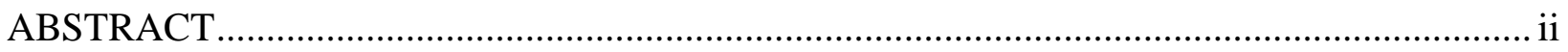

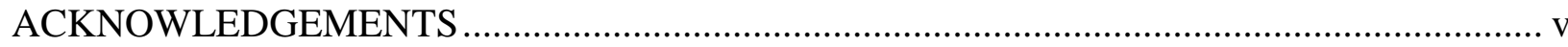

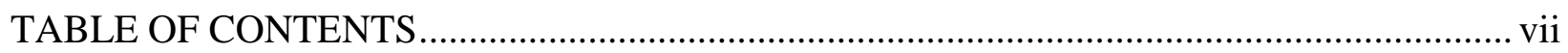

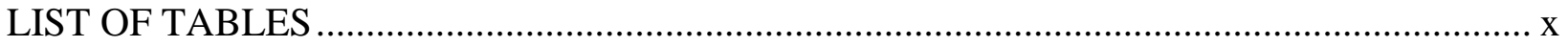

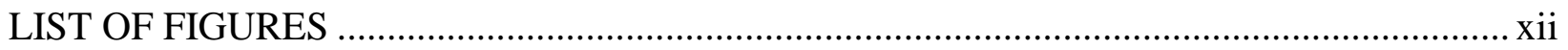

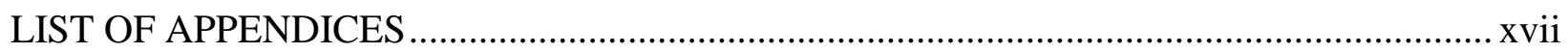

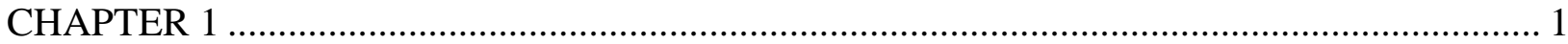

1. Young forests in West Virginia and the Appalachian Region.................................................. 1

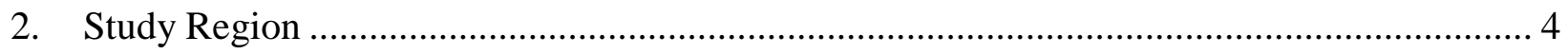

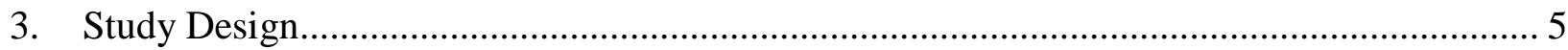

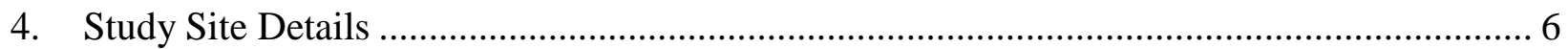

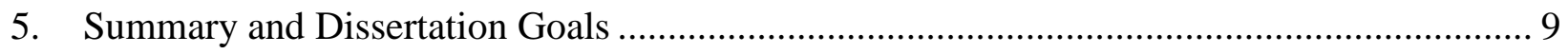

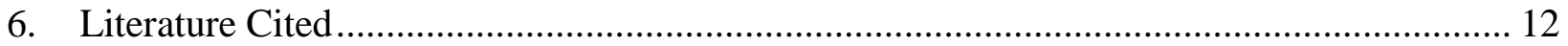

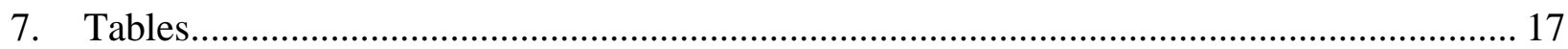

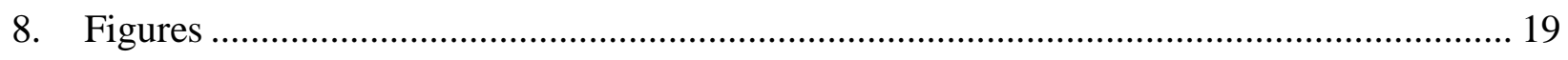

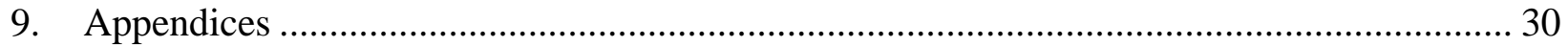

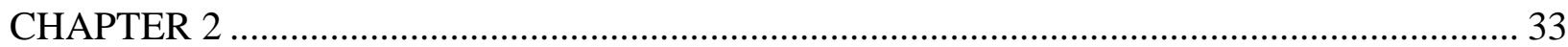

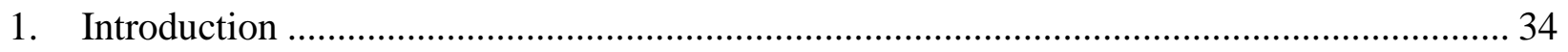

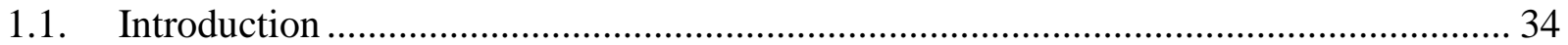

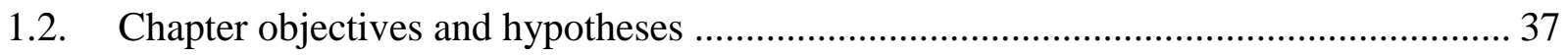

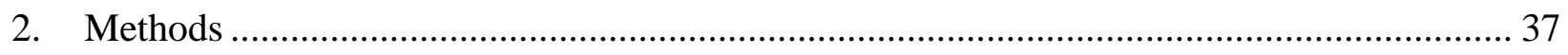

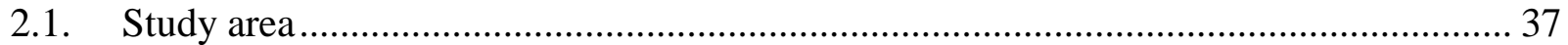

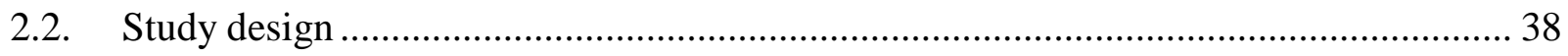

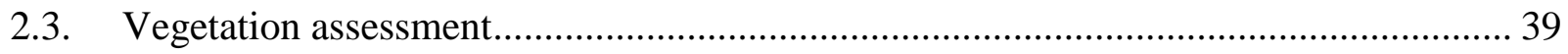

2.4. Avian sampling .................................................................................................. 42

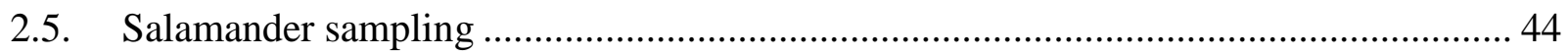

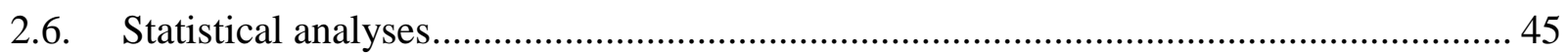

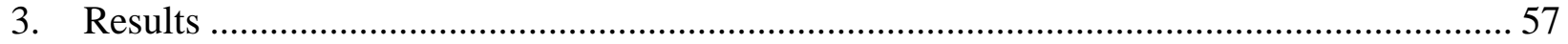


3.1. Topographic effects on vegetation regeneration in cut-back borders ........................ 57

3.2. Ruffed grouse and American woodcock response to cut-back borders ..................... 58

3.3. Focal songbird response to cut-back borders ........................................................ 58

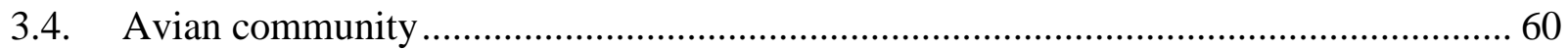

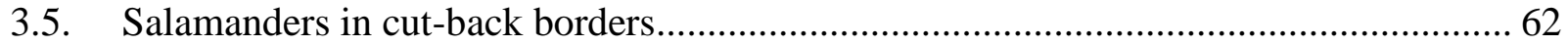

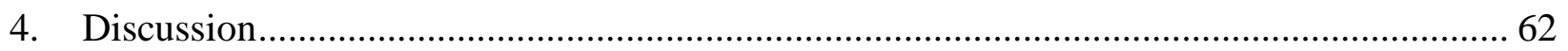

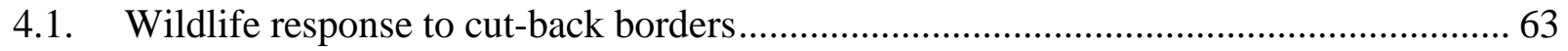

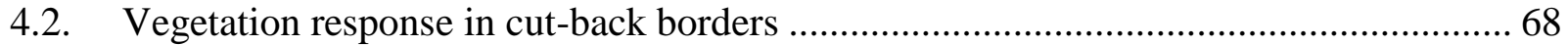

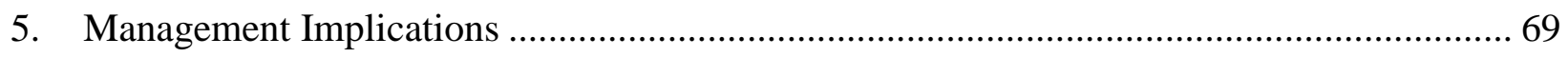

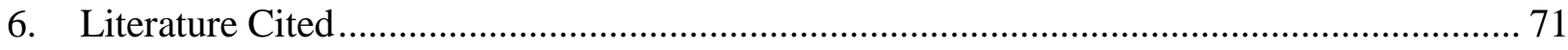

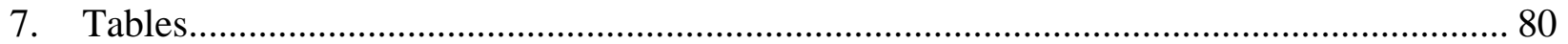

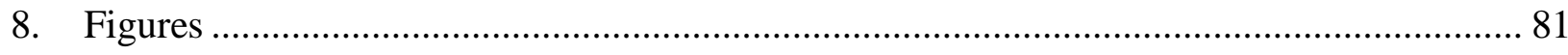

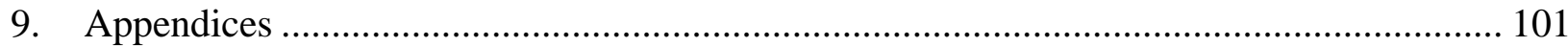

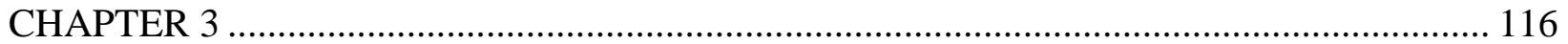

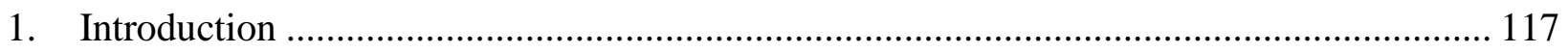

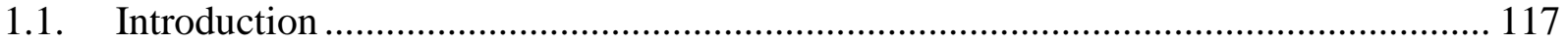

1.2. Chapter objectives and hypotheses .............................................................. 119

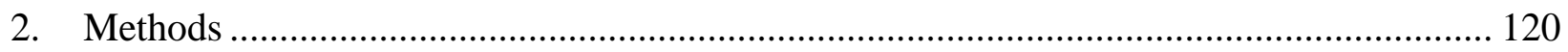

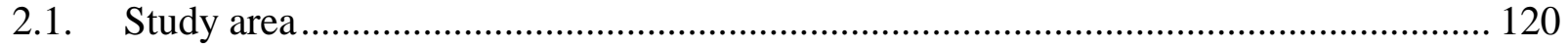

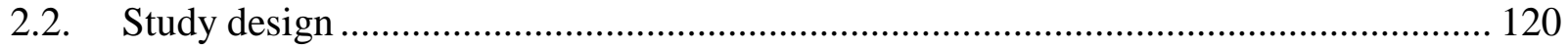

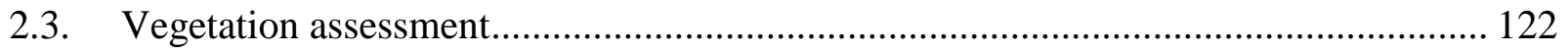

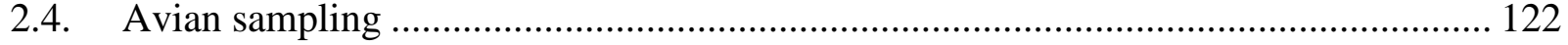

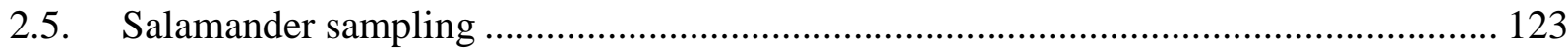

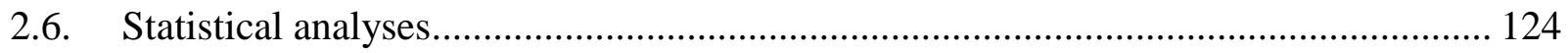

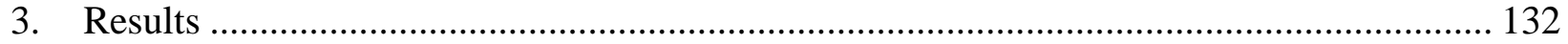

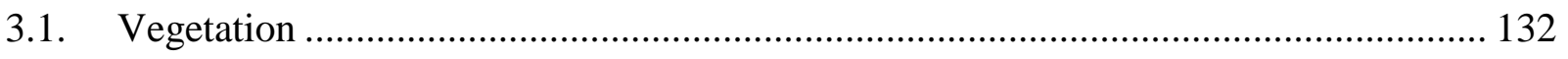

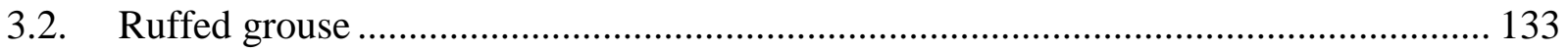

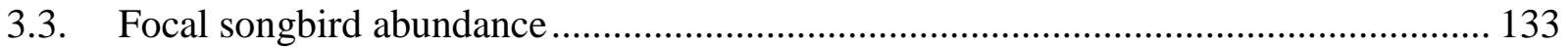

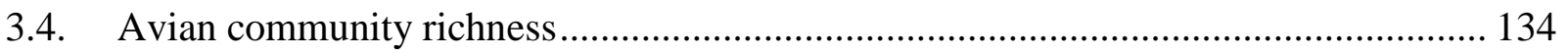

3.5. Salamander relative abundance and body condition index ................................... 134

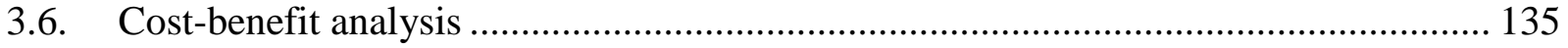




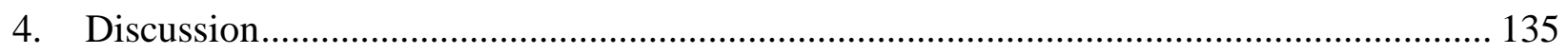

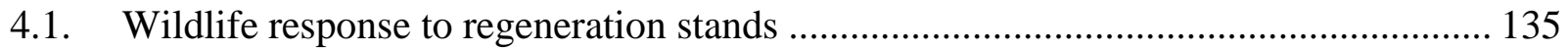

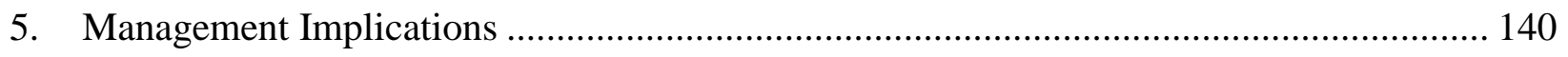

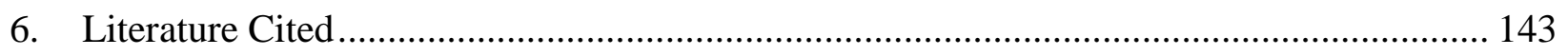

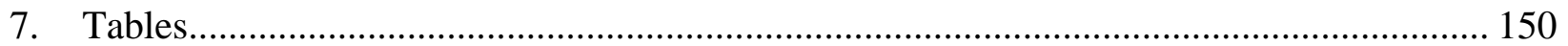

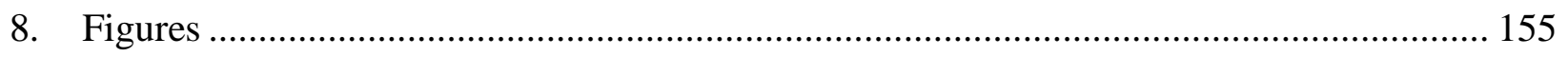

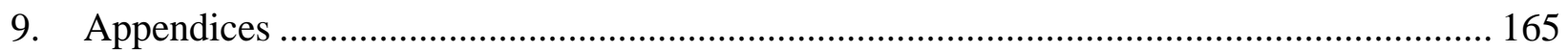

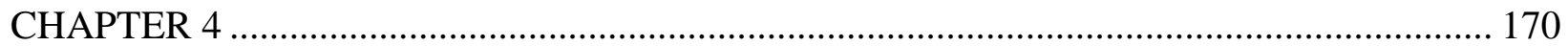

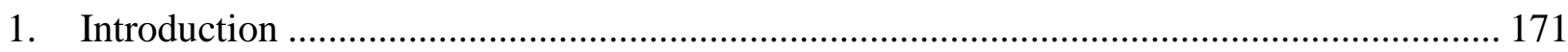

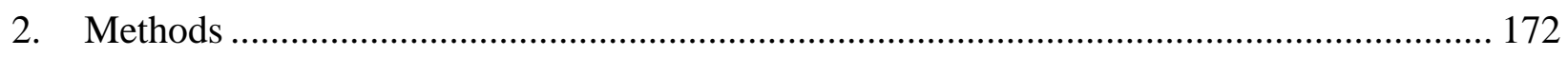

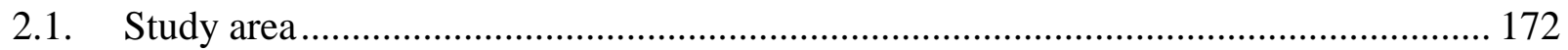

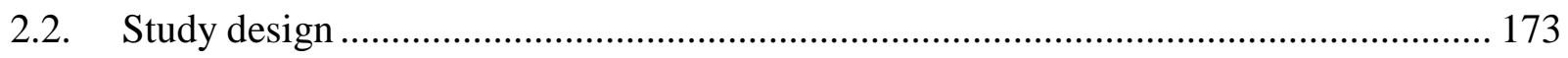

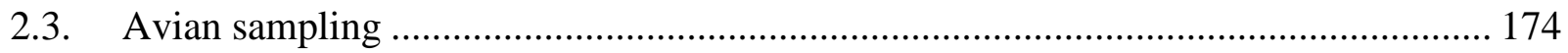

2.4. Local and landscape metric derivation .................................................................. 175

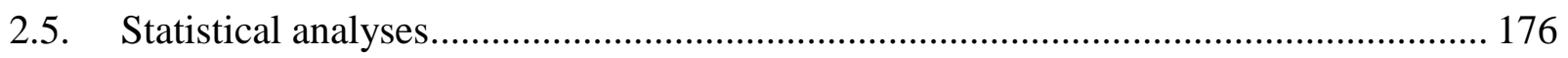

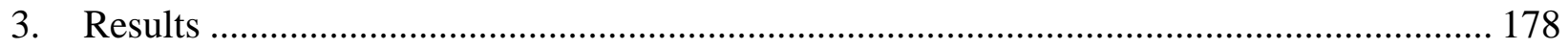

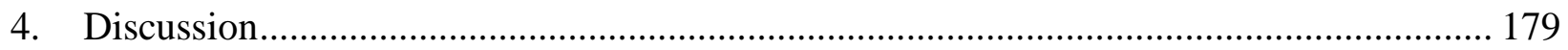

5. Management Implications ………………………………………………………….. 181

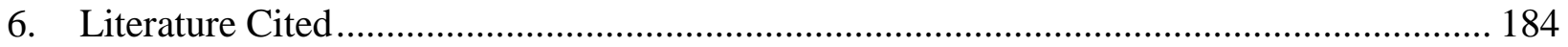

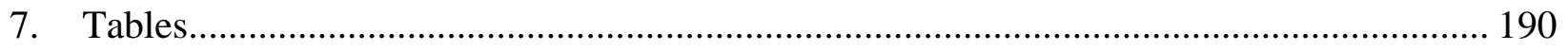

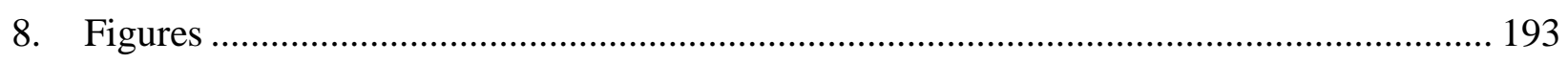

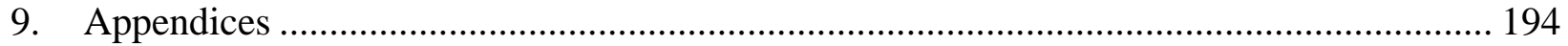




\section{LIST OF TABLES}

\section{CHAPTER 1}

Table 1-1. Species considered young or early-successional forest associates included in the West Virginia Division of Natural Resources' State Wildlife Action Plan (SWAP 2015). Species groups designed with “*” includes species associated with young/early-successional forest or

grasslands.

Table 1-2. Data collection timetable for 11 cut-back border blocks and 16 regeneration stand blocks at 11 wildlife management areas.

\section{CHAPTER 2}

Table 2-1. Data collection time-table for 11 cut-back border blocks at eight West Virginia Division of Natural Resource (WVDNR) wildlife management areas (WMA). "Blocks" in the table refers to number of block replicates at each site.

Table 2-2. Sampling schedule for assessing avian, salamander, and vegetation response in cutback borders during 2016-2019.

\section{CHAPTER 3}

Table 3-1. Data collection time-table for 16 regeneration stand blocks at six West Virginia Division of Natural Resource (WVDNR) wildlife management areas (WMA). "Blocks" in the table refers to number of block replicates at each site.

Table 3-2. Decay stage classifications used to assess canopy trees in regeneration stands. We condensed the eight Backhouse and Louiser (1991) classes into five (in parentheses) by combining classes $4-5$ into a single decay class and classes $6-8$ into a single decay class. ...... 150

Table 3-3. Posterior means of guild richness and cost (i.e., estimated performance scores) of regeneration stand treatments ("Cost" score was not generated via posterior mean). Guild richness values for each treatment were derived from Equation 1 and cost information was provided from the West Virginia Division of Natural Resources and the Wildlife Management Institute.

Table 3-4. Normalized performance scores (i.e., utility values) and 95\% confidence intervals (in parenthesis) of regeneration stand treatments. Scores are derived by taking the quotient of the cell-level performance score in Table 3-3 minus the maximum row-level performance score (numerator) and minimum row-level performance score minus the maximum row-level performance score (denominator). Scores range 0-1 $(0=$ low performance, $1=$ high performance). Weighted utility scores (WUS) of each regeneration stand treatment is the sum of the product of normalized performance scores and weights. Weights are as follows: young forest 
richness $=0.28$, species of conservation priority richness $=0.21$, cost $=0.20$, forest interior richness $=0.18$, and cavity nesting richness $=0.14$.

Table 3-5. Vegetation summary statistics (mean \pm standard error) in regeneration treatments over time. Treatment abbreviations include $\mathrm{CL}=$ clearcut-and-leave, $\mathrm{CW}=$ clearcut-and-windrow, and $\mathrm{HS}=$ hack-and-spray. Live and dead tree decay stages are defined in Table 3-2............. 153

Table 3-6. Total and mean (detections/plot) ruffed grouse (Bonasa umbellus) detections in regeneration stands over the study period. Mean values account for uneven sampling because Sleepy Creek WMA and Short Mountain WMA received no two-year post-treatment sampling and Center Branch WMA had no hack-and-spray (HS) treatments. Treatment abbreviations include CL = clearcut-and-leave, $\mathrm{CW}=$ clearcut-and-windrow, and HS = hack-and-spray...... 154

\section{CHAPTER 4}

Table 4-1. Percent cover (mean \pm SD) of local-level (100-m radius) and landscape-level (500-m radius) land cover variables surrounding each point count station at each Wildlife Management Area. Variable abbreviations include, MTN100 = proportion of maintained habitat (grassland, hay field, agriculture, row crop) within 100-m surrounding the point count, YF100 = proportion of young forest/shrubland within 100-m surrounding the point count, YF500 = proportion of young forest/shrubland within 500-m surrounding the point count, $\mathrm{CF}=$ core forest within 500-m surrounding the point count, and MF = proportion of mature forest within 500-m surrounding the point count.

Table 4-2. Model posterior predictive check for each species and guild used in analysis. Bayesian $p$-value was the probability to obtain a Chi-square test statistic that is at least as extreme as the observed Chi-square test statistic. We assumed reasonable model fit if the Bayesian $p$-value of $>0.1$ and $<0.9$.

Table 4-3. Mean effect size (on the response scale) of local- and landscape-level variables on species abundance and guild richness. Table values indicate the percent change in speciesspecific abundance or guild-specific species richness when local- and landscape-level variables increase by one standard deviation ("Variable Increase" in table). Numbers in bold indicate a significant positive or negative change of species abundance or guild richness based on the $95 \%$ credible intervals not overlapping zero. Variable abbreviations include, MTN100 = proportion of maintained habitat within 100-m surrounding the point count, YF100 = proportion of young forest/shrubland within 100-m surrounding the point count, $\mathrm{CC}=$ percent canopy cover at the point count, WID = width of right-of-way or wildlife opening, YF500 = proportion of young forest/shrubland within 500-m surrounding the point count, $\mathrm{CF}=$ core forest within $500-\mathrm{m}$ surrounding the point count, $\mathrm{MF}=$ proportion of mature forest within 500-m surrounding the point count, DIST = distance to nearest young forest/shrubland patch, and SIZE = size of nearest young forest/shrubland patch. 


\section{LIST OF FIGURES}

\section{CHAPTER 1}

Figure 1-1. Land classification of West Virginia (2011 National Land Cover Database). ......... 19

Figure 1-2. Age class distribution of forests in West Virginia (Morin et al. 2016).................... 19

Figure 1-3. Total area of agriculture land in West Virginia (USDA 1940-2012)...................... 20

Figure 1-4. Delineated area (red) of the Appalachian region of the eastern United States. ........ 20

Figure 1-5. Level III ecoregions in West Virginia with study sites (circles) and major cities (stars) overlaid.

Figure 1-6. Allegheny Wildlife Management Area plot layout. There is one replication of cutback borders along a transmission powerline and gas pipeline at Allegheny..... 22

Figure 1-7. Beury Mountain Wildlife Management Area plot layout. There are two replications of cut-back borders along transmissions powerlines, and five replications of regeneration stands at Beury Mountain. Colors denote different block replicates.

Figure 1-8. Bluestone Wildlife Management Area plot layout. There is one replication of cutback borders along wildlife openings at Bluestone.

Figure 1-9. Burnsville Lake Wildlife Management Area plot layout. There is one replication of cut-back borders along a gas pipeline at Burnsville.

Figure 1-10. Center Branch Wildlife Management Area plot layout. There are three replications of regeneration plots at Center Branch, with no hack-and-spray treatments. Colors denote separate block replicates.

Figure 1-11. Lewis Wetzel Wildlife Management Area plot layout, with two replications of cutback borders along gas pipelines at Lewis Wetzel. Colors denote separate block replicates....... 26 Figure 1-12. Little Canaan Wildlife Management Area plot layout. There are two cut-back border replications along transmission powerlines, and four replications of regeneration stands. Colors denote different block replicates.

Figure 1-13. Moncove Lake Wildlife Management Area plot layout. There are two replications of regeneration stands. Colors denote different block replicates.

Figure 1-14. Short Mountain Wildlife Management Area plot layout. There is one replication of regeneration stands.

Figure 1-15. Sleepy Creek Wildlife Management Area plot layout. There is one replication of cutback borders along wildlife openings, and one replication of regeneration stands. 28

Figure 1-16. Stonewall Jackson Wildlife Management Area plot layout. There is one replication of cut-back border along wildlife openings. 


\section{CHAPTER 2}

Figure 2-1. County map of West Virginia showing locations of wildlife management areas (WMA) where cut-back border plots were located (circles) as well as major cities (stars)........ 81

Figure 2-2. Examples of pre-treatment forest edge habitat prior to management along an underground gas pipeline at Lewis Wetzel Wildlife Management Area (LWWMA) (A), an overhead utility powerline at Little Canaan Wildlife Management Area (LCWMA) (B), and a wildlife opening at Bluestone Wildlife Management Area (BSWMA) (C)........................... 82

Figure 2-3. Cut-back border plot layout with avian and vegetation sampling point (black dots) and salamander sampling point (black + ) placements within each treatment width $(15,30$, and 45 $\mathrm{m}$ ) along rights-of-ways (ROWs) and wildlife openings (WO). Each cut-back border plot extended $300 \mathrm{~m}$ (violet arrow) along the forest-ROW/WO boundary (dashed line), and was either 15,30 , or $45 \mathrm{~m}$ (blue arrows) into the forest in a perpendicular direction respective to the forestROW/WO boundary. Avian and salamander sampling points were located $15 \mathrm{~m}$ (green arrow) off the forest-ROW/WO boundary. Avian sampling points were $150 \mathrm{~m}$ apart (red arrow) and 75 $\mathrm{m}$ (gray arrow) from cut-back border plot ends. Salamander sampling points were $75 \mathrm{~m}$ apart (pink arrow) and $37.5 \mathrm{~m}$ from plot ends. No salamander sampling occurred in the 15-m cut-back border treatments. Sampling point locations were consistent across all cut-back border widths with respect to forest-ROW/WO boundary (green arrow), intra-plot paired point counts (red arrow), and cut-back border plot ends (gray arrow).

Figure 2-4. Diagram of nested circular sampling plot for sampling vegetation variables in cutback borders. Each cut-back border plot contained two vegetation sampling plots located at avian sampling point-count locations (see Figure 3). Within the 0.04 ha (11.3 m radius) plot, overstory tree variables (e.g., overstory cover and basal area) were measured. Within the 0.01 ha (5.6 m radius) plot, counts of midstory stems $<11.4 \mathrm{~cm} \mathrm{DBH}$ and $\geq 1.4 \mathrm{~m}$ in height were grouped into two size categories (0-5 $\mathrm{cm}$ DBH and 5.1-11.3 cm DBH). Within the 0.004 ha (3.6 $\mathrm{m}$ radius) plot, ground cover was estimated.

Figure 2-5. Example of a reading from $25 \mathrm{~cm}$ x $25 \mathrm{~cm}$ transparent plexiglass to estimate overstory cover in cut-back border vegetation sampling plot (Hachè et al. 2013). Plexiglass panel is divided into a $5 \mathrm{~cm} \times 5 \mathrm{~cm}$ grid. Cells that are covered, to the nearest $1 / 2$ cell, by overstory (delineated at $\geq 5 \mathrm{~m}$ above ground) are counted towards an overstory closure value.

Figure 2-6. Example of differences in solar insolation based on plot location and edge orientation relative to the sun's position. In this scenario, Plot 1 receives full sunlight during the growing season compared to Plot 2 which is in the shadow of the adjacent forest. These differences in plot location could influence successional trajectories of vegetation in cut-back borders over time. . 85

Figure 2-7. Model-averaged predictions of percent change of vegetation variables in cut-back borders between one-year post-treatment and two-year post-treatment in relation to relative soil conditions (i.e., xeric and mesic). We graphically represent our continuous soil moisture index 
on a relative scale from xeric to mesic soil conditions. Black line indicates predicted mean change and blue space indicates $95 \%$ confidence intervals.

Figure 2-8. Plot-level estimated occupancy and 95\% confidence intervals of ruffed grouse detected within 100-m radius of sampling points in cut-back borders. There were no differences in occupancy rates between years within treatments based on $95 \%$ credible intervals.

Figure 2-9. Plot-level estimated abundance and 95\% confidence intervals of young forest focal songbird species during the summer breeding season. Differences in abundance within cut-back border treatments between pre-treatment/control and one-year or two-year post-treatment are indicated by alphabetical notation based on non-overlapping $95 \%$ credible intervals.

Figure 2-10. Plot-level estimated abundance and 95\% confidence intervals of interior-edge focal songbird species during the summer breeding season. Differences in abundance within cut-back border treatments between pre-treatment/control and one-year or two-year post-treatment are indicated by alphabetical notation based on non-overlapping $95 \%$ credible intervals.

Figure 2-11. Plot-level estimated abundance and 95\% confidence intervals of forest gap focal songbird species during the summer breeding season. Differences in abundance within cut-back border treatments between pre-treatment/control and one-year or two-year post-treatment are indicated by alphabetical notation based on non-overlapping $95 \%$ credible intervals....

Figure 2-12. Plot-level estimated abundance and 95\% confidence intervals of forest interior focal songbird species during the summer breeding season. Differences in abundance within cut-back border treatments between pre-treatment/control and one-year or two-year post-treatment are indicated by alphabetical notation based on non-overlapping $95 \%$ credible intervals.

Figure 2-13. Cut-back border harvest intensity main effects. Differences in abundance or richness within cut-back border factor levels are indicated by alphabetical notation based on nonoverlapping $95 \%$ credible intervals. Only significant main effects are reported.

Figure 2-14. Cut-back border width main effects. Differences in abundance or richness within cut-back border factor levels are indicated by alphabetical notation based on non-overlapping $95 \%$ credible intervals. Only significant main effects are reported.

Figure 2-15. Correlation biplot from canonical correspondence analysis (CCA) output. Vegetation variables include: elevation, understory cover 1-2 $\mathrm{m}$ in height (Foliage2), ground cover, number of live trees $<28.0 \mathrm{~cm}$ DBH (Md.Trees), overstory cover, snags, topographic relative moisture index (TRMI), and woody stems 5-11.3 cm DBH (Midstory.Stem2). Avian species are color coded to indicate habitat guild groupings (red = young forest, blue = interioredge, green $=$ forest gap, purple $=$ forest interior, orange $=$ predators/parasites $)$ and referenced by their 4-letter USGS alpha code (see Appendix 1-A). 96

Figure 2-16. Plot-level species richness and 95\% confidence intervals of the avian community in cut-back border treatments during spring stopover. Differences in species richness within cut- 
back border treatments between pre-treatment/control and one-year or two-year post-treatment are indicated by alphabetical notation based on non-overlapping $95 \%$ credible intervals. 97

Figure 2-17. Plot-level apparent species richness and 95\% confidence intervals of avian habitat guilds during the summer breeding season. Differences in species richness within cut-back border treatments between pre-treatment/control and one-year or two-year post- treatment are indicated by alphabetical notation based on non-overlapping $95 \%$ credible intervals................ 98

Figure 2-18. Plot-level apparent species richness and 95\% confidence intervals of avian guilds during the summer breeding season. Differences in species richness within cut-back border treatments between pre-treatment/control and one-year or two-year post-treatment are indicated by alphabetical notation based on non-overlapping $95 \%$ credible intervals

Figure 2-19. Plot-level relative abundance and $95 \%$ confidence intervals of eastern red-backed salamanders (Plethodon cinereus). Differences in relative abundance within cut-back border treatments between pre-treatment/control and one-year or two-year post-treatment are indicated by alphabetical notation based on non-overlapping $95 \%$ credible intervals 100

Figure 2-20. Body condition index (BCI) of eastern red-backed salamander (Plethodon cinereus) in cut-back border treatments at BMWMA and LWWMA. Differences in BCI within cut-back border treatments between pre-treatment/control and one-year or two-year post-treatment are indicated by alphabetical notation based on non-overlapping $95 \%$ credible intervals.... 100

\section{CHAPTER 3}

Figure 3-1. County map of West Virginia showing locations of wildlife management areas (WMA) where regeneration stands were located (circles) as well as major cities (stars)....... 1555

Figure 3-2. Regeneration stand layout with avian sampling point (black square) and salamander sampling point (black dot) placements. Vegetation sampling points were located at each avian and salamander sampling point. 1566

Figure 3-3. Plot-level estimated abundance and 95\% confidence intervals of young forest focal songbird species during the breeding season. Differences in abundance within regeneration treatments between pre-treatment/control and one-year or two-year post-treatment are indicated by alphabetical notation based on non-overlapping $95 \%$ credible intervals. 1577

Figure 3-4. Plot-level estimated abundance and 95\% confidence intervals of forest interior focal songbird species during the breeding season. Differences in abundance within regeneration treatments between pre-treatment/control and one-year or two-year post-treatment are indicated by alphabetical notation based on non-overlapping $95 \%$ credible intervals. 1588

Figure 3-5. Plot-level estimated abundance and 95\% confidence intervals of forest gap focal songbird species during the breeding season. Differences in abundance within regeneration treatments between pre-treatment/control and one-year or two-year post-treatment are indicated by alphabetical notation based on non-overlapping $95 \%$ credible intervals. 1599 
Figure 3-6. Plot-level estimated abundance and 95\% confidence intervals of focal songbird species during the breeding season. Differences in abundance between regeneration treatments are indicated by alphabetical notation based on non-overlapping 95\% credible intervals ........ 160 Figure 3-7. Plot-level species richness and 95\% confidence intervals of avian habitat guilds during the breeding season. Differences in richness within regeneration treatments between pretreatment/control and one-year or two-year post-treatment are indicated by alphabetical notation based on non-overlapping $95 \%$ credible intervals. 16161

Figure 3-8. Plot-level species richness and 95\% confidence intervals of avian guilds during the breeding season. Differences in richness within regeneration treatments between pretreatment/control and one-year or two-year post-treatment are indicated by alphabetical notation based on non-overlapping $95 \%$ credible intervals. 16262

Figure 3-9. Plot-level estimated abundance and 95\% confidence intervals of focal songbird species during the breeding season. Differences in abundance between regeneration treatments are indicated by alphabetical notation based on non-overlapping $95 \%$ credible intervals

Figure 3-10. Plot-level relative abundance and 95\% confidence intervals of eastern red-backed salamanders (Plethodon cinereus). Differences in relative abundance within the HS treatment between pre-treatment/control and one-year or two-year post-treatment are indicated by alphabetical notation based on non-overlapping $95 \%$ credible intervals.

Figure 3-11. Plot-level body condition index (BCI) and 95\% confidence intervals of eastern redbacked salamanders (Plethodon cinereus). Differences in BCI within the HS treatment between pre-treatment/control and one-year or two-year post-treatment are indicated by alphabetical notation based on non-overlapping $95 \%$ credible intervals. 16464

\section{CHAPTER 4}

Figure 4-1. Expected point-level mean species abundance or guild richness and $85 \%$ confidence intervals as a function of local- and landscape-level variables surrounding point counts in cutback borders. Data on x-axis for variables includes the $95 \%$ quantile to reduce inflation of estimates near data outliers. 


\section{LIST OF APPENDICES}

\section{CHAPTER 1}

Appendix 1-A. Passerine species detected during study period (2016-2019) at study sites. Column labeled "Status" refers to breeding status: breeding - spends majority of summer but not fall, winter, or spring in WV, migrating - spends fall and winter in WV or passes through WV during the spring but does not spend the majority of the summer in $\mathrm{WV}$, resident - spends summer, fall, winter, and spring in WV.

\section{CHAPTER 2}

Appendix 2-A. Acreage managed by wildlife management area (WMA) and year. 101

Appendix 2-B. Decision rules for analyses to assess avian, salamander, and vegetation response in cut-back borders. 102

Appendix 2-C. Total detections for songbird species in cut-back borders heard within 50-m of point count. Auditory detection type indicates which vocalizations were used to determine species presence. An “*” indicates species was included in species-specific analysis, and “^” indicates species was included in the community CCA. All species listed were included in guild richness analyses. See Appendix 1-A for scientific names of species and guild assignments. Species of conservation priority (SCP) are those identified by Appalachian Mountains Joint Venture (AMJV), Partners-in-Flight (PIF) Appalachian region (BCR 28), or the West Virginia Division of Natural Resources (WVDNR) State Wildlife Action Plan (SWAP). Guild codes are: $\mathrm{FG}=$ forest gap, $\mathrm{FI}=$ forest interior, $\mathrm{IE}=$ interior-edge, $\mathrm{YF}=$ young forest, $\mathrm{PP}=$ predator/parasite. 104

Appendix 2-D. Avian guild descriptions. 107

Appendix 2-E. Model outputs for assessing effects of topographic variables on five vegetation variables between one-year post-treatment and two-year post-treatment in cut-back borders. HLI $=$ heat load index, $\mathrm{SPI}=$ shade proportion index, $\mathrm{TRMI}=$ topographic relative moisture index, and $\mathrm{K}=$ number of parameters. We report the top six models for each model set. 108 Appendix 2-F. Vegetation summary statistics (mean \pm standard error) in cut-back border treatments over time

Appendix 2-G. Model posterior predictive check for focal songbird species, avian guild, and eastern red-backed salamander (Plethodon cinereus) treatment-time interaction and main effects model analyses. Bayesian $p$-value is the probability to obtain a Chi-square test statistic that is at least as extreme as the observed Chi-square test statistic. We assumed reasonable model fit if the Bayesian $p$-value of $>0.1$ and $<0.9$.

Appendix 2-H. Output table from canonical correspondence analysis (CCA) assessing avian species correlations with vegetation variables in cut-back borders. Numeric values in each 
column (CCA1, CCA2, etc.) indicate correlation with that canonical axis, with higher absolute numbers (positive or negative) being more strongly associated within that axis (e.g., CCA1 is strongly influenced by elevation, hence "Elevation" has the highest absolute value of vegetation variables in CCA1, and is correlated with CSWA, COYE, RUGR, etc. which have the highest absolute value of species). Positive correlations between vegetation variables and species are indicated with similar signs ("+" or "“-") within each column.

Appendix 2-I. Capture breakdown of salamander species by cut-back border treatment over the study period. Table excludes recaptures.

Appendix 2-J. Total number detections in cut-back border treatments over time for species of conservation concern in the Appalachian region (Bird Conservation Region 28; PIF 2019) that did not meet the detection count criteria ( $\geq 40$ detections) or the detection probability criteria ( $\geq 0.200$ probability of detection).

\section{CHAPTER 3}

Appendix 3-A. Acreage managed by wildlife management area and year......

Appendix 3-B. Total detections for bird species in regeneration stands heard within 100-m of point count and used in analyses for this chapter. Auditory detection type indicates which vocalizations were used to determine species presence. An "** indicates species was included in species-specific analysis. See Appendix 1-A for scientific names of species and guild assignments. Species of conservation priority (SCP) include those identified by Appalachian Mountains Joint Venture, Partners-in-Flight Appalachian region, or the West Virginia Division of Natural Resources State Wildlife Action Plan. Guild codes are: BF = bark foraging, FG = forest gap, $\mathrm{FI}=$ forest interior, $\mathrm{IE}=$ interior-edge, $\mathrm{PC}=$ primary cavity nester, $\mathrm{SC}=$ secondary cavity nester, $\mathrm{YF}=$ young forest. 166

Appendix 3-C. Model posterior predictive check for focal songbird species, avian guild, and eastern red-backed salamander (Plethodon cinereus) treatment-time interaction and main effects model analyses. Bayesian $p$-value is the probability to obtain a Chi-square test statistic that is at least as extreme as the observed Chi-square test statistic. We assumed reasonable model fit if the Bayesian $p$-value of $>0.1$ and $<0.9$. XXX

Appendix 3-D. Total number of individuals captured (excluding recaptures) of salamander species by regeneration stand treatment over the study period.

\section{CHAPTER 4}

Appendix 4-A. Coordinates of treatment plot corners for cut-back borders. All coordinates are in NAD83, UTM Zone 17. Control plots have two corners indicating the location of their plot location along the forest edge. 194 
Appendix 4-B. Coordinates of treatment plot corners for regeneration stands. All coordinates are

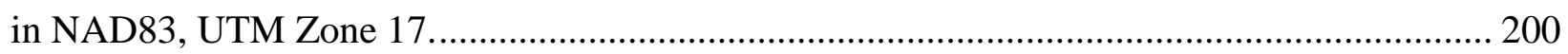

Appendix 4-C. Avian point count coordinates in cut-back borders. All coordinates are in

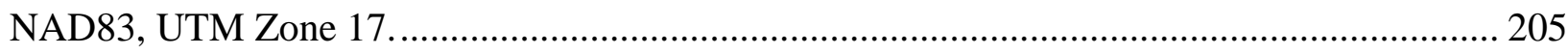

Appendix 4-D. Avian point count coordinates in regeneration stands. All coordinates are in

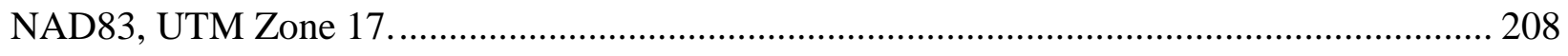

Appendix 4-E. Salamander coverboard coordinates in cut-back borders. All coordinates are in

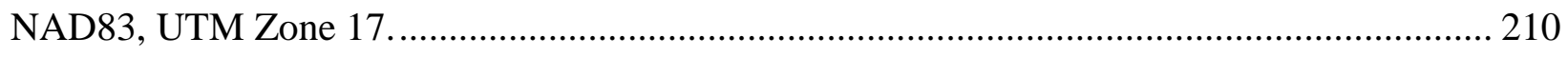

Appendix 4-F. Salamander coverboard coordinates in regeneration stands. All coordinates are in

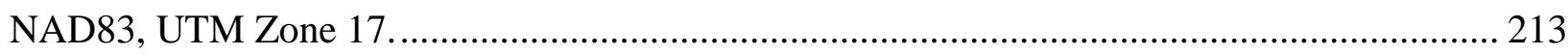




\section{CHAPTER 1}

\section{PROJECT INTRODUCTION}

\section{Young forests in West Virginia and the Appalachian Region}

West Virginia is the third most densely forested state in the United States (US) with 79\% (ca. 5 million ha) of all land being classified as forest (Homer et al. 2015, Morin et al. 2016; Figure 1-1). Forestlands in West Virginia are principally comprised of 61-100 years old stands (83\% of all forestland, Morin et al. 2016; Figure 1-2), which is a common pattern for many forests throughout the Appalachian region (Oswalt et al. 2010). The unimodal age distribution of forestlands (Figure 1-2) is the result of fluctuating landscape-scale forest disturbances (e.g., large-scale logging, wildfire) and socio-economic factors - which led to increases in wildfire suppression and farm abandonment - over the past 80 years. A major consequence of this shift towards greater proportions of mature forest stands ( $\geq 40$ years old) is the loss of disturbanceassociated flora and fauna (i.e., young forest obligates). Forest disturbances are essential components of forest ecosystems, as they provide the necessary stimuli to facilitate forest stand development and provide resources vital to many wildlife species (Tash and Litvaitis 2007, McDermott and Wood 2010, Dey 2014). The continued maturation of young forests without replacement in the Appalachian region in recent decades has raised concerns among natural resource managers about the capability of young forest obligate wildlife species to persist under contemporary disturbance regimes (Askins 2001, Trani et al. 2001, Oswalt et al. 2010, Greenberg et al. 2011a).

The vegetation successional stage immediately following a disturbance is often referred to as "early-successional" and typically encompasses grassland, shrubland, and young forest plant communities (Harper 2017). These areas are defined as: recently disturbed with minimal overstory cover and a dense understory vegetation layer occupied by disturbance-adapted, shadeintolerant, or pioneer plant species (Schlossberg and King 2007, Tavernia et al. 2016). However, the term "early-successional" can be misleading as grasslands, shrublands, and young forests describe distinct plant communities with different affiliated wildlife species. Young forests are the result of disturbances in forested systems, where saplings sprout from the root systems of felled trees (i.e., advanced regeneration) but hardwood species remain the dominant plant group 
with minor amounts of grasses, forbs, and brambles (King and Schlossberg 2014). The term "early-successional" represents the third or fourth seral stage of a grassland plant community and thus, is distinct from a young forest plant community. Therefore, "young forest" is used throughout this document when describing recently disturbed forest systems.

The distribution and area of young forests - defined as forests 0-20 years old - has fluctuated considerably over the past century. Present-day forest conditions in West Virginia and the Appalachian region can be attributed to a legacy of stand-replacing human disturbances dating from the 1700s through the early 1900s (Lorimer 2001). Forest disturbances during this period were prevalent due to Native American and European presence in the region, as forested areas were converted to agriculture or logging-centered landscape matrices. Land that was useful for agriculture was cleared of trees where needed, contributing to an increase in open areas during the late nineteenth century. Following the Great Depression (ca. early 1940s), large extents of farmland were abandoned and allowed to revert to forest cover. As of 2012, $41 \%$ of farmland that existed in West Virginia in the 1940's remains (USDA 1940-2012; Figure 1-3). Between the 1840s and 1920s, logging was the primary source of forest disturbance in West Virginia and by the late 1920s over $99 \%$ of forestland in the state had been logged. By 1940, forestlands, of all ages, still accounted for the majority of land in West Virginia (about 60\%) but forestry and the perception of logging had transitioned towards a conservative timber management approach, dramatically reducing large-scale disturbance in the state (Williams 1989).

Historically, anthropogenic and natural wildfires played a minor role in creating young forests in West Virginia relative to the Appalachian region and the eastern USA (Lorimer 2001, Lynch and Hessl 2010, White et al. 2011, Greenberg et al. 2015). Native Americans often used fire for clearing land or hunting, and European settlers adopted this practice. But by the early 1900s, political pressure led to policies that restricted the use of fire and these restrictions continued through the century due to an emphasis on commodity production (White et al. 2011). By the late nineteenth century, wildfire, logging, and farm abandonment combined to create large areas of young forest, accounting for 55-60\% of all forest cover (Lorimer 2001). However, the combined effects of fire suppression, reduced logging, and maturation of old farmlands has reduced the extent of young forests we see today. Since 1949, the total area of young forestland in West Virginia has decreased from $19 \%$ to $7 \%$ while mature forestland has increased from $46 \%$ 
to $78 \%$ (referred to as "small diameter" and "large diameter" forests, respectively, in Morin et al. 2016).

The decline in total area and distribution of young forestland has negatively affected young forest obligate wildlife communities (Dessecker and McAuley 2001, Hunter et al. 2001, DeGraaf and Yamasaki 2003, Dettmers 2003). Wildlife species that are adapted to disturbancemediated habitats are often restricted by forest regeneration and the succession of plant composition into later seral stages (i.e., temporal specialists). Litvaitis (1993) suggested young forest-associated birds be considered habitat specialists, rather than generalists, because they occupy a narrower range of habitats compared to mature forest birds. Due to woody and herbaceous vegetation growth following forest disturbance (Roberts and Gilliam 2003, Roberts 2004), young forests provide food resources from fruiting plants (Greenberg et al. 2005, Reynolds-Hogland et al. 2006) and arthropods (Buddle et al. 2006, Greenberg et al. 2011b, Wilson et al. 2014), as well as nesting and juvenile dispersal cover from predators (Thompson III and Dessecker 1997, McDermott and Wood 2010). Additionally, songbird species not typically associated with disturbances (i.e., mature forest obligate species) use young forest areas prior to fall migration because high fruit production facilitates fat storage buildup (Suthers et al. 2000, Rodewald and Brittingham 2004).

While many songbird species respond positively to disturbance, wildlife taxa that are physiologically constrained to moist conditions (e.g., amphibians) may respond negatively to the same forest disturbance (Hillman et al. 2009). Salamanders are at an increased risk of desiccation following disturbances that result in a warmer, drier microclimate and reduced leaf litter cover and depth, although responses to disturbance are often species-specific and vary with disturbance intensity (deMaynadier and Hunter Jr. 1995, Duguay and Wood 2002, Homyack and Haas 2009, Moorman et al. 2011, Mahoney et al. 2016). Because salamanders provide important ecosystem functions (e.g., breakdown course woody debris, cycle nutrients throughout the ecosystem) in forest systems, maintaining salamander populations and community richness is an important desired outcome when planning forest management operations (Petranka et al. 1994).

The loss of young forest obligate wildlife in the eastern USA has prompted state and federal wildlife agencies as well as many non-profit organizations to focus efforts on ways to create and promote young forests in the region. Currently, $23 \%$ of all of terrestrial vertebrates listed as species of concern in West Virginia's State Wildlife Action Plan (SWAP) are 
considered young forest obligates (WVDNR 2015, Table 1-1). However, uncertainty exists surrounding the tradeoffs between taxa groups following young forest-directed management. Because traditional forms for young forest creation are unlikely (e.g., large-scale logging) or unreliable (e.g., wildfire) in West Virginia, young forest-directed management is needed to promote this stage of forest succession and to understand the benefits and drawbacks associated with young forest habitat creation (DeGraaf and Yamasaki 2003). This research will focus on quantifying avian and salamander community responses to various young forest management activities in West Virginia.

\section{Study Region}

This study was conducted throughout West Virginia on wildlife management areas (WMAs, Table 1-2) owned by the West Virginia Division of Natural Resources (WVDNR). West Virginia lies solely within the Appalachian region (Figure 1-4). West Virginia's humid continental climate is characterized by warm summers and cool to cold winters with average spring and fall temperatures of $10.0{ }^{\circ} \mathrm{C}$ and an average summer temperature of $22.0^{\circ} \mathrm{C}$. Annual precipitation levels range from 76,127, and $102 \mathrm{~cm}$ in the western, central, and eastern portions of the state, respectively (NOAA 2015) with precipitation distributed evenly throughout the year but heaviest from June-September. West Virginia lies within the path of predominantly westerly winds which are influenced by cold northern air and warm southern air which can produce considerable amounts of precipitation (Lee et al. 1977, Green and Pauley 1987). In addition, the mountains along the Central Appalachian-Ridge and Valley border cause prevailing winds to rise and cool, thus releasing higher precipitation to the west and lower precipitation to the east of the mountains.

\section{Central Appalachian}

The central and southern parts of West Virginia are contained within the Central Appalachian region (Figure 1-5). This region consists of extensive forests with a highly dissected, rugged plateau composed of sandstone, shale, conglomerate, and coal. The rugged terrain, cool climate, and infertile soil limit agriculture, resulting in mostly forested land cover (Woods et al. 1999). Forests are primarily mixed mesophytic (Braun 1950), with areas of Appalachian oak (dominated by white [Quercus alba], and red oaks [Q. rubra]) and northern hardwoods (dominated by sugar maple [Acer saccharum], yellow birch [Betula alleghaniensis], beech [Fagus spp.], and eastern hemlock [Tsuga canadensis]; Kuchler 1964). Higher elevations 
(ranging from 549 to $1,402 \mathrm{~m}$ above mean sea level) in this ecoregion produce greater annual mean precipitation $(96-152 \mathrm{~cm})$ and lower mean temperatures $\left(11.5^{\circ} \mathrm{C}\right)$ than the adjacent ecoregion to the east (e.g., Ridge and Valley).

Ridge and Valley

The eastern panhandle of West Virginia is contained within the Ridge and Valley ecoregion (Figure 1-5). This region's topography is a result of extreme folding and faulting events, creating parallel ridges and valleys in a northeast-southwest orientation (Woods et al. 1999). Ridges are mostly composed of resistant sandstone or conglomerate while valleys have generally weaker strata of limestone and shale. Due to this, land use is characterized by alternating forested ridges and agricultural valleys that are elongated. Forest cover is extensive in this ecoregion, mostly Appalachian oak and oak-hickory-pine forests (dominated by hickories [Carya spp.], shortleaf pine [Pinus echinata], white oak, and post oak [Quercus stellata]; Kuchler 1964). Elevations range from 244 to $1,311 \mathrm{~m}$ in this ecoregion but is bordered by the higher Blue Ridge (east) and Central Appalachian (west) ecoregions, resulting in less severe winters, considerably warmer summers $\left(12.0{ }^{\circ} \mathrm{C}\right.$ mean annual temperature $)$, and lower annual precipitation $(93 \mathrm{~cm})$ than its neighbors (Woods et al. 1999).

\section{Western Alleghany Plateau}

The northern and western part of West Virginia is contained within the Western Alleghany Plateau region (Figure 1-5). This region consists of a mostly unglaciated, dissected plateau with local relief and crestal elevations of less than $600 \mathrm{~m}$ (Woods et al. 1999). Land use and land cover is a mosaic of forests, urban-suburban-industrial activity, dairy and livestock farms, coal mines, and oil-gas fields. Soils support Appalachian oak forests in the northwest portion of this ecoregion, while mixed-mesophytic forest is more common in the southern part (Kuchler 1964). The Western Alleghany Plateau, with elevations ranging from 61 to $488 \mathrm{~m}$, is less rugged, not as forested and warmer than the Central Appalachian ecoregion to the east and south.

\section{Study Design}

We created young forest by tree cutting and herbicide application. Young forest created with these methods varied in size, intensity, and landscape context. Firstly, young forest was created within fragmented forest landscapes that included rights-of-way (ROWs; gas pipeline or transmission powerline) and wildlife openings. ROWs were long, linear openings maintained via 
cutting, mowing, or herbicide spraying. Wildlife openings were fields planted with an agricultural crop (e.g., corn, clover) or left fallow. Tree cutting along forest edges of ROWs and wildlife openings was done at three different depths (i.e., plot sizes) into the forest $(15,30$, and $45 \mathrm{~m}$ into the forest, perpendicular to forest edge; $0.5,1.0$, and 1.5 ha plot sizes, respectively) and two different cutting intensities (4.5 and $14.0 \mathrm{~m}^{2} /$ ha basal area retention). Young forest management along ROWs and wildlife openings are hereafter referred to as "cut-back borders". Secondly, young forest was created within surrounding intact forests consisting of three different management techniques (clearcut-and-leave, clearcut-and-windrow, and hack-and-spray) on individual 4 ha plots. Young forest management within surrounding forests are herein referred to as "regeneration stands". All cutting and spraying was contracted through Wildlife Management Institute. Further details of each young forest management technique will be addressed in later chapters. We followed a before-after-control-impact (BACI) framework to study causal effects of these management techniques on the plant and animal communities, with one year of pretreatment data collection and one or two years of post-treatment data collection (Table 1-2).

A single block replicate of cut-back borders refers to all combinations of three different cutting depths $(15,30$, and $45 \mathrm{~m})$ and two cutting intensities $\left(4.5\right.$ and $\left.14.0 \mathrm{~m}^{2} / \mathrm{ha}\right)$ with the addition of a control (no tree cutting or canopy manipulation). A single block replicate of regeneration stands includes three management prescriptions (clearcut-and-leave, clearcut-andwindrow, and hack-and-spray) with the addition of a control (no tree cutting or canopy manipulation).

\section{Study Site Details}

Allegheny Wildlife Management Area.-Allegheny WMA (AGWMA) is located in eastern West Virginia (Mineral County), near the city of Keyser on the West Virginia-Maryland state border (Figure 1-6; site coordinates in Appendices 4-A and 4-C). The management area covers 2,509 ha, consisting of flat, rocky mountaintop and steep slopes leading to foothills and hollows. Predominant forest cover is oak-hickory with interspersed mountain laurel (Kalmia latifolia). Elevation ranges from 319 to $950 \mathrm{~m}$. AGWMA has one block replicate of cut-back borders along a transmission powerline/gas pipeline. AGWMA was cut and treated between fall of 2018 and spring of 2019, with pre-treatment data collected in the summer of 2018 and posttreatment data collected in the summer of 2019 (Table 1-2). 
Beury Mountain Wildlife Management Area.-Beury Mountain WMA (BMWMA) is located in the south-central part of West Virginia (Fayette County), near the city of Beckley (Figure 1-7; site coordinates in Appendices 4-A through 4-F). The management area covers 1,238 ha, consisting of gentle to steep slopes with mixed hardwood and oak-hickory forests. Elevation ranges from 610 to 1,108 m. BMWMA has two block replicates of cut-back borders along two separate transmission powerlines (one block on each powerline) and five block replicates of regeneration stands. All research plots at BMWMA were cut and treated between fall of 2017 and spring of 2018. Pre-treatment data were collected during the summer of 2017 and post-treatment data were collected in the summers of 2018 and 2019 (Table 1-2).

Bluestone Wildlife Management Area.-Bluestone WMA (BSWMA) is located in southern West Virginia (Summers County), near the city of Hinton on the West VirginiaVirginia state border (Figure 1-8; site coordinates in Appendices 4-A and 4-C). The management area covers 7,292 ha, consisting of flat bottomlands to rolling uplands with predominantly oakhickory forests. BSWMA is located around the periphery of a reservoir 797 ha in size. Elevation ranges from 432 to $865 \mathrm{~m}$. BSWMA has a single block of cut-back borders along wildlife openings. All research plots at BSWMA were cut and treated between fall 2017 and spring of 2018. Pre-treatment data were collected during the summer of 2017 and post-treatment data were collected in the summers of 2018 and 2019 (Table 1-2).

Burnsville Lake Wildlife Management Area.-Burnsville Lake WMA (BLWMA) is located in central West Virginia (Braxton County) near the town of Burnsville (Figure 1-9; site coordinates in Appendices 4-A and 4-C). The management area covers 5,090 ha, mainly consisting of hilly and steep terrain, with some gently sloping upland areas and fairly flat creek bottoms with a mixture of young timber, brush, and old fields. BLWMA is mainly composed of mixed pine-hardwood forests. Elevation ranges from 243 to $472 \mathrm{~m}$. BLWMA has one block replicate of cut-back borders along a gas pipeline that runs along a ridgeline. Research plots at BLWMA were cut and treated between fall of 2016 and spring 2017. Pre-treatment data were collected in the summer of 2016 and post-treatment data were collected in the summers of 2017 and 2018 (Table 1-2).

Center Branch Wildlife Management Area.-Center Branch WMA (CBWMA) is in north-central West Virginia (Harrison County) near the city of Clarksburg (Figure 1-10; site 
coordinates in Appendices 4-B and 4-D). The management area cover 394 ha, with strip-bench flats to moderately steep slopes interspersed with gas wells and access roads. CBWMA is mainly composed of mixed and cove hardwoods. Elevation ranges between 300 and $465 \mathrm{~m}$. CBWMA has three block replicates of regeneration stands, but excludes hack-and-spray treatments. All research plots were cut between fall of 2017 and spring of 2018, with pre-treatment data collected in the summer of 2017 and post-treatment data collected in summers of 2018 and 2019 (Table 1-2).

Lewis Wetzel Wildlife Management Area.-Lewis Wetzel WMA (LWWMA) is located in northwestern West Virginia (Doddridge, Tyler, and Wetzel Counties) near the town of Jacksonburg (Figure 1-11; site coordinates in Appendices 4-A, 4-C, and 4-E) and covers 5,500 ha, consisting of moderate to steep slopes. LWWMA is heavily forested and dominated by oakhickory and cove hardwoods, with numerous gas wells and pipelines located throughout the area. Elevation ranges from 224 to 475 m. LWWMA has two block replicates of cut-back borders along gas pipelines. LWWMA was cut and treated between fall of 2017 and spring of 2018, with pre-treatment data collected in the summer of 2017 and post-treatment data collected in the summers of 2018 and 2019 (Table 1-2).

Little Canaan Wildlife Management Area.-Little Canaan WMA (LCWMA) is located in eastern West Virginia (Tucker County), near the town of Davis (Figure 1-12; site coordinates in Appendices 4-A through 4-F). LCWMA covers 1,282 ha and is primarily forested with gently sloping hills comprised mainly of maple-beech-birch forests interspersed with rhododendron (Rhododendron maximum) and mountain-laurel. Elevation ranges from 944 to 1,132 m. LCWMA has two block replicates of cut-back borders along two transmission powerlines (one block on each powerline) and four block replicates of regeneration stands. Research plots were cut and treated between fall 2016 and spring 2017, with pre-treatment being data collected in the summer of 2016 and post-treatment data collected in the summers of 2017 and 2018 (Table 1-2).

Moncove Lake Wildlife Management Area.-Moncove Lake WMA (MLWMA) is located in southern West Virginia (Monroe County), near the town of Union (Figure 1-13; site coordinates in Appendices 4-B and 4-D). MLWMA covers 313 ha, consisting of gently rolling hills to steep mountain sides with a predominately oak-hickory forest composition. Elevation ranges between 763 and 947 m. MLWMA has two block replicates of regeneration stands. 
Research plots were cut and treated between fall 2017 and spring 2018. Pre-treatment data were collected in the summer of 2017 and post-treatment data were collected in the summers of 2018 and 2019 (Table 1-2).

Short Mountain Wildlife Management Area.-Short Mountain WMA (SMWMA) is located in the eastern panhandle of West Virginia (Hampshire and Hardy Counties), near the city of Romney (Figure 1-14; site coordinates in Appendices 4-B and 4-D). The management area covers 3,239 ha and consists of mixed oak and Virginia pine. Elevation ranges between 389 and 793 m. SMWMA has one block of regeneration stands. Research plots were cut and treated between fall of 2018 and spring 2019. Pre-treatment data were collected in the summer of 2018 and post-treatment data were collected in the summer of 2019 (Table 1-2).

Sleepy Creek Wildlife Management Area.-Sleepy Creek WMA (SCWMA) is located in the eastern panhandle of West Virginia (Berkeley and Morgan County), near the city of Martinsburg (Figure 1-15; site coordinates in Appendices 4-A through 4-D). SCWMA covers 9,278 ha and consists of oak-hickory and Virginia pine-oak forest. Elevation ranges between 304 and $660 \mathrm{~m}$. SCWMA has one block replicate of cut-back borders along wildlife openings and one block replicate of regeneration stands. Research plots were cut and treated between fall 2018 and spring 2019. Pre-treatment data were collected in 2018 and post-treatment data were collected in 2019 (Table 1-2).

Stonewall Jackson Wildlife Management Area.-Stonewall Jackson WMA (SJWMA) is located in central West Virginia (Lewis County), near the city of Weston (Figure 1-16; site coordinates in Appendices 4-A, 4-C, and 4-E). The management areas covers 7,401 ha, consisting of farmlands reverting to woodland and rolling hills covered with mixed hardwood forest. Elevation ranges between 329 and 509 m. SJWMA has one block replicate of cut-back borders along wildlife openings. Research plots were cut and treated between fall 2016 and spring 2017. Pre-treatment data were collected in 2016 and post-treatment data collected in 2017 and 2018 (Table 1-2).

\section{Summary and Dissertation Goals}

The decline of young forest communities throughout the eastern USA is the result of the disruption of disturbance regimes, changes in anthropogenic land use, and the conversion of 
forest ecosystems to non-forest habitat (e.g., urban, commercial, or agriculture). In West Virginia, total area and distribution of young forests has receded to concerning levels in recent decades and because of this, many wildlife species associated with young forests have experienced regional population declines. Low levels of disturbance have shifted forest tree composition as a result of forest maturation (Fei and Steiner 2007), invasive species introductions (Webster et al. 2018), and increases in natural regeneration barriers (e.g., ungulate browsing; Russell et al. 2017, Dey et al. 2018) which will have unknown implications on the wildlife community in the future. Unless attention is given to managing for young forests and understanding regeneration dynamics and their effects on the wildlife community, species associated with this vegetation stage will continue to experience regionally-depressed populations.

In the following chapters, I will look at the effects of various young forest management techniques on the avian (Appendix 1-A) and salamander communities. In Chapter 2, I studied the effects of cut-back borders along powerlines, pipelines, and wildlife openings on the avian and salamander community and developed best management approaches for implementing cut-back borders on WVDNR lands. In Chapter 3, I studied the effects of different young forest management regeneration stand techniques on the avian and salamander community and assessed the tradeoffs between maximizing species responses and minimizing treatment cost using a cost-benefit analysis. In Chapter 4, I focused on evaluating the importance of local- and landscape-level habitat variables on the songbird community to assist land managers in developing young forest management guidelines along pipelines, powerlines, and wildlife openings within forest landscapes.

The over-arching goal of this research was to better understand young forest management techniques and their effects on bird and salamander communities in order to develop management guidelines for implementation throughout West Virginia and the eastern USA. Conservation decisions on public lands regarding both game and non-game wildlife species need to maximize investments and withstand public scrutiny to ensure continued support of wildlife habitat programs. Results from this research provide guidelines and recommendations for land managers to efficiently implement young forest management practices with the goal of promoting young forests that provide vital developmental conditions and resources for healthy 
and diverse plant and animal communities. Funding for the bird (game and non-game) portion of this project was provided through the Pittman-Robertson Wildlife Restoration Act Grant 48-R. 


\section{Literature Cited}

Askins, R.A. 2001. Sustaining biological diversity in early successional communities: The challenge of managing unpopular habitats. Wildlife Society Bulletin 29 (2): 407-412. http://www.jstor.org/stable/3784165

Braun, E.L. 1950. Deciduous forests of eastern North America. The Blakiston Company, Philadelphia, PA, USA, 596 p.

Buddle, C.M., D.W. Langor, G.R. Pohl, and J.R. Spence. 2006. Arthropod responses to harvesting and wildfire: Implications for emulation of natural disturbance in forest management. Biological Conservation 128 (3): 346-357. http://doi.org/10.1016/j.biocon.2005.10.002

DeGraaf, R.M., and M. Yamasaki. 2003. Options for managing early-successional forest and shrubland bird habitats in the northeastern United States. Forest Ecology and Management 185: 179-191. http://doi.org/10.1016/S0378-1127(03)00254-8

deMaynadier, P.G., and M.L. Hunter Jr. 1995. The relationship between forest management and amphibian ecology: A review of the North American literature. Environmental Reviews 3: $230-261$.

Dessecker, D.R., and D.G. McAuley. 2001. Importance of early successional habitat to ruffed grouse and American woodcock. Wildlife Society Bulletin 29 (2): 456-465. http://www.jstor.org/stable/3784169

Dettmers, R. 2003. Status and conservation of shrubland birds in the northeastern US. Forest Ecology and Management 185: 81-93. https://doi.org/10.1016/S0378-1127(03)00248-2

Dey, D.C. 2014. Sustaining oak forests in eastern North America: Regeneration and recruitment, the pillars of sustainability. Forest Science 60 (5): 926-942. http://doi.org/10.5849/forsci.13-114

Dey, D.C., B.O. Knapp, M.A. Battaglia, R.L. Deal, J.L. Hart, K.L. O’Hara, C.J. Schweitzer, and T.M. Schuler. 2018. Barriers to natural regeneration in temperate forests across the USA. New Forests 50 (1): 11-40. http://doi.org/10.1007/s11056-018-09694-6

Duguay, J.P., and P.B. Wood. 2002. Salamander abundance in regenerating forest stands on the Monongahela National Forest, West Virginia. Forest Science 48 (2): 331-335.

Fei, S., and K.C. Steiner. 2007. Evidence for increasing red maple abundance in the eastern United States. Forest Science 53 (4): 473-477.

Green, N.B., and T.K. Pauley. 1987. Amphibians and Reptiles in West Virginia. University of Pittsburgh Press, Feffer and Simons, Inc. 241 p.

Greenberg, C.H., B. Collins, F.R. Thompson III, and W.H. McNab. 2011a. Introduction: What are early successional habitats, why are they important, and how can they be sustained? Pages 1-10 in C.H. Greenberg, B.S. Collins, and F.R. Thompson III (eds.). Sustaining 
Young Forest Communities, Managing Forest Ecosystems 21. http://doi.org/10.1007/97894-007-1620-9_2

Greenberg, C.H., D.J. Levey, and D.L. Loftis. 2005. Fruit production in mature and recently regenerated forests of the Appalachians. Journal of Wildlife Management 71 (2): 321335 .

Greenberg, C.H., R.W. Perry, C.A. Harper, D.J. Levey, and J.M. McCord. 2011b. The role of young, recently disturbed upland hardwood forest as high quality food patches. Pages 121-142 in C.H. Greenberg, B.S. Collins, and F.R. Thompson III (eds.). Sustaining Young Forest Communities, Managing Forest Ecosystems 21. https://doi.org/10.1007/978-94-007-1620-9_8

Greenberg, C.H., K. Weeks, and G.S. Warburton. 2015. The historic role of humans and other keystone species in shaping central hardwood forests for disturbance-dependent wildlife. Pages 319-354 in C.H. Greenberg and B.S. Collins (eds.). Natural Disturbances and Historic Range of Variation: Type, Frequency, Severity, and Post-disturbance Structure in Central Hardwood Forests USA, Managing Forest Ecosystems 32.

Harper, C.A. 2017. Managing Early Successional Plant Communities for Wildlife in the Eastern US. University of Tennessee Press.

Hillman, S.S., P.C. Withers, R.C. Drewers, and S.D. Hillyard. 2009. Ecological and Environmental Physiology of Amphibians. Oxford University Press, New York, NY, USA. 469 p.

Homer, C.G., J.A. Dewitz, L. Yang, S. Jin, P. Danielson, G. Xian, J. Coulston, N.D. Herold, J.D. Wickham, and K. Megown. 2015. Completion of the 2011 National Land Cover Database for the conterminous United States-Representing a decade of land cover change information. Photogrammetric Engineering and Remote Sensing 81 (5): 345-354.

Homyack, J.A., and C.A. Haas. 2009. Long-term effects of experimental forest harvesting on abundance and reproductive demography of terrestrial salamanders. Biological Conservation 142 (1): 110-121. http://doi.org/10.1016/j.biocon.2008.10.003

Hunter, W.C., D.A. Buehler, R.A. Canterbury, J.L. Confer, and P.B. Hamel. 2001. Conservation of disturbance-dependent birds in eastern North America. Wildlife Society Bulletin 29 (2): 440-455.

King, D.I., and S. Schlossberg. 2014. Synthesis of the conservation value of the earlysuccessional stage in forests of eastern North America. Forest Ecology and Management 324: 186-195. http://doi.org/10.1016/j.foreco.2013.12.001

Kuchler, A.M. 1964. Potential natural vegetation of the conterminous United States. American Geographical Society. Special Publication No. 36.

Lee, R., S. Tajehman, D.G. Boyer, and E.W. Repa. 1977. Normal precipitation in West Virginia (Climate). West Virginia Agriculture and Forestry 7: 12-18. 
Litvaitis, J.A. 1993. Responses of early-successional vertebrates to historic changes in land use. Conservation Biology 7 (4): 866-873.

Lorimer, C.G. 2001. Historical and ecological roles of disturbance in eastern North American forests: 9,000 years of change. Wildlife Society Bulletin 29 (2): 425-439.

Lynch, C., and A. Hessl. 2010. Climatic controls on historical wildfires in West Virginia, 19392008. Physical Geography 31 (3): 254-269. http://doi.org/10.2747/0272-3646.31.3.254

Mahoney, K.R., K.R. Russell, W.M. Ford, J.L. Rodrigue, J.D. Riddle, T.M. Schuler, and M.B. Adams. 2016. Woodland salamander responses to a shelterwood harvest-prescribed burn silvicultural treatment within Appalachian mixed-oak forests. Forest Ecology and Management 359: 277-285. http://doi.org/10.1016/j.foreco.2015.09.042

McDermott, M.E, and P.B. Wood. 2010. Influence of cover and food resource variation on postbreeding bird use of timber harvests with residual canopy trees. The Wilson Journal of Ornithology 122 (3): 545-555. http://doi.org/10.1676/09-050.1

Moorman, C.E., K.R. Russell, and C.H. Greenberg. 2011. Reptile and amphibian response to hardwood forest management and early successional habitats. Pages 191-208 in C.H. Greenberg, B.S. Collins, and F.R. Thompson III (eds.). Sustaining Young Forest Communities, Managing Forest Ecosystems 21. http://doi.org/10.1007/978-94-007-16209_11

Morin, R.S., G.W. Cook, C.J. Barnett, B.J. Butler, S.J. Crocker, M.A. Hatfield, C.M. Kurtz, T.W. Lister, W.G. Luppold, W.H. McWilliams, P.D. Miles, M.D. Nelson, C.H. Perry, R.J. Piva, J.E. Smith, J.A. Westfall, R.H. Widmann, C.W. Woodall. 2016. West Virginia Forests 2013. Resource Bulletin. NRS-105. Newtown Square, PA: U.S. Department of Agriculture, Forest Service, Northern Research Station. 128 p. https://doi.org/10.2737/NRS-RB-105

NOAA (National Oceanic and Atmospheric Administration). 2015. Climate of West Virginia. https://www.ncdc.noaa.gov/climatenormals/clim60/states/Clim_WV_01.pdf. Accessed on June 6, 2018.

Oswalt, S.J., K.E. Franzreb, and D.A. Buehler. 2010. Changes in early-successional hardwood forest area in four bird conservation regions across four decades. Joint Meeting of the Forest Inventory and Analysis (FIA) Symposium and the Southern Mensurationists, 8793.

Petranka, J.W., M.P. Brannon, M.E. Hopey, and C.K. Smith. 1994. Effects of timber harvesting on low elevation populations of southern Appalachian salamanders. Forest Ecology and Management 67: 135-147.

Reynolds-Hogland, M.J., M.S. Mitchell, and R.A. Powell. 2006. Spatio-temporal availability of soft mast in clearcuts in the Southern Appalachians. Forest Ecology and Management 237: 103-114. http://doi.org/10.1016/j.foreco.2006.09.035 
Roberts, M.R. 2004. Response of the herbaceous layer to natural disturbance in North American forests. Canadian Journal of Botany 82: 1273-1283.

Roberts, M.R., and F.S. Gilliam. 2003. Response of the herbaceous layer to disturbance in eastern forests. The herbaceous layer in forests of eastern North America, 302-320.

Rodewald, P.G., and M.C. Brittingham. 2004. Stopover habitats of landbirds during fall: Use of edge-dominated and early-successional forests. The Auk: Ornithological Advances 121 (4): 1040-1055. https://doi.org/10.1642/0004-8038(2004)121[1040:SHOLDF]2.0.CO;2

Russell, M.B., C.W. Woodall, K.M. Potter, B.F. Walter, G.M. Domke, and C.M. Oswalt. 2017. Interactions between white-tailed deer density and the composition of forest understories in the northern United States. Forest Ecology and Management 384: 26-33. http://doi.org/10.1016/j.foreco.2016.10.038

Schlossberg, S., and D.I. King. 2007. Ecology and management of scrub-shrub birds in New England: A comprehensive review. USDA Natural Resources Conservation Service, Beltsville, Maryland, USA.

Schlossberg, S., and D.I. King. 2009. Postlogging succession and habitat usage of shrubland birds. The Journal of Wildlife Management 73 (2): 226-231. http://doi.org/10.2193/2007$\underline{518}$

Suthers, H.B., J.M. Bickal, and P.G. Rodewald. 2000. Use of successional habitat and fruit resources by songbirds during autumn migration in central New Jersey. The Wilson Bulletin 112 (2): 249-260. http://www.jstor.org/stable/4164202

Tash, J.P., and J.A. Litvaitis. 2007. Characteristics of occupied habitats and identification of sites for restoration and translocation of New England cottontail populations. Biological Conservation 137 (4): 584-598. http://doi.org/10.1016/j.biocon.2007.03.017

Tavernia, B.G., M.D. Nelson, J.D. Garner, and C.H. Perry. 2016. Spatial characteristics of early successional habitat across the Upper Great Lakes states. Forest Ecology and Management 376: 164-174. http://doi.org/10.1016/j.foreco.2016.04.003

Thompson III, F.R., and D.R. Dessecker. 1997. Management of early-successional communities in central hardwood forests: With special emphasis on the ecology and management of oaks, ruffed grouse, and forest songbirds. General Technical Report NC-195. St. Paul, MN: U.S. Department of Agriculture, Forest Service, North Central Forest Experiment Station.

Trani, M.K., R.T. Brooks, T.L. Schmidt, V.A. Rudis, and C.M. Gabbard. 2001. Patterns and trends of early successional forests in the eastern United States. Wildlife Society Bulletin 29 (2): 413-424.

USDA (United States Department of Agriculture). 1940-2012. United States Census of Agriculture, USDA, National Agricultural Statistics Service. 
Webster, C.R., Y.L. Dickinson, J.I. Burton, L.E. Frelich, M.A. Jenkins, C.C.Kern, P. Raymond, M.R. Saunders, M.B. Walters, and J.L.Willis. 2018. Promoting and maintaining diversity in contemporary hardwood forests: Confronting contemporary drivers of change and the loss of ecological memory. Forest Ecology and Management 421: 98-108.

http://doi.org/10.1016/j.foreco.2018.01.010

WVDNR (West Virginia Division of Natural Resources). 2015. West Virginia Division of Natural Resources State Wildlife Action Plan, pp 1103.

White, P.S., B. Collins, and G.R. Wein. 2011. Natural disturbances and early successional habitats. Pages 27-40 in C.H. Greenberg, B.S. Collins, and F.R. Thompson III (eds.). Sustaining Young Forest Communities, Managing Forest Ecosystems 21. http://doi.org/10.1007/978-94-007-1620-9_3

Williams, M. 1989. Americans and their forests. Cambridge University Press. New York, NY, USA.

Wilson, M.K., W.H. Lowe, and K.H. Nislow. 2014. Family richness and biomass of understory invertebrates in early and late successional habitats of northern New Hampshire. Journal of Forestry 112 (4): 337-345. http://doi.org/10.5849/jof.14-017

Woods, A.J., J.M. Omernik, and D.D. Brown. 1999. Level III and IV ecoregions of Delaware, Maryland, Pennsylvania, Virginia, and West Virginia. U.S. Environmental Protection Agency, National Health and Environmental Effects Research Laboratory. 


\section{Tables}

Table 1-1. Species considered young or early-successional forest associates included in the West Virginia Division of Natural Resources' State Wildlife Action Plan (SWAP 2015). Species groups designed with “*” includes species associated with young/early-successional forest or grasslands.

\begin{tabular}{ll}
\hline Common Name & Scientific Name \\
\hline Amphibians & \\
\hline Fowler's Toad & Anaxyrus fowleri \\
\hline Birds & Scolopax minor \\
\hline American Woodcock & Coccyzus erythrophthalmus \\
Black-billed Cuckoo & Vermivora cyanoptera \\
Blue-winged Warbler & Antrostomus carolinensis \\
Chuck-will's-widow & Antrostomus vociferus \\
Eastern Whip-poor-will & Spizella pusilla \\
Field Sparrow & Vermivora chrysoptera \\
Golden-winged Warbler & Lanius ludovicianus \\
Loggerhead Shrike & Asio otus \\
Long-eared Owl & Setophaga discolor \\
Prairie Warbler & Bonasa umbellus \\
Ruffed Grouse & Icteria virens \\
Yellow-breasted Chat & \\
\hline Mammals & Reithrodontomys humulis \\
\hline Eastern Harvest Mouse & Ochrotomys nuttalli \\
Golden Mouse & Cryptotis parva \\
Least Shrew & Zapus hudsonius \\
Meadow Jumping Mouse & Microtus ochrogaster \\
Prairie Vole & Synaptomys cooperi \\
Southern Bog Lemming & Corynorhinus townsendii virginianus \\
Virginia Big-eared Bat & \\
\hline Reptiles* & Terrapene carolina carolina \\
\hline Eastern Box Turtle & Virginia valeriae valeriae \\
Eastern Earthsnake & Lampropeltis getula \\
Eastern Kingsnake & Scinella lateralis \\
Little Brown Skink & Virginia valeriae pulchra \\
Mountain Earthsnake & Coluber constrictor constrictor \\
Northern Black Racer & Pituophis melanoleucus melanoleucus \\
Northern Pinesnake & Opheodrys aestivus \\
Rough Greensnake & Liochlorophis vernalis \\
Smooth Greensnake & \\
\hline & \\
\hline &
\end{tabular}


Table 1-2. Data collection timetable for 11 cut-back border blocks and 16 regeneration stand blocks at 11 wildlife management areas.

\begin{tabular}{|c|c|c|c|c|}
\hline & 2016 & 2017 & 2018 & 2019 \\
\hline Cut-back Borders & \multirow{9}{*}{$\begin{array}{l}1 \text { Year Pre- } \\
\text { harvest }\end{array}$} & \multirow{9}{*}{$\begin{array}{l}1 \text { Year Post- } \\
\text { harvest }\end{array}$} & \multirow{9}{*}{$\begin{array}{l}2 \text { Years Post- } \\
\text { harvest }\end{array}$} & \\
\hline Right-of-way & & & & \\
\hline Gas Pipeline & & & & \\
\hline Burnsville Lake WMA (1 block) & & & & \\
\hline $\begin{array}{l}\text { Transmission Powerline } \\
\text { Little Canaan WMA ( } 2 \text { blocks) }\end{array}$ & & & & \\
\hline Wildlife Opening & & & & \\
\hline Stonewall Jackson WMA (1 block) & & & & \\
\hline Regeneration Stands & & & & \\
\hline Little Canaan WMA (4 blocks) & & & & \\
\hline
\end{tabular}

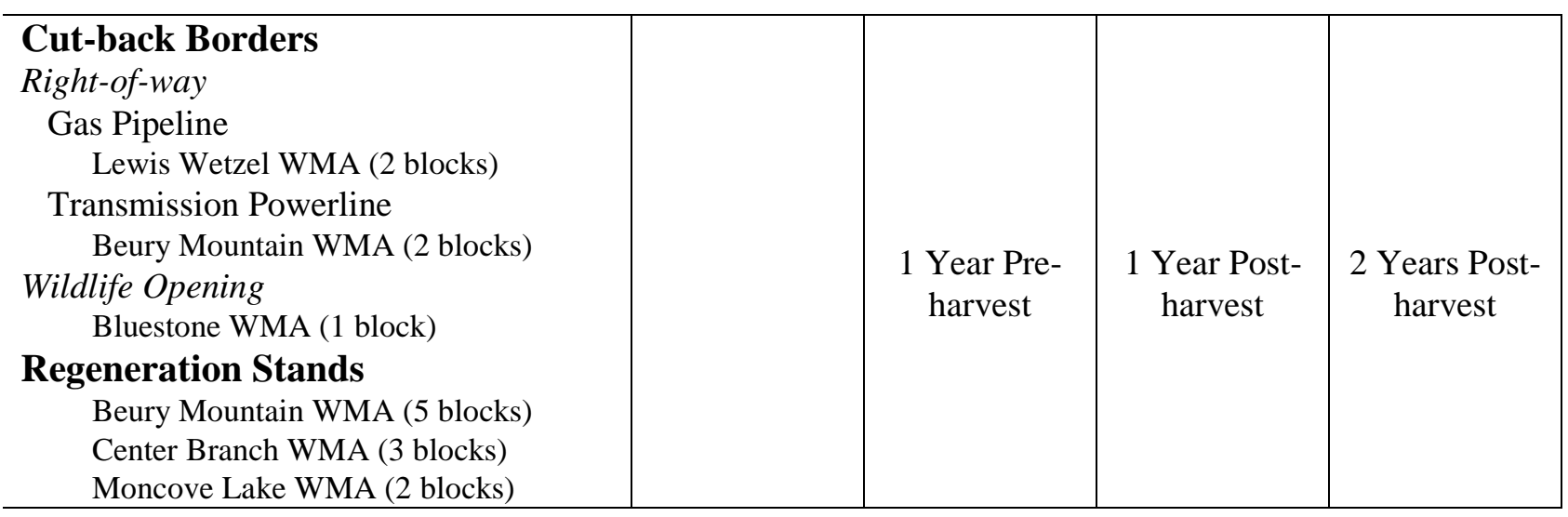

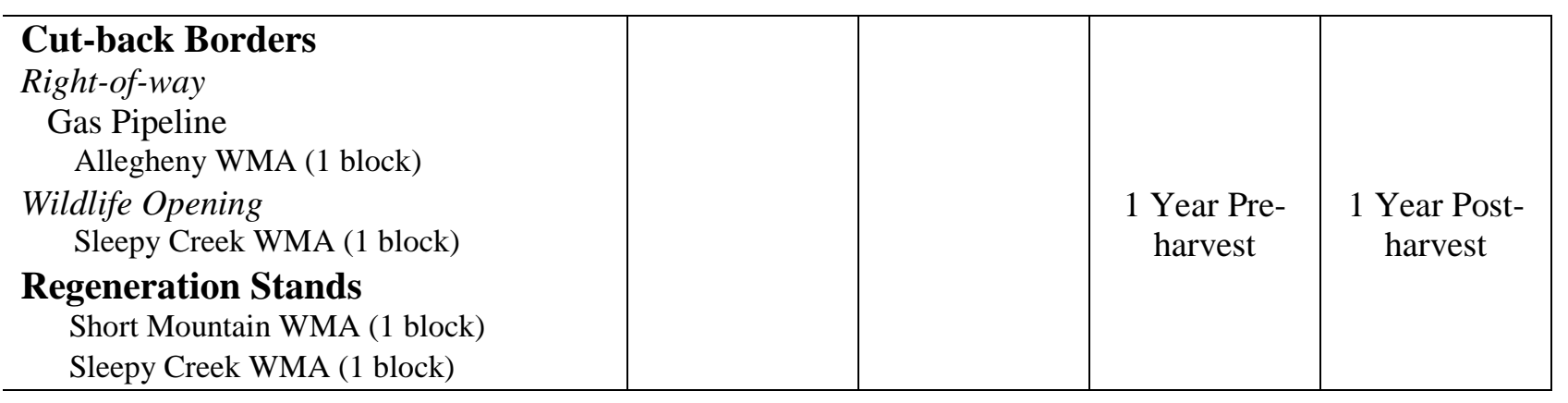




\section{Figures}

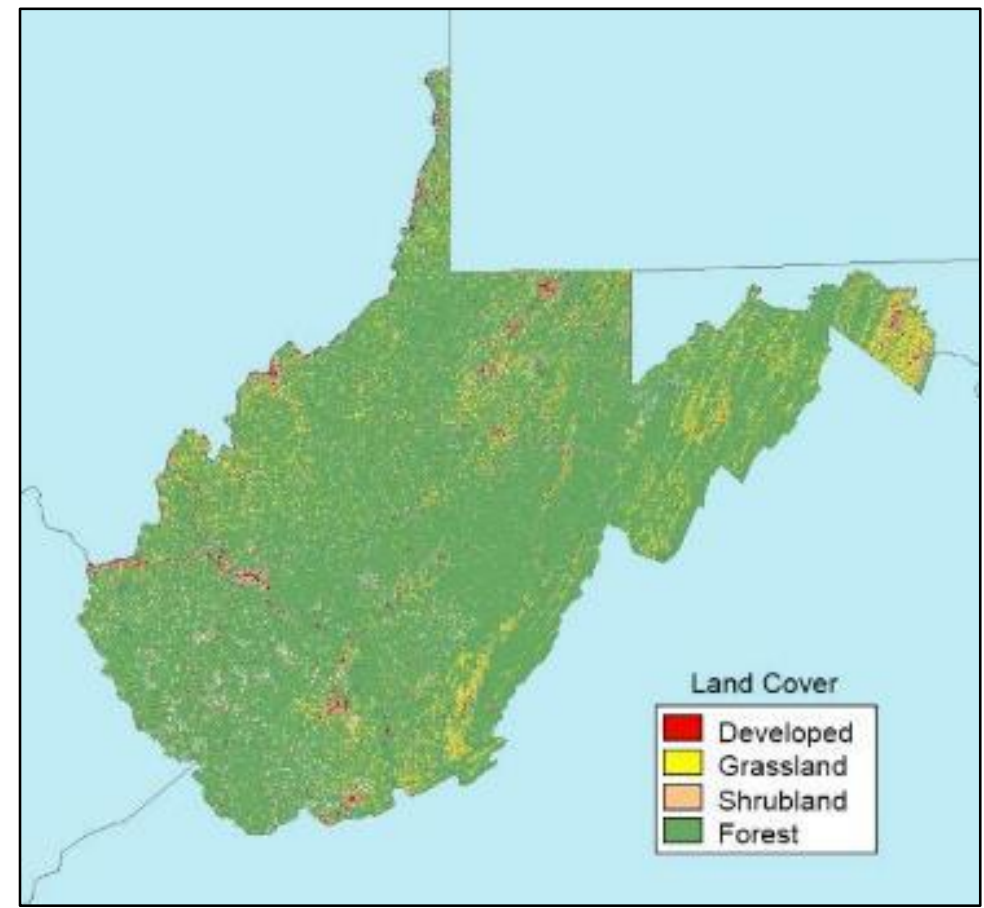

Figure 1-1. Land classification of West Virginia (2011 National Land Cover Database).

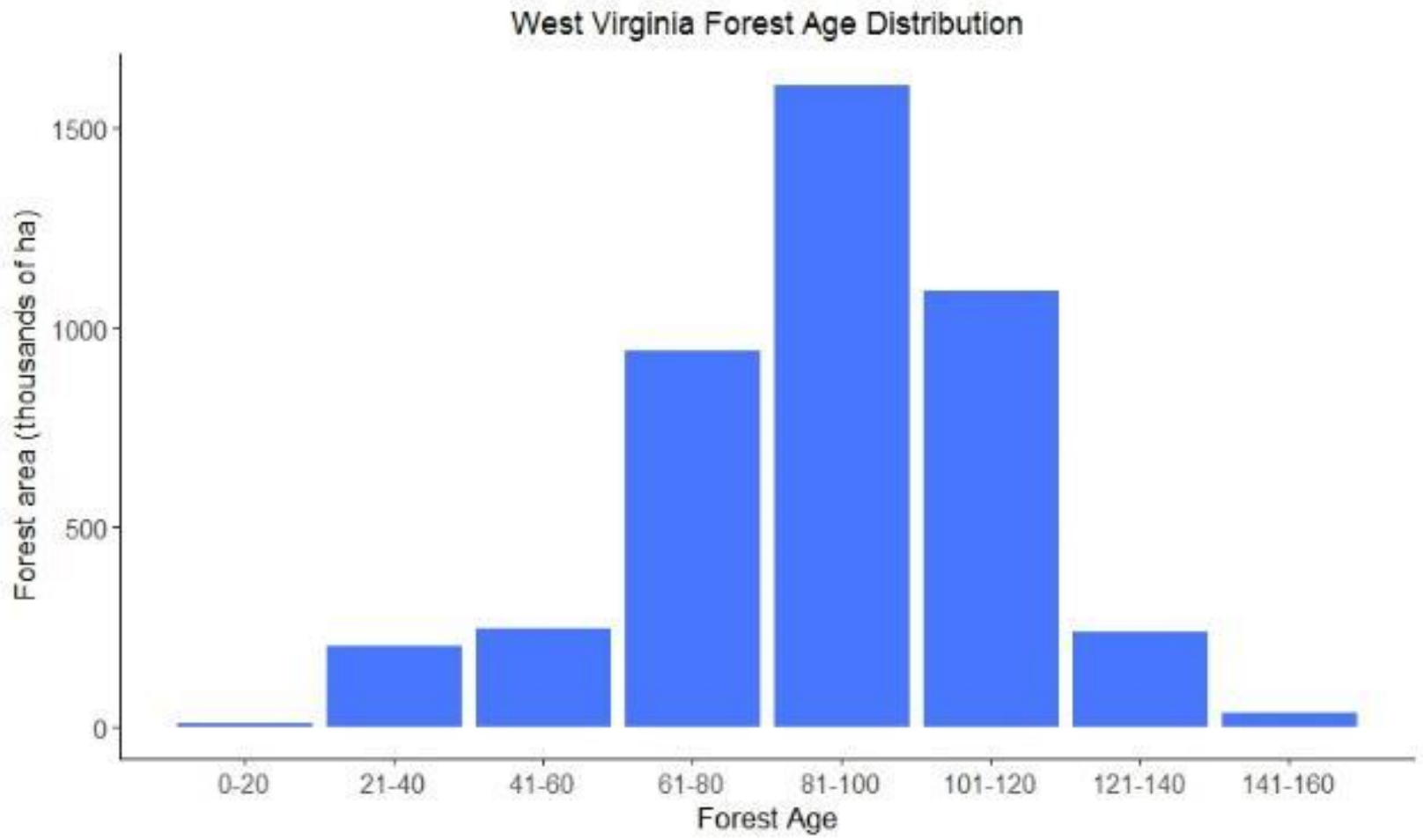

Figure 1-2. Age class distribution of forests in West Virginia (Morin et al. 2016). 


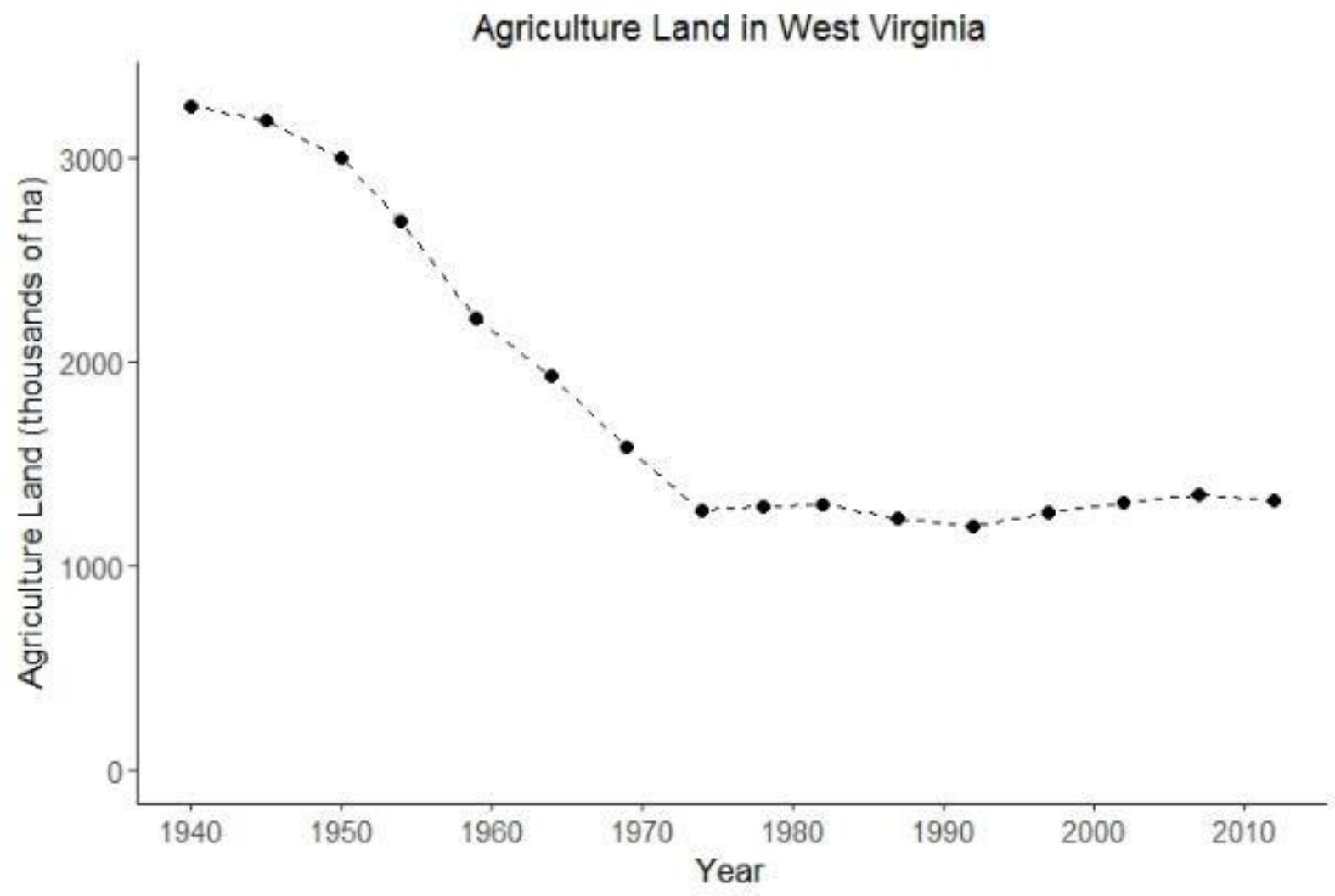

Figure 1-3. Total area of agriculture land in West Virginia (USDA 1940-2012).

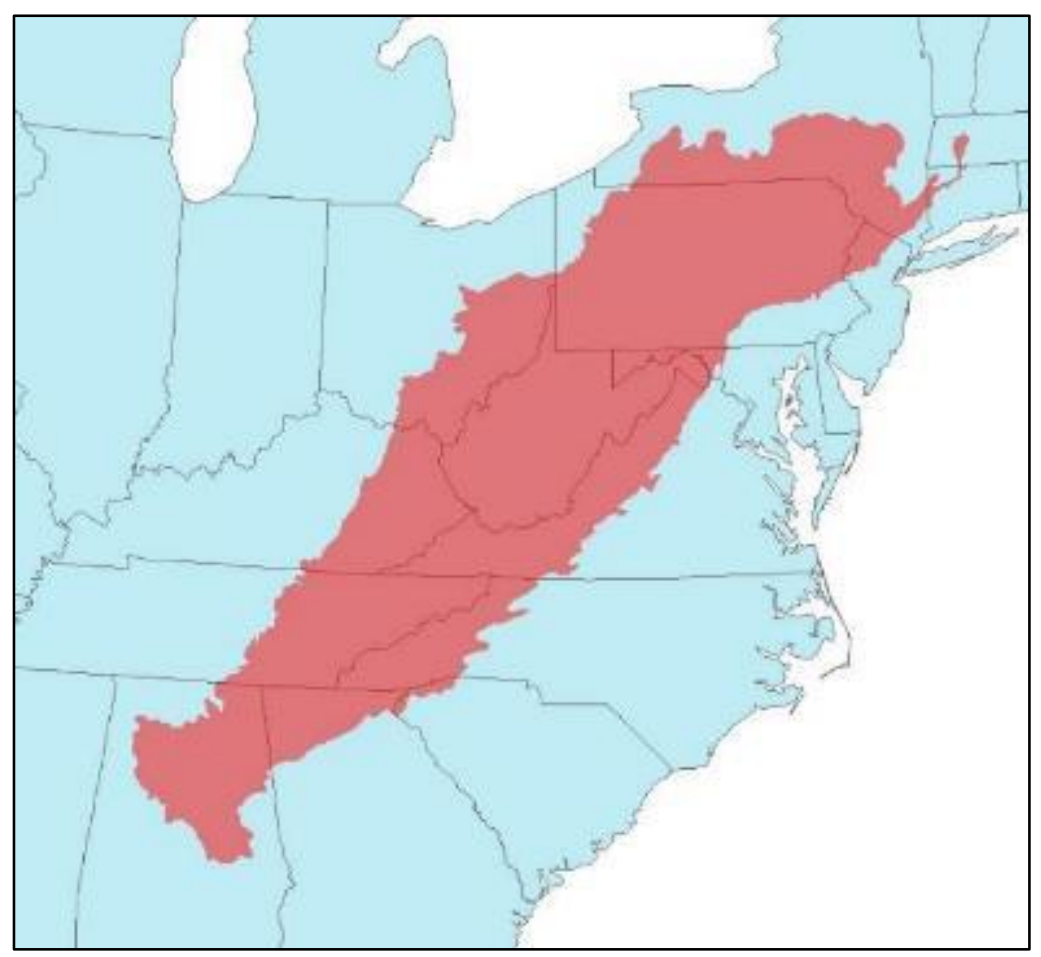

Figure 1-4. Delineated area (red) of the Appalachian region of the eastern United States. 


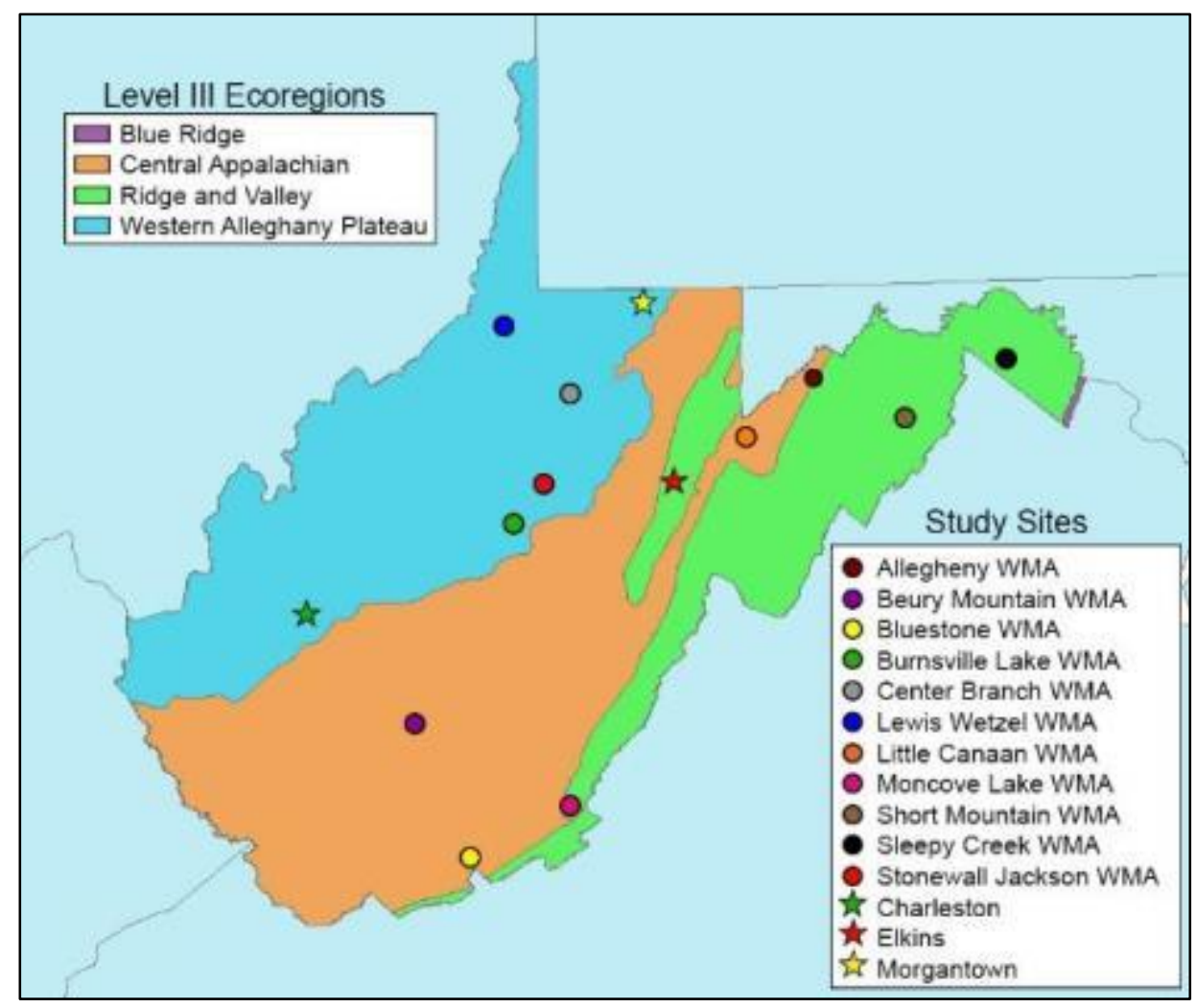

Figure 1-5. Level III ecoregions in West Virginia with study sites (circles) and major cities (stars) overlaid. 


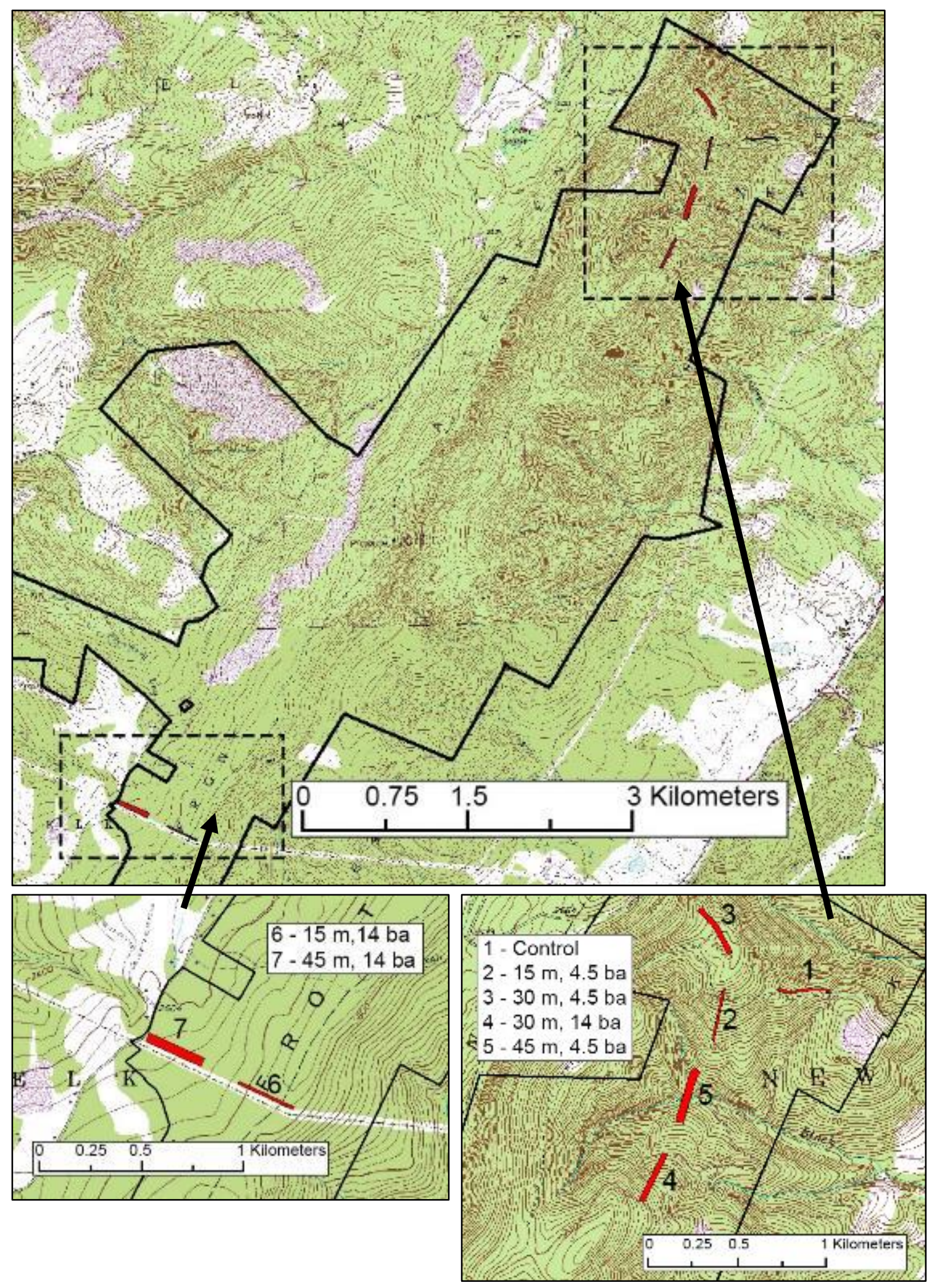

Figure 1-6. Allegheny Wildlife Management Area plot layout. There is one replication of cutback borders along a transmission powerline and gas pipeline at Allegheny. 


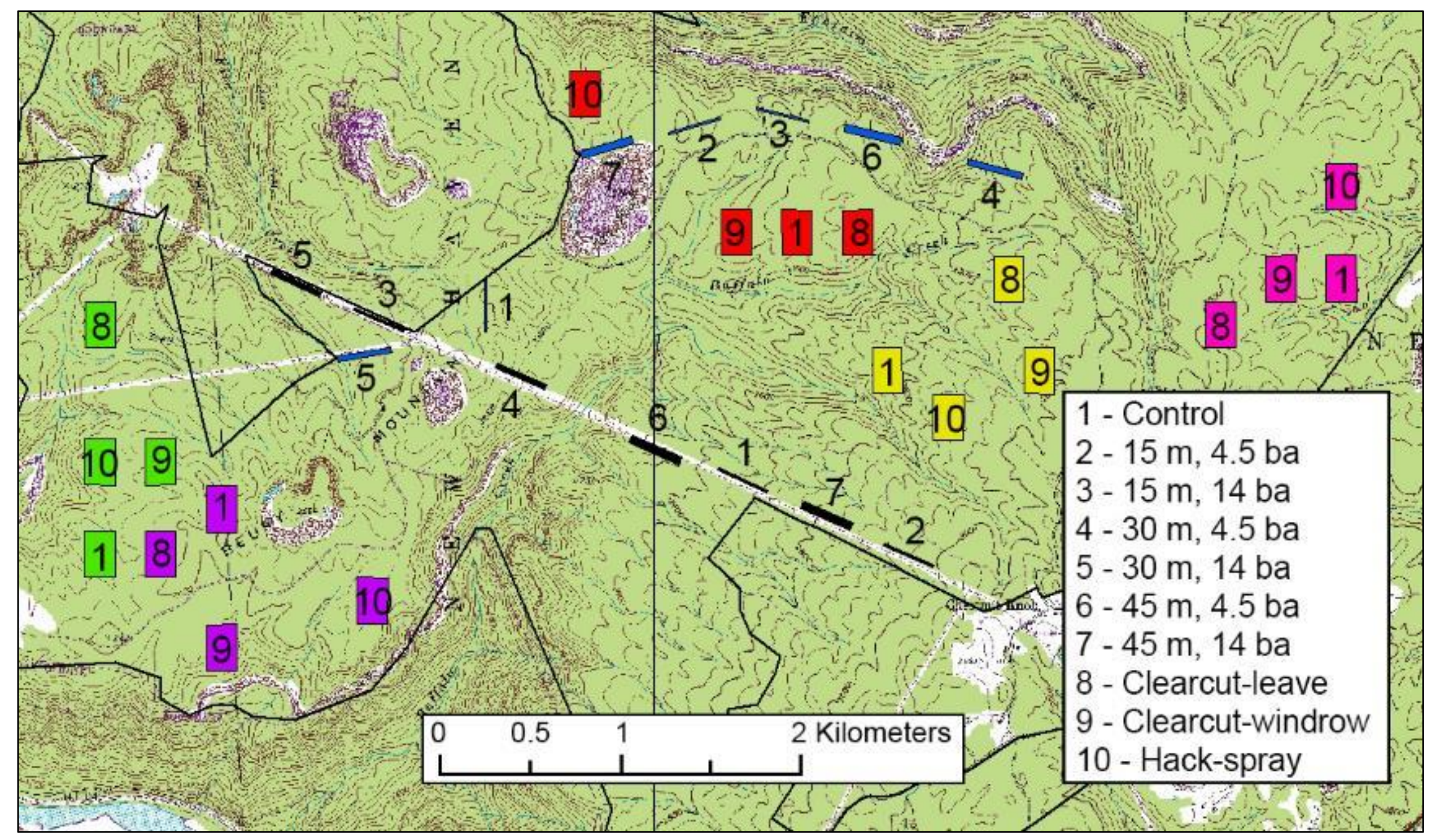

Figure 1-7. Beury Mountain Wildlife Management Area plot layout. There are two replications of cut-back borders along transmissions powerlines, and five replications of regeneration stands at Beury Mountain. Colors denote different block replicates. 


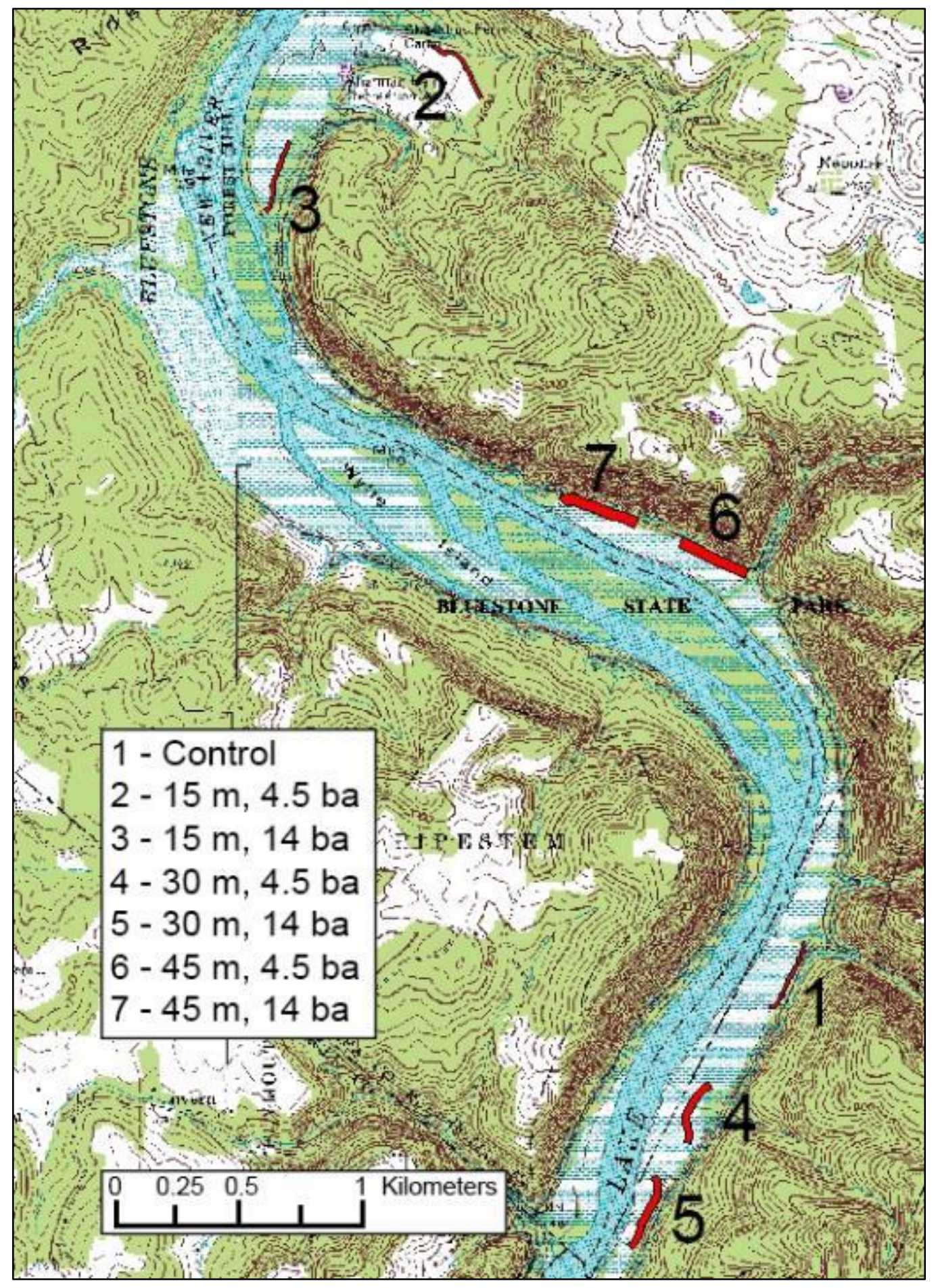

Figure 1-8. Bluestone Wildlife Management Area plot layout. There is one replication of cutback borders along wildlife openings at Bluestone. 


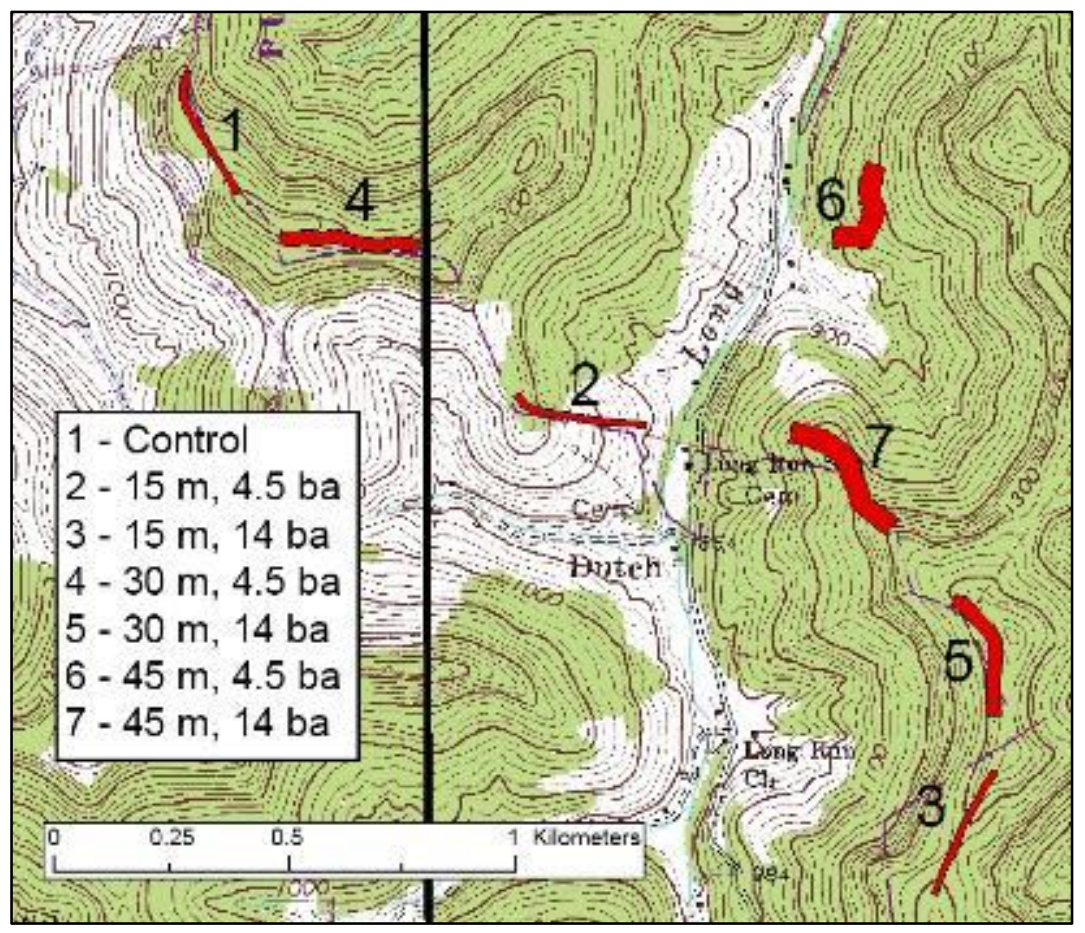

Figure 1-9. Burnsville Lake Wildlife Management Area plot layout. There is one replication of cut-back borders along a gas pipeline at Burnsville.

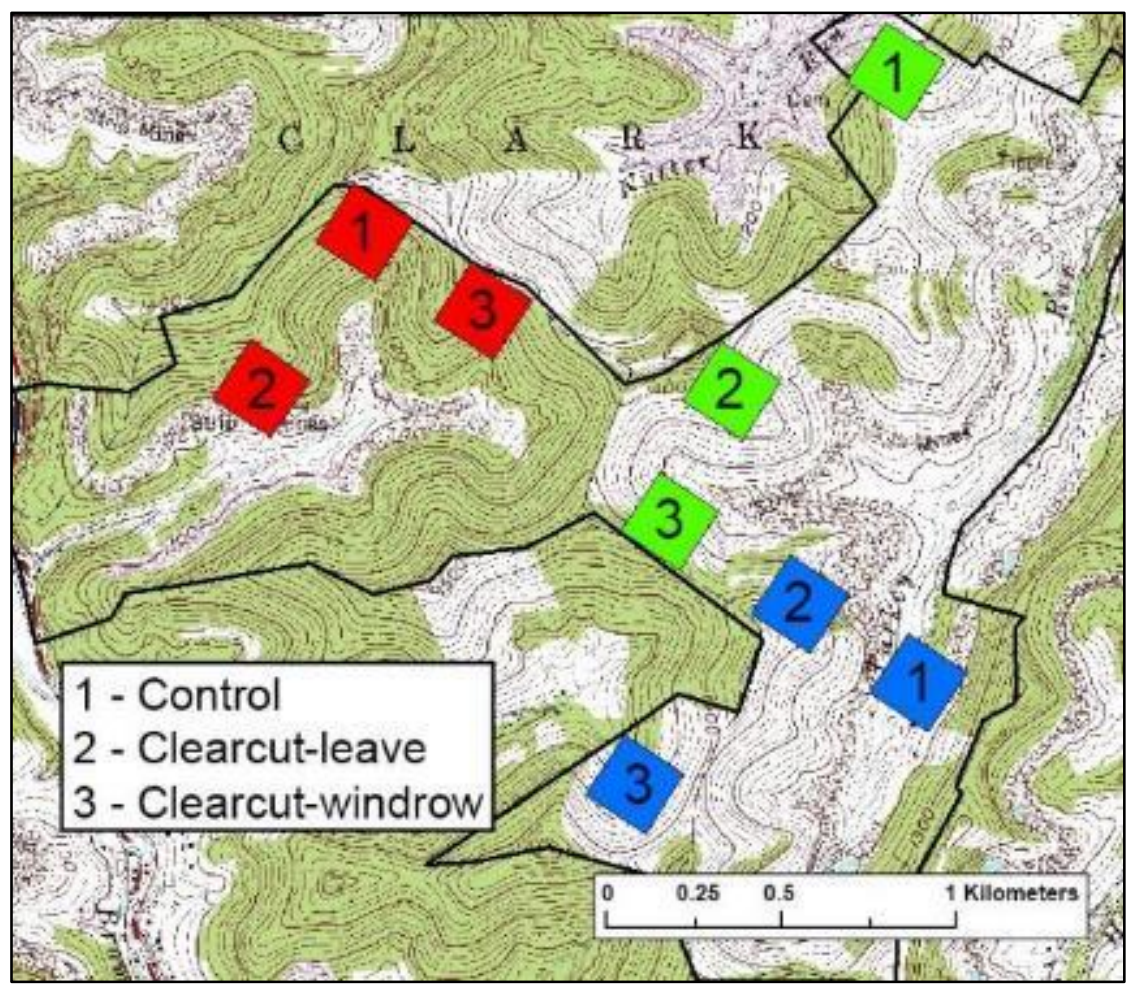

Figure 1-10. Center Branch Wildlife Management Area plot layout. There are three replications of regeneration plots at Center Branch, with no hack-and-spray treatments. Colors denote separate block replicates. 


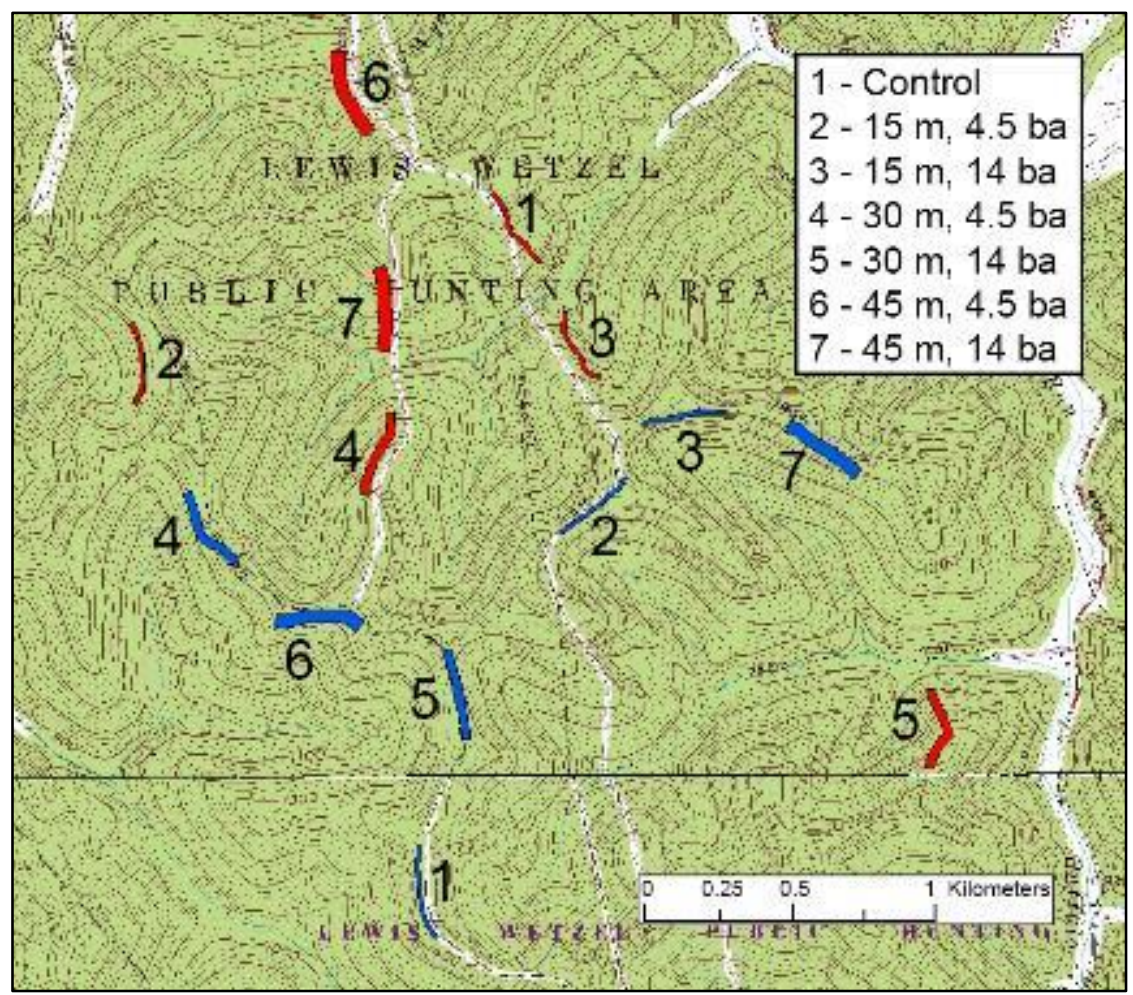

Figure 1-11. Lewis Wetzel Wildlife Management Area plot layout, with two replications of cutback borders along gas pipelines at Lewis Wetzel. Colors denote separate block replicates.

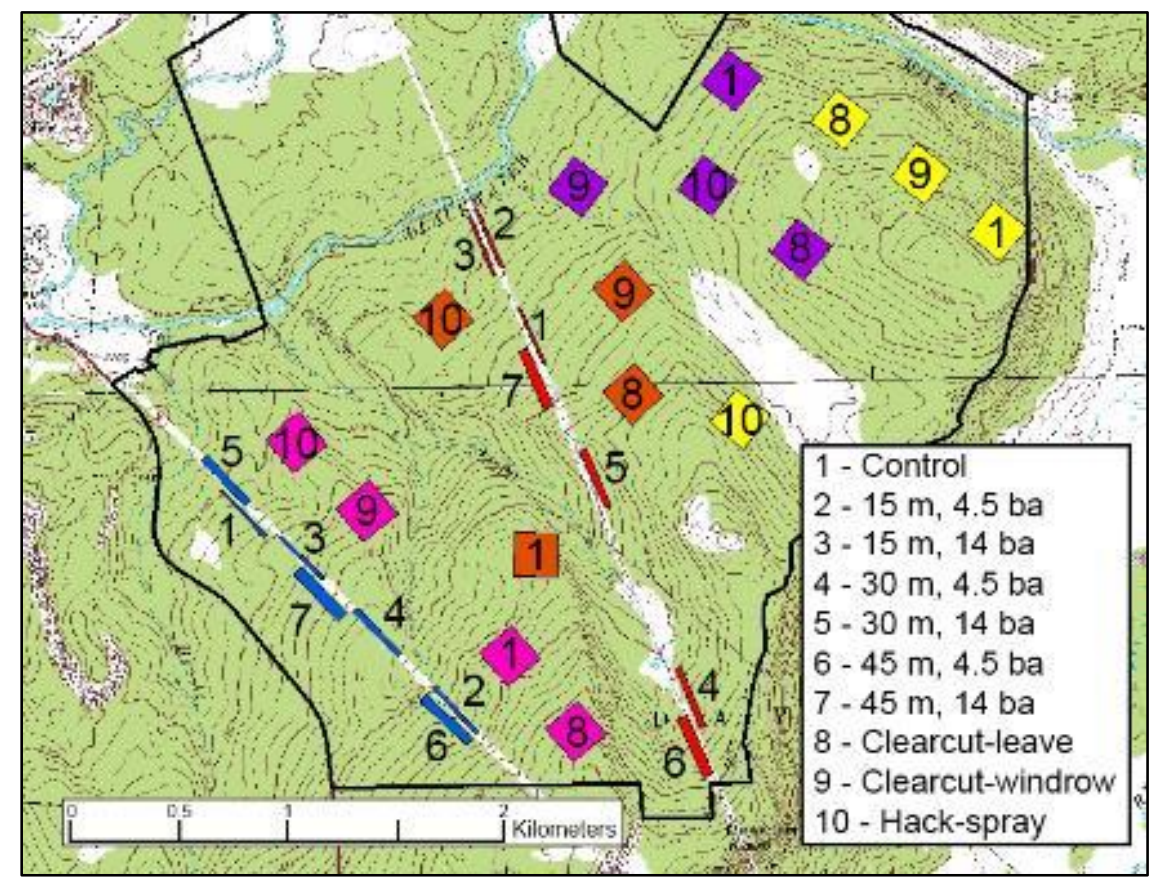

Figure 1-12. Little Canaan Wildlife Management Area plot layout. There are two cut-back border replications along transmission powerlines, and four replications of regeneration stands. Colors denote different block replicates. 


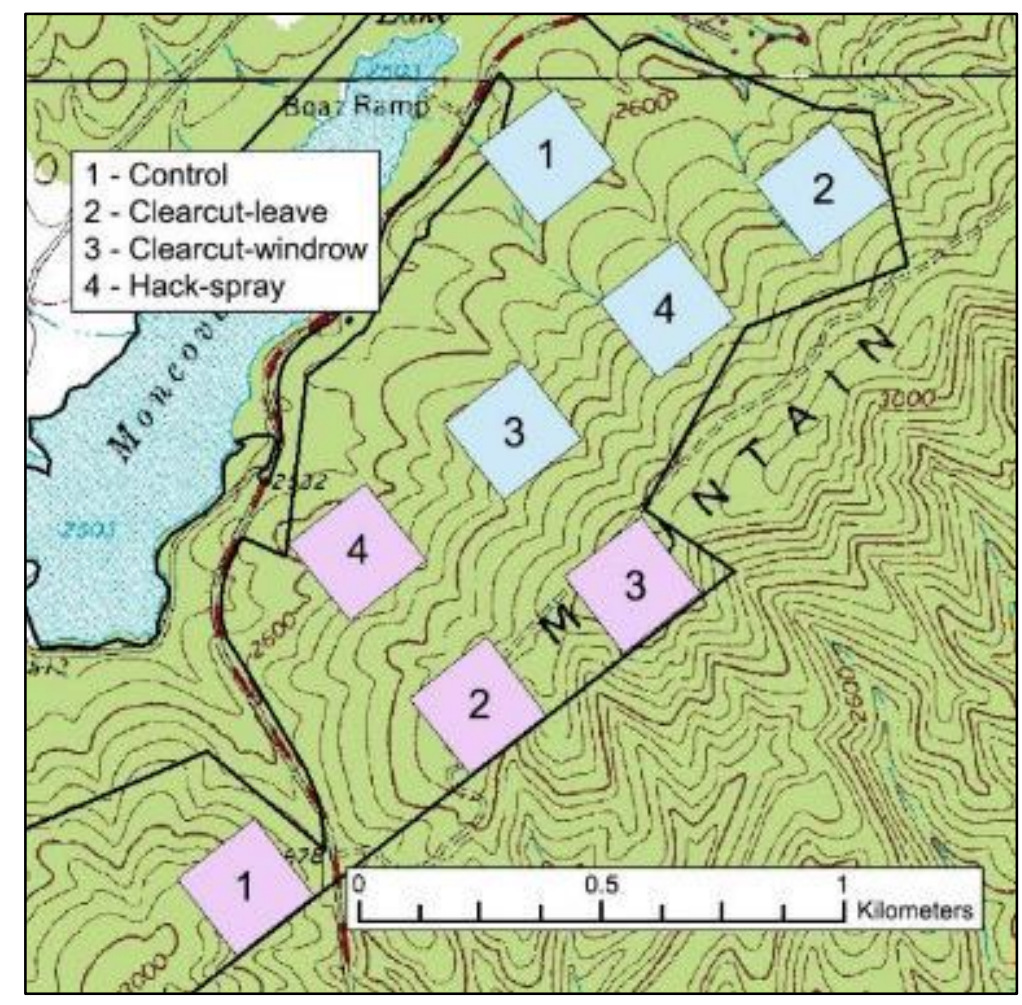

Figure 1-13. Moncove Lake Wildlife Management Area plot layout. There are two replications of regeneration stands. Colors denote different block replicates.

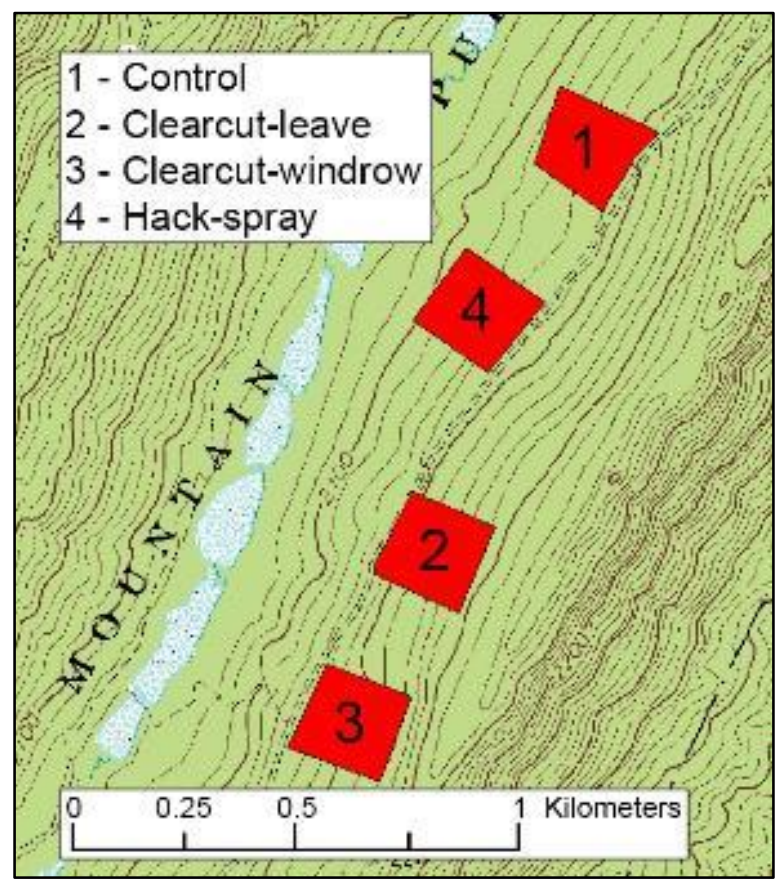

Figure 1-14. Short Mountain Wildlife Management Area plot layout. There is one replication of regeneration stands. 


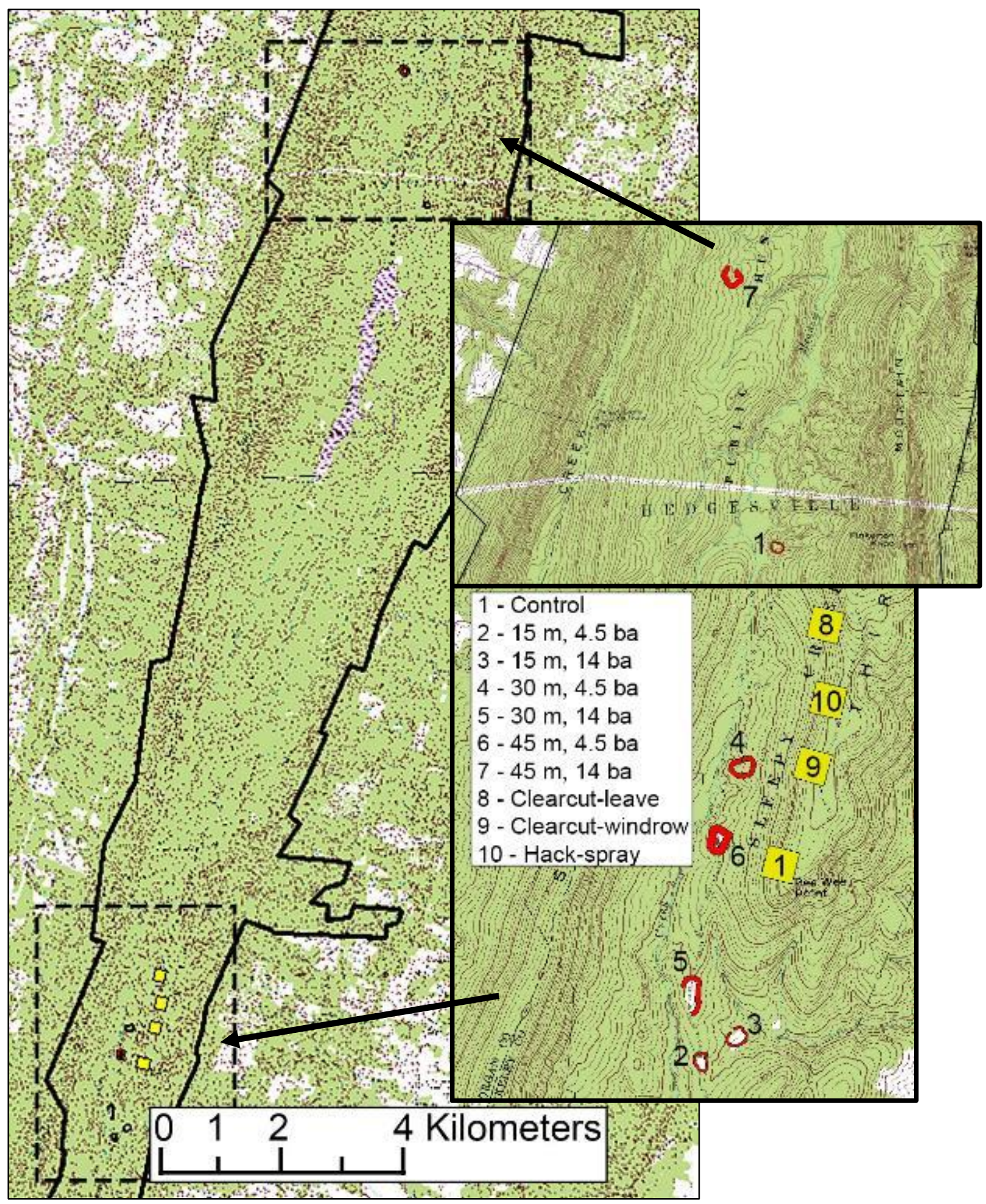

Figure 1-15. Sleepy Creek Wildlife Management Area plot layout. There is one replication of cutback borders along wildlife openings, and one replication of regeneration stands. 


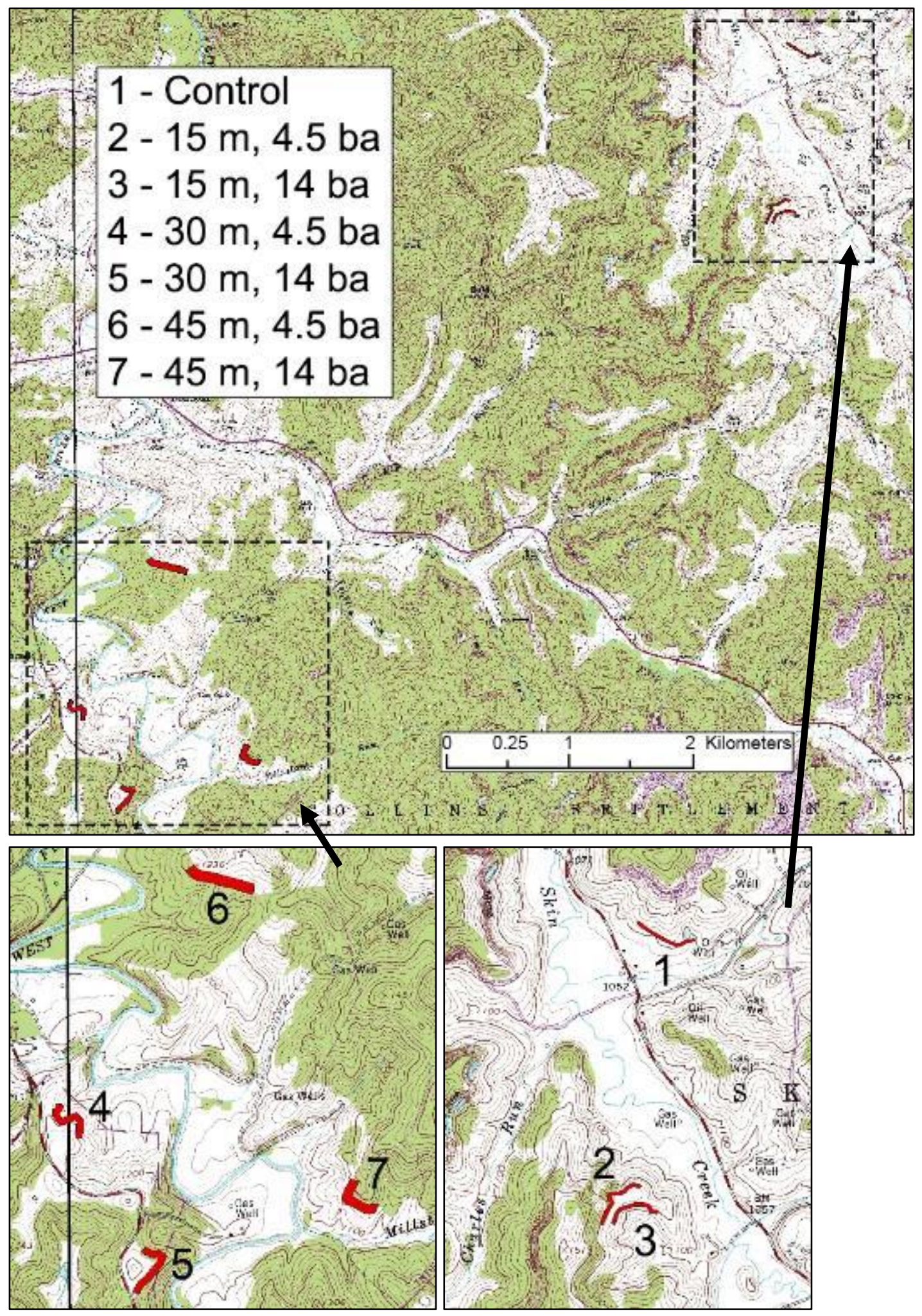

Figure 1-16. Stonewall Jackson Wildlife Management Area plot layout. There is one replication of cut-back border along wildlife openings. 


\section{Appendices}

Appendix 1-A. Passerine species detected during study period (2016-2019) at study sites. Column labeled "Status" refers to breeding status: breeding - spends majority of summer but not fall, winter, or spring in WV, migrating - spends fall and winter in WV or passes through WV during the spring but does not spend the majority of the summer in WV, resident - spends summer, fall, winter, and spring in WV.

\begin{tabular}{|c|c|c|c|c|c|c|}
\hline Common Name & Scientific Name & Alpha Code & Status & Habitat Guild & Nesting Guild & Foraging Guild \\
\hline Acadian Flycatcher & Empidonax virescens & ACFL & Breeding & Forest Gap & Sub-canopy & Air \\
\hline Alder Flycatcher & Empidonax alnorum & ALFL & Breeding & Young Forest & Shrub & Air \\
\hline American Crow & Corvus brachyrhynchos & AMCR & Resident & Interior-edge & Sub-canopy & Predator \\
\hline American Goldfinch & Spinus tristis & AMGO & Breeding & Young Forest & Sub-canopy & Foliage \\
\hline American Redstart & Setophaga ruticilla & AMRE & Breeding & Interior-edge & Sub-canopy & Foliage \\
\hline American Robin & Turdus migratorius & AMRO & Resident & Interior-edge & Sub-canopy & Foliage \\
\hline Baltimore Oriole & Icterus galbula & BAOR & Breeding & Interior-edge & Sub-canopy & Foliage \\
\hline Black-and-white Warbler & Mniotilta varia & BAWW & Breeding & Forest Interior & Ground & Bark \\
\hline Black-capped Chickadee & Poecile atricapillus & $\mathrm{BCCH}$ & Resident & Interior-edge & Secondary Cavity & Bark \\
\hline Black-throated Blue Warbler & Setophaga caerulescens & BTBW & Breeding & Forest Interior & Shrub & Foliage \\
\hline Black-throated Green Warbler & Setophaga virens & BTNW & Breeding & Forest Gap & Sub-canopy & Foliage \\
\hline Blackburnian Warbler & Setophaga fusca & BLBW & Migrating & Forest Interior & Canopy & Foliage \\
\hline Blackpoll Warbler & Setophaga striata & BLPW & Migrating & Interior-edge & Sub-canopy & Foliage \\
\hline Blue-gray Gnatcatcher & Polioptila caerulea & BGGN & Breeding & Interior-edge & Sub-canopy & Foliage \\
\hline Blue-headed Vireo & Vireo solitarius & BHVI & Breeding & Forest Interior & Sub-canopy & Foliage \\
\hline Blue-winged Warbler & Vermivora cyanoptera & BWWA & Breeding & Young Forest & Shrub & Foliage \\
\hline Brown-headed Cowbird & Molothrus ater & $\mathrm{BHCO}$ & Resident & Interior-edge & Parasite & Ground \\
\hline Brown Creeper & Certhia americana & BRCR & Resident & Forest Interior & Secondary Cavity & Bark \\
\hline Brown Thrasher & Toxostoma rufum & BRTH & Breeding & Young Forest & Shrub & Ground \\
\hline Cape May Warbler & Setophaga tigrina & CMWA & Migrating & Interior-edge & Sub-canopy & Foliage \\
\hline Canada Warbler & Cardellina canadensis & CAWA & Breeding & Interior-edge & Shrub & Foliage \\
\hline Carolina Chickadee & Poecile carolinensis & $\mathrm{CACH}$ & Resident & Interior-edge & Secondary Cavity & Bark \\
\hline Carolina Wren & Thryothorus ludovicianus & CARW & Resident & Young Forest & Secondary Cavity & Ground \\
\hline Cedar Waxwing & Bombycilla cedrorum & CEDW & Resident & Interior-edge & Sub-canopy & Foliage \\
\hline Cerulean Warbler & Setophaga cerulea & CERW & Breeding & Forest Gap & Canopy & Foliage \\
\hline Chestnut-sided Warbler & Setophaga pensylvanica & CSWA & Breeding & Young Forest & Shrub & Foliage \\
\hline
\end{tabular}


Appendix 1-A continued.

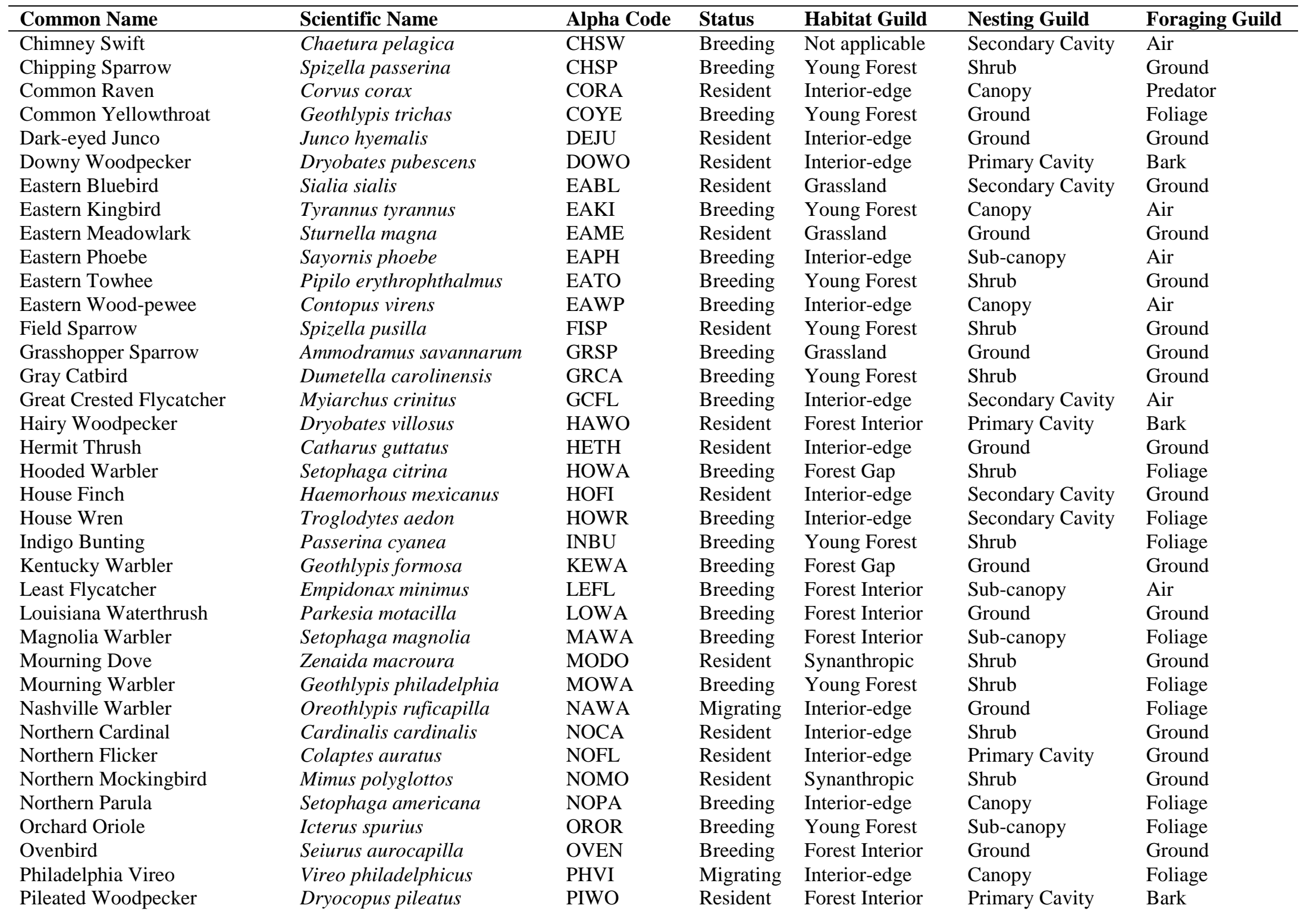


Appendix 1-A continued.

\begin{tabular}{|c|c|c|c|c|c|c|}
\hline Common Name & Scientific Name & Alpha Code & Status & Habitat Guild & Nesting Guild & Foraging Guild \\
\hline Pine Warbler & Setophaga pinus & PIWA & Breeding & Forest Interior & Shrub & Foliage \\
\hline Prairie Warbler & Setophaga discolor & PRAW & Breeding & Young Forest & Shrub & Foliage \\
\hline Red-bellied Woodpecker & Melanerpes carolinus & RBWO & Resident & Interior-edge & Primary Cavity & Bark \\
\hline Red-breasted Nuthatch & Sitta canadensis & RBNU & Resident & Forest Interior & Secondary Cavity & Bark \\
\hline Red-eyed Vireo & Vireo olivaceus & REVI & Breeding & Forest Gap & Sub-canopy & Foliage \\
\hline Red-winged Blackbird & Agelaius phoeniceus & RWBL & Resident & Grassland & Shrub & Foliage \\
\hline Rose-breasted Grosbeak & Pheucticus ludovicianus & RBGR & Breeding & Interior-edge & Sub-canopy & Foliage \\
\hline Ruby-crowned Kinglet & Regulus calendula & RCKI & Migrating & Forest Interior & Sub-canopy & Foliage \\
\hline Ruffed Grouse & Bonasa umbellus & RUGR & Resident & Young Forest & Ground & Ground \\
\hline Scarlet Tanager & Piranga olivacea & SCTA & Breeding & Forest Interior & Canopy & Foliage \\
\hline Song Sparrow & Melospiza melodia & SOSP & Resident & Synanthropic & Shrub & Foliage \\
\hline Swainson's Thrush & Catharus ustulatus & SWTH & Breeding & Forest Interior & Shrub & Ground \\
\hline Swainson's Warbler & Limnothlypis swainsonii & SWWA & Breeding & Forest Gap & Shrub & Ground \\
\hline Tennessee Warbler & Oreothlypis peregrina & TEWA & Migrating & Young Forest & Ground & Foliage \\
\hline Tree Swallow & Tachycineta bicolor & TRES & Breeding & Not applicable & Secondary Cavity & Air \\
\hline Tufted Titmouse & Baeolophus bicolor & TUTI & Resident & Forest Interior & Secondary Cavity & Foliage \\
\hline Warbling Vireo & Vireo gilvus & WAVI & Breeding & Interior-edge & Sub-canopy & Foliage \\
\hline White-breasted Nuthatch & Sitta carolinensis & WBNU & Resident & Forest Gap & Secondary Cavity & Bark \\
\hline White-eyed Vireo & Vireo griseus & WEVI & Breeding & Young Forest & Shrub & Foliage \\
\hline Willow Flycatcher & Empidonax traillii & WIFL & Breeding & Young Forest & Shrub & Air \\
\hline Wilson's Warbler & Cardellina pusilla & WIWA & Migrating & Young Forest & Ground & Foliage \\
\hline Winter Wren & Troglodytes hiemalis & WIWR & Resident & Forest Interior & Secondary Cavity & Ground \\
\hline Wood Thrush & Hylocichla mustelina & WOTH & Breeding & Forest Interior & Sub-canopy & Ground \\
\hline Worm-eating Warbler & Helmitheros vermivorum & WEWA & Breeding & Forest Interior & Ground & Foliage \\
\hline Yellow-bellied Sapsucker & Sphyrapicus varius & YBSA & Resident & Interior-edge & Primary Cavity & Bark \\
\hline Yellow-billed Cuckoo & Coccyzus americanus & YBCU & Breeding & Interior-edge & Sub-canopy & Foliage \\
\hline Yellow-breasted Chat & Icteria virens & $\mathrm{YBCH}$ & Breeding & Young Forest & Shrub & Foliage \\
\hline Yellow-throated Vireo & Vireo flavifrons & YTVI & Breeding & Interior-edge & Canopy & Foliage \\
\hline Yellow-throated Warbler & Setophaga dominica & YTWA & Breeding & Forest Interior & Canopy & Foliage \\
\hline Yellow Warbler & Setophaga petechia & YEWA & Breeding & Young Forest & Shrub & Foliage \\
\hline
\end{tabular}




\title{
CHAPTER 2
}

\section{SHORT-TERM AVIAN AND SALAMANDER RESPONSE TO CUT-BACK BORDERS}

\begin{abstract}
Throughout the eastern United States, young forest wildlife species continue to experience declining populations from habitat loss stemming from altered disturbance regimes and habitat conversion. However, the recent proliferation of linear energy infrastructure throughout the central Appalachian region has prompted managers to explore ways of managing the young forest bird community in association with these long, linear openings but little empirical data exist. At the same time, forest interior wildlife (e.g., songbirds and woodland salamanders) are often negatively affected by energy infrastructure within forest dominated landscapes and any young forest management in these landscapes may further degrade habitats for forest interior species. In this chapter we studied how harvest size $(15 \mathrm{~m}, 30 \mathrm{~m}$, and $45 \mathrm{~m}$ wide) and intensity $\left(14 \mathrm{~m}^{2} /\right.$ ha and $4.5 \mathrm{~m}^{2} /$ ha residual basal area) of cut-back borders, which are linear tree cuttings adjacent to gas/oil pipeline and utility powerline rights-of-way (ROWs) or wildlife openings, influenced habitat suitability along ROWs and wildlife openings for the young forest and forest interior communities. The objectives of this chapter were to examine whether the presence of cut-back borders increased habitat suitability for wildlife species and which cut-back border treatments optimized the tradeoff between maximizing positive responses of disturbancedependent species (i.e., young forest species) and minimizing negative responses of disturbanceavoidant species (i.e., forest interior species). We found that young forest species' abundances and species richness increased one-year and two-years after treatment, particularly in the 15-m wide borders, likely due to the increase of young forest habitat in conjunction with existing habitat in ROW corridors or wildlife openings. Additionally, we found that forest interior species, a group that is often negatively affected by ROWs in forested landscapes, did not decrease in cut-back borders following treatment likely because the retention of canopy trees in combination with adjacent mature forests retained suitable habitat conditions. These results suggest that cut-back borders along abrupt forest edges of ROWs and wildlife openings create suitable habitat conditions for young forest avifauna without negatively affecting forest interior
\end{abstract}


avifauna. Cut-back borders, particularly those $15-\mathrm{m}$ in width, appear to be a viable management option for managing forest bird communities in ROW and wildlife opening landscapes.

\section{Introduction}

\subsection{Introduction}

The central Appalachian region, United States (US) is predominantly comprised of mature (>60 years old), large diameter forestlands (Oswalt et al. 2010, Morin et al. 2016). Current forest conditions are the result of socio-economically driven shifts in disturbance regimes (e.g., fire suppression, reduction of large-scale timber management) over the past century (Lorimer 2001). The decreased prevalence of forest disturbance has resulted in conditions unsuitable for wildlife species that are specialized in exploiting the seral stage immediately following disturbance (i.e., young forest). Further, habitat loss from human influences (e.g., agriculture, urbanization) has exacerbated pressures of changing disturbance regimes on young forest species. Declining total area and conversion of young forests are among the primary causes of young forest wildlife population declines (Dettmers 2003, King and Schlossberg 2014). These factors have limited the accessibility to suitable habitat while reducing the probability of movements between habitat patches leading to greater likelihood of local population loss (Wiens 1997, Villard et al. 1999). Moreover, current available habitat for young forest species is ephemeral, subject to natural forest succession and often existing $<15$ years thereby requiring periodic maintenance for populations to locally persist (Schlossberg and King 2009, Twedt and Somershoe 2009). These culminating factors have led to the decline of populations of young forest wildlife species in the central Appalachian region and have prompted natural resource agencies to develop solutions that increase young forest habitat in order to conserve priority species in the region (Pardieck et al. 2019).

The central Appalachian region, along with much of the eastern US, contains extensive linear infrastructure (e.g., pipelines, powerlines, roads) that is expanding further due to increased human influences. Electricity powerlines connecting rural communities into the power grid involves a complex network of overhead transmission (long distance lines) and distribution (short distance lines) powerlines traveling from power plant to consumer. Of the 83 power plants ( $\geq 1$-megawatt capacity) currently in operation in West Virginia, 14 have been constructed within the past 12 years with nine more planned for construction in 2021 and 2022 (EIA 2020). The continued increase in energy demand in West Virginia and adjacent states will certainly add to 
the 9975 kilometers of transmission powerlines (includes high voltage lines $69-765 \mathrm{kV}$ only) currently in West Virginia as of 2019 (HIFLD 2019). Further, since 2010, the central Appalachian region has experienced a steady increase in natural gas extraction due to the advancement of horizontal drilling techniques and high-volume hydraulic fracturing leading to increased access to the Marcellus-Utica shale basin (EIA 2020). During this period, natural gas production in West Virginia has increased 27\% annually and West Virginia is currently the seventh-largest producer of marketed natural gas in the country (EIA 2020). To accommodate the supply of natural gas, underground gas pipelines have become a prominent landscape feature throughout West Virginia, totaling 24621 kilometers of inter- and intrastate pipeline (includes field and gathering, transmission, and distribution pipelines) as of 2018 (AGA 2019).

A consequence of rights-of-way (ROWs; e.g., gas pipelines and utility powerlines) corridors throughout West Virginia, which is $\sim 79 \%$ forested, is the juxtaposing of land cover types of forest and non-forest (e.g., grassland or shrubland due to mowing or herbicide spraying in ROWs) which results in extensive stretches of abrupt forest edge (Harris 2020). Abrupt forest edges can pose serious threats to wildlife conservation due to novel species interactions (Chasko and Gates 1982, Murcia 1995). Songbirds experience increased rates of brood parasitism by brown-headed cowbirds (Molothrus ater) and increased rates of nest predation by mammalian mesocarnivores and corvids (Corvidae) at forest edges relative to interiors (Brittingham and Temple 1983, Heske et al. 1999, Shake et al. 2011). Mature forest interior species generally avoid ROWs because abrupt forest edges reduce habitat suitability in these areas (deMaynadier and Hunter Jr. 1998, Farwell et al. 2016). Abundances of forest interior songbirds decline near forest edges due their inability to compete with habitat generalist species that are better adapted to areas with greater habitat interspersion. Woodland salamanders avoid abrupt forest edges because of their inability to physiologically cope with greater microclimate variability (Hofmeister et al. 2019). Presence of ROW corridors within forested landscapes can benefit early-successional bird species though, because they are maintained in a grassland or shrubland successional community (Bulluck and Buehler 2006, Askins et al. 2012). However, vegetation in ROW corridors does not offer the full complement of vegetation features for young forest species, which includes greater amounts of understory and midstory woody stems and greater vertical vegetation structure (Jones et al. 2008, Culbert et al. 2013). These young forest vegetation features are never fully attained within ROW corridors because of periodic mowing or 
herbicide spraying. Therefore, despite the abundance of grassland and shrubland habitat available in West Virginia via ROWs, little of this habitat is considered optimal for young forest species, a group considered in need of immediate conservation action.

The abundance of ROW corridors in West Virginia and the central Appalachian region has led land managers and natural resource scientists to explore ways that incorporate these features into their management plans. A potential management strategy to improve habitat quality of ROW corridors for young forest wildlife is the reduction of abrupt forest edges along ROWs that mimic ecotone-like characteristics (Fleming and Giuliano 1998, Conover et al. 2009). Additionally, the transition of forest edges from abrupt edge towards ecotone has potentially beneficial consequences for forest interior species (DeGraaf and Yamasaki 2002, Yahner et al. 2003). Cut-back borders (also referred to as edge-feathering, conservation buffers, or field border-cuts) are a management technique that creates intermediate vegetation structure between two distinctly different land cover types (e.g., between grassland and mature forest) to increase habitat diversity and soften abrupt forest edge. Benefits for avifauna from cut-back borders includes increased abundance and density of management priority game and non-game species (Wunz 1990, Burger et al. 2013, Evans et al. 2015), increased nest success (Slay and Smith 2009, Foggia et al. 2018), and increased species richness (Yahner et al. 2003). However, past studies have been limited to agricultural-dominated landscapes (e.g., cattle and row crop farms) or where small woodlots are the only available forest habitat (Morgan and Gates 1982, Fleming and Giuliano 2001). Information pertaining to cut-back border effects on wildlife within forest-dominated landscapes is limited but desired, with an emphasis on cut-back border size and tree harvest intensity prescriptions to develop management guidelines. Considering the increased prevalence of forest edges due to the presence of wildlife openings and the proliferation of gas pipelines and utility powerlines in West Virginia and the central Appalachian region, cut-back borders are understudied and thus a potentially underutilized wildlife habitat management technique in these human-modified landscapes. Additionally, cut-back borders may be a promising management strategy for creating young forest habitat for priority young forest avifauna to help reverse declining regional population trends, but their effectiveness remains ambiguous (Pardieck et al. 2019). Therefore, rigorous experimental studies delineating size and harvest intensity of cut-back borders within forest-dominated landscapes and elucidating wildlife responses are needed to develop cut-back border guidelines for the region. 


\subsection{Chapter objectives and hypotheses}

The primary objective of this chapter was to assess avian and woodland salamander responses to creation of young forest habitat along forest edges via cut-back borders. We used a before-after-control-impact (BACI) framework, which allows for causal inference, to elucidate individual species and community responses to specific cut-back border treatments over time. We examined combinations of three cut-back border size manipulations and two harvest intensity manipulations over three years (with the initial year having no manipulation) to inform our inferences about avian and salamander response to cut-back borders. For avifauna, we hypothesized that (1) young forest avifauna will respond positively to cut-back borders along a gradient from greatest increases in the larger-sized, heavier harvest intensity treatments to least increases in the smaller-sized, less intensive harvest treatments and (2) mature forest avifauna will respond negatively to cut-back borders along a gradient from greatest decreases in the larger-sized, heavier harvest intensity treatments to least decreases in the smaller-sized, less intensive harvest treatments. Considering salamander responses to cut-back borders, we hypothesized that salamanders will respond negatively to cut-back borders along a gradient from greatest decreases in the larger-sized, heavier harvest intensity treatments to least decreases in the smaller-sized, less intensive harvest treatments. Additionally, we examined which cut-back border treatments optimized the tradeoff between maximizing positive responses of disturbancedependent species and minimizing negative responses of disturbance-avoidant species. Finally, we assessed the response of vegetation characteristics to help infer avian and salamander responses in cut-back border treatments but also to inform decisions regarding cut-back border placement with respect to abiotic factors (e.g., slope aspect, edge orientation). Results from this study provide species- and community-level guidelines for cut-back border harvest sizes and intensities to assist managers with habitat management goals along forest edges in West Virginia and the central Appalachian region.

\section{Methods}

\subsection{Study area}

West Virginia lies within the central Appalachian region, which is characterized by extensive forests, comprised of mixed mesophytic, Appalachian oak, transition Appalachian oaknorthern hardwood, and oak-hickory-pine forest types (Küchler 1964). Elevations at study sites range from $224 \mathrm{~m}$ in the northwestern part of the state (Lewis Wetzel Wildlife Management Area 
[LWWMA]) to $1132 \mathrm{~m}$ in the eastern part of the state (Little Canaan WMA [LCWMA]). West Virginia's humid continental climate is characterized by warm summers and cool to cold winters with average spring and fall temperatures of $10.0^{\circ} \mathrm{C}$ and an average summer temperature of 22.0 ${ }^{\circ} \mathrm{C}$. Annual precipitation levels are 76, 127, and $102 \mathrm{~cm}$ in the western, central, and eastern portions of the state, respectively, distributed relatively uniformly throughout the year but highest in spring and summer (NOAA 2019).

This study was conducted on eight West Virginia Division of Natural Resources' (WVDNR) wildlife management areas (WMAs) located throughout central and eastern West Virginia (Figure 2-1; see Figures 1-6, 1-7, 1-8, 1-9, 1-11, 1-12, 1-15, and 1-16 for site-level maps). Study sites were selected based on presence of overhead utility powerlines, underground gas pipelines, or wildlife openings, their accessibility for managers, and proximity to other study sites. Powerlines and pipelines used in this study were narrow linear openings (9.4-39.2 m [(mean) $25.7 \pm(\mathrm{SD}) 17.9 \mathrm{~m}]$ in width) with varying purposes (i.e., gathering pipelines and shortand long-distance powerlines). Vegetation in powerlines and pipelines consisted of primarily grassland or occasionally low shrubland vegetation, was void of a mid- or over-story vegetation layer, and was distinct from adjacent forests (see Figure 1-2 for examples). Pipelines and powerlines are hereafter referred to as "ROWs". Wildlife openings used in this study were fields planted with a row crop (e.g., corn, clover) or left fallow, ranged 0.3-11.5 ha (3.1 \pm 3.1 ha) in size, and were of varying shapes.

\subsection{Study design}

The eight study sites included 11 block replicates (Table 2-1, Appendix 2-A) located along underground gas pipelines $(n=4)$, overhead utility powerlines $(n=4)$, or wildlife openings $(n=3)$. Block replicates were presumed to be subjected to similar biotic and abiotic environmental constraints; block replicates along ROWs (pipelines and powerlines) were located along one or two ROWs of similar widths within the same WMA and block replicates along wildlife openings were within the same WMA. A single block replicate consisted of seven independent experimental units (hereafter referred to as "cut-back borders") with each assigned one of seven experimental treatments. Treatment designation for each cut-back border consisted of randomly selecting one of two target residual basal area levels $\left(4.5 \mathrm{~m}^{2} / \mathrm{ha}\right.$ or $14.0 \mathrm{~m}^{2} / \mathrm{ha}$ basal area retention) and one of three cutting depths into the forest (15 m [0.5 ha total area], $30 \mathrm{~m}$ [0.9 ha], or $45 \mathrm{~m}$ [1.4 ha] perpendicular to forest edge) with one cut-back border designated as a 
control (i.e., no tree cutting). Each cut-back border was $300 \mathrm{~m}$ in linear distance along the forest edge (Figure 2-3) and they were $\geq 200 \mathrm{~m}$ apart to ensure sampling independence for birds and salamanders.

Target basal area retention in each cut-back border was obtained via tree cutting using a feller-buncher or hand crew to mimic WVDNR forest management prescriptions for clearcuts with reserves $\left(4.5 \mathrm{~m}^{2} / \mathrm{ha}\right)$ or crop tree/shelterwood stands $\left(14.0 \mathrm{~m}^{2} / \mathrm{ha}\right)$ forest management prescription. WVDNR managers/foresters cruised all cut-back borders and selected residual trees based on species desirability (i.e., species of high wildlife value, such as oaks [Quercus spp.] and hickories [Carya spp.]). All trees $\geq 5 \mathrm{~cm} \mathrm{DBH}$ were felled, excluding selected residual trees. Felled trees were dropped within the cut-back border and remained on the ground. Non-native shrub species (e.g., autumn olive [Elaeagnus umbellate], Tatarian honeysuckle [Lonicera tatarica], and multiflora rose [Rosa multiflora]) were sprayed with herbicide $\left(15 \%\right.$ Garlon ${ }^{\circledR} 4$ Ultra in an oil carrier) to reduce presence in cut-back borders. Plant stems were sprayed at 30-38 $\mathrm{cm}$ above the ground to the point of runoff to ensure the root crown was treated. Herbicide was applied in the fall after pre-treatment data collection but prior to tree cutting. Tree cutting began 1 September or 15 November (if the study site was $<5$ miles from an Indiana bat [Myotis sodalis] roosting area) and was completed by 31 March.

We used a before-after-control-impact (BACI) framework to infer causal relationships between cut-back border treatments and the response of avian and salamander communities through time (Eberhardt 1976). At each cut-back border, we collected one-year of pre-treatment data and one- or two-years of post-treatment data on the vegetation, avian, and salamander communities (Table 2-1). Vegetation, avian, and salamander sampling points were located $15 \mathrm{~m}$ from the edge into the forest and were consistent across all cut-back border widths and harvest intensities (Figure 2-3). In each cut-back border, two avian sampling points were spaced $150 \mathrm{~m}$ apart and $75 \mathrm{~m}$ from cut-back border ends. Vegetation sampling plots were placed at the same locations as avian sampling points. In each cut-back border, four salamander sampling plots were spaced $75 \mathrm{~m}$ apart and $37.5 \mathrm{~m}$ from cut-back border ends.

\subsection{Vegetation assessment}

We measured vegetation characteristics within cut-back borders (Figure 2-3) each year using a nested circular plot design (Fettinger 2002; Figure 2-4; see Appendix 2-B for a list of all variables collected). This approach partitions overstory, midstory, and understory vegetation 
variables into three nested circles: largest sampling plot measuring overstory, intermediate sampling plot measuring midstory, and smallest sampling plot measuring understory. This vegetation protocol followed previous young forest wildlife studies in the central Appalachian region (Fettinger 2002, Schumacher 2002).

The largest circular plot was $11.3 \mathrm{~m}$ radius (0.04 ha; Figure 2-4). Within this plot, we measured diameter-at-breast height $(\mathrm{DBH})$ of all trees $\geq 11.4 \mathrm{~cm} \mathrm{DBH}$ to the nearest $0.1 \mathrm{~cm}$ using DBH tapes and recorded status ("live" or "dead"). Live trees were subsequently placed into two diameter classes $(\geq 11.4-<28.0 \mathrm{~cm} \mathrm{DBH}$, and $\geq 28.0 \mathrm{~cm} \mathrm{DBH}$; USDA Forest Service 2018) for analyses. Trees that received a "dead" status (i.e., snags) were enumerated but not placed into separate diameter classes. Individual live tree $\mathrm{DBH}$ data were converted to tree basal area $\left(\mathrm{m}^{2} / \mathrm{ha}\right)$, then summed for each $11.3 \mathrm{~m}$ circular plot (hereafter "basal area"). We estimated the amount of live foliage understory cover within two vertical zones (0-1.0 m and >1.0-2.0 m; hereafter "understory cover $0-1 \mathrm{~m}$ " and "understory cover $>1-2 \mathrm{~m}$ ", respectively) using a modified Nudds (1977) profile board. The profile board was placed 15-m from plot center in the four cardinal directions. Observers kneeled at the plot center, to reduce variation due to differing observer heights, and estimated understory cover into one of five categories $(0-20 \%,>20-40 \%$, $>40-60 \%,>60-80 \%$, or $>80-100 \%$ ) for each of the two zones. Standing at the plot center, we measured the percentage of live overstory cover (delineated at $\geq 5 \mathrm{~m}$ above ground) using a 25 $\mathrm{cm}$ x $25 \mathrm{~cm}$ transparent plexiglass panel, divided into a 5 x 5 grid, held overhead (Figure 2-5; Hachè et al. 2013; hereafter “overstory cover").

Nested within the $11.3 \mathrm{~m}$ radius circular plot was a smaller $5.6 \mathrm{~m}$ radius plot $(0.01 \mathrm{ha}$; Figure 2-4). Within this plot, we enumerated woody saplings and primary shrub stems (i.e., main shoot growth extending from the ground) that were $<11.4 \mathrm{~cm} \mathrm{DBH}$ and $\geq 1.4 \mathrm{~m}$ in height into one of two diameter classes (0-5.1 cm DBH and >5.1-<11.4 cm DBH; hereafter "midstory stems 0$5.1 \mathrm{~cm} \mathrm{DBH"} \mathrm{and} \mathrm{"midstory} \mathrm{stems}>5.1-11.3 \mathrm{~cm} \mathrm{DBH",} \mathrm{respectively).} \mathrm{Nested} \mathrm{within} \mathrm{the} 5.6 \mathrm{~m}$ radius circular plot was a smaller $3.6 \mathrm{~m}$ radius plot (0.004 ha; Figure 2-4). Within this plot, we estimated the percentage of live vegetation ground cover $\leq 0.25 \mathrm{~m}$ in height into one of five categories $(0-5 \%,>5-25 \%,>25-50 \%,>50-75 \%$, or $>75-100 \%$; hereafter "ground cover") using ocular assessment.

We measured canopy height and topographic variables using 3-m scale digital elevation models (DEMs) and 0.7 m nominal pulse spacing light detection and ranging (LIDAR) data 
sourced from the Federal Emergency Management Agency (FEMA), U.S. Geological Survey (USGS), and West Virginia Statewide Addressing and Mapping Board (SAMB; WVGIS 2019). Variables were calculated using zonal statistics in the program ArcMAP (version 10.0; ESRI 2014) to generate a mean value within a 50-m radius surrounding each vegetation sampling point (Figure 2-3). Topographic variables included slope percent, slope aspect, slope position (Weiss 2001), slope configuration, and elevation and were derived using DEMs. Slope percent, slope aspect, slope position, and slope configuration were combined using ModelBuilder in ArcGIS (ESRI 2014) to derive a topographic relative moisture index (TRMI) ranging from 0 (xeric soil) to 60 (mesic soil; Parker 1982). Additionally, we measured heat load index (HLI; McCune and Keon 2002) and Beers aspect (Beers et al. 1966) using DEMs. Both HLI and Beers aspect index soil moisture based on topographic position, similar to TRMI. Canopy height was derived using LIDAR data or ground sampling using a clinometer when LIDAR data were not available. When calculating canopy height using LIDAR, we moved the sampling point 50-m away from ROWs/wildlife openings into the forest interior to avoid bias from the 50-m radius used to calculate zonal statistics extending into the ROW/wildlife opening where there are no trees. We assumed canopy height within cut-back borders was similar to canopy height in the forest interior. Additionally, we measured ROW (e.g., powerlines and pipelines) corridor width and wildlife opening width (defined as the narrowest location within the wildlife opening) using aerial imagery.

We developed a shade proportional index (SPI) modified from Buffo et al. (1972) to calculate the proportion of shade from the adjacent mature forest overstory covering each cutback border plot based on canopy height, slope percent, and edge orientation (i.e., compass direction of forest edge).

$$
\begin{gathered}
\text { shadow. length }=\text { canopy. } h t \times(\sin (28) / \sin (180-(90-\text { slope })-28) \\
\text { true. shadow }=\text { shadow.length } \times(\sin (90-\text { edge. orient }) / \sin (90)) \\
\text { shade.proportion. } \text { index }=\text { true. shadow } / \text { border. width }
\end{gathered}
$$

In Equation 1, the value 28 is derived from 90 (degrees altitude a tree grows at) minus 62 (mean solar altitude from dates: 30 April [first frost-free date], 20 June [peak altitude in northern hemisphere], and 10 October [first frost killing date; WVU Extension 2019], which constitutes the beginning, middle, and end of the growing season). The variable slope was the slope percent, 
in degrees, at the cut-back border plot and shadow.length was output in the same units as canopy height. Shadow.length was then input into Equation 2 with edge.orient (i.e., edge orientation) to generate true.shadow, the length of the shadow while accounting for edge orientation. Edge orientation of each cut-back border was obtained from 2018 National Agriculture Imagery Program (NAIP) aerial imagery in ArcGIS (ESRI 2014). Plots with edge orientations between $90^{\circ}$ and $270^{\circ}$ (east $\rightarrow$ south $\rightarrow$ west) were automatically given a true.shadow value of zero because these plots receive full direct sunlight. Edge.orient values for plots whose edge orientation was between $0-89^{\circ}$ were left unchanged, but values between $271-359^{\circ}$ were taken from 360 to calculate degrees from north (e.g., $360^{\circ}$ minus $301^{\circ}$ [plot edge orientation] equals $59^{\circ}$ from north). The proportion of the cut-back border plot that was subject to shading (shade.proportion.index [SPI]) was calculated by dividing true.shadow by the width of the cutback border (border.width; Equation 3).

\subsection{Avian sampling}

Ruffed grouse.-We assessed ruffed grouse response to cut-back borders during 5-minute drumming surveys (McBurney 1989) at the two point count locations in each cut-back border (Figure 2-3). Drumming surveys were conducted twice at each point count location between 12 April and 17 May during 2016-2019 (Table 2-2) during 0530-1000 (EST) on days that were considered optimal for sampling (e.g., no rain, no heavy or gusty winds, and minimal peripheral noise). Observers recorded presence or absence of drumming grouse during each survey and if present, placed detected individuals into one of five distance intervals $(0-25 \mathrm{~m},>25-50 \mathrm{~m},>50-$ $75 \mathrm{~m},>75-100 \mathrm{~m}$, or >100 m). Observers also recorded any opportunistic detections associated with drumming surveys that occurred while within cut-back border plots (e.g., flushing grouse while walking to point count location). Survey-level data collected during each sampling visit included time of survey and ordinal day. Prior to surveys, observers were trained in survey protocol. Surveyor skill was assessed based on their previous experience conducting point counts in the region and identification skills of avian species of the region and ranged from 1-5, where a score of 5 indicated thorough knowledge of species with extensive experience conducting point counts, a score of 1 indicated no knowledge of species with no previous experience conducting point counts, and a score of 3 indicated introductory knowledge of species with minimal experience conducting point counts (most technicians that lacked previous point count experience were scored as 3 following training). We included all opportunistic detections and 
drumming detections within $100 \mathrm{~m}$ for analysis. In 2016, four observers conducted all drumming surveys, 11 observers (nine new, two from the previous year) conducted all drumming surveys in 2017, 11 observers (four new, seven from the previous year) conducted all drumming surveys in 2018, and ten observers (three new, seven from the previous year) conducted all drumming surveys in 2019.

American woodcock.-We assessed American woodcock response to cut-back borders during one, 2-minute singing-ground survey at the two point count locations in each cut-back border (Figure 2-3). Singing-ground surveys were conducted between 15 April and 5 May during 2016-2019 (Table 2-2; USFWS 2011) on days that were considered optimal for sampling (e.g., no rain, no heavy or gusty winds, and minimal peripheral noise). Survey start times were based on sky conditions. If the sky was $<75 \%$ overcast, surveys began 22 minutes after sunset and lasted for 38 minutes. If the sky was $\geq 75 \%$ overcast, surveys began 15 minutes after sunset and lasted for 38 minutes (USFWS 2011). Observers recorded presence or absence of "peenting" woodcock during each survey and if present, placed detected individual into one of five distance intervals $(0-25 \mathrm{~m},>25-50 \mathrm{~m},>50-75 \mathrm{~m},>75-100 \mathrm{~m}$, or >100 m). Observers also recorded the total number of "peents" heard from each individual detected. Prior to surveys, observers were trained in survey protocol. In 2016, four observers conducted all singing-ground surveys, 13 observers (11 new, two from previous year) conducted all surveys in 2017, 12 observers (two new, ten from previous year) conducted all surveys in 2018, and 12 observers (four new, eight from previous year) conducted all surveys in 2019.

Songbird.-We assessed songbird response to cut-back borders during the spring migration period and summer breeding period using 10-minute standardized fixed-radius point counts (Ralph et al. 1993, Bibby et al. 2002). At the two point count locations within each cutback border (Figure 2-3), we conducted a single visit during the spring migration period (1-22 May) and two visits during the summer breeding period (18 May-27 June) during 2016-2019 (Table 2-2). Surveys began after 0530 and before 1000 (EST) on days that were considered optimal for sampling (e.g., no rain, no heavy or gusty winds, and minimal peripheral noise). Observers recorded species of each individual bird detected, type of detection (song, call, visual, or flyover), demographic information (male, female, juvenile, or unknown), distance from observer placed into one of five distance intervals $(0-25 \mathrm{~m},>25-50 \mathrm{~m},>50-75 \mathrm{~m},>75-100 \mathrm{~m}$, 
or $>100 \mathrm{~m}$ ), and time interval the individual was first detected (0-2 min, >2-4 min, >4-6 min, >6-8 min, and >8-10 min). Survey-level data were collected during each visit and included time of survey and ordinal day. Prior to surveys, observers were trained to independently identify all species visually and aurally while simultaneously recording distance and time interval. In 2016 four observers conducted all counts, seven observers (five new, two from the previous year) conducted all counts in 2017, nine observers (four new, five from the previous year) conducted all counts in 2018, and six observers (four new, two from the previous year) conducted all counts in 2019.

For all songbird data analyses, we used only detections within 50-m of the sampling point. We included birds detected by sight and sound (excluding flyovers) for individual species and community statistical analyses. See Appendix 2-B for complete decision rules for bird data analyses and Appendix 2-C for detection types used for each species.

\subsection{Salamander sampling}

We assessed salamander response to cut-back borders using a combination of artificial and natural cover object surveys at four locations within each 30-m and 45-m wide cut-back border plot, as well as the control (Figure 2-3). Data were collected at Beury Mountain WMA (BMWMA [two powerline block replicates]), LCWMA (two powerline block replicates), LWWMA (two pipeline block replicates), and Stonewall Jackson WMA (SJWMA [one wildlife opening block replicate]). At each location, we conducted three daytime surveys annually during 2016-2019. Visit 1 was 15-30 April, visit 2 was 1-15 May, and visit 3 was 11 July-9 August (Table 2-2). Artificial coverboards at each location consisted of nine (3 x 3 arrangement spaced $\sim 1 \mathrm{~cm}$ apart), $20.0 \mathrm{~cm}$ (length) x $10.0 \mathrm{~cm}$ (width) x $2.5 \mathrm{~cm}$ (height) wooden blocks cut from hardwood species from the region (American basswood [Tilia americana], American sycamore [Platanus occidentalis], and yellow poplar). Artificial coverboards were placed in cut-back border plots at least one month prior to sampling to allow them to weather (Hesed 2012). Natural cover objects sampled included logs and rocks that measured $\geq 40 \mathrm{~mm}$ at the narrowest dimension and occurred within a 5-m radius of each artificial coverboard location. All eligible natural cover object dimensions (length and width, in $\mathrm{mm}$ ) were measured prior to salamander sampling during the pre-harvest period. We marked natural cover objects with stake flags to maintain consistent sampling effort across visits and years and did not add new natural cover objects following tree cutting. 
Data recorded for each captured salamander included snout-vent length (SVL, anterior edge of the snout to the distal end of the cloaca) to the nearest $0.1 \mathrm{~mm}$ using a dial caliper. We recorded body mass to the nearest $0.1 \mathrm{~g}$ using a Pesola spring scale. We recorded species of captured individual and whether it was captured under a coverboard or natural cover object. If captured under a natural cover object, we recorded the dimensions (length and width) and type of object (log or rock). We clipped the tail of each individual to identify recaptures in subsequent sampling visits and sprayed an antiseptic to the clipped tail to minimize risk of infection. Clippers were flame-sterilized with $95 \%$ ethanol to reduce potential disease transmission between captures. Salamanders were released at their original point of capture. Salamander sampling was conducted under methods approved by the WVDNR (permits 2016.143, 2017.104, 2018.110, and 2019.110) and the West Virginia University Institutional Animal Care and Use Committee (protocol 1602000305).

\subsection{Statistical analyses}

Vegetation regeneration in cut-back borders.-We used general linear models to predict understory vegetation variables (ground cover, understory cover $0-1$, understory cover $>1-2 \mathrm{~m}$, midstory stems $0-5.1 \mathrm{~cm} \mathrm{DBH}$, and midstory stems $>5.1-11.3 \mathrm{~cm} \mathrm{DBH}$ ) in cut-back borders as functions of SPI (generated using Equations 1-3), TRMI, HLI, and the modified Beers aspect. Due to the shape of cut-back borders (i.e., narrow, strip cuttings) canopy cover from adjacent stands could block direct sunlight onto the forest floor (Figure 2-6) and affect understory plant successional trajectories within plots (Messier 1996, Stage and Salas 2007). Additionally, plant growth in the central Appalachian region is influenced by soil properties and slope aspect. Therefore, TRMI, HLI, and Beers aspect were included as primary predictor variables because these are topographic indices that account for soil moisture and slope aspect, which influence plant growth in the Appalachian region (Huebner and McGill 2018), but do not account for adjacent forest influence (i.e., shade from nearby tree canopy; Baker et al. 2016, Curzon et al. 2017). SPI, TRMI, and Beers aspect all index soil environments on various scales but are consistent in quantifying soil moisture where lower values indicate xeric conditions and higher values indicate mesic conditions. HLI, however, indexes soil conditions from 0 -1 where zero represents mesic conditions and 1 represents xeric conditions. To ensure consistency with other indices, we calculated the inverse of HLI (i.e., 1/HLI) to be used for analysis. We tested for collinearity between each topographic variable and SPI using Pearson's correlation coefficient 
prior to inclusion. Additionally, we tested for spatial autocorrelation of each variable using a global Moran's I at $\alpha=0.05$ indicating no spatial autocorrelation (HLI, $p$-value $<0.001$; SPI, $p$ value $<0.001$; TRMI $p$-value $<0.001$; Beers aspect, $p$-value $=0.381$ ).

We developed 11 a priori candidate models to test the effect of local topographic factors on the regeneration of five understory vegetation variables. We included a model where each topographic variable (SPI, TRMI, HLI, and Beers aspect) was the only predictor variable, a model that included an interactive term between each topographic variable and canopy cover, a model that included an additive term between SPI and Beers aspect (SPI does not account for slope aspect), and a model that included the additive term between SPI and Beers aspect and an interaction with canopy cover. We included understory cover $0-1 \mathrm{~m}$, understory cover 1-2 m, ground cover, midstory stems $0-5.1 \mathrm{~cm} \mathrm{DBH}$, and midstory stems $>5.1-11.3 \mathrm{~cm} \mathrm{DBH}$ as vegetation response variables. For our response metrics, we calculated the percent change from one-year post-treatment (immediately after tree cutting) to two-year post-treatment. Predictor variables were standardized to have a mean of 0 and standard deviation of one prior to analyses. Response variables were specified with a Gaussian distribution. Control plots were excluded from analysis because no canopy manipulation occurred in these plots.

We used an information-theoretic approach to test our 11 a priori models (Table 2-3) and implemented a model-averaging approach to predict percent change of vegetation variables. Model-averaged predictions were derived from all candidate models $<2 \Delta$ Akaike's Information Criterion adjusted for small sample sizes ( $\mathrm{AIC}_{\mathrm{c}}$; Burnham and Anderson 2002) using the 'AICcmodavg' package (Mazerolle 2016) in the statistical software R (R Core Team 2019). When making predictions, canopy cover was held constant at the mean (i.e., 0) where applicable. Because all topographic predictor variables are indexed from low (xeric conditions) to high (mesic conditions) values, we graphically represent our continuous soil index on a relative scale from xeric to mesic soil conditions.

Ruffed grouse and American woodcock occupancy in cut-back borders.-We estimated the probability of ruffed grouse occupancy in cut-back border treatments over time with a stacked Bayesian occupancy model (MacKenzie et al. 2017). We fit two models for ruffed grouse. Model \#1 incorporated a cut-back border treatment and time interaction and model \#2 incorporated cut-back border treatments without a time interaction. Both models used the same detection-level sub-model but a different occupancy-level sub-model. In our detection-level sub- 
model, we modeled probability of detecting a grouse, conditional on true presence, using a Bernoulli process model. We modeled survey-level covariates (ordinal day and time since sunrise) thought to influence an observer's probability of detecting a grouse on the logit-linear scale.

For both occupancy-level sub-models, we modeled the probability of ruffed grouse occurrence using a Bernoulli process model. For model \#1, we modeled logit expected occupancy probability, $y_{i k}$, as a function of cut-back border width and harvest intensity prescriptions with time and nuisance variables on the logit-linear scale (Equation 4).

$$
\begin{aligned}
\operatorname{logit}\left(y_{i k}\right)= & \beta_{0}+\beta_{1} \times \text { trt }_{i k}+\beta_{2} \times w 30_{i k}+\beta_{3} \times w 45_{i k}+\beta_{4} \times r 4.5_{i k}+ \\
& \beta_{5} \times\left(\text { trt }_{i k} \times \text { time }_{i k}\right)+\beta_{6} \times\left(w 30_{i k} \times \text { time }_{i k}\right)+ \\
& \beta_{7} \times\left(w 45_{i k} \times \text { time }_{i k}\right)+\beta_{8} \times\left(r 4.5_{i k} \times \text { time }_{i k}\right)+ \\
& \beta_{9} \times \text { elev }_{i}+\beta_{10} \times \text { TRMI }_{i}+\beta_{11} \times R O W / W O_{i}+ \\
& \text { rand.point }_{i}+\text { rand.plot }_{i}
\end{aligned}
$$

For model \#2, we modeled logit expected occupancy probability, $y_{i k}$, as a function of cut-back border width and harvest intensity prescriptions and nuisance variables on the logit-linear scale (Equation 5). The difference between Equation 4 and Equation 5 is that Equation 5 does not contain a unique interaction term between time and each cut-back border width or harvest intensity prescription. Rather, time interacts the same with all cut-back border width and harvest intensity prescriptions.

$$
\begin{aligned}
\operatorname{logit}\left(y_{i k}\right)= & \beta_{0}+\beta_{1} \times \operatorname{trt}_{i k}+\beta_{2} \times w 30_{i k}+\beta_{3} \times w 45_{i k}+\beta_{4} \times r 4.5_{i k}+ \\
& \beta_{5} \times\left(\text { trt }_{i k} \times \text { time }_{i k}\right)+\beta_{6} \times \text { elev }_{i}+ \\
& \beta_{7} \times \text { TRMI }_{i}+\beta_{8} \times R O W / W O_{i}+ \\
& \text { rand.point }_{i}+\text { rand.plot }_{i}
\end{aligned}
$$

For both equations, $i$ references each sampling point location (Figure 2-3) and $k$ references year. On the right-hand side of the equation, the pre-treatment period is included in the intercept $\left(\beta_{0}\right)$. This approach allows the control treatment across all years and the pre-treatment year for all cutback border factor levels $\left(15 \mathrm{~m}, 30 \mathrm{~m}, 45 \mathrm{~m} ; 14.0 \mathrm{~m}^{2} / \mathrm{ha}, 4.5 \mathrm{~m}^{2} / \mathrm{ha}\right)$ to be used as baseline values for comparison with cut-back border factor levels at one-year and two-year post-treatment. The term trt $_{i k}$, corresponds to the $15 \mathrm{~m}$ and $14.0 \mathrm{~m}^{2} /$ ha factor levels used as reference factor levels. The term $w 30_{i k}$, corresponds to factor level $30 \mathrm{~m}, w 45_{i k}$ corresponds to factor level $45 \mathrm{~m}$, and 
$r 4.5_{i k}$ corresponds to factor level $4.5 \mathrm{~m}^{2} / \mathrm{ha}$. In Equation 4 the term time $_{i k}$ was included as an interactive term with each factor level to allow the effect of time to vary for each treatment. In Equation 5 the time $_{i k}$ term was included as an interactive term applied the same to all cut-back border factor levels (i.e., reference factor levels $\operatorname{trt}_{i k}$ ) and not each factor level separately. All factor levels were dummy coded with " 0 " or " 1 " depending on whether that factor level occurred at each point, except for the reference factor levels ( $t_{t} t_{i k}$; i.e., $15 \mathrm{~m}$ and $14.0 \mathrm{~m}^{2} / \mathrm{ha}$ ) which were dummy coded with a "1" unless it was the control treatment. Time was treated as a continuous variable with 0,1 , or 2 corresponding to pre-treatment, one-year post-treatment, or two-year post-treatment, respectively. Elevation $\left(e l e v_{i}\right)$, TRMI $\left(T R M I_{i}\right)$, and ROW/wildlife opening width $\left(R O W / W O_{i}\right)$ were included as nuisance predictor variables. We included a random point count effect $\left(\right.$ rand.point $\left._{i}\right)$ to account for heterogeneity among points and repeated observations at the same point, and a random plot effect (rand.plot ${ }_{i}$ ) to account for co-dependence between points within cut-back borders. Continuous variables were standardized to have a mean of 0 and standard deviation of one prior to analysis.

For both models, we used diffuse prior distributions for the detection-level sub-model survey-level covariates (Gaussian $[$ mean $=0$, variance $=100]$ ) and the occupancy-level submodel factor levels and nuisance covariates (Gaussian [mean $=0$, variance $=10]$ ). We used diffuse covariate priors because we were uncertain of the relationships between cut-back border treatments and grouse. For our random point count and plot effect, we used a Gaussian (mean = 0 , variance $=\tau)$ prior with a hyperparameter $\tau$ from an inverse Gamma $(\alpha=1, \beta=1)$ distribution. We obtained posterior distributions of model parameters by running three parallel Markov chain Monte Carlo (MCMC) simulations of 40000 iterations with a burn-in of 20000 iterations at a thinning rate of 100, yielding 600 samples for posterior distributions for each model. We assessed model fit separately for both models with a posterior predictive check, where we compared Chi-square goodness-of-fit tests between an observed posterior predictive distribution and a simulated posterior predictive distribution. We calculated a Bayesian $p$-value, $p_{B}$, as the probability to obtain a Chi-square test statistic that is at least as extreme as the observed Chisquare test statistic and assumed reasonable fit if $0.1<p_{B}<0.9$ (Gelman et al. 2014). Model convergence was assessed using the Brooks-Gelman-Rubin statistic and assumed adequate convergence when all parameter Rhat values <1.1 (Brooks and Gelman 1998). Data analyses were performed in R (R Core Team 2019) using a Bayesian framework in JAGS (Plummer 
2017) called from the package jagsUI (Kellner 2015). We assessed model performance between the treatment-time interaction model (model \#1) and the main effects model (model \#2) using deviance information criterion (DIC).

For model \#1, we transformed model outputs using the inverse logit-link and calculated expected ruffed grouse occurrence in each cut-back border treatment in each year using Equation 4 terms. We calculated the log odds ratio of occupancy values within each respective cut-back border treatment at one-year post-treatment period and two-year post-treatment period against the pre-treatment period (e.g., pre-treatment versus one-year post-treatment in $15 \mathrm{~m}-14 \mathrm{~m}^{2} / \mathrm{ha}$ ) and between cut-back border treatments within each time period, and assessed differences based on $95 \%$ credible intervals not overlapping 0 . For model $\# 2$, we transformed model outputs using the inverse logit-link and calculated expected ruffed grouse occurrence in each cut-back border width and harvest intensity prescription using Equation 5 terms. We calculated the log odds ratio of expected occupancy between width and harvest intensity factor levels, separately. We assessed differences based on 95\% credible intervals not overlapping 0 .

American woodcock were detected a total of two times during the study period. Therefore, we did not have enough detections to complete a statistical analysis with enough predictive power to warrant analyzing these data further. Sampling effort and a descriptive summary of American woodcock data are provided in results.

Focal breeding songbird abundance.-We estimated abundance of breeding songbird species in cut-back border treatments over time with a stacked Bayesian $N$-mixture model (Kéry and Royle 2016). We included species with $\geq 40$ detections within 50-m of the sampling point and $\geq 0.200$ cumulative detection probability (i.e., probability of detecting a species at least once across two annual survey visits) (see Appendix 2-C for species-level detections). These criteria were based on a power analysis. We fit two models for each songbird species. Model \#1 incorporated a cut-back border treatment and time interaction and model \#2 incorporated cutback border treatments without a unique treatment-time interaction. Both models used the same detection-level sub-model but a different abundance-level sub-model. In our detection-level submodel, we modeled probability of detecting an individual, conditional on true presence, using a Binomial process model. We modeled survey-level covariates (e.g., ordinal day, surveyor skill, and time since sunrise) thought to influence an observer's probability of detecting an individual on the logit-linear scale. 
For both biological-level sub-models, we modeled expected species abundance using a Poisson process model. For model \#1, we modeled log expected species abundance, $y_{i k}$, as a function of cut-back border width and harvest intensity prescriptions with time and nuisance variables on the log-linear scale (Equation 4). For model \#2, we modeled log expected species abundance, $y_{i k}$, as a function of cut-back border width and harvest intensity prescriptions and nuisance variables on the log-linear scale (Equation 5). For both models, we used diffuse prior distributions for the detection-level sub-model survey-level covariates (Gaussian [mean =0, variance $=100]$ ) and the biological-level sub-model the factor levels and nuisance covariates $($ Gaussian $[$ mean $=0$, variance $=10])$. We used diffuse covariate priors because we were uncertain of the relationships between cut-back border treatments and songbirds. For our random point count and plot effect, we used a Gaussian $($ mean $=0$, variance $=\tau)$ prior with a hyperparameter $\tau$ from an inverse Gamma $(\alpha=1, \beta=1)$ distribution. We obtained posterior distributions of model parameters by running three parallel MCMC simulations of 40000 iterations with a burn-in of 20000 iterations at a thinning rate of 100, yielding 600 samples for posterior distributions. We assessed model fit with a posterior predictive check, where we compared Chi-square goodness-of-fit tests between an observed posterior predictive distribution and a simulated posterior predictive distribution. We calculated a Bayesian $p$-value, $p_{B}$, as the probability to obtain a Chi-square test statistic that is at least as extreme as the observed Chisquare test statistic and assumed reasonable fit if $0.1<p_{B}<0.9$ (Gelman et al. 2014). Model convergence was assessed using the Brooks-Gelman-Rubin statistic and assumed adequate convergence when all parameter Rhat values <1.1 (Brooks and Gelman 1998). Data analyses were performed in R (R Core Team 2019) using a Bayesian framework in JAGS (Plummer 2017) called from the package jagsUI (Kellner 2015). We assessed model performance between the treatment-time interaction model (model \#1) and the main effects model (model \#2) for each species using DIC.

For model \#1, we transformed model outputs using the inverse log-link and calculated expected abundance in each cut-back border treatment in each year using Equation 4 terms. We calculated the log proportional change of abundance within each respective cut-back border treatment at one-year post-treatment period and two-year post-treatment period against the pretreatment period and between cut-back border treatments within each time period, and assessed differences based on $95 \%$ credible intervals not overlapping 0. For model \#2, we transformed 
model outputs using the inverse log-link and calculated expected abundance in each cut-back border width and harvest intensity prescription using Equation 5 terms. We calculated the log proportional change of expected abundance between width and harvest intensity factor levels, separately. We assessed differences based on $95 \%$ credible intervals not overlapping 0 .

Species-vegetation correlations.-We assessed correlations between species counts (response variables) and vegetation data (predictor variables) at each point count location using constrained ordination techniques. For each species, we used the maximum count across the two survey visits at each point count location for each year (see Appendix 2-B for complete decision rules). Species with $\geq 20$ detections over the whole study period were included in analysis (Appendix 2-C). We chose this criterion because it encompassed a relatively equal number of species from each guild (seven forest gap, 10 forest interior, 11 interior-edge, and 10 young forest, two predator/parasite) and minimized the potential for spurious relationships resulting from low detections. We used a detrended correspondence analysis (DCA) to inform model type specification based on gradient length of the data using the 'decorana' from package 'vegan' (Oksanen 2019). Gradient length of species count data had a standard deviation >4 (SD = 5.26) indicating high species turnover across study sites, and thus a unimodal method (canonical correspondence analysis [CCA]; Lepš and Šmilauer 2003) was used for the analysis. A forward selection approach was used to select a subset of predictor variables that maximized the model's adjusted $\mathrm{R}^{2}$ using a 1000 step permutation test in 'ordiR2step' from package 'vegan'. This approach increases parsimony in our CCA model and removes strong linear correlations among explanatory variables. We tested whether there was a relationship between response data and the explanatory variables using a 999 step permutational ANOVA for each individual canonical axis in our CCA model at $\alpha=0.05$. Vegetation data were standardized to have a mean of 0 and standard deviation of one prior to analysis. Species-vegetation correlations were visualized using a correlation biplot displaying response variables and predictor variables.

Spring stopover songbird richness.-We used a Bayesian generalized linear mixedeffects model (GLMM) using model \#1 which incorporated a cut-back border treatment and time interaction and model \#2 which incorporated cut-back border treatments without a unique treatment-time interaction to assess apparent species richness during the spring migration 
stopover period. We included all resident, breeding, and migrant passerine species for this analysis (Appendix 1-A).

We modeled expected apparent species richness using Equation 4 (model \#1) and Equation 5 (model \#2), with log expected apparent richness, $y_{i k}$, specified with a Poisson process model in both equations. We used diffuse prior distributions for the factor levels and nuisance covariates (Gaussian [mean $=0$, variance $=10]$ ). We used diffuse covariate priors because we were uncertain of the relationships between cut-back border treatments and songbirds. For our random point count and plot effect, we used a Gaussian (mean $=0$, variance $=\tau)$ prior with a hyperparameter $\tau$ from an inverse Gamma $(\alpha=1, \beta=1)$ distribution. We obtained posterior distributions of model parameters by running three parallel MCMC simulations of 40000 iterations with a burn-in of 20000 iterations at a thinning rate of 100, yielding 600 samples for posterior distributions. We assessed model fit with a posterior predictive check, where we compared Chi-square goodness-of-fit tests between an observed posterior predictive distribution and a simulated posterior predictive distribution. We calculated a Bayesian $p$-value, $p_{B}$, as the probability to obtain a Chi-square test statistic that is at least as extreme as the observed Chisquare test statistic and assumed reasonable fit if $0.1<p_{B}<0.9$ (Gelman et al. 2014). Model convergence was assessed using the Brooks-Gelman-Rubin statistic and assumed adequate convergence when all parameter Rhat values <1.1 (Brooks and Gelman 1998). Data analyses were performed in R (R Core Team 2019) using a Bayesian framework in JAGS (Plummer 2017) called from the package jagsUI (Kellner 2015). We assessed model performance between the treatment-time interaction model (model \#1) and the main effects model (model \#2) using DIC.

For model \#1, we transformed model outputs using the inverse log-link and calculated expected apparent species richness in each cut-back border treatment in each year using Equation 4 terms. We calculated the log proportional change of expected richness within each respective cut-back border treatment at one-year post-treatment period and two-year post-treatment period against the pre-treatment period and between cut-back border treatments within each time period, and assessed differences based on $95 \%$ credible intervals not overlapping 0 . For model \#2, we transformed model outputs using the inverse log-link and calculated expected apparent species richness in each cut-back border width and harvest intensity prescription using Equation 5 terms. We calculated the log proportional change of expected richness between width and harvest 
intensity factor levels, separately. We assessed differences based on $95 \%$ credible intervals not overlapping 0 .

Avian guild richness in cut-back borders.-We used a Bayesian GLMM with model \#1 which incorporated a cut-back border treatment and time interaction and model \#2 which incorporated cut-back border treatments without a unique treatment-time interaction to assess apparent species richness of avian guilds to cut-back border treatments through time. We categorized avian species into ecological guilds based on habitat (forest gap, forest interior, interior-edge, and young forest), foraging (aerial insectivore), nesting (cavity), or predator/parasite (see Appendix 2-D for guild definitions). Additionally, we assessed species of conservation priority in the region as a distinct group for analysis (Appendix 2-C). We considered a species as conservation priority if it was listed by Appalachian Mountains Joint Venture (AMJV 2018), Partners-in-Flight Appalachian region Bird Conservation Region 28 (PIF 2019), or WVDNR State Wildlife Action Plan (WVDNR 2015).

We modeled expected apparent species richness using Equation 4 (model \#1) and Equation 5 (model \#2), with log expected apparent richness, $y_{i k}$, specified with a Poisson process model in both models. We used diffuse prior distributions for the factor levels and nuisance covariates (Gaussian [mean $=0$, variance $=10]$ ). We used diffuse covariate priors because we were uncertain of the relationships between cut-back border treatments and avian guilds. For our random point count and plot effect, we used a Gaussian (mean $=0$, variance $=\tau$ ) prior with a hyperparameter $\tau$ from an inverse Gamma $(\alpha=1, \beta=1)$ distribution. We obtained posterior distributions of model parameters by running three parallel MCMC simulations of 40000 iterations with a burn-in of 20000 iterations at a thinning rate of 100, yielding 600 samples for posterior distributions. We assessed model fit with a posterior predictive check, where we compared Chi-square goodness-of-fit tests between an observed posterior predictive distribution and a simulated posterior predictive distribution. We calculated a Bayesian $p$-value, $p_{B}$, as the probability to obtain a Chi-square test statistic that is at least as extreme as the observed Chisquare test statistic and assumed reasonable fit if $0.1<p_{B}<0.9$ (Gelman et al. 2014). Model convergence was assessed using the Brooks-Gelman-Rubin statistic and assumed adequate convergence when all parameter Rhat values <1.1 (Brooks and Gelman 1998). Data analyses were performed in R (R Core Team 2019) using a Bayesian framework in JAGS (Plummer 2017) called from the package jagsUI (Kellner 2015). We assessed model performance between 
the treatment-time interaction model (model \#1) and the main effects model (model \#2) using DIC.

For model \#1, we transformed model outputs using the inverse log-link and calculated expected apparent species richness in each cut-back border treatment in each year using Equation 4 terms. We calculated the log proportional change of expected richness within each respective cut-back border treatment at one-year post-treatment period and two-year post-treatment period against the pre-treatment period and between cut-back border treatments within each time period, and assessed differences based on $95 \%$ credible intervals not overlapping 0. For model \#2, we transformed model outputs using the inverse log-link and calculated expected apparent species richness in each cut-back border width and harvest intensity prescription using Equation 5 terms. We calculated the log proportional change of expected richness between width and harvest intensity factor levels, separately. We assessed differences based on $95 \%$ credible intervals not overlapping 0 .

Salamander surface relative abundance in cut-back borders.-We estimated surface relative abundance of terrestrial salamanders in cut-back border treatments over time using a Bayesian GLMM. We estimated surface relative abundance because terrestrial salamanders spend the majority of their time underground and we did not incorporate detection probability into the analysis. We fit two models for salamander species. Model \#3 incorporated a cut-back border treatment and time interaction and model \#4 incorporated cut-back border treatments without a time interaction. We treated capture data at the four sampling plots within a single cutback border plot (Figure 2-3). Sampling plots within a single cut-back border were considered independent because of the small home range size of terrestrial salamanders (Kleeberger and Werner 1982). Recaptures were not used in analysis.

For model \#3, we modeled expected relative abundance using a Poisson process model. Log expected relative abundance, $y_{i k}$, was modeled as a function of cut-back border width and harvest intensity prescriptions with time and nuisance variables on the log-linear scale (Equation $6)$.

$$
\begin{aligned}
\log \left(y_{i k}\right)= & \beta_{0}+\beta_{1} \times \operatorname{trt}_{i k}+\beta_{2} \times w 45_{i k}+\beta_{3} \times r 4.5_{i k}+ \\
& \beta_{4} \times\left(\operatorname{trt}_{i k} \times \text { time }_{i k}\right)+\beta_{5} \times\left(w 45_{i k} \times \text { time }_{i k}\right)+ \\
& \beta_{6} \times\left(r 4.5_{i k} \times \text { time }_{i k}\right)+\beta_{7} \times \text { elev }_{i}+ \\
& \beta_{8} \times \text { TRMI }_{i}+\beta_{9} \times \text { Cover }_{i}+\text { rand.point }_{i}
\end{aligned}
$$


For model \#4, we modeled expected relative abundance using a Poisson process model. Log expected relative abundance, $y_{i k}$, was modeled as a function of cut-back border width and harvest intensity prescriptions and nuisance variables on the log-linear scale (Equation 7).

$$
\begin{aligned}
& \log \left(y_{i k}\right)=\beta_{0}+\beta_{1} \times t r t_{i k}+\beta_{2} \times w 45_{i k}+\beta_{3} \times r 4.5_{i k}+ \\
& \beta_{4} \times\left(\operatorname{trt}_{i k} \times \text { time }_{i k}\right)+\beta_{5} \times \text { elev }_{i}+ \\
& \beta_{6} \times T_{R M I_{i}}+\beta_{7} \times \text { Cover }_{i}+\text { rand. } \text { point }_{i}
\end{aligned}
$$

For both models, $i$ references each sampling point location (Figure 2-3) and $k$ references year. On the right-hand side of the equation, the pre-treatment period is included in the intercept $\left(\beta_{0}\right)$. This approach allows the control treatment across all years and the pre-treatment year for all cutback border factor levels to be used as baseline values for comparison with cut-back border factor levels ( $30 \mathrm{~m}, 45 \mathrm{~m} ; 14.0 \mathrm{~m}^{2} / \mathrm{ha}, 4.5 \mathrm{~m}^{2} / \mathrm{ha}$ ) at one-year and two-year post-treatment. The term $\mathrm{trt}_{i k}$, corresponds to the $30 \mathrm{~m}$ and $14.0 \mathrm{~m}^{2} /$ ha factor levels used as reference factor levels. The term $w 45_{i k}$ corresponds to factor level $45 \mathrm{~m}$, and $r 4.5_{i k}$ corresponds to factor level $4.5 \mathrm{~m}^{2} / \mathrm{ha}$. In Equation 6 the term time $_{i k}$ was included as an interactive term with each factor level to allow the effect of time to vary for each treatment. In Equation 7 the $t_{i m e}$ ik term was included as an interactive term applied the same to all cut-back border factor levels (i.e., reference factor levels ${ } r t_{i k}$ ) and not each factor level separately. All factor levels were dummy coded with " 0 " or " 1 " depending on whether that factor level occurred at each point, except for the reference factor levels (30 $\mathrm{m}$ and $14.0 \mathrm{~m}^{2} / \mathrm{ha}$ ) which were dummy coded with a " 1 " unless it was the control treatment. Time was treated as a continuous variable with 0,1 , or 2 corresponding to pretreatment, one-year post-treatment, or two-year post-treatment, respectively. Elevation $\left(\right.$ elev $\left._{i}\right)$, TRMI $\left(T R M I_{i}\right)$, and number of natural cover objects $\left(\right.$ Cover $\left._{i}\right)$ were included as nuisance predictor variables. We included a random point count effect to account for heterogeneity among points and repeated observations at the same point. Continuous variables were standardized to have a mean of 0 and standard deviation of one prior to analyses.

For both models, we used diffuse prior distributions for factor levels and nuisance covariates (Gaussian [mean $=0$, variance $=10]$ ). We used diffuse covariate priors because we were uncertain of the relationships between cut-back border treatments and salamanders. For our random point effect, we used a Gaussian $($ mean $=0$, variance $=\tau)$ prior with a hyperparameter $\tau$ from an inverse Gamma $(\alpha=1, \beta=1)$ distribution. We obtained posterior distributions of model parameters by running three parallel MCMC simulations of 40000 iterations with a burn-in of 
20000 iterations at a thinning rate of 100, yielding 600 samples for posterior distributions. We assessed model fit with a posterior predictive check, where we compared Chi-square goodnessof-fit tests between an observed posterior predictive distribution and a simulated posterior predictive distribution. We calculated a Bayesian $p$-value, $p_{B}$, as the probability to obtain a Chisquare test statistic that is at least as extreme as the observed Chi-square test statistic and assumed reasonable fit if $0.1<p_{B}<0.9$ (Gelman et al. 2014). Model convergence was assessed using the Brooks-Gelman-Rubin statistic and assumed adequate convergence when all parameter Rhat values <1.1 (Brooks and Gelman 1998). Data analyses were performed in R (R Core Team 2019) using a Bayesian framework in JAGS (Plummer 2017) called from the package jagsUI (Kellner 2015). We assessed model performance between the treatment-time interaction model (model \#3) and the main effects model (model \#4) using DIC.

For model \#3, we transformed model outputs using the inverse log-link and calculated expected relative abundance in each cut-back border treatment in each year using Equation 6 terms. We calculated the log proportional change of relative abundance values within each respective cut-back border treatment at one-year post-treatment period and two-year posttreatment period against the pre-treatment period and between cut-back border treatments within each time period, and assessed differences based on $95 \%$ credible intervals not overlapping 0 . For model \#4, we transformed model outputs using the inverse log-link and calculated expected relative abundance in each cut-back border width and harvest intensity prescription using Equation 7 terms. We calculated the log proportional change of expected relative abundance between width and harvest intensity factor levels, separately. We assessed differences based on $95 \%$ credible intervals not overlapping 0 . We assessed model performance between the treatment-time interaction model (model \#3) and the main effects model (model \#4) using DIC.

Salamander body condition in cut-back borders.-We assessed body condition index (BCI) of each terrestrial salamanders species, separately, in cut-back border treatments over time with a model which had a unique treatment-time interaction and a model where time had a constant relationship with treatment using a Bayesian GLMM. We calculated BCI by regressing the natural logarithm of body mass on the natural logarithm of SVL and using the residuals as the BCI values for each individual following Gabor (1995). BCI was calculated independently at each study site for each species. Recaptures were not used for analysis. 
We modeled the mean expected BCI using the right-hand side of equations 6 (model \#3) and equation 7 (model \#4) with a Gaussian process model. For both models we used diffuse prior distributions for the process model variance $($ variance $=\tau$ ) from an inverse Gamma distribution and for the factor levels and nuisance variables (Gaussian [mean $=0$, variance $=10]$ ). We used diffuse covariate priors because we were uncertain of the relationships between cut-back border treatments and BCI. For our random point effect, we used an inverse Gaussian (mean =0, variance $=\tau)$ prior with a hyperparameter $\tau$ from a Gamma $(\alpha=1, \beta=1)$ distribution. We obtained posterior distributions of model parameters by running three parallel MCMC simulations of 40000 iterations with a burn-in of 20000 iterations at a thinning rate of 100 , yielding 600 samples for posterior distributions. We assessed model fit with a posterior predictive check, where we compared Chi-square goodness-of-fit tests between an observed posterior predictive distribution and a simulated posterior predictive distribution. We calculated a Bayesian $p$-value, $p_{B}$, as the probability to obtain a Chi-square test statistic that is at least as extreme as the observed Chi-square test statistic and assumed reasonable fit if $0.1<p_{B}<0.9$ (Gelman et al. 2014). Model convergence was assessed using the Brooks-Gelman-Rubin statistic and assumed adequate convergence when all parameter Rhat values < 1.1 (Brooks and Gelman 1998). Data analyses were performed in $R$ ( $R$ Core Team 2019) using a Bayesian framework in JAGS (Plummer 2017) called from the package jagsUI (Kellner 2015). We assessed model performance between the treatment-time interaction model (model \#3) and the main effects model (model \#4) using DIC.

For model \#3, we calculated the change of expected BCI values within each respective cut-back border treatment at one-year post-treatment period and two-year post-treatment period against the pre-treatment period and between cut-back border treatments within each time period, and assessed differences based on $95 \%$ credible intervals not overlapping 0. For model \#4, we calculated the change of expected BCI values within each cut-back border width and harvest intensity prescription. We assessed differences based on $95 \%$ credible intervals not overlapping 0.

\section{Results}

\subsection{Topographic effects on vegetation regeneration in cut-back borders}

We tested 11 a priori models to assess whether differences in vegetation response between one-year post-treatment and two-year post-treatment could be predicted from 
topographic indices (see Appendix 2-E for model results). Shade proportion index (SPI), the proportion of the vegetation sampling plot which was shaded, ranged between 0-94\% $($ mean = $15 \%)$ in $15-\mathrm{m}$ cut-back borders and between $0-71 \%($ mean $=13 \%)$ in 30 -m cut-back borders. No vegetation sampling plots in the $45-\mathrm{m}$ cut-back borders were shaded.

No single model received strong support (Appendix 2-E) and thus, we used modelaveraging to predict percent change for all vegetation variables. Percent change from one-year post-treatment to two-year post-treatment of understory cover $0-1 \mathrm{~m}$, understory cover $>1-2 \mathrm{~m}$, and midstory stems $0-5.1 \mathrm{~cm} \mathrm{DBH}$ were greater on mesic soils relative to xeric soils in cut-back borders (Figure 2-7). Percent change of ground cover and midstory stems $>5.1-11.3 \mathrm{~cm} \mathrm{DBH}$ did not differ across xeric and mesic soil conditions in cut-back borders (Figure 2-7). For all vegetation variables collected, we provide summary statistics in Appendix 2-F.

\subsection{Ruffed grouse and American woodcock response to cut-back borders}

We conducted a total of 840 grouse drumming surveys during the study. We detected a total of 24 grouse ( 21 during drumming surveys, 3 opportunistic detections) during the study. Our posterior predictive check indicated models were a reasonable fit (Appendix 2-G). Based on on DIC, the treatment-time interaction model performed better than the main effects model (Appendix 2-G). Estimated effective detection probability (i.e., probability of detecting an individual over two annual surveys) during drumming surveys was 0.326 (mean) \pm 0.08 (SD). We did not detect any differences in occupancy between control and cut-back border treatments, nor any differences in occupancy between pre-treatment and one-year post-treatment or two-year post-treatment for any cut-back border treatment (Figure 2-8). Grouse occupancy was strongly positively influenced by elevation (slope coefficient [log odds scale] $=$ [mean] $2.85 \pm$ [SD] 1.50).

We conducted 434 woodcock singing-ground surveys during the study. We detected two woodcock during the study period. One of the detected woodcock was at AGWMA in the 15-m width, $14 \mathrm{~m}^{2} /$ ha intensity treatment at one-year post-treatment, and the other at LWWMA in the $30 \mathrm{~m}$ wide, $14 \mathrm{~m}^{2} /$ ha intensity treatment at two year post-treatment. Additionally, woodcock were heard at BLWMA and SJWMA but not during surveys.

\subsection{Focal songbird response to cut-back borders}

We conducted a total of 868 avian point counts over the course of the study period. We detected a total of 102 species of songbirds. Of the 24 species that met the detection criteria $(\geq 40$ 
detections), 16 species also met the cumulative detection probability criteria $(\geq 0.200$; Appendix 2-C). Of these 16 species, five were from the young forest guild (American goldfinch, Carolina wren, common yellowthroat, eastern towhee, and indigo bunting), four were from the interioredge guild (American redstart, blue-gray gnatcatcher, eastern wood-pewee, and northern cardinal), four were from the forest gap guild (black-throated green warbler, cerulean warbler, hooded warbler, and red-eyed vireo), and three were in the forest interior guild (black-and-white warbler, ovenbird, and wood thrush). Our posterior predictive checks indicated all individual species models were a reasonable fit (Appendix 2-G). The treatment-time interaction model performed better, based on DIC, for ten species whereas the main effects model performed better for six species (Appendix 2-G).

Of the 16 species analyzed, nine responded positively to at least one cut-back border treatment in the treatment-time interaction model (Figures 2-9-2-12). In the $15 \mathrm{~m}$ wide, $14 \mathrm{~m}^{2} / \mathrm{ha}$ intensity treatment, hooded warbler and indigo bunting abundances increased from pre-treatment to one-year post-treatment (Figures 2-9 and 2-11) and hooded warbler and red-eyed vireo abundances increased from pre-treatment to two-year post-treatment (Figure 2-11). In the $15 \mathrm{~m}$ wide, $4.5 \mathrm{~m}^{2} /$ ha intensity treatment, American goldfinch and black-and-white warbler abundances increased from pre-treatment to one-year post-treatment (Figures 2-9 and 2-12). Additionally, in the $15 \mathrm{~m}$ wide, $4.5 \mathrm{~m}^{2} /$ ha intensity treatment, blue-gray gnatcatcher, Carolina wren, eastern towhee, hooded warbler, indigo bunting, northern cardinal, and red-eyed vireo abundances increased from pre-treatment to two-year post-treatment (Figure 2-9-2-11). In the 45 $\mathrm{m}$ wide, $14 \mathrm{~m}^{2} /$ ha intensity treatment, indigo bunting abundance increased from pre-treatment to one-year and two-year post-treatment (Figure 2-9), and blue-gray gnatcatcher abundance increased from pre-treatment to one-year post-treatment (Figure 2-10).

Two forest gap species, black-throated green warbler and hooded warbler responded negatively to cut-back border treatments. Black-throated green warbler abundance decreased from pre-treatment to one-year post-treatment in the $45 \mathrm{~m}$ wide, $14 \mathrm{~m}^{2} /$ ha intensity treatment (Figure 2-11). Hooded warbler abundance decreased from pre-treatment to one-year posttreatment in the $30 \mathrm{~m}$ wide and $45 \mathrm{~m}$ wide, $4.5 \mathrm{~m}^{2} /$ ha intensity treatments (Figure 2-11). Abundances of both species rebounded by two-year post-treatment.

In the main effects model, harvest intensity had a strong influence on eight species. American goldfinch, black-and-white warbler, blue-gray gnatcatcher, Carolina wren, eastern 
towhee, hooded warbler, indigo bunting, and northern cardinal abundances were higher in the 4.5 $\mathrm{m}^{2} /$ ha intensity treatment than the control (Figure 2-13). Eastern towhee, hooded warbler, and indigo bunting abundances were higher in the $14 \mathrm{~m}^{2} /$ ha intensity treatment than the control (Figure 2-13). The main effect of width had a strong influence on three species. Eastern towhee and indigo bunting abundances were higher in the $45 \mathrm{~m}$ wide treatment than the control (Figure 2-14). Eastern towhee, hooded warbler, and indigo bunting abundances were higher in the $15 \mathrm{~m}$ wide treatment than the control (Figure 2-14). Eastern towhee abundance was higher in the $30 \mathrm{~m}$ wide treatment than the control

\subsection{Avian community}

Avian community-vegetation relationships.-Of the 102 songbird species detected during the study, 40 met the detection criteria ( $\geq 20$ detections) to be included in a CCA to assess species correlations with vegetation variables. Representation from each habitat guild included 10 species from the young forest guild, 11 from the interior-edge guild, seven from the forest gap guild, 10 from the forest interior guild, and two from the predator/parasite guild (Appendix 2-D).

The constrained proportion of variance in species count data (response data) explained by vegetation data was $8.9 \%$. The permutation test on each canonical axis indicated the first five canonical axes each had a significant relationship with response data (Appendix 2-G). The first principal component axis, which explained 3.5\% of response data, had a strong elevational gradient and was positively correlated with the black-throated blue warbler, black-throated green warbler, Canada warbler, chestnut-sided warbler, common yellowthroat, dark-eyed junco, and ruffed grouse (Appendix 2-G, Figure 2-15). The second principal component axis, which explained $1.1 \%$ of response data, described a gradient from mature forest-like characteristics (high overstory cover and basal area) to disturbed forest-like characteristics (high ground cover and understory cover $>1-2 \mathrm{~m}$ ). Young forest, forest gap, and interior-edge species were spread across the second principal axis with no obvious trends, and forest interior species were generally associated with high overstory cover and basal area (Figure 2-15). The remaining eight principal component axes explained a combined $2.0 \%$ of the variation in response data.

Species richness in cut-back borders during spring migration.-We conducted 364 point counts and detected 84 different species during the spring stopover period. Our posterior predictive checks indicated our models were a reasonable fit (Appendix 2-G). Based on DIC, the 
main effects model performed better than the treatment-time interaction model (Appendix 2-G). Species richness during the spring stopover period was lower in the $15 \mathrm{~m}$ wide, $14 \mathrm{~m}^{2} / \mathrm{ha}$ and 4.5 $\mathrm{m}^{2} /$ ha intensity treatments and $45 \mathrm{~m}$ wide, $14 \mathrm{~m}^{2} /$ ha intensity treatment at one-year posttreatment compared to pre-treatment (Figure 2-16). Additionally, species richness was lower in the $30 \mathrm{~m}$ wide and $45 \mathrm{~m}$ wide, $14 \mathrm{~m}^{2} /$ ha intensity treatments at two-year post-treatment compared to pre-treatment levels (Figure 2-16). The main effect of harvest intensity and width had a strong influence on spring stopover richness. Species richness was higher in the control than the 14 and $4.5 \mathrm{~m}^{2}$ /ha intensity treatment (Figure 2-13), and species richness was higher in the control treatment than the $15 \mathrm{~m}, 30 \mathrm{~m}$, and $45 \mathrm{~m}$ wide treatments (Figure 2-14).

Avian guild richness in cut-back borders.-Our posterior predictive checks indicated all avian guild models were a reasonable fit (Appendix 2-G). The treatment-time interaction model performed better for four avian guilds whereas the main effects model performed better for two avian guilds (Appendix 2-G).Three of the four habitat guilds, the cavity nesting guild, and species of conservation priority generally responded positively to cut-back border treatments of narrower width at two-year post-treatment (Figures 2-17 and 2-18). In the $15 \mathrm{~m}$ wide, $14 \mathrm{~m}^{2} / \mathrm{ha}$ intensity treatment, richness of species of conservation priority increased from pre-treatment to one-year post-treatment and two-year post-treatment (Figure 2-18), and richness of the cavity nesting, interior-edge habitat, and young forest habitat guilds increased from pre-treatment to two-year post-treatment (Figures 2-17 and 2-18). In the $15 \mathrm{~m}$ wide, $4.5 \mathrm{~m}^{2} /$ ha intensity treatment, species of conservation priority and the young forest habitat guild increased from pre-treatment to one-year post-treatment (Figures 2-17 and 2-18), and the interior-edge and young forest habitat guilds increased from pre-treatment to two-year post-treatment (Figure 2-17). In the $30 \mathrm{~m}$ wide, $14 \mathrm{~m}^{2} /$ ha intensity treatment, the interior-edge habitat guild and cavity nesting guild increased from pre-treatment to two-year post-treatment (Figures 2-17 and 2-18). In the $45 \mathrm{~m}$ wide, $14 \mathrm{~m}^{2} /$ ha intensity treatment, richness of species of conservation priority and the young forest guild increased from pre-treatment to two-year post-treatment (Figures 2-17 and 2-18). No guilds declined in richness.

The main effect of harvest intensity had a strong influence on the young forest, interioredge, and forest gap habitat guilds and the species of conservation priority. Young forest, interior-edge, forest gap, and species of conservation priority species richness was higher in the $14 \mathrm{~m}^{2} /$ ha and $4.5 \mathrm{~m}^{2} /$ ha intensity treatments than the control (Figure 2-13). The main effect of 
width had a strong influence on the young forest, interior-edge, and forest gap habitat guilds and the species of conservation priority. Species richness of the young forest, interior-edge, forest gap, and species of conservation priority was higher in the $15 \mathrm{~m}$ wide treatment than the control (Figure 2-14). Young forest species richness was higher in the $45 \mathrm{~m}$ wide treatment than the control, and interior-edge species richness was higher in the $30 \mathrm{~m}$ wide treatment than the control (Figure 2-14).

\subsection{Salamanders in cut-back borders}

Salamander surface relative abundances in cut-back borders.-We captured a total of 229 salamanders of five species during the study period (Appendix 2-H). The majority of captures $(187,82 \%)$ were eastern red-backed salamanders (Plethodon cinereus) and thus, we performed analysis only on this species. Our posterior predictive check indicated the model was a reasonable fit (Appendix 2-G). The main effects model performed better than the treatmenttime interaction model based on DIC (Appendix 2-G). Relative abundance of eastern red-backed salamanders decreased in the $30 \mathrm{~m}$ wide, $14 \mathrm{~m}^{2} /$ ha intensity treatment from pre-treatment to oneyear post-treatment but returned to pre-treatment levels the subsequent year (Figure 2-19).

Abundance increased from pre-treatment to one-year post-treatment in the $45 \mathrm{~m}$ wide, $4.5 \mathrm{~m}^{2} / \mathrm{ha}$ intensity treatment but returned to pre-treatment levels at two-year post-treatment.

Salamander body condition in cut-back borders.-We assessed BCI of 154 eastern redbacked salamanders from BMWMA and LWWMA (some captures did not have morphological measurements taken) because too few eastern red-backed salamanders were captured at LCWMA (11 captures) or SJWMA (4 captures) to obtain reliable site-level BCI estimates. We selected these two study sites because they accounted for the majority of eastern red-backed salamander captures (154 of 169, 91\%) during the study. Our posterior predictive check indicated the model was a reasonable fit (Appendix 2-G). The main effects model performed better than the treatment-time interaction model based on DIC (Appendix 2-G). BCI increased from pre-treatment to two-year post-treatment in the $30 \mathrm{~m}$ wide, $4.5 \mathrm{~m}^{2} /$ ha intensity treatment and the $45 \mathrm{~m}$ wide, $14 \mathrm{~m}^{2} /$ ha intensity treatment (Figure 2-20). BCI did not decrease in any cutback border treatment.

\section{Discussion}


With the proliferation of linear infrastructure due to increased energy demand and extraction in West Virginia and the central Appalachian region, there is a growing need to find ways that use pipelines and powerlines to meet conservation objectives. Habitat management along ROW forest edges via cut-back borders provides a unique opportunity to incorporate wildlife habitat management concepts into human-modified landscape features to meet these conservation objectives. Here we have provided a short-term assessment of cut-back border treatments and associated vegetation and their effects on birds and salamanders to develop management guidelines that can assist wildlife managers in their decision-making when confronted with managing wildlife along abrupt forest edges of ROW corridors or wildlife openings (hereafter "ROW/WO”).

\subsection{Wildlife response to cut-back borders}

Prior to cut-back border implementation, habitats at study sites consisted of earlysuccessional habitat (i.e., primarily grasses, forbs, and low shrubs) immediately adjacent to mature forests. Following cut-back border treatment, habitats within cut-back borders consisted of a developed understory vegetation component (with similarities to habitat in ROW/WO) with the retention of some canopy trees that created a transitional area between ROW/WO and adjacent mature forests. This reduction of the abrupt forest edge along ROW/WO created conditions suitable to avian and salamander species from a broad spectrum of forest successional stages.

Prior to cut-back border treatment, we observed populations of young forest avian species in mature forests immediately adjacent to ROW/WO (i.e., future locations of cut-back borders) and within ROW/WO. Following treatment, cut-back borders along ROW/WO supported higher populations of young forest species than no cut-back borders along ROW/WO. Young forest avifauna responded positively to $15-\mathrm{m}, 30-\mathrm{m}$, and 45-m cut-back border widths at both cutting intensities $\left(14 \mathrm{~m}^{2} / \mathrm{ha}\right.$ and $4.5 \mathrm{~m}^{2} / \mathrm{ha}$ basal area retention), with significant positive responses to the 15-m and 45-m wide cut-back border treatments and both cutting intensities from American goldfinch, Carolina wren, eastern towhee, indigo bunting, and the young forest habitat guild (Figures 2-9, 2-13, 2-14, and 2-17). These positive responses were likely due to vegetation in ROW/WO complimenting vegetation in cut-back borders (or vice versa). The reduction of a portion of the overstory layer in cut-back borders stimulated ground and understory vegetation growth in cut-back borders and increased locally available habitat when combined with 
vegetation in ROW/WO, effectively widened ROW/WO. Right-of-way/wildlife opening widening via cut-back borders likely alleviates area-sensitivity pressures (e.g., territory elongation, width sensitivity) observed in some young forest species (Rodewald and Vitz 2005, Shake et al. 2012). Anderson et al. (1977) and Confer and Pascoe. (2003) reported young forest birds were scarce or absent in narrow ROW corridors but increased with increasing corridor width, which may be a manifestation of edge-avoidance by young forest species (Schlossberg and King 2009). Our nuisance variable, ROW/WO width, strongly positively influenced American goldfinch abundance and young forest guild richness were positively correlated with ROW/WO width (slope coefficients $=0.34$ and 0.16 , respectively). It would then follow that wider ROW/WO-cut-back border combinations would elicit greater avian responses. However, we observed the majority (9 of 16) of our significant responses to width in the 15-m cut-back border treatments. Previous studies have reported young forest avifauna exhibit a quadratic relationship with ROW width (i.e., lower abundance in narrow and wide-width ROWs and high abundance in intermediate-width ROWs; King et al. 2009) which may explain the few significant responses to the 30-m and 45-m cut-back border treatments observed in our study. This may indicate the relative success of managing young forest avifauna using cut-back borders is contingent on ROW/WO width.

Ruffed grouse, a young forest species of conservation priority in the region, did not show a significant response to cut-back border treatments, although we did observe greatest mean occupancy at two-year post-treatment in the 30-m and 45-m treatments (Figure 2-8). However, low detections at few study sites resulted in low model precision, limiting our ability to discern effects from cut-back border treatments. The ruffed grouse is a species that prefers diversely aged forest stands to meet their year-round needs (Thompson and Dessecker 1997). The positioning of cut-back borders optimizes these needs in a relatively small area, where ROW/WO offer travel lanes between suitable young forest patches (i.e., cut-back borders) and adjacent mature forests provide reliable hard mast and roosting habitat (Thompson and Fritzell 1988, Whitaker et al. 2006). Ruffed grouse presence was positively correlated with elevation, whereas all other vegetation correlations were weak. One explanation for the correlation with elevation is the prevalence of West Nile Virus (WNV) in the region and its negative effects on grouse populations at lower elevations (Stauffer et al. 2018). While information about the effects of WNV on grouse in West Virginia is limited, WNV may prove to be an additional hurdle for 
ruffed grouse management in the state. Weak correlations between grouse and other vegetation variables could be due to vegetation lag following cut-back border treatment. Two years may not be enough time to allow major young forest vegetation components like midstory stems, an important vegetation characteristic for ruffed grouse (Whitaker and Stauffer 2003, Jones et al. 2008), to fully develop, especially at sites with rocky or shallow soils (e.g., AGWMA, LCWMA, and SCWMA). Some young forest species exhibit a delayed response to timber harvesting practices, which could result from the slow vegetation regeneration and possibly explain the weak species-vegetation correlations we observed for many young forest species (Figure 2-15; Schlossberg and King 2009). Future monitoring of the vegetation and avian community may highlight some important vegetation characteristics to assist managers in creating optimal habitat conditions for young forest avifauna in cut-back borders.

Forest gap avifauna responded positively to 15-m cut-back border widths at both 14 $\mathrm{m}^{2} / \mathrm{ha}$ and $4.5 \mathrm{~m}^{2} /$ ha cutting intensities whereas responses were negative to the $30-\mathrm{m}$ and $45-\mathrm{m}$ cut-back border widths in the treatment-time interaction model. Forest gap specialists are associated with forest interior habitats with a preference for irregular canopy structures (Bowen et al. 2007, Perkins and Wood 2014). Within forested landscapes, forest gaps species are often closely associated with canopy disturbances (Boves et al. 2013) that retain suitable levels of canopy (Sheehan et al. 2014). The moderate levels of canopy trees retained in the 15-m cut-back borders following treatment created an irregular, but sufficient canopy layer that when combined with adjacent mature forest maintained suitable habitat conditions in cut-back borders. Two-age silviculture harvests (much like the harvest prescriptions used in our study) have proven to benefit forest gap species immediately following harvesting (Nareff et al. 2019). However, these conditions are ephemeral and habitat quality for forest gap species declines as tree crowns expand into unoccupied canopy gaps, eliminating sallying or singing perches for this group (Sheehan et al. 2014). Future monitoring can assess how long cut-back borders provide suitable habitat for forest gap species.

The forest interior avifauna was of interest for this study as this group of species is negatively affected by the presence of ROWs in forest-dominated landscapes (Barton et al. 2016, Farwell et al. 2016). We did not detect any significant negative responses by individual species or the community following treatment, indicating cut-back borders did not significantly reduce habitat quality for forest interior species. Rather, black-and-white warblers increased in the 15-m 
wide, $4.5 \mathrm{~m}^{2} /$ ha intensity treatment (Figure 2-12) and was higher in the $4.5 \mathrm{~m}^{2} /$ ha intensity treatment than control (Figure 2-13). Considering forest interior species were positively correlated with mature forest characteristics (basal area and overstory cover) in the CCA (Figure 2-15), and live basal area and overstory cover significantly decreased following treatment (Appendix 2-C), we might expect habitat suitability to be reduced for forest interior species in cut-back borders. However, it appears that the cut-back borders in our study which were relatively narrow, in conjunction with adjacent mature forest, retained enough key habitat features to maintain forest interior populations along ROW/WO.

We assessed another forest interior species of interest to cut-back borders: the eastern red-backed salamander. Surprisingly, we detected a significant negative response to the $30-\mathrm{m}$ wide, $14 \mathrm{~m}^{2} /$ ha intensity treatment and a significant positive response to the $45-\mathrm{m}$ wide, 4.5 $\mathrm{m}^{2} /$ ha intensity treatment at one-year post-treatment, although abundances returned to pretreatment levels during the two-year post-treatment period. This appears counter to expectations, as we would predict the narrower, least intensive treatment to support greater salamander abundances relative to the widest, heaviest intensity treatments based on the physiology of terrestrial salamanders and previous studies from the region (Duguay and Wood 2002). Additionally, we observed an increase in BCI of eastern red-backed salamanders in the $30 \mathrm{~m}$ wide and $45 \mathrm{~m}$ wide, $14 \mathrm{~m}^{2} /$ ha intensity treatments at two-year post-treatment. Higher BCI in the lighter intensity treatments (i.e., $14 \mathrm{~m}^{2} /$ ha intensity) compared to control/pre-treatment could result from greater food availability or more foraging opportunities. Eastern red-backed salamanders forage on the forest floor surface and suitable environmental conditions (e.g., cool, moist) allow them to actively forage for longer periods without desiccation. These conditions are often met in undisturbed areas (i.e., control/pre-treatment) but our $14 \mathrm{~m}^{2} /$ ha intensity treatments appear to support healthier eastern red-backed salamanders relative to individuals in the control/pre-treatment. Traditional timber harvests remove felled trees and CWD which are important surface refugia for salamanders (Petranka et al. 1994, Semlitsch et al. 2009). Our study was unique in that we did not remove any CWD from the stand (see Section 2.2) which may have mitigated the detrimental effects associated with canopy removal (e.g., dry leaf litter and soils).

However, it is unlikely this effect alone explained the responses we observed. One potential source of sampling bias may be related to greater rates of felled trees near salamander 
sampling plots which may influence the number of captures, as we did not sample under newly felled trees. Despite this potential source of error, the short-term evidence suggests that cut-back borders provide suitable habitat conditions for eastern red-backed salamanders. Lag effects of amphibians to forest disturbance have been reported (Ash 1988, Popescu et al. 2012), but the presence of CWD could reduce or eliminate detrimental effects associated with reduced canopy cover (McKenny et al. 2006). Continued monitoring to fully assess the long-term effects of cutback borders on eastern red-backed salamanders and other terrestrial salamanders will help develop management strategies for young forest and forest interior communities.

Finally, songbird richness during the spring stopover period decreased following treatments, particularly the first year (Figure 2-16). Decreased songbird stopover richness immediately following treatment is expected. Songbirds rely heavily on foliar-occurring arthropods during the spring migration period (Strode 2009). The lack of plant growth during the spring period combined with the recent tree cutting limited the available leaf area for foliaroccurring arthropods. Therefore, cut-back borders provided few foliar-occurring arthropods relative to uncut areas and reduced songbird richness during spring stopover during the one-year post-treatment period. Further, negative responses showed no consistent pattern with regard to cut-back border width or harvest intensity over time. Additionally, the inconsistent responses we observed could be a result of sampling during a highly variable period, particularly with Neotropical migrants. Migration times are often species-specific that fluctuate with continentalwide weather patterns but are also highly linked to plant phenology which is becoming increasingly variable (Mayor et al. 2017). We did not evaluate individual species' responses during the spring stopover period which may provide us a better assessment of the influences cut-back borders have on avifauna during this period. Continual monitoring of the spring migration period coupled with habitat assessments will elucidate Neotropical migrant responses to cut-back border treatments and help fill knowledge gaps to improve full annual-cycle conservation for priority species of the central Appalachian region.

Managing wildlife communities via cut-back borders has widespread potential for wildlife conservation in the region. We hypothesized that young forest species would exhibit positive responses to wider, heavy-intensity cut-back border treatments while forest interior species, both birds and salamanders, would exhibit negative responses to wider, heavy-intensity cut-back border treatments. Implementation of cut-back borders along forest edges of ROW/WO 
appeared to create suitable intermediate conditions between ROW/WO and mature forests for young forest species as well as forest interior species. Often there is a trade-off when managing wildlife habitats, between creating habitat for young forest communities or preserving habitat for mature forest and forest interior communities. Implementation of cut-back borders along abrupt forest edges created young forest conditions in the forest understory to the benefit of disturbancedependent species while retaining sufficient canopy that preserved suitable habitat conditions for disturbance-avoidant species. We have shown here that cut-back borders have widespread potential as a management technique along abrupt forest edges within forest-dominated landscapes in situations where young forest species are desired but concerns exist about further diminishing habitat for forest interior species.

\subsection{Vegetation response in cut-back borders}

We assessed the effects of multiple topographic indices (Beers aspect, head load index $[\mathrm{HLI}]$, shade proportion index [SPI], and topographic relative moisture index [TRMI]) on vegetation responses between one-year and two-year post-treatment to determine if responses could be explained by indices to help inform cut-back border placement with respect to local topography and edge orientation. We found no single index that consistently received strong support in explaining variation of vegetation regeneration in cut-back borders. This could be a result of the small sampling window (one year of plant growth) used for analysis. However, it was clear that vegetation regeneration was greater on mesic slopes for understory vegetation cover and small midstory stems. These two habitat features are important vegetation components for young forest species because they provide nesting cover from predators and important food resources via leaf-occurring invertebrates during the breeding season and fruit during the postbreeding season. Considering understory vegetation cover is an important habitat feature for young forest species, placement of cut-back borders should be prioritized on mesic slopes.

We observed weak correlations between individual bird species abundances and vegetation variables. These weak relationships could indicate that loose species-vegetation relationships exist along forest edges, that relationships are strong but sporadic resulting from spatially complex interactions at forest edges (Laurance et al. 2007), that microsite-level vegetation variables alone do not explain species' responses, or that short sampling intervals limited our ability to detect any strong relationships. Continued monitoring may elucidate 
species-vegetation relationships in cut-back borders to help develop vegetation-oriented guidelines for cut-back borders.

\section{Management Implications}

Cut-back borders were a useful approach for managing young forest and mature forest wildlife species along abrupt forest edges of ROW/WO. The majority (26 of 35) of our positive significant avian responses were in 15-m wide treatments suggesting this was the most effective treatment for managing forest birds along forest edges. We observed two positive responses and one negative response for birds in 30-m wide cut-back borders and a negative response by the eastern red-backed salamander. We observed four positive and two negative avian responses to 45-m wide cut-back borders, as well as a positive response by the eastern red-backed salamander. Additionally, we observed 16 positive avian responses to $14 \mathrm{~m}^{2} /$ ha intensity cutback borders and 18 positive avian responses to $4.5 \mathrm{~m}^{2} /$ ha intensity cut-back borders. Continued monitoring to assess species-vegetation relationships over time will help elucidate important habitat characteristics that change temporally and that will inform land managers in developing long-term management goals for cut-back borders.

Considering 15-m cut-back borders elicited the highest proportion of significant responses from young forest and other avian species, this treatment width seems to be the most effective approach for managing wildlife habitat in the short-term, as long as target basal area is reduced to $<14 \mathrm{~m}^{2} /$ ha to stimulate understory and midstory vegetation. This is also the most aesthetically pleasing treatment. In areas of heavy human use, wider cut-back borders will likely prompt public pushback (personal observation) which can potentially limit further use of cutback borders on public lands. Additionally, 15-m cut-back borders are the most economically viable treatment relative to $30-\mathrm{m}$ or $45-\mathrm{m}$ treatments, as managers could create wildlife habitat in 15-m borders in a single day versus using multiple days with multiple people to create wider borders. Considering the number of trees that need to be felled in the 15, 30, and 45-m treatments and the wildlife response generated from each treatment, 15-m cut-back borders are the most cost-effective treatment that maximizes short-term wildlife response.

Young forest wildlife communities have experienced continual declines in the region due to the lack of suitable habitat. Although ROW corridors were used by young forest species in some forested landscapes, vegetation control in ROW corridors (e.g., mowing, herbicide spraying) and their shape (i.e., long and narrow) often limit habitat suitability and availability for 
many species (Askins 1994, Bulluck and Buehler 2006). These factors likely make conservation strategies for young forest species that are centered within ROW corridors inefficient.

Conversely, cut-back borders increased the amount of young forest habitat that surrounded ROW/WO and widened ROW/WO, effectively enhancing these areas for young forest avifauna. Further, cut-back borders did not negatively affect forest interior wildlife species due to the retention of canopy trees in conjunction with adjacent mature forest. The retention of canopy trees in cut-back borders effectively created a transitional area between ROW/WO and mature forest that softened a previously abrupt forest edge and simultaneously created habitat conditions suitable for young forest and forest interior wildlife.

With the continued development of energy infrastructure within the central Appalachian region, it is important that natural resource managers and scientists continue to find ways to incorporate ROWs into habitat management to meet conservation goals for at-risk species and communities. While much work has focused on passive management of ROWs, few studies have examined how active habitat management affects these areas for young forest wildlife species. We have provided information herein to fill this knowledge gap. Still, more research and longerterm studies will be necessary to develop sound management strategies that can inform managers and improve these approaches for long-term management. Study on how topography affects vegetation regeneration (and subsequent wildlife response) and non-native/invasive species spread will help inform managers on ways to promote healthy and robust forest systems adjacent to ROWs. Additionally, information on a variety of cut-back border widths and harvest intensities will provide managers with a greater arsenal of strategies to meet specific objectives in a variety of settings. 


\section{Literature Cited}

AGA (American Gas Association). 2019. Annual Distribution and Transmission Miles of Pipeline: Miles of Pipeline and Main by State and Type (Table 5-3). https://www.aga.org/research/data/distribution-and-transmission-miles-of-pipeline/ Accessed 10 February 2020.

AMJV (Appalachian Mountains Joint Venture). 2018. AMJV Priority Landbirds. https://amjv.org/priority-species/

Anderson, S.H., K. Mann, and H.H. Shugart Jr. 1977. The effect of transmission-line corridors on bird populations. The American Midland Naturalist 97 (1): 216-221.

Ash, A.N. 1988. Disappearance of salamanders from clearcut plots. The Journal of the Elisha Mitchell Scientific Society 104 (2): 116-122.

Askins, R.A. 1994. Open corridors in a heavily forested landscape: impact on shrubland and forest-interior birds. Wildlife Society Bulletin 22 (2): 339-347.

Askins. R.A., C.M. Folsom-O'Keefe, and M.C. Hardy. 2012. Effects of vegetation, corridor width and regional land use on early successional birds on powerline corridors. PLoS ONE 7 (2): e31520. http://doi.org/10.1371/journal.pone.0031520

Baker, T.P., G.J. Jordan, and S.C. Baker. 2016. Microclimate edge effects in a recently harvest forest: Do remnant forest patches create the same impact as large forest areas? Forest Ecology and Management 365: 128-136. http://doi.org/10.1016/j.foreco.2016.01.022

Barton, E.P., S.E. Pabian, and M.C. Brittingham. 2016. Bird community response to Marcellus shale gas development. The Journal of Wildlife Management 80 (7): 1301-1313. http://doi.org/10.1002/jwmg.21117

Beers, T.W., P.E. Dress, and L.C. Wensel. 1966. Notes and observations: aspect transformations in site productivity research. Journal of Forestry 64 (10): 691-692.

Bibby, C.J., N.D. Burgess, D.A. Hill, and S.H. Mustoe. 2002. Bird Census Techniques, $2^{\text {nd }}$ edition. Academic Press, London, UK. 302 p.

Boves, T.J., D.A. Buehler, J. Sheehan, P.B. Wood, A.D. Rodewald, J.L. Larkin, P.D. Keyser, F.L. Newell, A. Evans, G.A. George, and T.B. Wigley. 2013. Spatial variation in breeding habitat selection by cerulean warblers (Setophaga cerulea) throughout the Appalachian Mountains. The Auk 130 (1): 46-59. http://doi.org/10.1525/auk.2012.12104

Bowen, L.T., C.E. Moorman, and J.C. Kilgo. 2007. Seasonal bird use of canopy gaps in a bottomland forest. The Wilson Journal of Ornithology 119 (1): 77-88. http://doi.org/10.1676/05-091.1 
Brittingham, M.C., and S.A. Temple. 1983. Have cowbirds caused forest songbirds to decline? BioScience 33 (1): 31-35.

Brooks, S.P., and A. Gelman. 1998. General methods of monitoring convergence of iterative simulations. Journal of Computational and Graphical Statistics 7 (4): 434-455.

Buffo, J., L.J. Fritschen, and J.L. Murphy. 1972. Direct solar radiation on various slopes from 0 to 60 degrees north latitude. USDA Forest Service Research Paper PNW-142.

Bulluck, L.P., and D.A. Buehler. 2006. Avian use of early-successional habitats: Are regenerating forest, utility right-of-ways and reclaimed surface mines the same? Forest Ecology and Management 236: 76-84. http://doi.org/10.1016/j.foreco.2006.08.337

Burger, W., K.O. Evans, M.D. Smith, and S. Riffell. 2013. Conservation Research Program. CP33-Habitat Buffers for Upland Birds. Bird Monitoring and Evaluation Plan, 2006-2011 Final Report. 84 pp.

Burnham, K.P., and D.R. Anderson. 2002. Model selection and multimodel inference: a practical information-theoretic approach. Second edition, Springer, New York, New York, USA.

Chasko, G.G., and J.E. Gates. 1982. Avian habitat suitability along a transmission-line corridor in an oak-hickory forest region. Wildlife Monographs 82: 3-41.

Confer, J.L., and S.M. Pascoe. 2003. Avian communities on utility rights-of-ways and other managed shrublands in the northeastern United States. Forest Ecology and Management 185: 193-205. http://doi.org/10.1016/S0378-1127(03)00255-X

Conover, R.R., L.W. Burger Jr., and E.T. Linder. 2009. Breeding bird response to field border presence and width. The Wilson Journal of Ornithology 121 (3): 548-555. $\underline{\text { http://doi.org/10.1676/08-082.1 }}$

Culbert, P.D., V.C. Radeloff, C.H. Flather, J.M. Kellndorfer, C.D. Rittenhouse, and A.M. Pidgeon. 2013. The influence of vertical and horizontal habitat structure on nationwide patterns of avian biodiversity. The Auk 130 (4): 656-665. http://doi.org/10.1525/auk.2013.13007

Curzon, M.T., S.C. Baker, C.C. Kern, B.J. Palik, and A.W. D’Amato. 2017. Influence of mature overstory trees on adjacent 12-year regeneration and the woody understory: Aggregated retention versus intact forest. Forests 8 (2): 31. http://doi.org/10.3390/f8020031

DeGraaf, R.M., and M. Yamasaki. 2002. Effects of edge contrast on redback salamander distribution in even-aged northern hardwoods. Forest Science 48 (2): 351-363.

deMaynadier, P.G., and M.L. Hunter Jr. 1998. Effects of silvicultural edges on the distribution and abundance of amphibians in Maine. Conservation Biology 12 (2): 340-352. 
Dettmers, R. 2003. Status and conservation of shrubland birds in the northeastern US. Forest Ecology and Management 185: 81-93. https://doi.org/10.1016/S0378-1127(03)00248-2

Duguay, J.P., and P.B. Wood. 2002. Salamander abundance in regenerating forest stands on the Monongahela National Forest, West Virginia. Forest Science 48 (2): 331-335.

Eberhardt, L.L. 1976. Quantitative ecology and impact assessment. Journal of Environmental Management 4 (1).

EIA (Energy Information Administration). 2020. Natural Gas Overview and Summary. U.S. Department of Energy, Washington, D.C. https://www.eia.gov/naturalgas/

ESRI (Environmental Systems Research Institute). 2014. ArcGIS Desktop: Release 10.3. Redlands, CA.

Evans, K.O., L.W. Burger Jr., S.K. Riffell, M.D. Smith, D.J. Twedt, R.R. Wilson, S. Vorisek, C. Rideout, and K. Heyden. 2015. Avian response to conservation buffers in agricultural landscapes during winter. Wildlife Society Bulletin 38 (2): 257-264. http://doi.org/10.1002/wsb.405

Farwell, L.S., P.B. Wood, J. Sheehan, and G.A. George. 2016. Shale gas development effects on the songbird community in a central Appalachian forest. Biological Conservation 201:7891. http://dx.doi.org/10.1016/j.biocon.2016.06.019

Fettinger, J.L. 2002. Ruffed grouse nesting ecology and brood habitat in western North Carolina. Thesis. University of Tennessee, Knoxville, Tennessee, USA.

Fleming, K.K, and W.M. Giuliano. 1998. Effect of border-edge cuts on birds at woodland edges in southwestern Pennsylvania. The Journal of Wildlife Management 62 (4): 1430-1437.

Fleming, K.K., and W.M. Giuliano. 2001. Reduced predation of artificial nests in border-edge cuts on woodlots. The Journal of Wildlife Management 65 (2): 351-355.

Foggia, J.R., S.A. Rush, D.A. Miller, T.B. Wigley, and J.A. Martin. 2018. Effects of forest structure and harvest-induced edges on predation risk. Wildlife Society Bulletin 42 (2): 237-245. http://doi.org/10.1002/wsb.879

Gabor, C.R. 1995. Correlational test of Mathis' hypothesis that bigger salamanders have better territories. Copeia 3: 729-735.

Gelman, A., J.B. Carlin, H.S. Stern, D.B. Dunson, A. Vehtari, and D.B. Rubin. 2014. Bayesian data analysis. Third edition. CRC Press, Boca Raton, Florida, USA, 661 p.

Hachè, S., T. Pètry, and M.-A. Villard. 2013. Numerical response of breeding birds following experimental selection harvesting in northern hardwood forests. Avian Conservation and Ecology 8 (1): 4. http://doi.org/10.5751/ACE-00584-080104 
Harris, K.J. 2020. Disturbance related to unconventional oil and gas development in the Appalachian Basin. Thesis. West Virginia University, Morgantown, West Virginia, USA.

Hesed, K.M. 2012. Uncovering salamander ecology: a review of coverboard design. Journal of Herpetology 46 (4): 442-450. http://doi.org/10.1670/10-220

Heske, E.J., S.K. Robinson, and J.D. Brawn. 1999. Predator activity and predation on songbird nests on forest-field edges in east-central Illinois. Landscape Ecology 14: 345-354.

HIFLD (Homeland Infrastructure Foundation-Level Data). 2019. Electric Power Transmission Lines. https://hifld-geoplatform.opendata.arcgis.com/datasets/electric-powertransmission-lines Accessed 10 February 2020.

Hofmeister, J., J. Hošek, M. Brabec, R. Střalkova, P. Mỳlová, M. Bouda, J.L. Pettit, M. Rydval, and M. Svoboda. 2019. Microclimate edge effects in small fragments of temperate forests in the context of climate change. Forest Ecology and Management 448: 48-56. http://doi.org/10.1016/j.foreco.2019.05.069

Huebner, C.D., and D.W. McGill. 2018. The importance of disturbance versus physiography in defining vegetation composition and predicting possible successional trajectories. Castanea 83 (1): 54-76. http://doi.org/10.2179/17-139

Jones, B.C., J.L. Kleitch, C.A. Harper, and D.A. Buehler. 2008. Ruffed grouse brood habitat use in a mixed hardwood forest: implications for forest management in the Appalachians. Forest Ecology and Management 255: 3580-3588. http://doi.org/10.1016/j.foreco.2008.02.019

Kellner, K.F. 2015. jagsUI: a wrapper around rjags to streamline JAGS analyses. R package version 1.4.1.

Kéry, M., and J.A. Royle. 2016. Applied Hierarchical Modeling in Ecology: Analysis of distribution, abundance and species richness in R and BUGS, Volume 1. Academic Press. $783 \mathrm{pp}$.

King, D.I., R.B. Chandler, J.M. Collins, W.R. Petersen, and T.E. Lautzenheiser. 2009. Effects of width, edge and habitat on the abundance and nesting success of scrub-shrub birds in powerline corridors. Biological Conservation 142 (11): 2672-2680. http://doi.org/10.1016/j.biocon.2009.06.016

King, D.I., and S. Schlossberg. 2014. Synthesis of the conservation value of the earlysuccessional stage in forests of eastern North America. Forest Ecology and Management 324: 186-195. http://doi.org/10.1016/j.foreco.2013.12.001

Kleeberger, S.R., and J.K. Werner. 1982. Home range and homing behavior of Plethodon cinereus in northern Michigan. Copeia 2: 409-415. 
Küchler, A.W. 1964. Potential natural vegetation of the conterminous United States (map). Special Publication 36. American Geographic Society, New York.

Laurance, W.F., H.E.M. Nascimento, S.G. Laurance, A. Andrade, R.M. Ewers, K.E. Harms, R.C.C. Luizāo, and J.E. Ribeiro. 2007. Habitat fragmentation, variable edge effects, and the landscape-divergence hypothesis. PLoS ONE 2 (10): e1017. http://doi.org/10.1371/journal.pone.0001017

Lepš, J., and P. Šmilauer. 2003. Mulitivariate analysis of ecological data using CANOCO. Cambridge University Press, New York, New York, USA. http://doi.org/10.1017/CBO9780511615146

Lorimer, C.G. 2001. Historical and ecological roles of disturbance in eastern North American forests: 9,000 years of change. Wildlife Society Bulletin 29 (2): 425-439.

MacKenzie, D.L., J.D. Nichols, J.A. Royle, K.H. Pollock, L.L. Baily, and J.E. Hines. 2017. Occupancy estimation and modeling: inferring patterns and dynamics of species occurrence, $2^{\text {nd }}$ edition. Academic Press, Cambridge, Massachusetts, USA.

Mayor, S.J., R.P. Guralnick, M.W. Tingley, J. Otegui, J.C. Withley, S.C. Elmendorf, M.E. Andrew, S. Leyk, I.S. Pearse, and D.C. Schneider. 2017. Increasing phenological asynchrony between spring green-up and arrival of migratory birds. Scientific Reports 7 (1902). http://doi.org/10.1038/s41598-017-02045-z

Mazerolle, M.J. 2019. AICcmodavg: Model selection and multimodel inference based on (Q)AIC(c). R package version 2.2-2.

McBurney, R.S. 1989. Drumming. Pages 176-197 in S. Atwater and J. Schnell (eds.). The Wildlife Series: Ruffed Grouse. Stackpole Books, Harrisburg, Pennsylvania, USA.

McCune, B., and D. Keon. 2002. Equations for potential annual direct incident radiation and heat load index. Journal of Vegetation Science 13: 603-606.

McKenny, H.C., W.S. Keeton, and T.M. Donovan. 2006. Effects of structural complexity enhancement on eastern red-backed salamander (Plethodon cinereus) populations in northern hardwood forests. Forest Ecology and Management 230: 186-196. http://doi.org/10.1016/j.foreco.2006.04.034

Messier, C.H. 1996. Managing light and understory vegetation in boreal and temperate broadleaf-conifer forests. Pages 59-81 in P.G. Comeau and K.D. Thomas (eds.). Silviculture of temperate and boreal broadleaf-conifer mixtures. BC Ministry of Forests, Victoria, BC, Land Management Handbook 36.

Morgan, K.A., and J.E. Gates. 1982. Bird population patterns in forest edge and strip vegetation at Remington Farms, Maryland. The Journal of Wildlife Management 46 (4): 933-944. 
Morin, R.S., G.W. Cook, C.J. Barnett, B.J. Butler, S.J. Crocker, M.A. Hatfield, C.M. Kurtz, T.W. Lister, W.G. Luppold, W.H. McWilliams, P.D. Miles, M.D. Nelson, C.H. Perry, R.J. Piva, J.E. Smith, J.A. Westfall, R.H. Widmann, C.W. Woodall. 2016. West Virginia Forests 2013. Resource Bulletin. NRS-105. Newtown Square, PA: U.S. Department of Agriculture, Forest Service, Northern Research Station. 128 p. https://doi.org/10.2737/NRS-RB-105

Murcia, C. 1995. Edge effects in fragmented forests: implications for conservation. Trends in Ecology and Evolution 10 (2): 58-62.

Nareff, G.E., P.B. Wood, D.J. Brown, T. Fearer, J.L. Larkin, and W.M. Ford. 2019. Cerulean warbler (Setophaga cerulea) response to operational silviculture in the central Appalachian region. Forest Ecology and Management 448: 409-423. http://doi.org/10.1016/j.foreco.2019.05.062

NOAA (National Oceanic and Atmospheric Administration). 2019. National Weather Service Forecast Office, Charleston, WV. https://w2.weather.gov/climate/xmacis.php?wfo=rlx

Nudds, T.D. 1977. Quantifying the vegetative structure of wildlife cover. Wildlife Society Bulletin 5 (3): 113-117.

Oksanen, J. 2019. vegan: Community ecology package. R package version 2.5-6.

Oswalt, S.J., K.E. Franzreb, and D.A. Buehler. 2010. Changes in early-successional hardwood forest area in four bird conservation regions across four decades. Joint Meeting of the Forest Inventory and Analysis (FIA) Symposium and the Southern Mensurationists, 8793.

Pardieck, K.L., D.J. Ziolkowski, M. Lutmerding, V. Aponte, and M-A.R. Hudson. 2019. North American Breeding Bird Survey Dataset 1966-2018, version 2018.0. U.S. Geological Survey, Patuxent Wildlife Research Center. http://doi.org/10.5066/P9HE8XYJ

Parker, A.J. 1982. The topographic relative moisture index: An approach to soil-moisture assessment in mountain terrain. Physical Geography 3 (2): 160-168.

Perkins, K.A., and P.B. Wood. 2014. Selection of forest canopy gaps by male cerulean warblers in West Virginia. The Wilson Journal of Ornithology 126 (2): 288-297. http://doi.org/10.1676/13-067.1

Petranka, J.W., M.E. Eldridge, and K.E. Haley. 1994. Effects of timber harvesting on low elevation populations of southern Appalachian salamanders. Forest Ecology and Management 67: 135-147.

PIF (Partner in Flight). 2019. Avian Conservation Assessment Database, version 2019. Available at http://pif.birdconservancy.org/ACAD

Plummer, M. 2017. JAGS Version 4.3.0 user manual. 
Popescu, V.D., D.A. Patrick, M.L. Hunter Jr., and A.J.K. Calhoun. 2012. The role of forest harvesting and subsequent vegetative regrowth in determining patterns of amphibian habitat use. Forest Ecology and Management 270: 163-174.

http://doi.org/10.1016/j.foreco.2012.01.027

R Core Team. 2019. R: A language and environment for statistical computing. R Foundation for Statistical Computing, Vienna, Austria. https://www.R-project.org/

Ralph, C.J., G.R. Geupel, P. Pyle, T.E. Martin, and D.F. DeSante. 1993. Handbook of Field Methods for Monitoring Landbirds. General Technical Report PSW-GTR 144-www. U.S. Department of Agriculture, Forest Service, Pacific Southwest Research Station, Albany, California, USA. http://doi.org/10.2737/PSW-GTR-144

Ries, L., and T.D. Sisk. 2010. What is an edge species? The implications of sensitivity to habitat edges. Oikos 119 (10): 1636-1642. http://doi.org/10.1111/j.1600-0706.2010.18414.x

Rodewald, A.D., and A.C. Vitz. 2005. Edge- and area-sensitivity of shrubland birds. Journal of Wildlife Management 69 (2): 681-688.

Schlossberg, S., and D.I. King. 2009. Postlogging succession and habitat usage of shrubland birds. The Journal of Wildlife Management 73 (2): 226-231. http://doi.org/10.2193/2007$\underline{518}$

Schumacher, C.L. 2002. Ruffed grouse habitat use in western North Carolina. Thesis. University of Tennessee, Knoxville, Tennessee, USA.

Semlitsch, R.D., B.D. Todd, S.M. Blomquist, A.J.K. Calhoun, J.W. Gibbons, J.P. Gibbs, G.J. Graeter, E.B. Harper, D.J. Hocking, M.L. Hunter Jr., D.A. Patrick, T.A.G. Rittenhouse, and B.B. Rothermel. 2009. Effects of timber harvest on amphibian populations: understanding mechanisms from forest experiments. BioScience 59 (10): 853-862. http://doi.org/10.1525/bio.2009.59.10.7

Shake, C.S., C.E. Moorman, and M.R. Burchell II. 2011. Cropland edge, forest succession, and landscape affect shrubland bird nest predation. The Journal of Wildlife Management 75 (4): 825-835. http://doi.org/10.1002/jwmg.101

Shake, C.S., C.E. Moorman, J.D. Riddle, and M.R. Burchell II. 2012. Influence of patch size and shape on occupancy by shrubland birds. The Condor 114 (2): 268-278. http://doi.org/10.1525/cond.2012.110107

Sheehan, J., P.B. Wood, D.A. Buehler, P.D. Keyser, J.L. Larkin, A.D. Rodewald, T.B. Wigley, T.J. Boves, G.A. George, M.H. Bakermans, T.A. Beachy, A. Evans, M.E. McDermott, F.L. Newell, K.A. Perkins, and M. White. 2014. Avian response to timber harvesting applied experimentally to manage Cerulean Warbler breeding populations. Forest Ecology and Management 321: 5-18. http://doi.org/10.1016/j.foreco.2013.07.037 
Slay, C.M., and K.G. Smith. 2009. Nest success rates of four shrubland specialists in conservation-managed fields with comparisons to other managed and unmanaged shrublands. Proceedings of the International Partners in Flight Conference: Tundra to Tropics. 705-712.

Stage, A.R., and C. Salas. 2007. Interactions of elevation, aspect, and slope in models of forest species composition and productivity. Forest Science 53 (4): 486-492. http://doi.org/10.1093/forestscience/53.4.486

Stauffer, G.E., D.A.W. Miller, L.M. Williams, and J. Brown. 2018. Ruffed grouse population declines after introduction of West Nile Virus. The Journal of Wildlife Management 82 (1): 165-172. http://doi.org/10.1002/jwmg.21347

Strode, P.K. 2009. Spring tree species use by migrating yellow-rumped warblers in relation to phenology and food availability. The Wilson Journal of Ornithology 121 (3): 457-468. http://doi.org/10.1676/05-148.1

Thompson, III, F.R., and D.R. Dessecker. 1997. Management of early-successional communities in Central Hardwood Forests: With species emphasis on the ecology and management of oaks, ruffed grouse, and forest songbirds. General Technical Report NC-195. U.S. Department of Agriculture, Forest Service, North Central Research Station.

Thompson, F.R., and E.K. Fritzell. 1988. Ruffed grouse winter roost site preference and influence on energy demands. Journal of Wildlife Management 52 (3): 454-460.

Twedt, D.J., and S.G. Somershoe. 2009. Bird response to prescribed silvicultural treatments in bottomland hardwood forests. Journal of Wildlife Management 73 (7): 1140-1150. http://doi.org/10.2193/2008-441

USDA (United States Department of Agriculture), Forest Service. 2018. Forest Inventory and Analysis National Core Field Guild, Volume I: Field Data Collection Procedures for Phase 2 Plots. https://www.fia.fs.fed.us/library/field-guides-methodsproc/docs/2018/core_ver8-0_10_2018_final.pdf

USFWS (United States Fish and Wildlife Service). 2011. American woodcock singing-ground survey: Background and instructions. Division of Migratory Bird Management, Arlington, VA. https://migbirdapps.fws.gov/woodcock/training_tool_documents/US_survey_background instructions.pdf

Villard, M.-A., M.K. Trzcinski, and G. Merriam. 1999. Fragmentation effects on forest birds: relative influence of woodland cover and configuration on landscape occupancy. Conservation Biology 13 (4): 774-783. http://doi.org/10.1046/j.1523-1739.1999.98059.x 
Weiss, A.D. 2001. Topographic position and landforms analysis. Poster Presentation, ESRI Users Conference, San Diego, CA.

Whitaker, D.M., and D.E. Stauffer. 2003. Night roost selection during winter by ruffed grouse in the central Appalachians. Southeastern Naturalist 2 (3): 377-392. http://doi.org/10.1656/1528-7092(2003)002[0377:NRSDWB]2.0.CO;2

Whitaker, D.M., D.E. Stauffer, G.W. Norman, P.K. Devers, T.J. Allen, S. Bittner, D. Buehler, J. Edwards, S. Friedhoff, W.M. Giuliano, C.A. Harper, and B. Tefft. 2006. Factors affecting habitat use by Appalachian ruffed grouse. The Journal of Wildlife Management 70 (2): 460-471. http://doi.org/10.2193/0022-541X(2006)70[460:FAHUBA]2.0.CO;2

Wiens, J.A. 1997. Metapopulation Dynamics and Landscape Ecology. Pages 43-62 in I. Hanski and M.E. Gilpin (eds.). Metapopulation Biology: Ecology, Genetics, and Evolution. Academic Press.

Wunz, G.A. 1990. Relationship of wild turkey populations to clearings created for brood habitat in oak forests in Pennsylvania. Pages 32-38 in W.M. Healy and G.B. Healy (eds.). Proceedings of the Sixth National Wild Turkey Symposium.

WVDNR (West Virginia Division of Natural Resources). 2015. West Virginia State Wildlife Action Plan: West Virginia Division of Natural Resources. http://www.wvdnr.gov/wildlife/action_plan.shtm

WVU Extension. 2019. 2020 Garden Calendar. https://extension.wvu.edu/files/d/99343661-dff64106-9b4d-cd6be816439f/wvu-extension-service-garden-calendar.pdf. Accessed 6 December 2019.

WVGIS (West Virginia GIS Technical Center). 2019. WV State GIS Data Clearinghouse. http://wvgis.wvu.edu/about/about.php

Yahner, R.H., R.J. Hutnik, and S.A. Liscinsky. 2003. Long-term trends in bird populations on an electric transmission right-of-way. Journal of Arboriculture 29 (3): 156-160. 


\section{Tables}

Table 2-1. Data collection time-table for 11 cut-back border blocks at eight West Virginia Division of Natural Resource (WVDNR) wildlife management areas (WMA). "Blocks" in the table refers to number of block replicates at each site.

\begin{tabular}{|c|c|c|c|c|}
\hline & 2016 & 2017 & 2018 & 2019 \\
\hline \multicolumn{5}{|l|}{ Right-of-way } \\
\hline \multicolumn{5}{|l|}{ Underground Gas Pipeline } \\
\hline \multicolumn{5}{|l|}{ Burnsville Lake WMA (1 block) } \\
\hline \multicolumn{5}{|l|}{ Overhead Utility Powerline } \\
\hline \multicolumn{5}{|l|}{ Little Canaan WMA (2 blocks) } \\
\hline \multicolumn{5}{|l|}{ Wildlife Opening } \\
\hline \multicolumn{5}{|l|}{ Stonewall Jackson WMA (1 block) } \\
\hline \multicolumn{5}{|l|}{ Right-of-way } \\
\hline \multicolumn{5}{|l|}{ Underground Gas Pipeline } \\
\hline \multicolumn{5}{|l|}{ Lewis Wetzel WMA (2 blocks) } \\
\hline \multirow{2}{*}{\multicolumn{5}{|c|}{ Overhead Utility Powerline }} \\
\hline & & & & \\
\hline \multicolumn{5}{|l|}{ Wildlife Opening } \\
\hline \multicolumn{5}{|l|}{ Bluestone WMA (1 block) } \\
\hline \multicolumn{5}{|l|}{ Right-of-way } \\
\hline \multicolumn{5}{|l|}{ Underground Gas Pipeline } \\
\hline Allegheny WMA (1 block) & & & 1 Year Pre- & 1 Year Post- \\
\hline Wildlife Opening & & & & \\
\hline Sleepy Creek WMA (1 block) & & & & \\
\hline
\end{tabular}

Table 2-2. Sampling schedule for assessing avian, salamander, and vegetation response in cutback borders during 2016-2019.

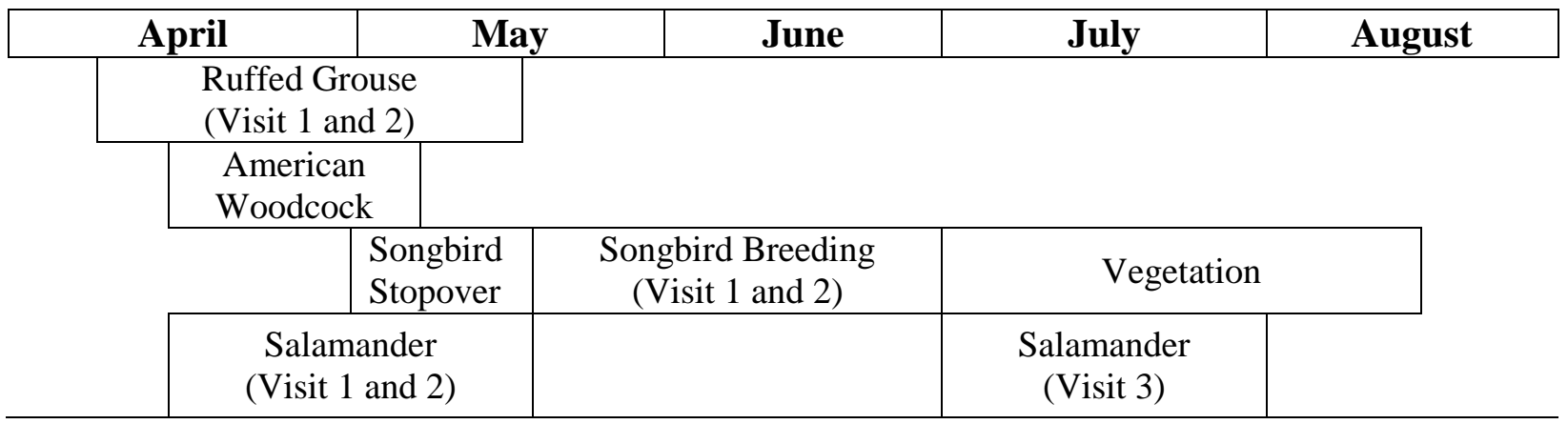




\section{Figures}

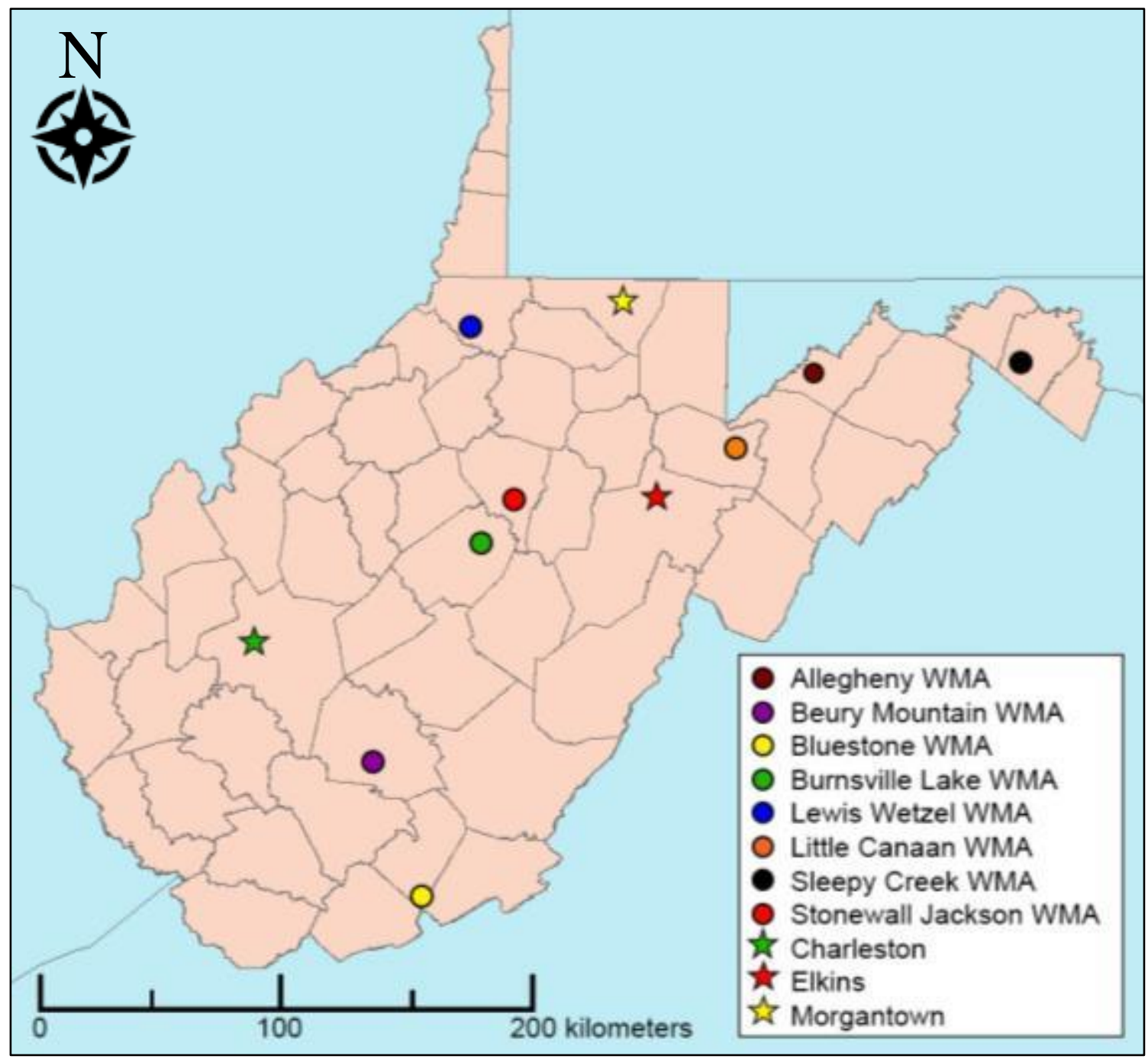

Figure 2-1. County map of West Virginia showing locations of wildlife management areas (WMA) where cut-back border plots were located (circles) as well as major cities (stars). 
A.

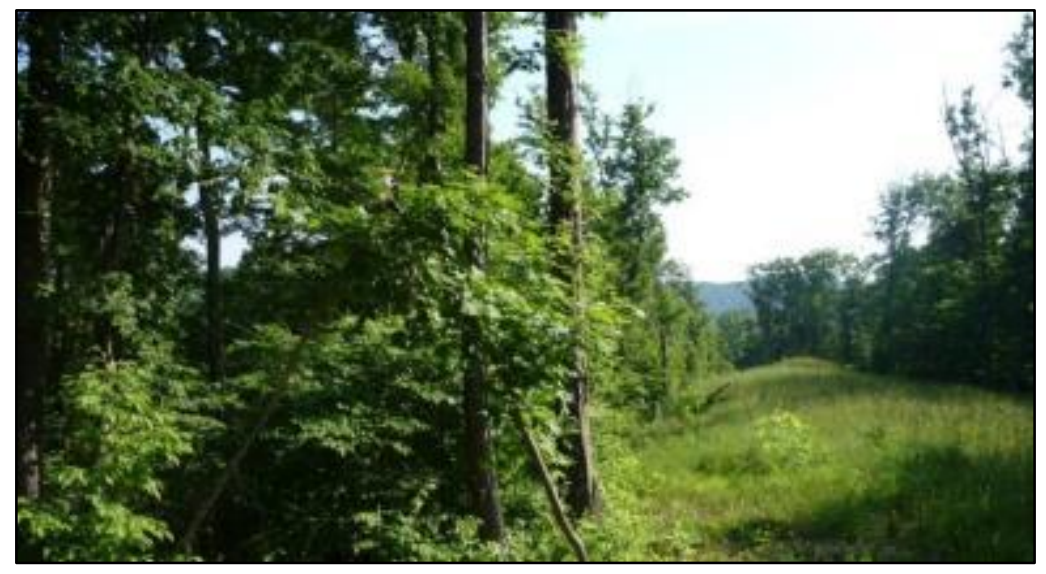

B.

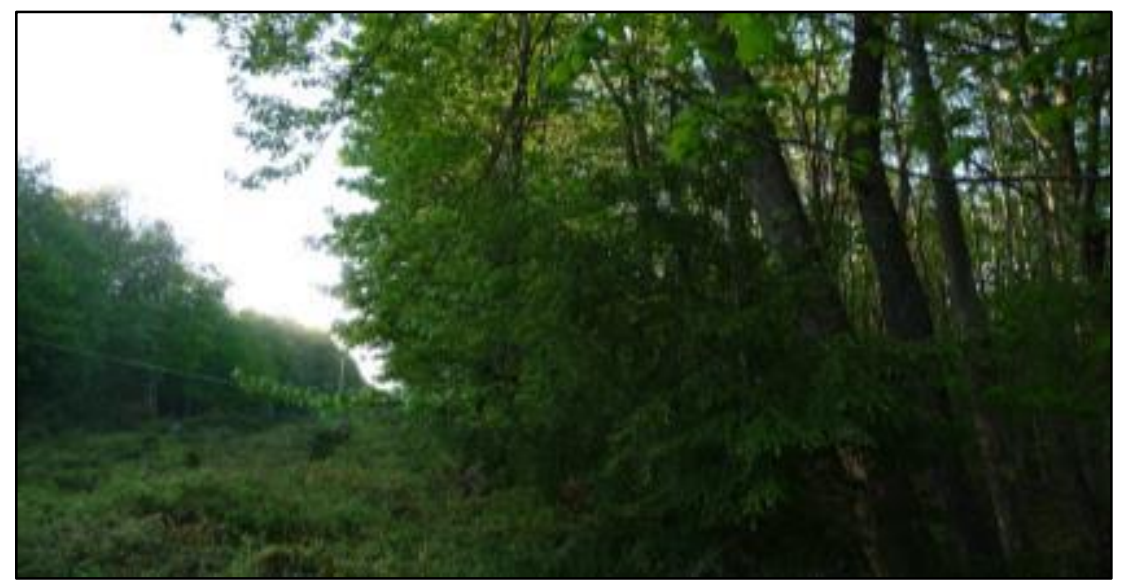

C.

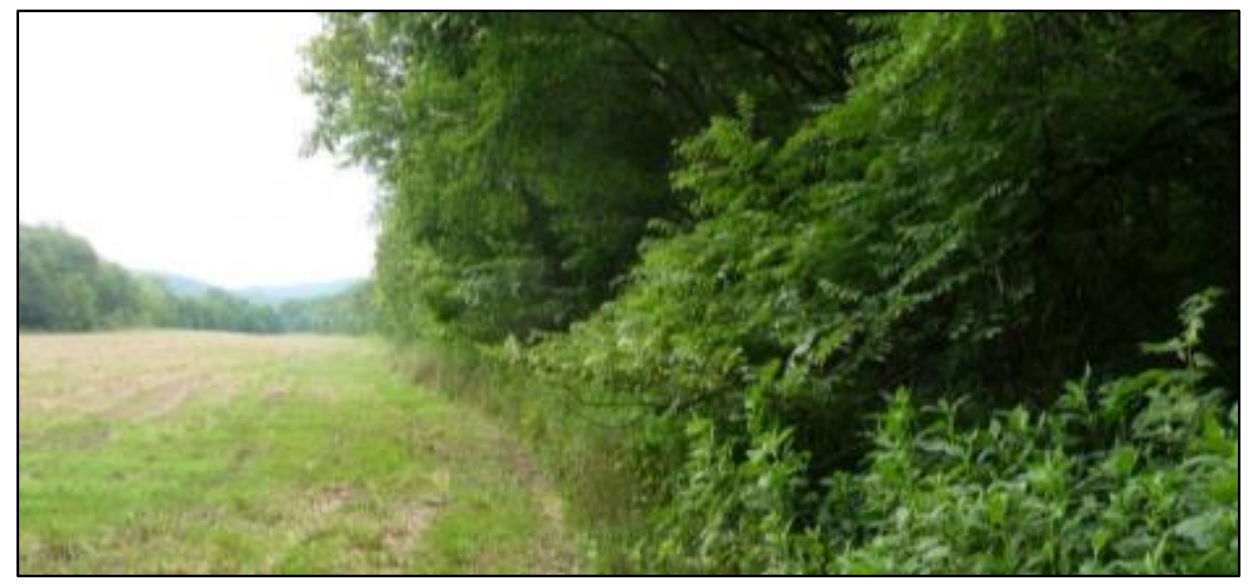

Figure 2-2. Examples of pre-treatment forest edge habitat prior to management along an underground gas pipeline at Lewis Wetzel Wildlife Management Area (LWWMA) (A), an overhead utility powerline at Little Canaan Wildlife Management Area (LCWMA) (B), and a wildlife opening at Bluestone Wildlife Management Area (BSWMA) (C). 


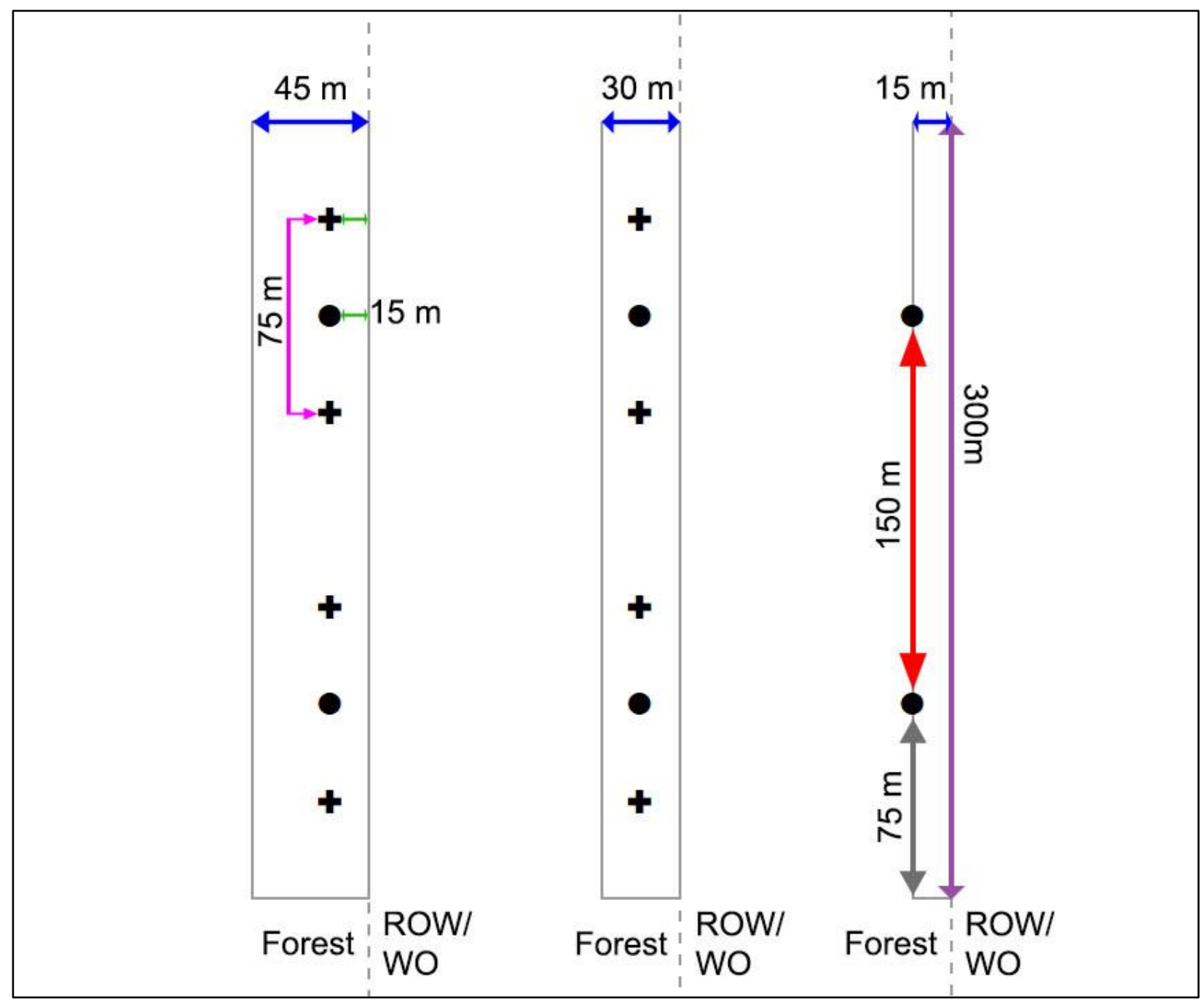

Figure 2-3. Cut-back border plot layout with avian and vegetation sampling point (black dots) and salamander sampling point (black + ) placements within each treatment width $(15,30$, and 45 $\mathrm{m})$ along rights-of-ways (ROWs) and wildlife openings (WO). Each cut-back border plot extended $300 \mathrm{~m}$ (violet arrow) along the forest-ROW/WO boundary (dashed line), and was either 15,30 , or $45 \mathrm{~m}$ (blue arrows) into the forest in a perpendicular direction respective to the forestROW/WO boundary. Avian and salamander sampling points were located $15 \mathrm{~m}$ (green arrow) off the forest-ROW/WO boundary. Avian sampling points were $150 \mathrm{~m}$ apart (red arrow) and 75 $\mathrm{m}$ (gray arrow) from cut-back border plot ends. Salamander sampling points were $75 \mathrm{~m}$ apart (pink arrow) and $37.5 \mathrm{~m}$ from plot ends. No salamander sampling occurred in the 15-m cut-back border treatments. Sampling point locations were consistent across all cut-back border widths with respect to forest-ROW/WO boundary (green arrow), intra-plot paired point counts (red arrow), and cut-back border plot ends (gray arrow). 


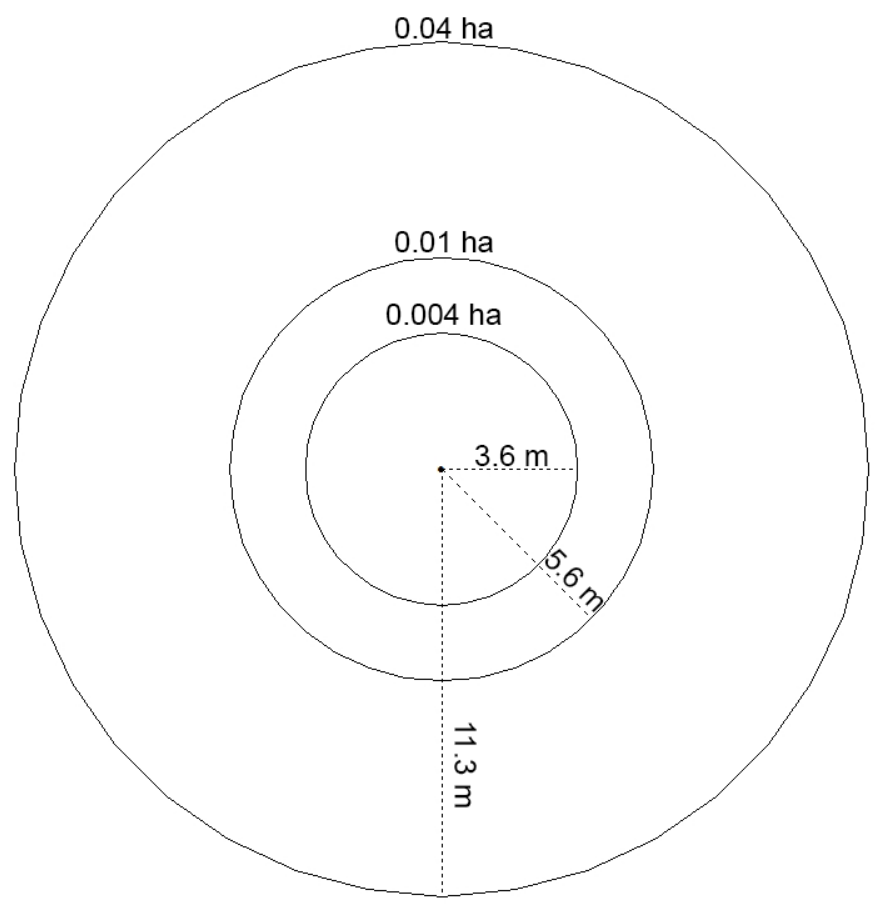

Figure 2-4. Diagram of nested circular sampling plot for sampling vegetation variables in cutback borders. Each cut-back border plot contained two vegetation sampling plots located at avian sampling point-count locations (see Figure 3). Within the 0.04 ha (11.3 m radius) plot, overstory tree variables (e.g., overstory cover and basal area) were measured. Within the 0.01 ha $(5.6 \mathrm{~m}$ radius) plot, counts of midstory stems $<11.4 \mathrm{~cm} \mathrm{DBH}$ and $\geq 1.4 \mathrm{~m}$ in height were grouped into two size categories (0-5 cm DBH and 5.1-11.3 cm DBH). Within the 0.004 ha (3.6 $\mathrm{m}$ radius) plot, ground cover was estimated.

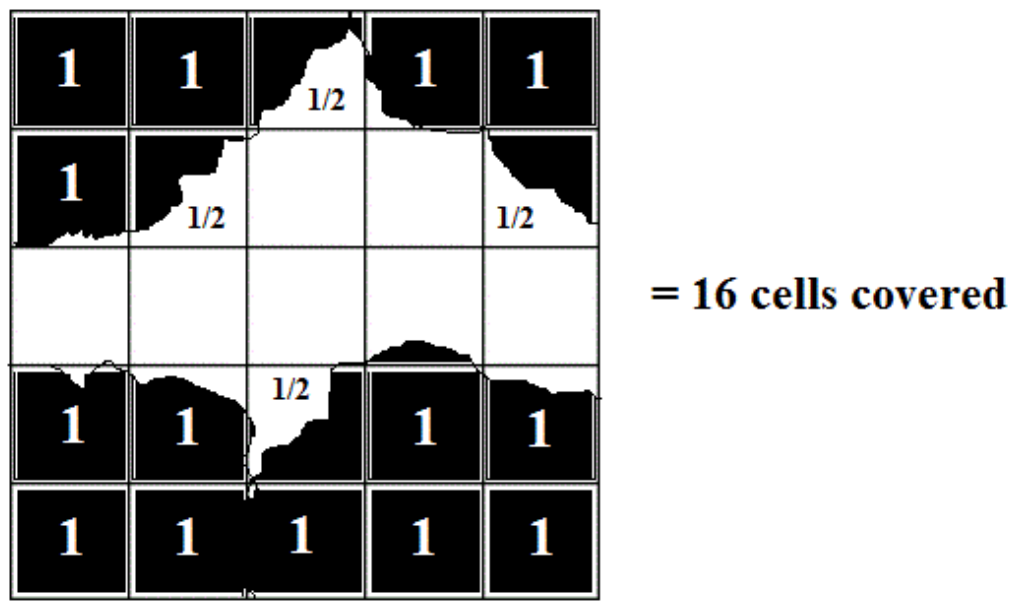

Figure 2-5. Example of a reading from $25 \mathrm{~cm}$ x $25 \mathrm{~cm}$ transparent plexiglass to estimate overstory cover in cut-back border vegetation sampling plot (Hachè et al. 2013). Plexiglass panel is divided into a $5 \mathrm{~cm} \times 5 \mathrm{~cm}$ grid. Cells that are covered, to the nearest $1 / 2$ cell, by overstory (delineated at $\geq 5 \mathrm{~m}$ above ground) are counted towards an overstory closure value. 


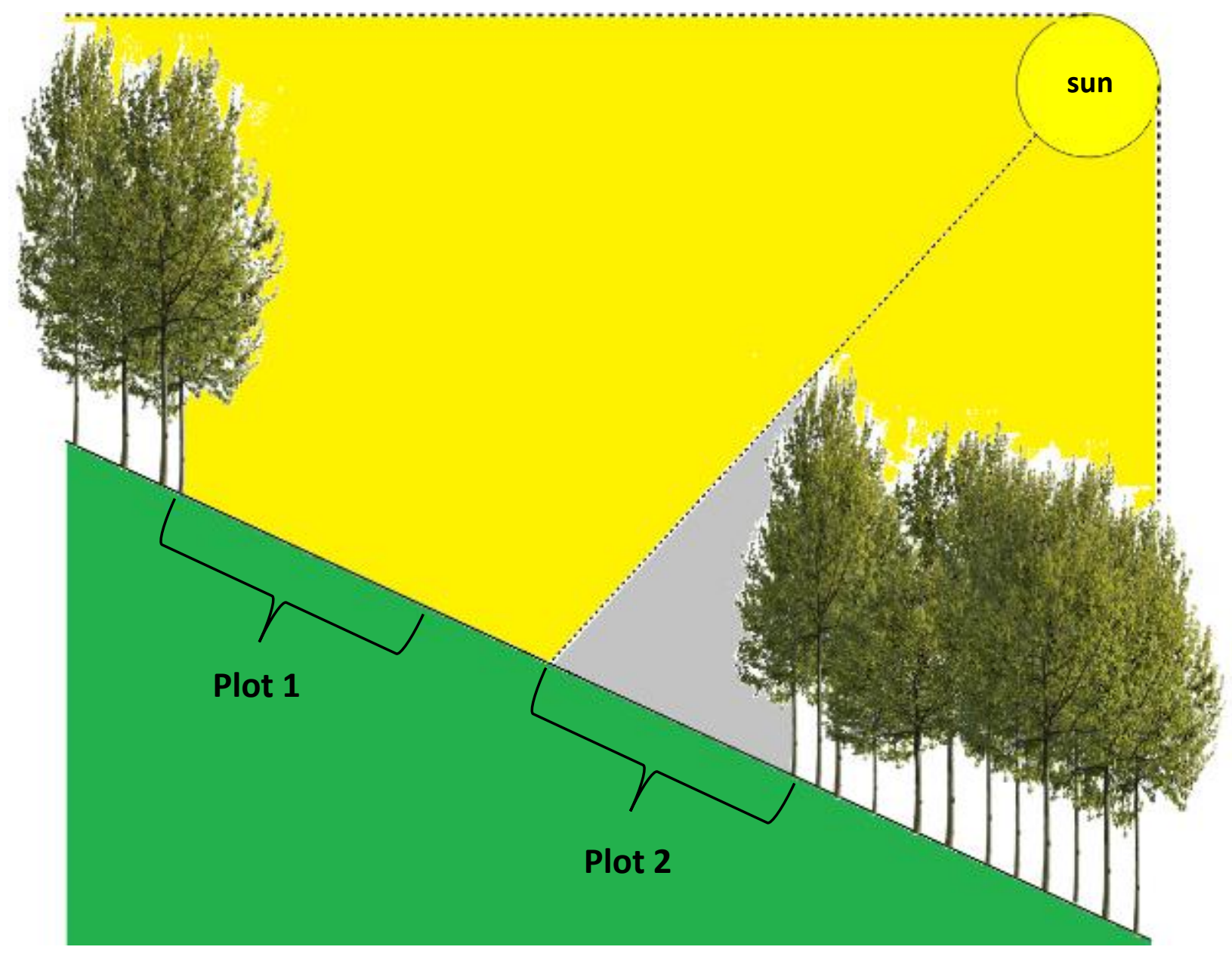

Figure 2-6. Example of differences in solar insolation based on plot location and edge orientation relative to the sun's position. In this scenario, Plot 1 receives full sunlight during the growing season compared to Plot 2 which is in the shadow of the adjacent forest. These differences in plot location could influence successional trajectories of vegetation in cut-back borders over time. 

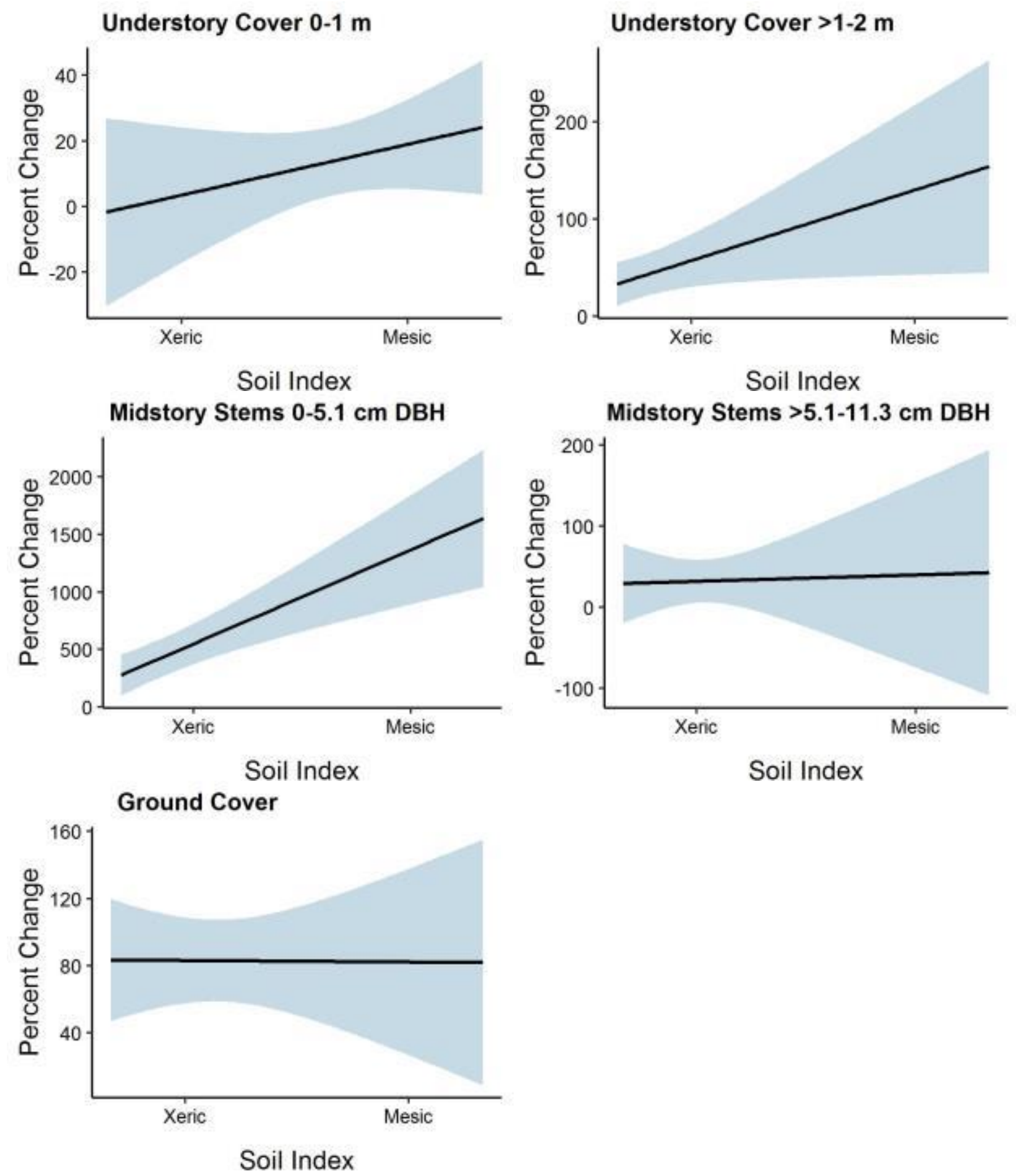

Figure 2-7. Model-averaged predictions of percent change of vegetation variables in cut-back borders between one-year post-treatment and two-year post-treatment in relation to relative soil conditions (i.e., xeric and mesic). We graphically represent our continuous soil moisture index on a relative scale from xeric to mesic soil conditions. Black line indicates predicted mean change and blue space indicates $95 \%$ confidence intervals. 


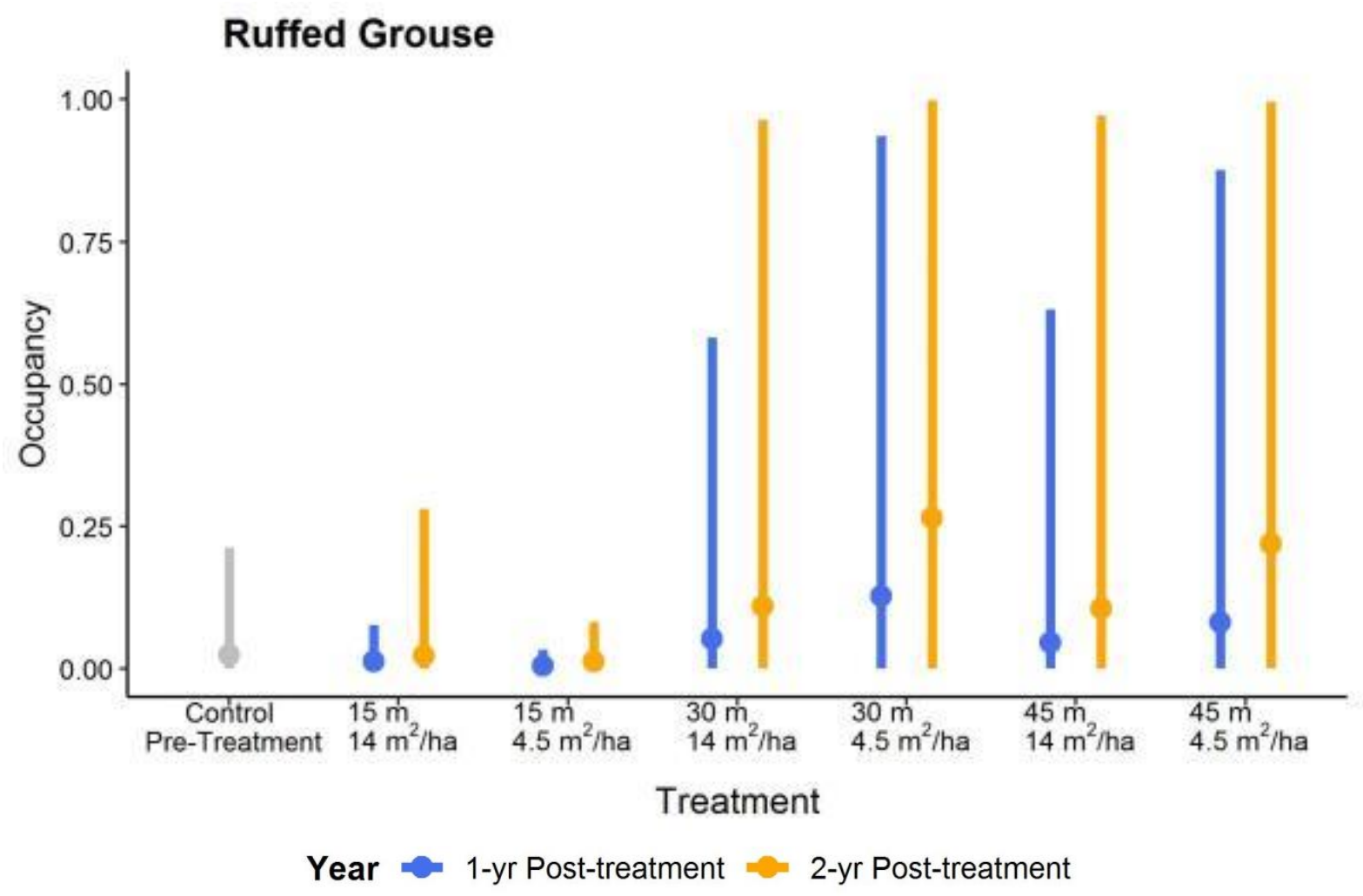

Figure 2-8. Plot-level estimated occupancy and 95\% confidence intervals of ruffed grouse detected within 100-m radius of sampling points in cut-back borders. There were no differences in occupancy rates between years within treatments based on $95 \%$ credible intervals. 


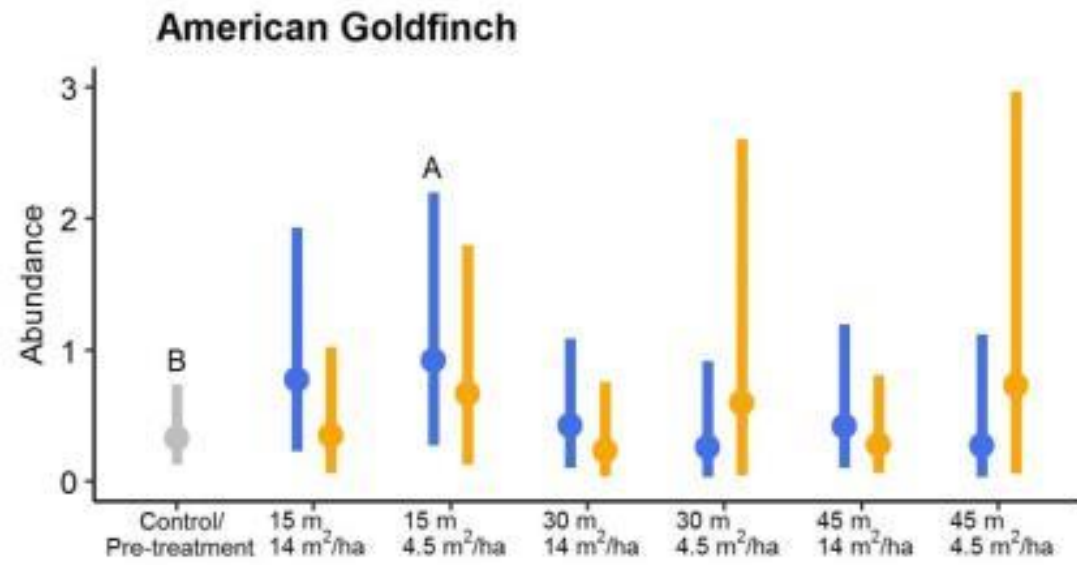

Treatment

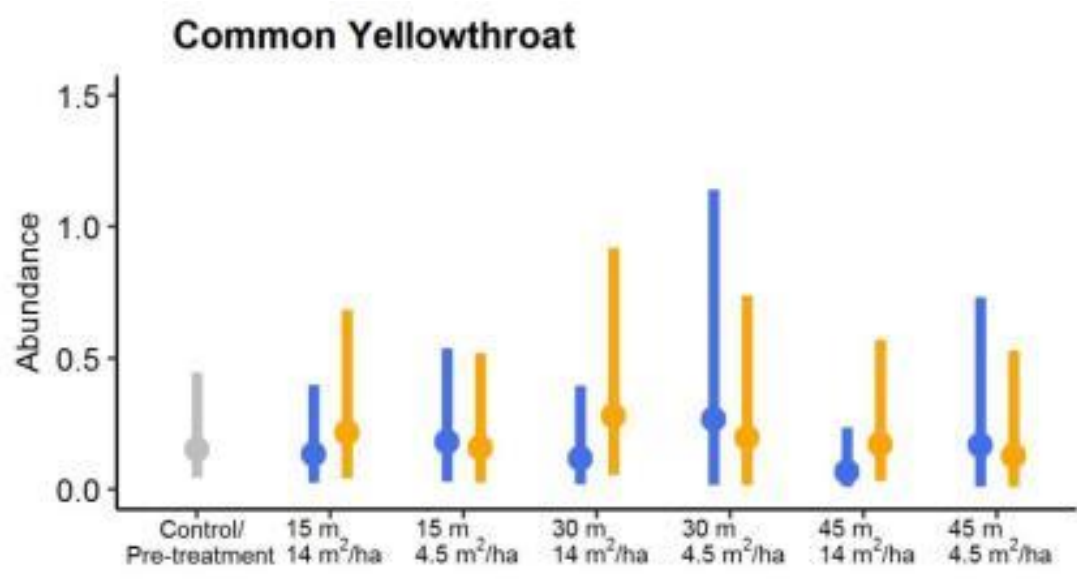

Treatment

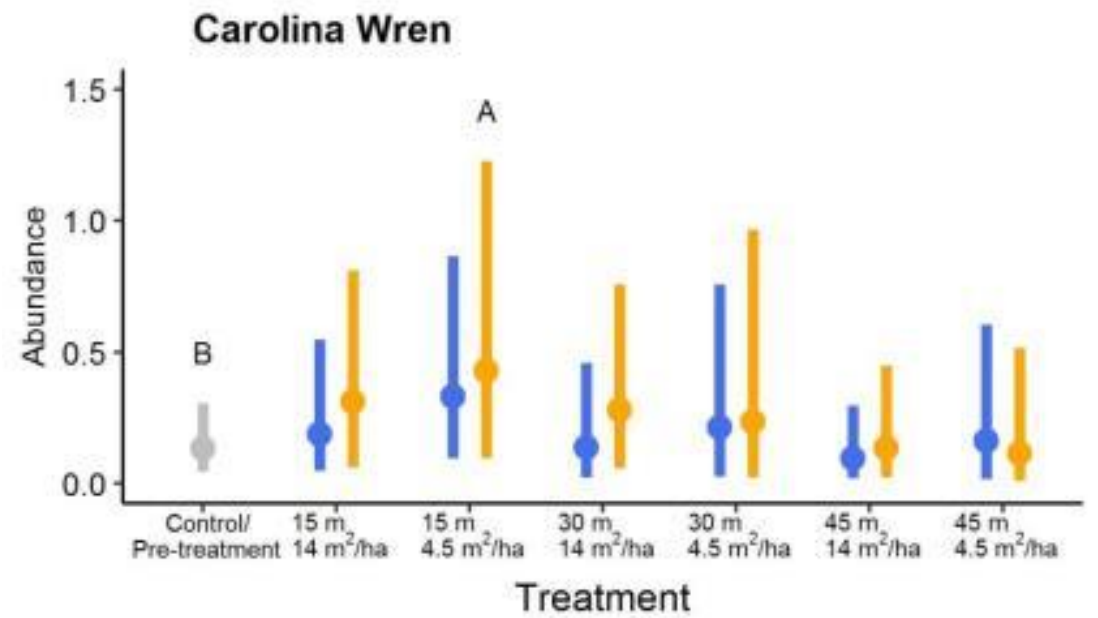

Eastern Towhee

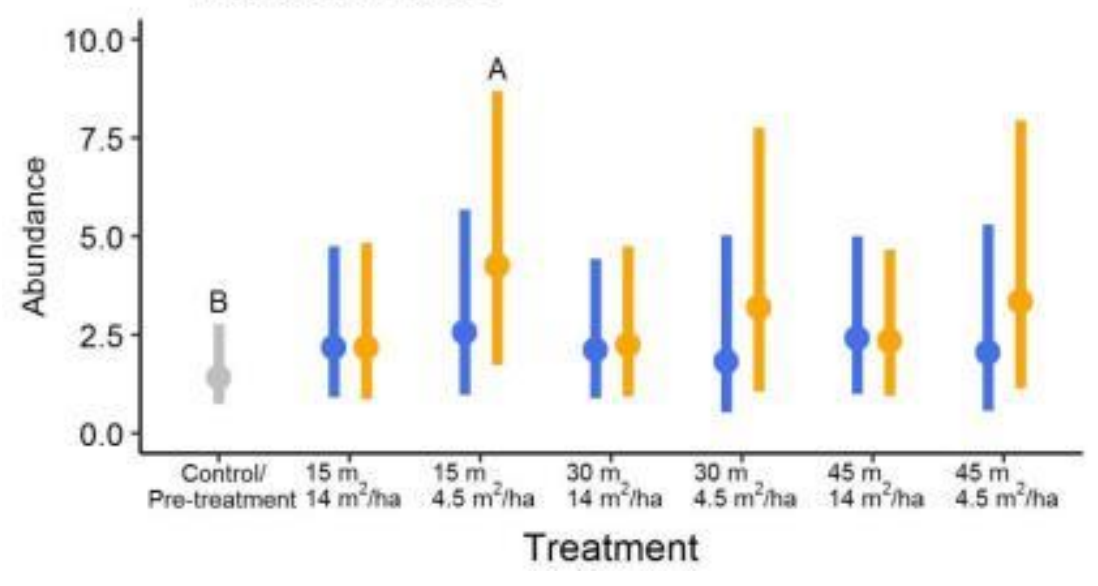

Year 1 -yr Post-treatment 2 -yr Post-treatment 


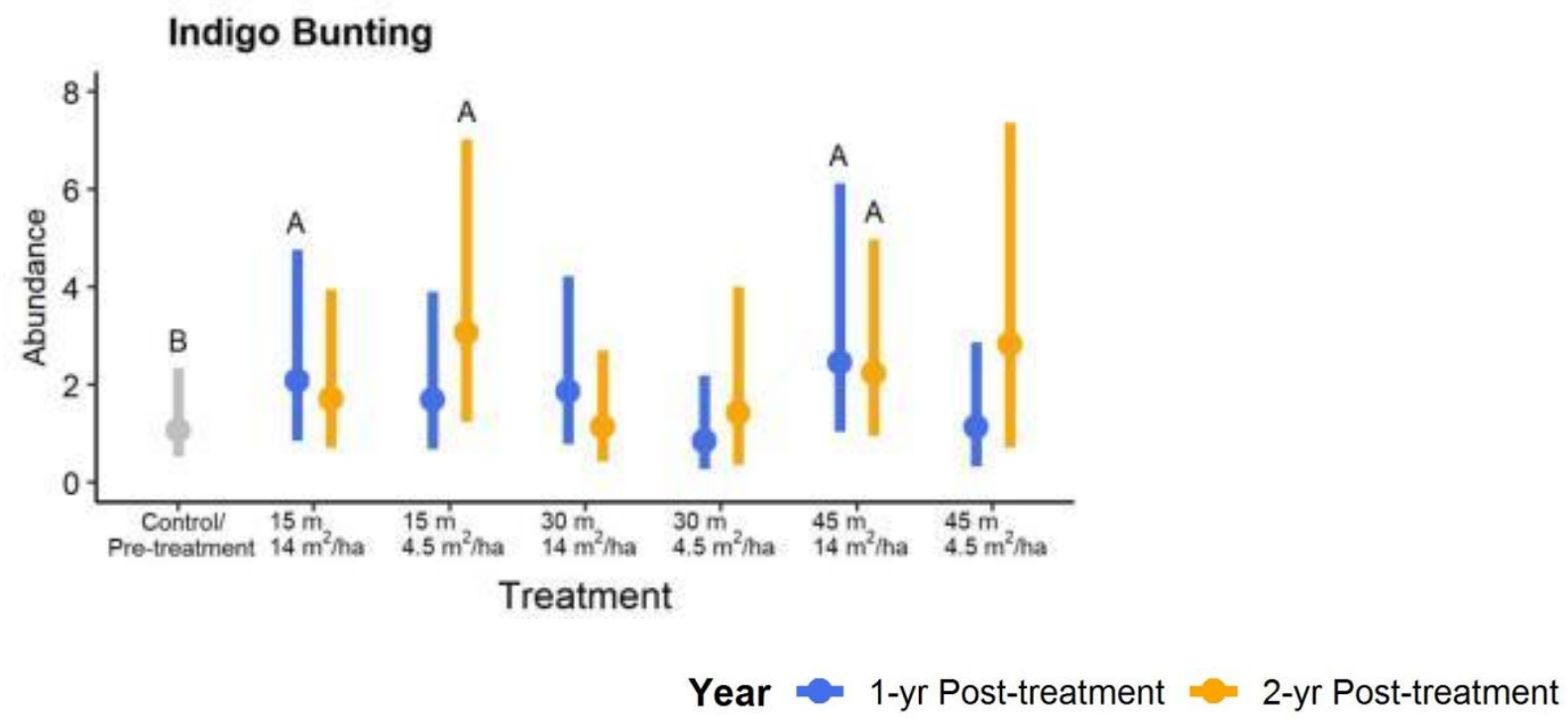

Figure 2-9. Plot-level estimated abundance and 95\% confidence intervals of young forest focal songbird species during the summer breeding season. Differences in abundance within cut-back border treatments between pre-treatment/control and one-year or two-year post-treatment are indicated by alphabetical notation based on non-overlapping $95 \%$ credible intervals. 

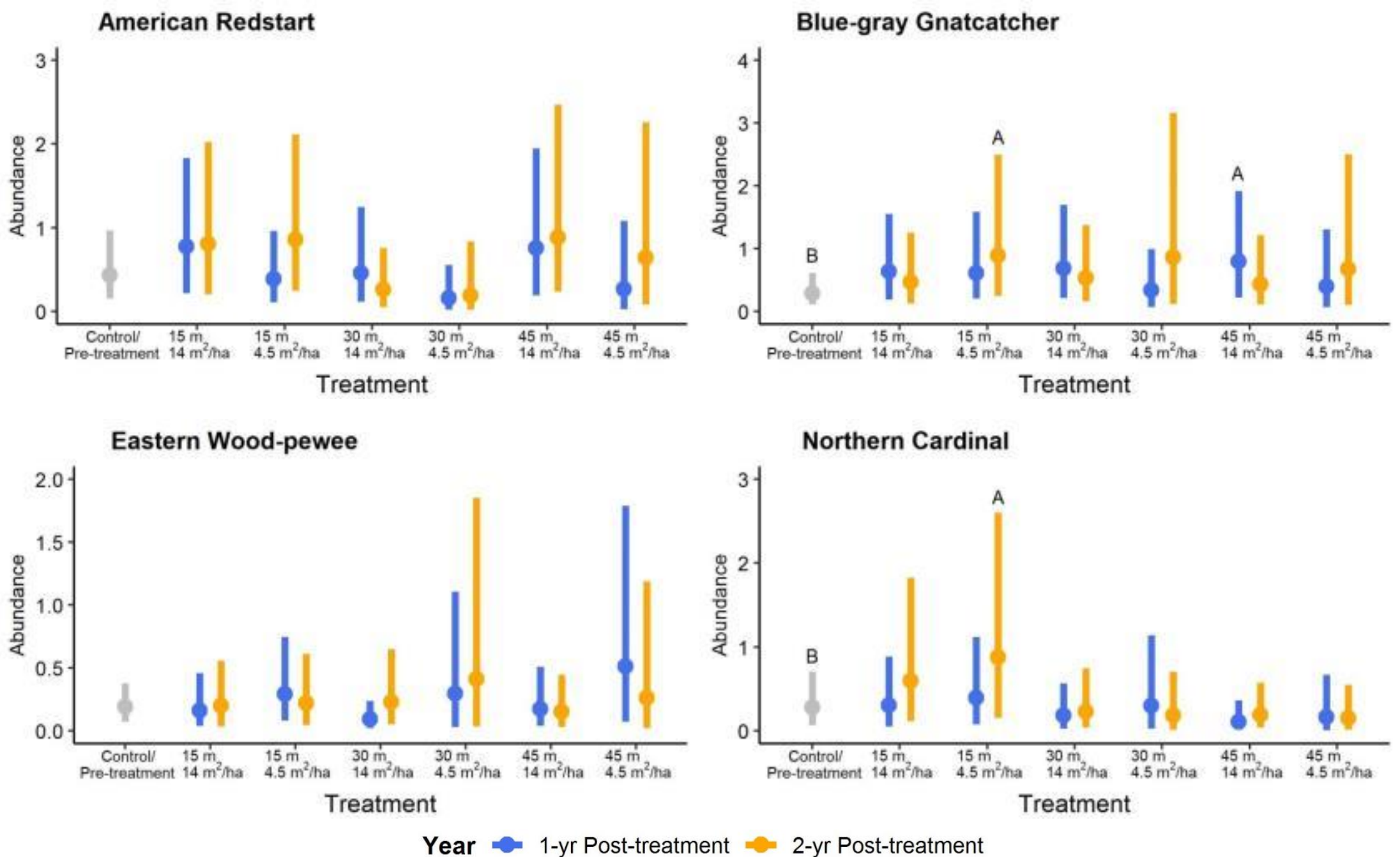

Figure 2-10. Plot-level estimated abundance and 95\% confidence intervals of interior-edge focal songbird species during the summer breeding season. Differences in abundance within cut-back border treatments between pre-treatment/control and one-year or two-year post-treatment are indicated by alphabetical notation based on non-overlapping $95 \%$ credible intervals. 

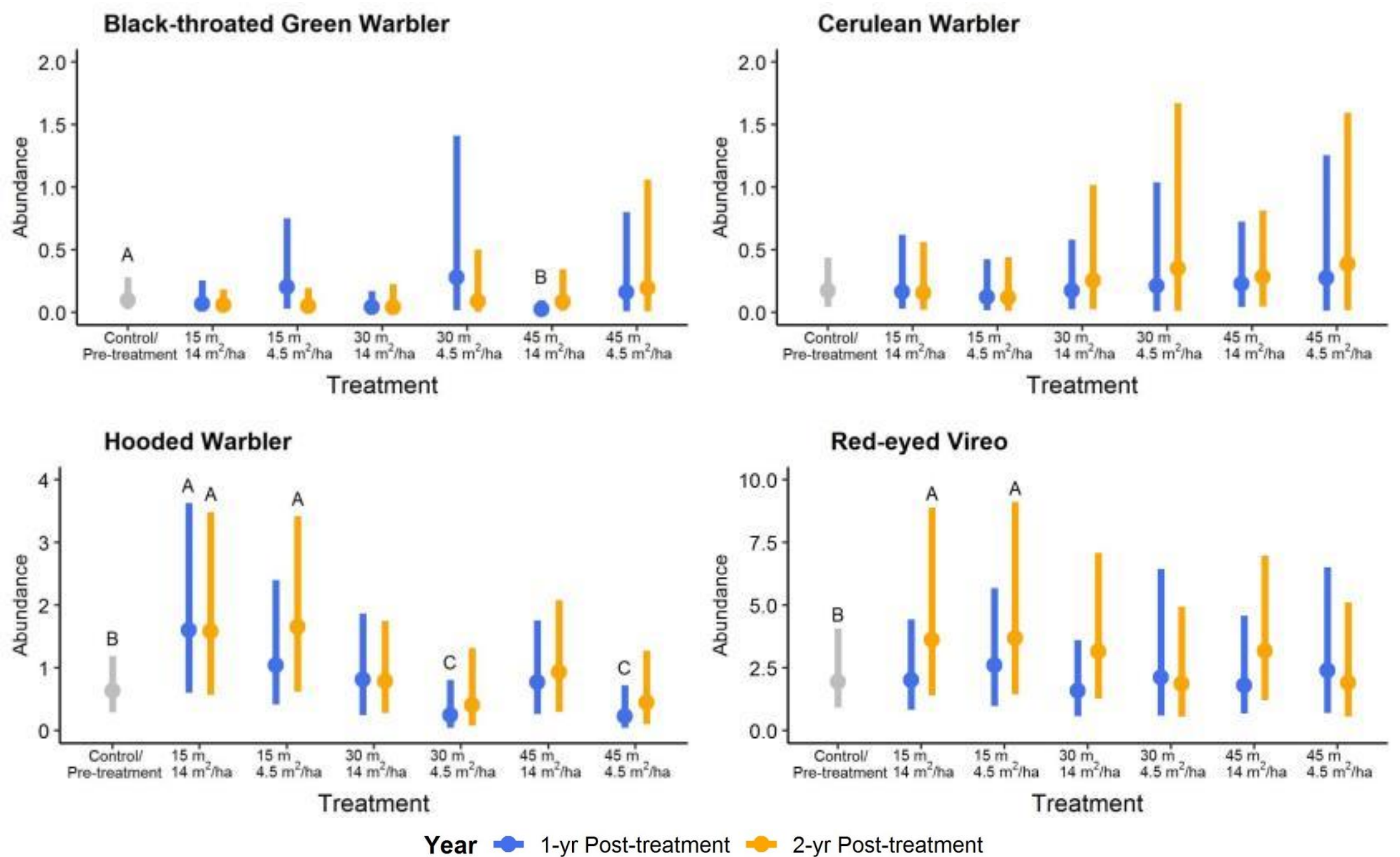

Figure 2-11. Plot-level estimated abundance and 95\% confidence intervals of forest gap focal songbird species during the summer breeding season. Differences in abundance within cut-back border treatments between pre-treatment/control and one-year or two-year post-treatment are indicated by alphabetical notation based on non-overlapping $95 \%$ credible intervals. 

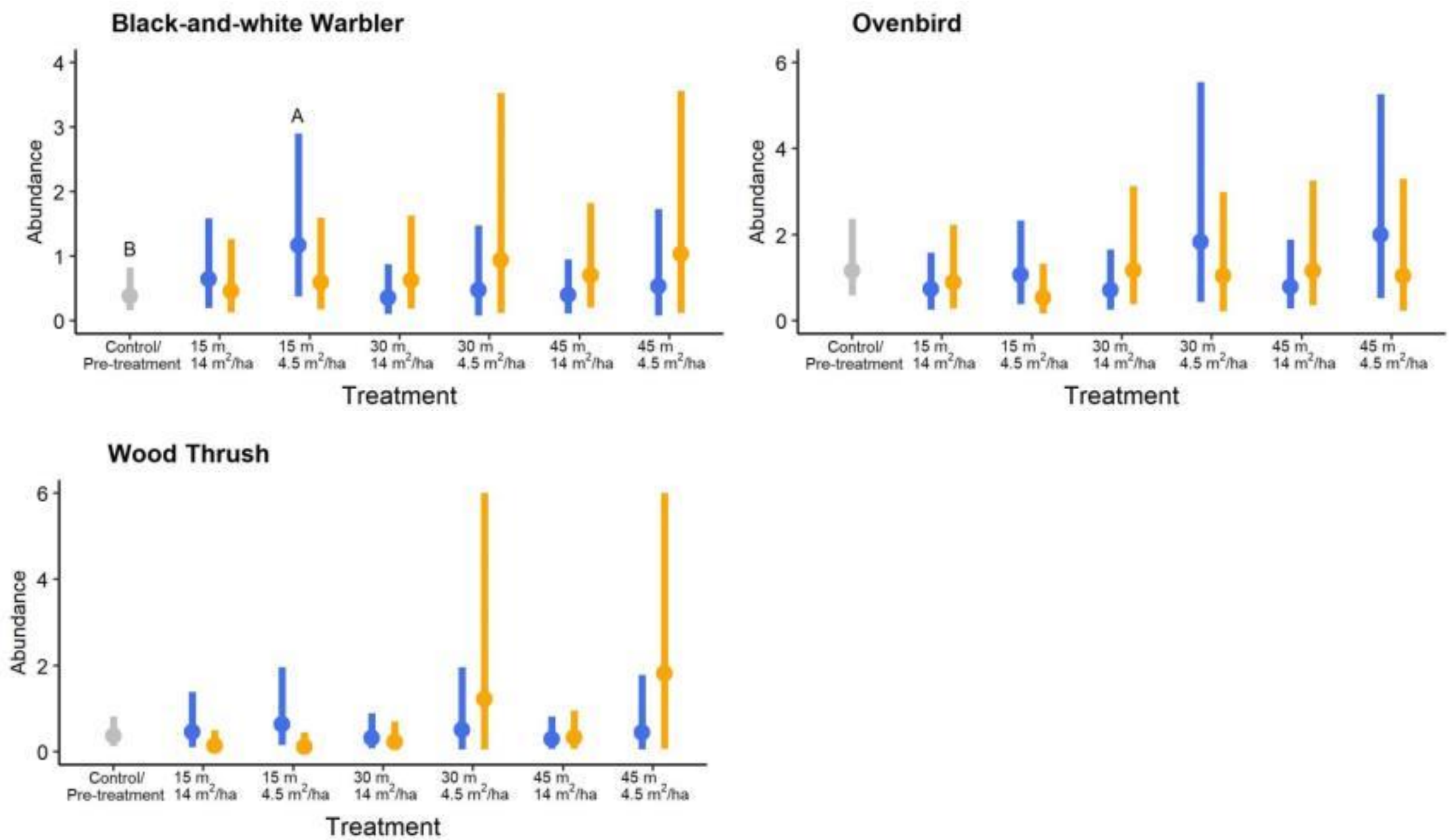

Year 1 -yr Post-treatment $=2$-yr Post-treatment

Figure 2-12. Plot-level estimated abundance and 95\% confidence intervals of forest interior focal songbird species during the summer breeding season. Differences in abundance within cut-back border treatments between pre-treatment/control and one-year or two-year post-treatment are indicated by alphabetical notation based on non-overlapping $95 \%$ credible intervals. 


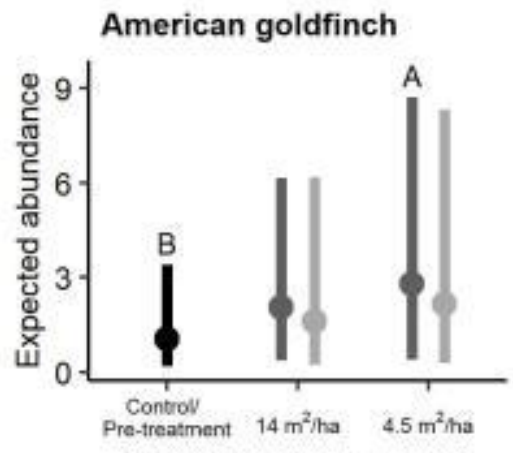

Residual basal area

Carolina wren

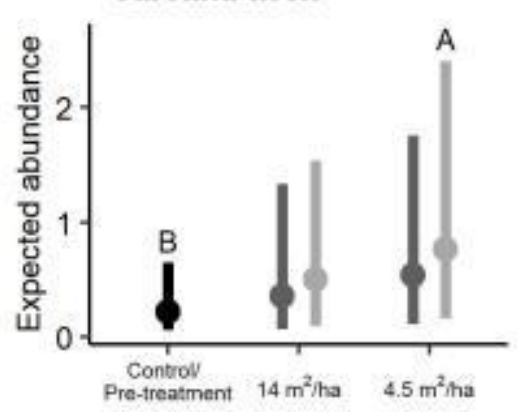

Residual basal area

Indigo bunting

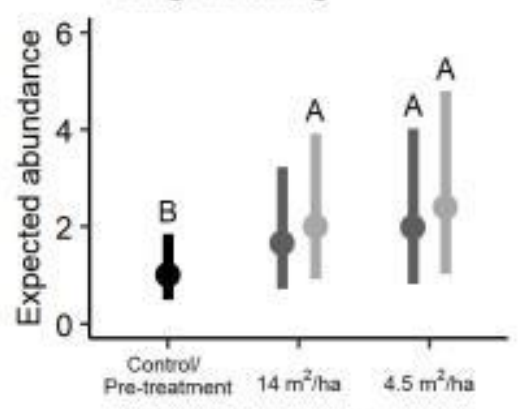

Residual basal area

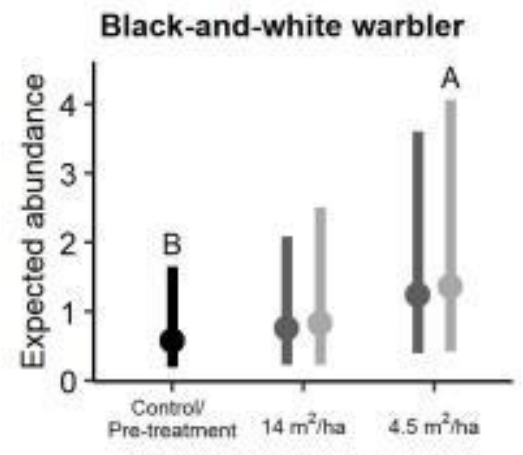

Residual basal area

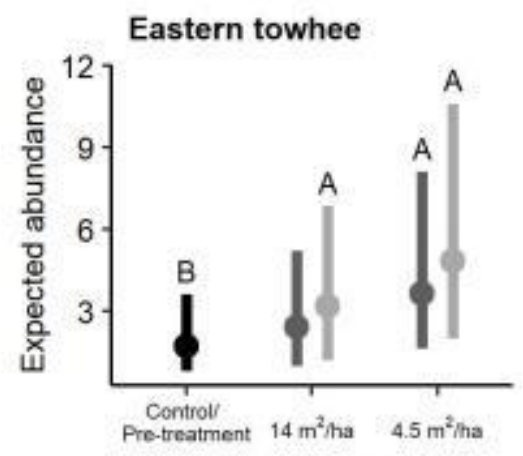

Residual basal area

Northern cardinal

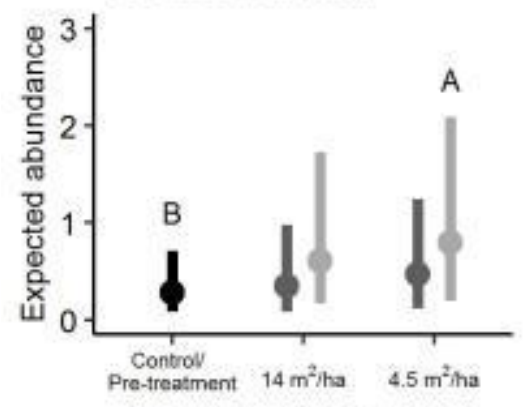

Residual basal area

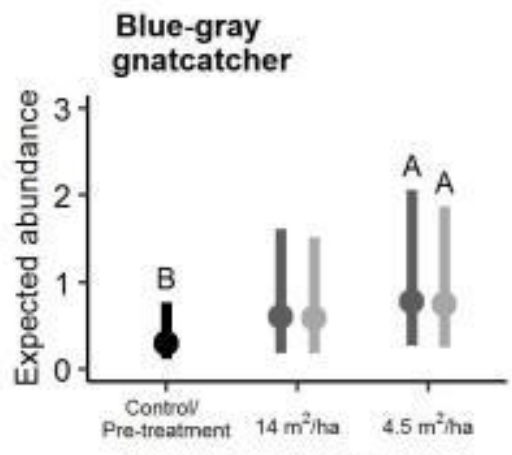

Residual basal area

Hooded warbler

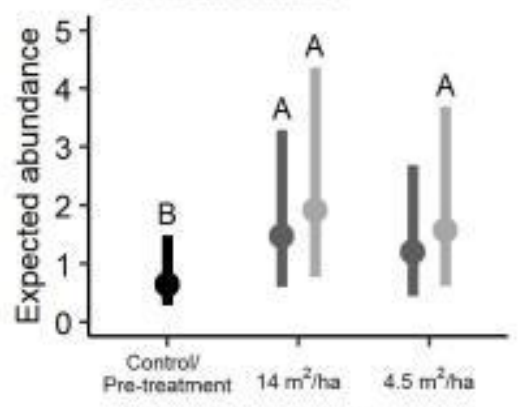

Residual basal area

1-yr Post-treatment $=2-y r$ Post-treatment 
Figure 2-13 continued.

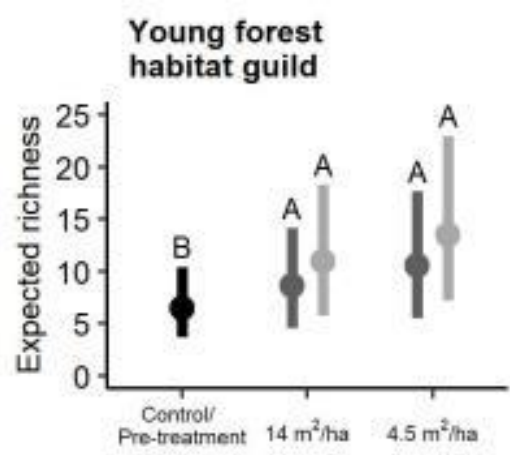

Residual basal area

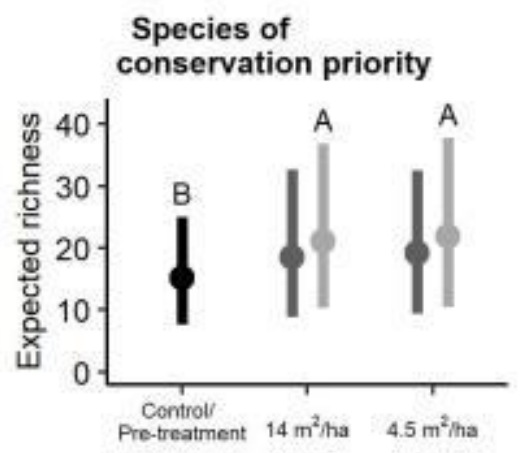

Residual basal area
Interior-edge

habitat guild

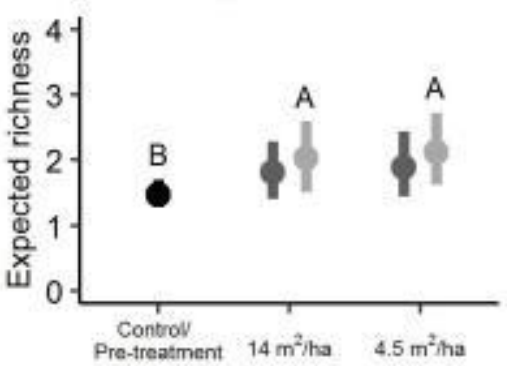

Residual basal area

Spring stopover

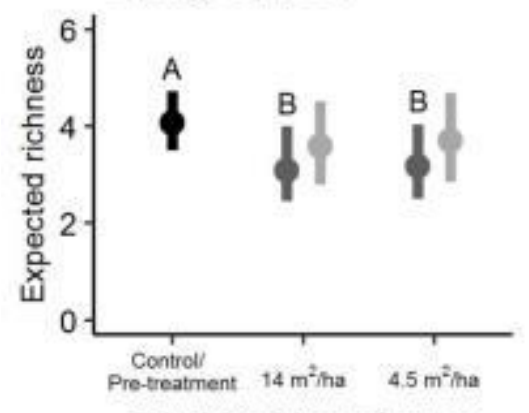

Residual basal area

Figure 2-13. Cut-back border harvest intensity main effects. Differences in abundance or richness within cut-back border factor levels are indicated by alphabetical notation based on nonoverlapping 95\% credible intervals. Only significant main effects are reported. 


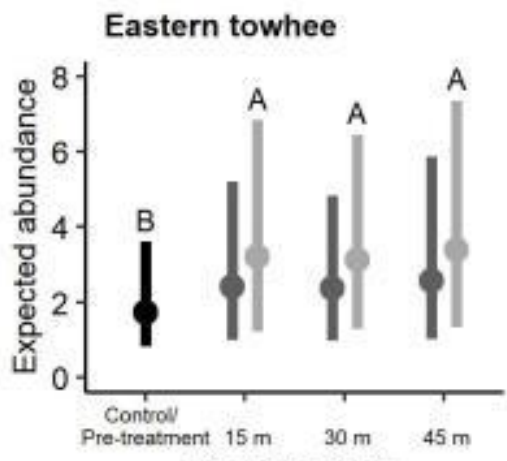

Border width

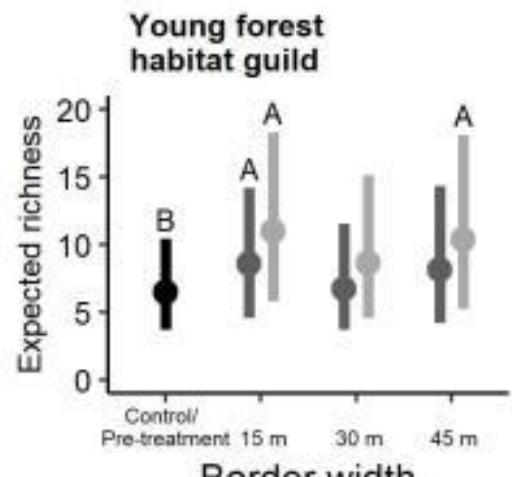

Border width

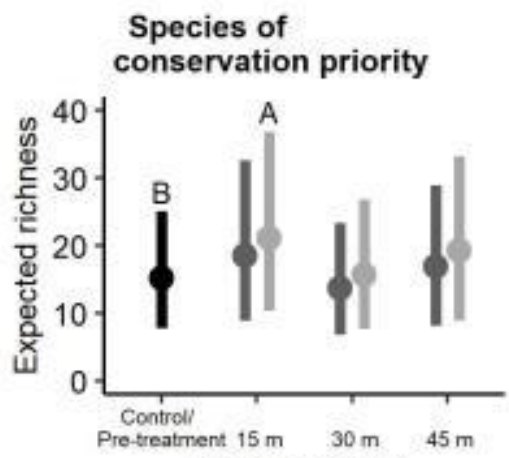

Border width
Hooded warbler

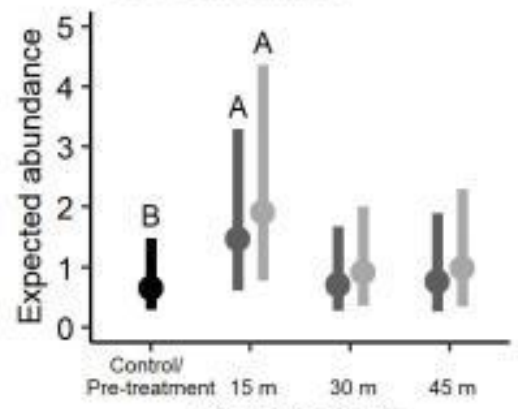

Border width

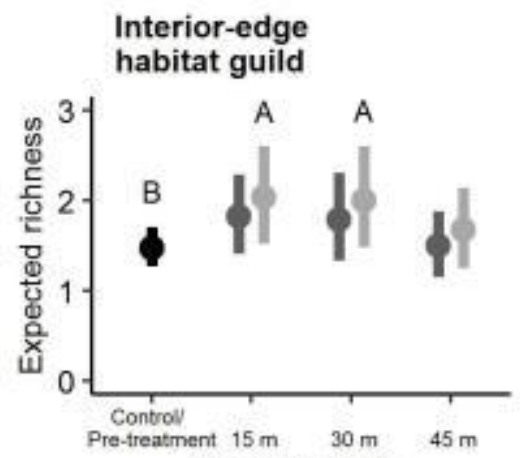

Border width

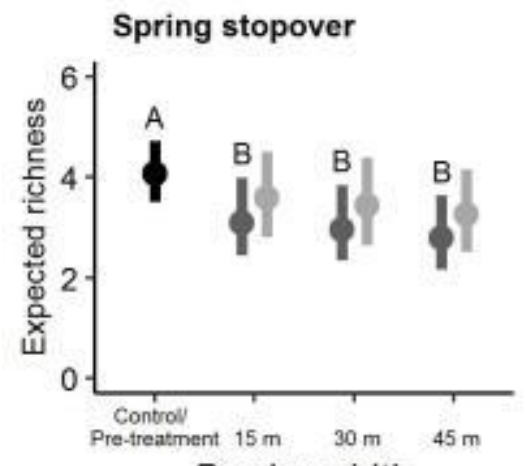

Border width

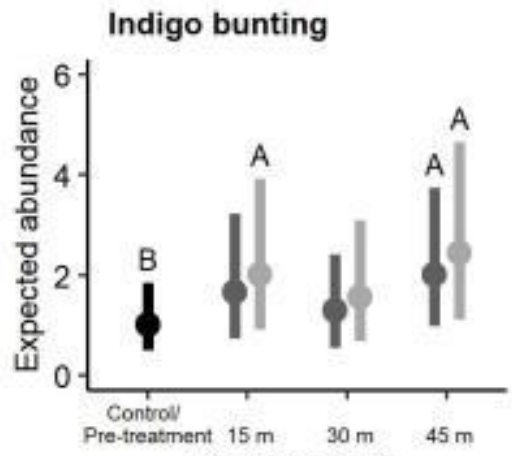

Border width

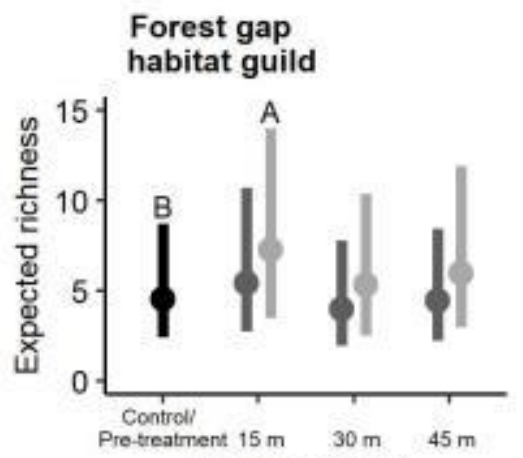

Border width

\section{1-yr Post-treatment $=2-y r$ Post-treatment}

Figure 2-14. Cut-back border width main effects. Differences in abundance or richness within cut-back border factor levels are indicated by alphabetical notation based on non-overlapping 95\% credible intervals. Only significant main effects are reported. 


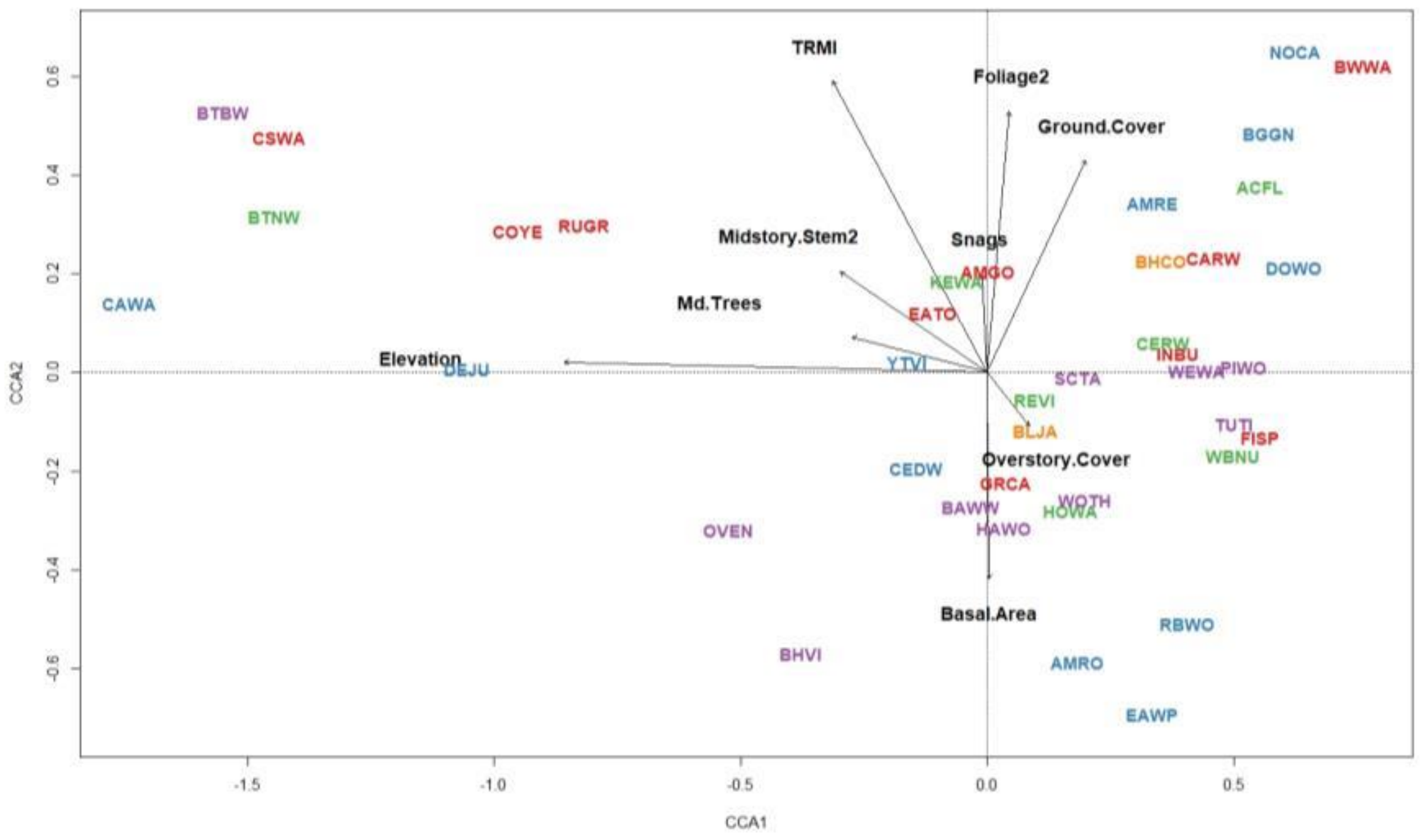

Figure 2-15. Correlation biplot from canonical correspondence analysis (CCA) output. Vegetation variables include: elevation, understory cover $1-2 \mathrm{~m}$ in height (Foliage2), ground cover, number of live trees $<28.0 \mathrm{~cm}$ DBH (Md.Trees), overstory cover, snags, topographic relative moisture index (TRMI), and woody stems 5-11.3 cm DBH (Midstory.Stem2). Avian species are color coded to indicate habitat guild groupings (red = young forest, blue $=$ interior-edge, green $=$ forest gap, purple $=$ forest interior, orange $=$ predators/parasites) and referenced by their 4-letter USGS alpha code (see Appendix 1-A). 


\section{Spring Stopover}

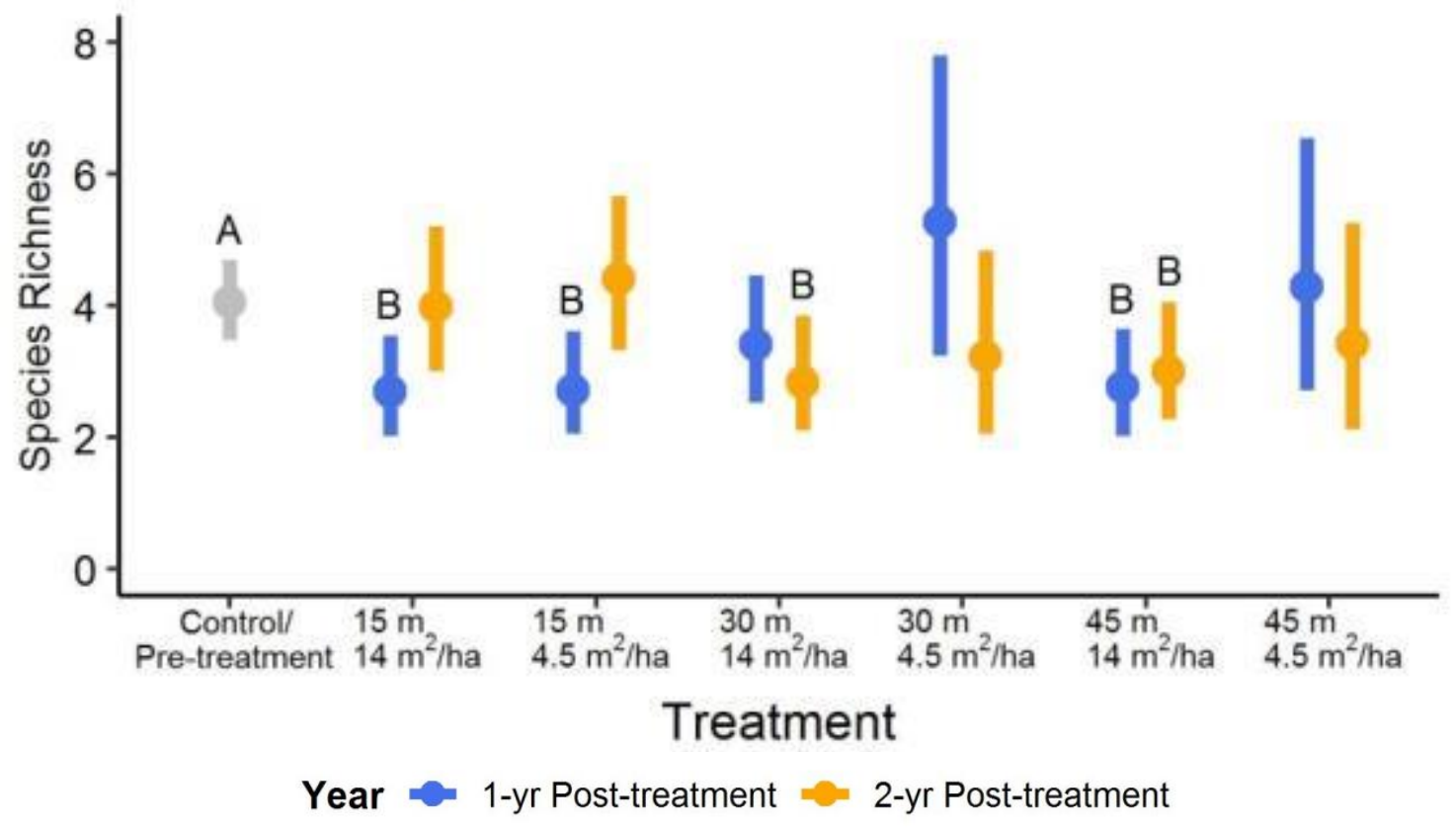

Figure 2-16. Plot-level species richness and 95\% confidence intervals of the avian community in cut-back border treatments during spring stopover. Differences in species richness within cutback border treatments between pre-treatment/control and one-year or two-year post-treatment are indicated by alphabetical notation based on non-overlapping $95 \%$ credible intervals. 

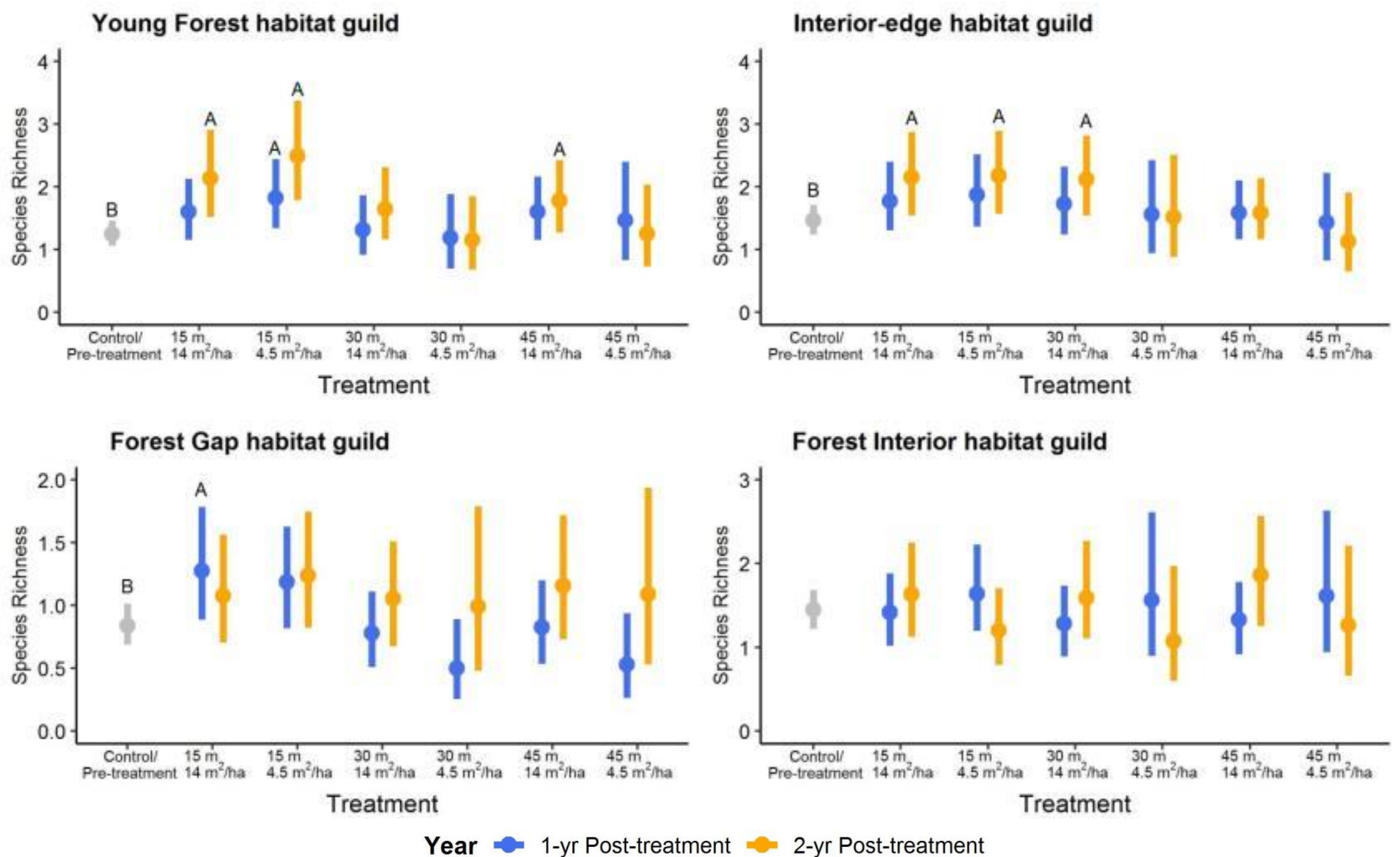

Figure 2-17. Plot-level apparent species richness and 95\% confidence intervals of avian habitat guilds during the summer breeding season. Differences in species richness within cut-back border treatments between pre-treatment/control and one-year or two-year post- treatment are indicated by alphabetical notation based on non-overlapping $95 \%$ credible intervals. 

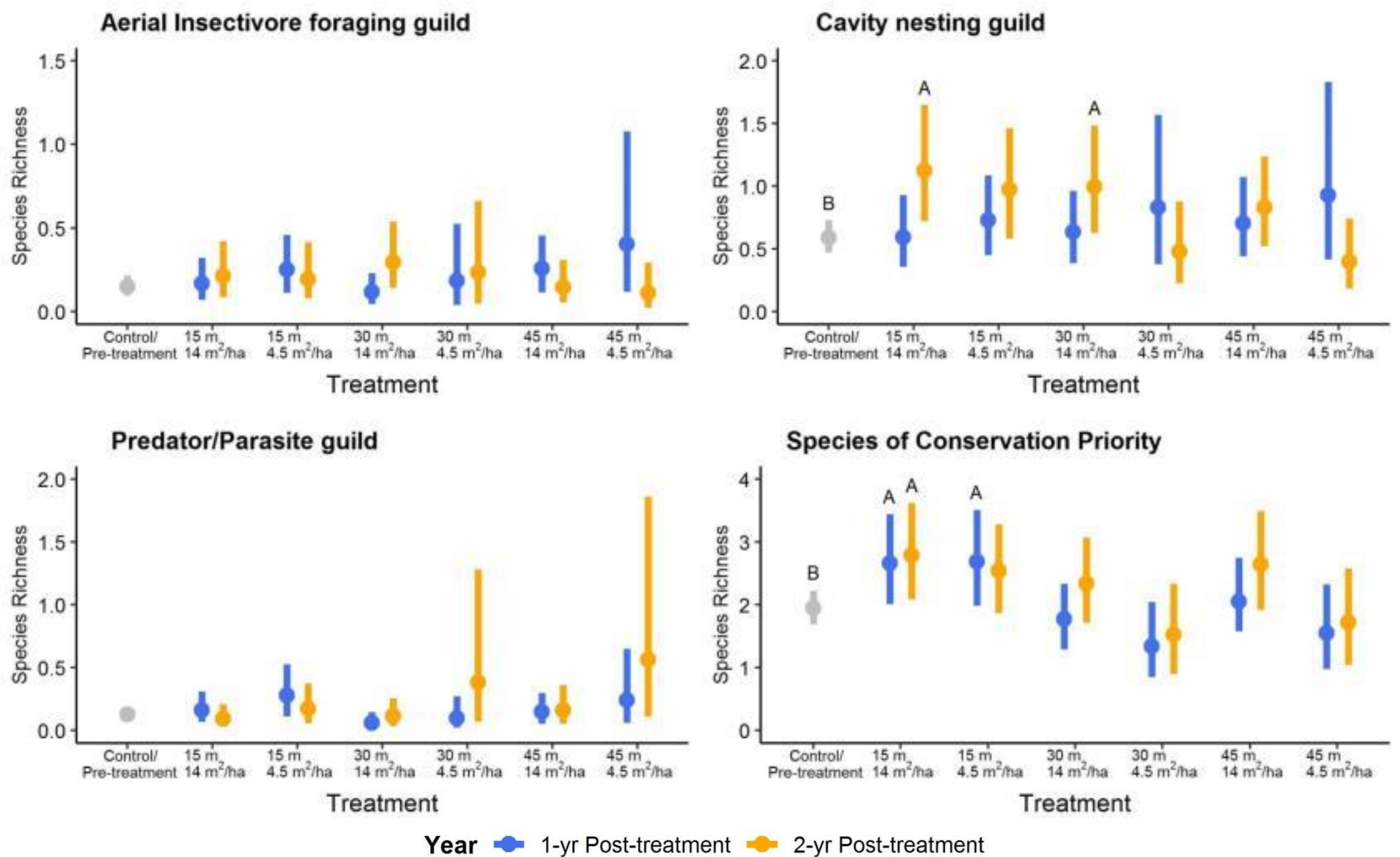

Figure 2-18. Plot-level apparent species richness and 95\% confidence intervals of avian guilds during the summer breeding season. Differences in species richness within cut-back border treatments between pre-treatment/control and one-year or two-year posttreatment are indicated by alphabetical notation based on non-overlapping $95 \%$ credible intervals. 


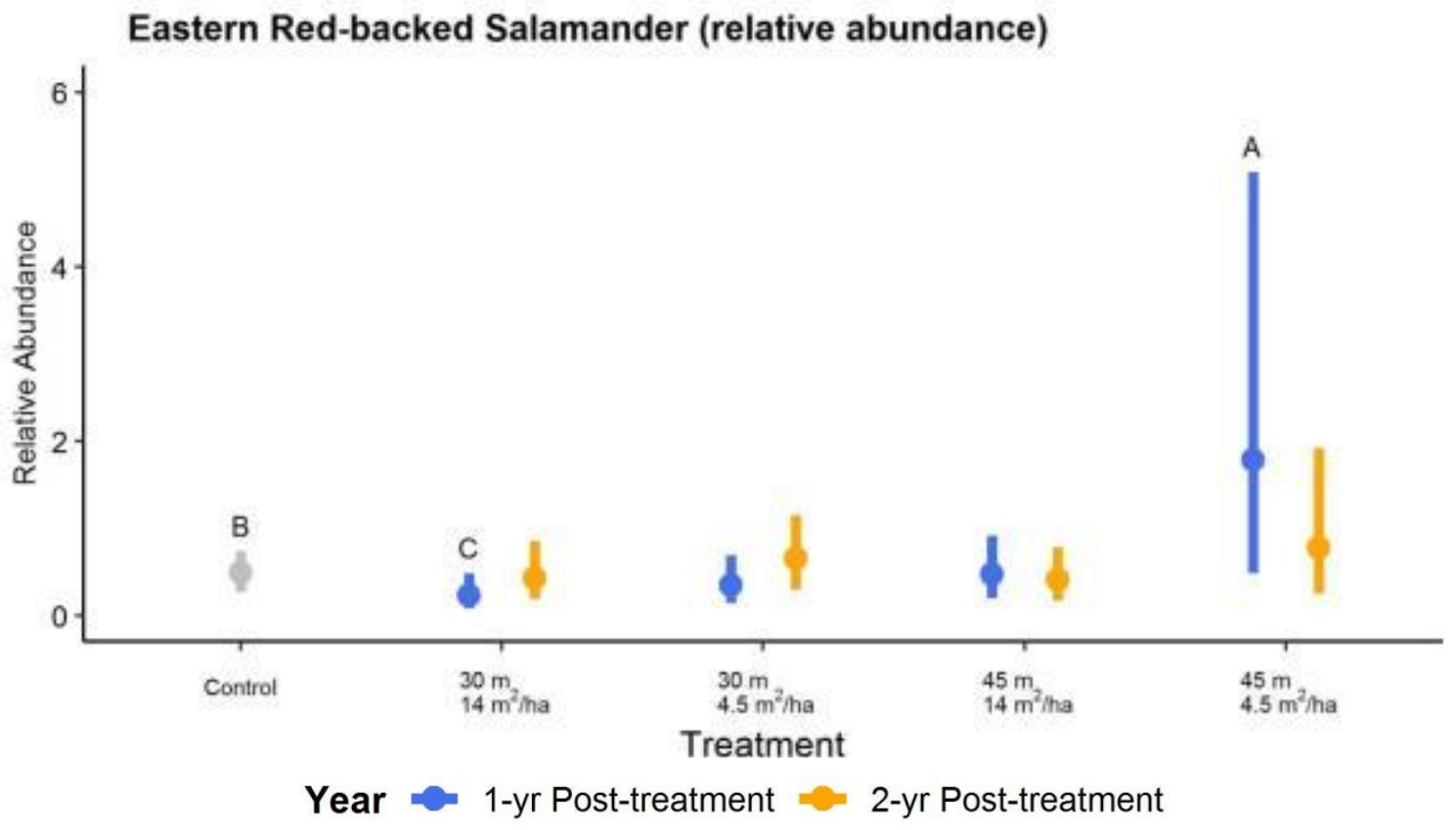

Figure 2-19. Plot-level relative abundance and $95 \%$ confidence intervals of eastern red-backed salamanders (Plethodon cinereus). Differences in relative abundance within cut-back border treatments between pre-treatment/control and one-year or two-year post-treatment are indicated by alphabetical notation based on non-overlapping $95 \%$ credible intervals.

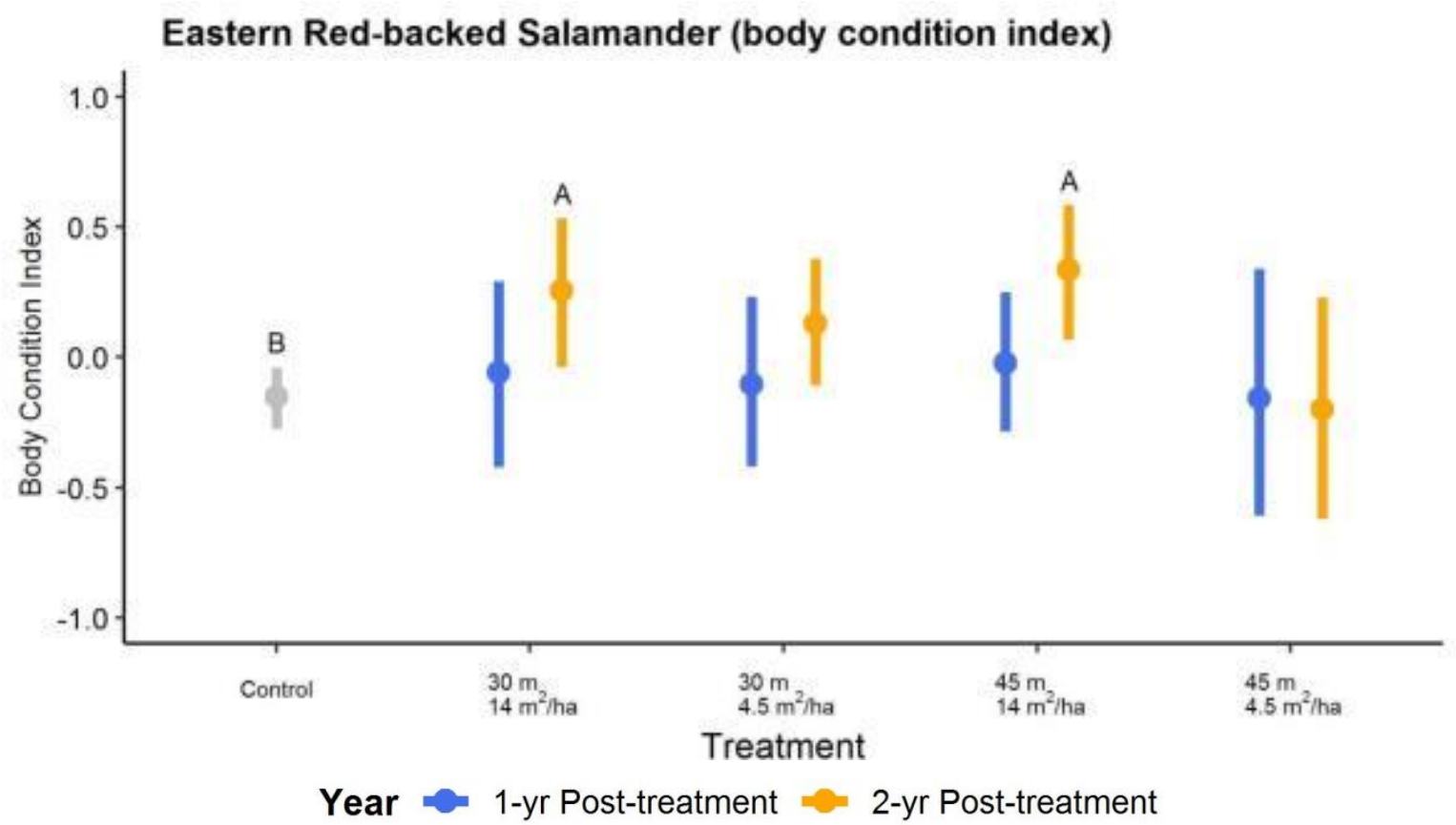

Figure 2-20. Body condition index (BCI) of eastern red-backed salamander (Plethodon cinereus) in cut-back border treatments at BMWMA and LWWMA. Differences in BCI within cut-back border treatments between pre-treatment/control and one-year or two-year post-treatment are indicated by alphabetical notation based on non-overlapping $95 \%$ credible intervals. 


\section{Appendices}

Appendix 2-A. Acreage managed by wildlife management area (WMA) and year.

\begin{tabular}{llr}
\hline Wildlife Management Area & Year & Acreage \\
\hline Allegheny & Winter 2018-19 & $13.3 \mathrm{ac}(5.4 \mathrm{ha})$ \\
Beury Mountain & Winter 2017-18 & $26.7 \mathrm{ac}(10.8 \mathrm{ha})$ \\
Bluestone & Winter 2017-18 & $13.3 \mathrm{ac}(5.4 \mathrm{ha})$ \\
Burnsville Lake & Winter 2016-17 & $13.3 \mathrm{ac}(5.4 \mathrm{ha})$ \\
Lewis Wetzel & Winter 2017-18 & $26.7 \mathrm{ac}(10.8 \mathrm{ha})$ \\
Little Canaan & Winter 2016-17 & $26.7 \mathrm{ac}(10.8 \mathrm{ha})$ \\
Sleepy Creek & Winter 2018-19 & $13.3 \mathrm{ac}(5.4 \mathrm{ha})$ \\
Stonewall Jackson & Winter 2016-17 & $13.3 \mathrm{ac}(5.4 \mathrm{ha})$ \\
\hline
\end{tabular}

\begin{tabular}{|c|c|}
\hline Year & Acreage \\
\hline Winter 2016-17 & $53.3 \mathrm{ac}$ (21.6 ha) \\
\hline Winter 2017-18 & $66.7 \mathrm{ac}(27.0 \mathrm{ha})$ \\
\hline Winter 2018-19 & $26.6 \mathrm{ac}(10.8 \mathrm{ha})$ \\
\hline
\end{tabular}


Appendix 2-B. Decision rules for analyses to assess avian, salamander, and vegetation response in cut-back borders.

\begin{tabular}{|c|c|c|c|c|c|c|}
\hline Analysis & Response Variable(s) & Predictor Variables & Detection type & Distance criteria & $\begin{array}{l}\text { Demography } \\
\text { criteria }\end{array}$ & $\begin{array}{l}\text { Quantity } \\
\text { criteria }\end{array}$ \\
\hline $\begin{array}{l}\text { Vegetation } \\
\text { regeneration } \\
\text { potential in cut- } \\
\text { back borders } \\
\text { (General linear } \\
\text { models) }\end{array}$ & $\begin{array}{l}\text { - Midstory stems } 0-5 \mathrm{~cm} \mathrm{DBH} \\
\text { - Midstory stems } 5.1-11.3 \mathrm{~cm} \mathrm{DBH} \\
\text { - Understory cover } 0-1 \mathrm{~m} \\
\text { - Understory cover } 1-2 \mathrm{~m} \\
\text { - Ground cover }\end{array}$ & $\begin{array}{l}\text { - Shade proportion index (SPI) } \\
\text { - Heat load index (HLI) } \\
\text { - Topographic relative moisture } \\
\text { index (TRMI) } \\
\text { - Beers aspect } \\
\text { - Overstory cover } \\
\end{array}$ & $\begin{array}{c}\text { Not } \\
\text { Applicable }\end{array}$ & $\begin{array}{c}\text { Not } \\
\text { Applicable }\end{array}$ & $\begin{array}{c}\text { Not } \\
\text { Applicable }\end{array}$ & $\begin{array}{c}\text { Not } \\
\text { Applicable }\end{array}$ \\
\hline $\begin{array}{l}\text { Ruffed grouse } \\
\text { (Hierarchical } \\
\text { occupancy model) }\end{array}$ & - Presence/absence of grouse per plot & $\begin{array}{l}\text { - Cut-back border factor levels } \\
\text { ○ } 15 \mathrm{~m} \\
\circ 30 \mathrm{~m} \\
\circ 45 \mathrm{~m} \\
\circ 14 \mathrm{~m}^{2} / \mathrm{ha} \\
\circ 4.5 \mathrm{~m}^{2} / \mathrm{ha} \\
\text { - Year }\end{array}$ & $\begin{array}{l}\text { - Drumming } \\
\text { individuals } \\
\text { - Opportunistic } \\
\text { detections }\end{array}$ & $\begin{array}{l}\cdot 0-25 \mathrm{~m} \\
\cdot \quad>25-50 \mathrm{~m} \\
\cdot>50-75 \mathrm{~m} \\
\cdot \quad>75-100 \mathrm{~m}\end{array}$ & $\begin{array}{l}\text { - Males } \\
\text { - Females } \\
\text { - Unknown }\end{array}$ & None \\
\hline $\begin{array}{l}\text { American } \\
\text { woodcock } \\
\text { (none) }\end{array}$ & - Presence/absence of woodcock & No analysis executed (lack of data) & $\begin{array}{l}\text { - Peenting } \\
\text { individuals }\end{array}$ & $\begin{array}{c}\text { No distance } \\
\text { criteria (i.e., } \\
\text { unlimited radius) }\end{array}$ & $\begin{array}{ll}\text { - } & \text { Males } \\
\text { - } & \text { Females } \\
\text { - } & \text { Unknown }\end{array}$ & None \\
\hline $\begin{array}{l}\text { Spring stopover } \\
\text { songbird richness } \\
\text { (Generalized } \\
\text { linear mixed } \\
\text { effects model } \\
\text { [GLMM]) }\end{array}$ & - Number of unique species per point & $\begin{array}{l}\text { - Cut-back border factor levels } \\
\text { ○ } 15 \mathrm{~m} \\
\circ 30 \mathrm{~m} \\
\circ 45 \mathrm{~m} \\
\circ 14 \mathrm{~m}^{2} / \mathrm{ha} \\
\text { ○ } 4.5 \mathrm{~m}^{2} / \mathrm{ha} \\
\text { - Year }\end{array}$ & $\begin{array}{l}\text { - Songs (males) } \\
\text { - Calls (males } \\
\text { and females) } \\
\text { - Visuals } \\
\text { (excluding } \\
\text { flyovers) }\end{array}$ & $\begin{array}{l}\cdot 0-25 \mathrm{~m} \\
\text { - }>25-50 \mathrm{~m}\end{array}$ & $\begin{array}{l}\text { - Adults } \\
\text { only } \\
\text { - Males } \\
\text { - Females } \\
\text { - Unknown }\end{array}$ & None \\
\hline $\begin{array}{l}\text { Focal breeding } \\
\text { songbird } \\
\text { abundance } \\
\text { (N-mixture model) }\end{array}$ & $\begin{array}{l}\text { - Number of unique individuals for } \\
\text { each focal species per plot }\end{array}$ & $\begin{array}{l}\text { - Cut-back border factor levels } \\
\text { ○ } 15 \mathrm{~m} \\
\circ 30 \mathrm{~m} \\
\circ 45 \mathrm{~m} \\
\circ 14 \mathrm{~m}^{2} / \mathrm{ha} \\
\text { ○ } 4.5 \mathrm{~m}^{2} / \mathrm{ha} \\
\text { - Year }\end{array}$ & $\begin{array}{l}\text { - Songs (males) } \\
\text { - Calls (males } \\
\text { and females) }\end{array}$ & $\begin{array}{l}\cdot 0-25 \mathrm{~m} \\
\cdot>25-50 \mathrm{~m}\end{array}$ & $\begin{array}{ll}\text { - } & \text { Audio } \\
\text { - Visuals } \\
\text { (excludes } \\
\text { flyovers) }\end{array}$ & $\begin{array}{l}\text { - } \geq 40 \\
\text { detections } \\
\text { - } \geq 0.200 \\
\text { detection } \\
\text { probability }\end{array}$ \\
\hline
\end{tabular}


Appendix 2-B continued.

\begin{tabular}{|c|c|c|c|c|c|c|}
\hline Analysis & Response Variable(s) & Predictor Variables & Detection type & Distance criteria & $\begin{array}{c}\text { Demography } \\
\text { criteria }\end{array}$ & $\begin{array}{c}\text { Quantity } \\
\text { criteria }\end{array}$ \\
\hline $\begin{array}{l}\text { Avian-vegetation } \\
\text { correlation in cut- } \\
\text { back borders } \\
\text { (Canonical } \\
\text { Correspondence } \\
\text { Analysis) }\end{array}$ & $\begin{array}{l}\text { - Number of individuals for each } \\
\text { songbird species }\end{array}$ & $\begin{array}{l}\text { - Basal area } \\
\text { - Overstory cover } \\
\text { - Midstory stems } 0-5 \mathrm{~cm} \mathrm{DBH} \\
\text { - Midstory stems } 5.1-11.3 \mathrm{~cm} \mathrm{DBH} \\
\text { - Understory cover } 0-1 \mathrm{~m} \\
\text { - Understory cover } 1-2 \mathrm{~m} \\
\text { - Ground cover } \\
\text { - Snags } \\
\text { - Elevation } \\
\text { - TRMI }\end{array}$ & $\begin{array}{l}\text { - Songs } \\
\text { - Calls } \\
\text { - Visuals } \\
\text { (excluding } \\
\text { flyovers) }\end{array}$ & $\begin{array}{l}\bullet 0-25 \mathrm{~m} \\
\bullet>25-50 \mathrm{~m}\end{array}$ & $\begin{array}{l}\text { - Adults } \\
\text { only } \\
\text { - Males } \\
\text { - Females } \\
\text { - Unknown }\end{array}$ & $\begin{array}{l}\text { - } \geq 20 \\
\text { detections }\end{array}$ \\
\hline $\begin{array}{l}\text { Avian guild } \\
\text { richness } \\
\text { (GLMM) }\end{array}$ & - Number of unique species & $\begin{array}{l}\text { - Cut-back border factor levels } \\
\quad \circ 15 \mathrm{~m} \\
\circ 30 \mathrm{~m} \\
\circ 45 \mathrm{~m} \\
\circ 14 \mathrm{~m}^{2} / \mathrm{ha} \\
\circ 4.5 \mathrm{~m}^{2} / \mathrm{ha} \\
\text { - Year }\end{array}$ & $\begin{array}{l}\text { - Songs (males) } \\
\text { - Calls (males } \\
\text { and females) } \\
\text { - Visuals } \\
\text { (excluding } \\
\text { flyovers) } \\
\end{array}$ & $\begin{array}{l}\text { - } 0-25 \mathrm{~m} \\
\bullet>25-50 \mathrm{~m}\end{array}$ & $\begin{array}{l}\text { - Adults } \\
\text { only } \\
\text { - Males } \\
\text { - Females } \\
\text { - Unknown }\end{array}$ & None \\
\hline $\begin{array}{l}\text { Salamander } \\
\text { abundance } \\
\text { (GLMM) }\end{array}$ & $\begin{array}{l}\text { - Number of captures of eastern red- } \\
\text { backed salamanders (Plethodon } \\
\text { cinereus) }\end{array}$ & $\begin{array}{l}\text { - Cut-back border factor levels } \\
\text { ○ } 30 \mathrm{~m} \\
\circ 45 \mathrm{~m} \\
\circ 14 \mathrm{~m}^{2} / \mathrm{ha} \\
\circ 4.5 \mathrm{~m}^{2} / \mathrm{ha} \\
\text { - Year }\end{array}$ & $\begin{array}{l}\text { - Captured } \\
\text { underneath } \\
\text { marked cover } \\
\text { object } \\
\text { (excluding } \\
\text { recaptures) } \\
\end{array}$ & $\begin{array}{c}\text { Not } \\
\text { Applicable }\end{array}$ & $\begin{array}{l}\text { - Adults and } \\
\text { juveniles } \\
\text { - Males } \\
\text { - Females }\end{array}$ & None \\
\hline $\begin{array}{l}\text { Salamander Body } \\
\text { Condition Index } \\
\text { (GLMM) }\end{array}$ & $\begin{array}{l}\text { - Body condition index of eastern red- } \\
\text { backed salamanders }\end{array}$ & $\begin{array}{l}\text { - Cut-back border factor levels } \\
\text { ○ } 30 \mathrm{~m} \\
\circ 45 \mathrm{~m} \\
\circ 14 \mathrm{~m}^{2} / \mathrm{ha} \\
\circ 4.5 \mathrm{~m}^{2} / \mathrm{ha} \\
\text { - Year }\end{array}$ & $\begin{array}{l}\text { - } \text { Captured } \\
\text { underneath } \\
\text { marked cover } \\
\text { object } \\
\text { (excluding } \\
\text { recaptures) } \\
\end{array}$ & $\begin{array}{c}\text { Not } \\
\text { Applicable }\end{array}$ & $\begin{array}{l}\text { - Adults and } \\
\text { juveniles } \\
\text { - Males } \\
\text { - Females }\end{array}$ & None \\
\hline
\end{tabular}


Appendix 2-C. Total detections for songbird species in cut-back borders heard within 50-m of point count. Auditory detection type indicates which vocalizations were used to determine species presence. An “*” indicates species was included in species-specific analysis, and "^" indicates species was included in the community CCA. All species listed were included in guild richness analyses. See Appendix 1-A for scientific names of species and guild assignments. Species of conservation priority (SCP) are those identified by Appalachian Mountains Joint Venture (AMJV), Partners-in-Flight (PIF) Appalachian region (BCR 28), or the West Virginia Division of Natural Resources (WVDNR) State Wildlife Action Plan (SWAP). Guild codes are: $\mathrm{FG}=$ forest gap, $\mathrm{FI}=$ forest interior, $\mathrm{IE}=$ interior-edge, $\mathrm{YF}=$ young forest, $\mathrm{PP}=$ predator/parasite.

\begin{tabular}{|c|c|c|c|c|c|}
\hline Common Name & Guild & $\begin{array}{c}\text { Auditory } \\
\text { Detection Type }\end{array}$ & SCP & Count & $\begin{array}{c}\text { Detection } \\
\text { Probability }\end{array}$ \\
\hline Acadian Flycatcher^ & FG & Song/Call & $\mathrm{X}$ & 36 & - \\
\hline Alder Flycatcher & YF & Song/Call & $\mathrm{X}$ & 3 & - \\
\hline American Crow & $\mathrm{PP}$ & Call & & 6 & - \\
\hline American Goldfinch*^ & YF & Song/Call & & 68 & 0.221 \\
\hline American Redstart*^ & $\mathrm{IE}$ & Song & & 86 & 0.222 \\
\hline American Robin^^ & IE & Song & & 37 & - \\
\hline Baltimore Oriole & IE & Song & & 7 & - \\
\hline Black-and-white Warbler*^ & FI & Song & $X$ & 103 & 0.276 \\
\hline Black-capped Chickadee & IE & Song & & 22 & - \\
\hline Black-throated Blue Warbler^^ & FI & Song & $X$ & 39 & - \\
\hline Black-throated Green Warbler*^ & $\mathrm{FG}$ & Song & & 52 & 0.310 \\
\hline Blue-gray Gnatcatcher^^ & IE & Song/Call & & 92 & 0.231 \\
\hline Blue-headed Vireo $^{\wedge}$ & FI & Song & & 71 & 0.196 \\
\hline Blue-winged Warbler ${ }^{\wedge}$ & YF & Song & $\mathrm{X}$ & 31 & - \\
\hline Blue Jay^ & $\mathrm{PP}$ & Call & & 56 & 0.177 \\
\hline Brown-headed Cowbird^ ${ }^{\wedge}$ & PP & Song/Call & & 38 & - \\
\hline Brown Creeper & FI & Song & $X$ & 10 & - \\
\hline Brown Thrasher & YF & Song & & 5 & - \\
\hline Canada Warbler^ & $\mathrm{IE}$ & Song & $X$ & 27 & - \\
\hline Carolina Chickadee & IE & Song & & 23 & - \\
\hline Carolina Wren*^ & YF & Song & & 58 & 0.316 \\
\hline Cedar Waxwing^ & IE & Song/Call & & 88 & 0.184 \\
\hline Cerulean Warbler^ & FG & Song & $X$ & 44 & 0.230 \\
\hline Chestnut-sided Warbler ${ }^{\wedge}$ & YF & Song & & 31 & - \\
\hline Chipping Sparrow & YF & Song & $X$ & 13 & - \\
\hline Common Raven & $\mathrm{PP}$ & Call & & 3 & - \\
\hline Common Yellowthroat*^ & YF & Song & & 70 & 0.343 \\
\hline Dark-eyed Junco*^ & IE & Song & & 53 & 0.187 \\
\hline Downy Woodpecker^^ & IE & Call & & 24 & - \\
\hline Eastern Phoebe & IE & Song & & 8 & - \\
\hline
\end{tabular}


Appendix 2-C continued.

\begin{tabular}{|c|c|c|c|c|c|}
\hline Common Name & Guild & $\begin{array}{c}\text { Auditory } \\
\text { Detection Type }\end{array}$ & SCP & Count & $\begin{array}{c}\text { Detection } \\
\text { Probability }\end{array}$ \\
\hline Eastern Towhee*^ & YF & Song & $X$ & 208 & 0.230 \\
\hline Eastern Wood-pewee*^ & $\mathrm{IE}$ & Song & $X$ & 65 & 0.364 \\
\hline Field Sparrow^^ & YF & Song & $\mathrm{X}$ & 36 & - \\
\hline Gray Catbird^ & YF & Song/Call & & 26 & - \\
\hline Great Crested Flycatcher & $\mathrm{IE}$ & Song/Call & & 12 & - \\
\hline Hairy Woodpecker^ & FI & Call & & 26 & - \\
\hline Hermit Thrush & IE & Song & & 1 & - \\
\hline Hooded Warbler*^ & FG & Song & $\mathrm{X}$ & 131 & 0.277 \\
\hline House Wren & IE & Song & & 8 & - \\
\hline Indigo Bunting*^ & YF & Song & & 205 & 0.250 \\
\hline Kentucky Warbler^ & FG & Song & $X$ & 28 & - \\
\hline Least Flycatcher & FI & Song/Call & $\mathrm{X}$ & 2 & - \\
\hline Louisiana Waterthrush & FI & Song & $X$ & 7 & - \\
\hline Magnolia Warbler & FI & Song & & 9 & - \\
\hline Mourning Dove & IE & Song/Call & & 18 & - \\
\hline Northern Cardinal*^ & IE & Song/Call & & 95 & 0.234 \\
\hline Northern Flicker & IE & Call & $\mathrm{X}$ & 11 & - \\
\hline Northern Mockingbird & IE & Song & & 2 & - \\
\hline Northern Parula & IE & Song & & 9 & - \\
\hline Orchard Oriole & YF & Song & & 6 & - \\
\hline Ovenbird*^ & FI & Song & & 181 & 0.271 \\
\hline Pileated Woodpecker ${ }^{\wedge}$ & FI & Call & & 23 & - \\
\hline Pine Warbler & FI & Song & & 5 & - \\
\hline Prairie Warbler & $\mathrm{YF}$ & Song & $X$ & 2 & - \\
\hline Red-bellied Woodpecker^ ${ }^{\wedge}$ & IE & Call & & 37 & - \\
\hline Red-breasted Nuthatch & FI & Song/Call & & 1 & - \\
\hline Red-eyed Vireo*^ & FG & Song & & 225 & 0.240 \\
\hline Rose-breasted Grosbeak & $\mathrm{IE}$ & Song & $X$ & 16 & - \\
\hline Ruby-throated Hummingbird & IE & Call & & 6 & - \\
\hline Scarlet Tanager^ & FI & Song & $X$ & 104 & 0.154 \\
\hline Song Sparrow & IE & Song & & 9 & - \\
\hline Swainson's Thrush & FI & Song & & 1 & - \\
\hline Tufted Titmouse ${ }^{\wedge}$ & FI & Song/Call & & 77 & 0.160 \\
\hline Veery $^{\wedge}$ & IE & Song & $X$ & 12 & - \\
\hline White-breasted Nuthatch^ & FG & Song/Call & & 22 & - \\
\hline White-eyed Vireo & YF & Song & & 14 & - \\
\hline Willow Flycatcher & YF & Song/Call & & 1 & - \\
\hline Winter Wren & FI & Song & & 3 & - \\
\hline Wood Thrush^ & FI & Song & $X$ & 61 & 0.241 \\
\hline
\end{tabular}


Appendix 2-C continued.

\begin{tabular}{lccrrc}
\hline \multicolumn{1}{c}{ Common Name } & Guild & $\begin{array}{c}\text { Auditory } \\
\text { Detection Type }\end{array}$ & SCP & Count & $\begin{array}{c}\text { Detection } \\
\text { Probability }\end{array}$ \\
\hline Worm-eating Warbler^ & FI & Song & X & 34 & - \\
Yellow-bellied Sapsucker & IE & Call & X & 3 & - \\
Yellow-billed Cuckoo & IE & Song/Call & X & 17 & - \\
Yellow-breasted Chat & YF & Song & X & 13 & - \\
Yellow-throated Vireo^ & IE & Song & & 54 & 0.190 \\
Yellow-throated Warbler & FI & Song & X & 4 & - \\
Yellow Warbler & YF & Song & & 5 & - \\
\hline
\end{tabular}

Species that were detected outside of 50-m during point count surveys included Barn Swallow, Barred Owl, Belted Kingfisher, Black-billed Cuckoo, Broad-winged Hawk, Canada Goose, Chimney Swift, Common Grackle, Cooper's Hawk, Eastern Kingbird, Eastern Whip-poor-will, Great-horned, Mourning Warbler, Red-shouldered Hawk, Red-tailed Hawk, Swainson's Warbler, Tree Swallow, Warbling Vireo, and Wild Turkey. 
Appendix 2-D. Avian guild descriptions.

\begin{tabular}{ll}
\hline Guild & Description \\
\hline Habitat guild & \\
\hline Young Forest & $\begin{array}{l}\text { Species that are primarily associated with recently disturbed forests } \\
\text { during the breeding season. }\end{array}$ \\
Interior-edge & $\begin{array}{l}\text { Species that can occupy a broad range of forest successional stages } \\
\text { during the breeding season. This group is sometimes referred to as } \\
\text { 'forest generalists'. This group is considered insensitive to forest } \\
\text { edge habitats (Ries and Sisk 2010). } \\
\text { Species that are associated with mature forest interiors but prefer } \\
\text { complex canopy structures (e.g., natural tree-fall gaps) and small } \\
\text { canopy openings. }\end{array}$ \\
Forest Gap & $\begin{array}{l}\text { Species that are primarily associated with mature forests during the } \\
\text { breeding season. This group is considered highly sensitive to forest } \\
\text { edges (Ries and Sisk 2010). }\end{array}$ \\
\hline Foraging guild & $\begin{array}{l}\text { Species whose primary foraging behavior consists of catching } \\
\text { insects during aerial forays, as opposed to catching insects while } \\
\text { gleaning foliage or under tree bark. }\end{array}$ \\
\hline Aerial Insectivore & $\begin{array}{l}\text { Species whose primary nesting substrate is in a tree (live or dead) } \\
\text { cavity. This group is comprised of primary (i.e., species who } \\
\text { excavate their own cavities; e.g., woodpeckers) and secondary (i.e., } \\
\text { species who use previously excavated or naturally formed cavities; } \\
\text { e.g., chickadees) cavity nesters. }\end{array}$ \\
\hline Cavity & $\begin{array}{l}\text { Species who predate on avian nests (e.g., blue jays and common } \\
\text { ravens) or parasitize avian nests (e.g., brown-headed cowbirds). }\end{array}$ \\
\hline Predator/Parasite guild &
\end{tabular}


Appendix 2-E. Model outputs for assessing effects of topographic variables on five vegetation variables between one-year post-treatment and two-year post-treatment in cut-back borders. HLI $=$ heat load index, $\mathrm{SPI}=$ shade proportion index, TRMI = topographic relative moisture index, and $\mathrm{K}=$ number of parameters. We report the top six models for each model set.

\begin{tabular}{|c|c|c|c|c|}
\hline \multicolumn{5}{|l|}{ Ground Cover } \\
\hline Beers aspect $*$ Canopy cover & 5 & - & 0.24 & 0.24 \\
\hline SPI $*$ Canopy cover & 5 & 0.15 & 0.22 & 0.46 \\
\hline HLI * Canopy cover & 5 & 0.17 & 0.22 & 0.68 \\
\hline TRMI $*$ Canopy cover & 5 & 0.25 & 0.21 & 0.89 \\
\hline$($ SPI + Beers aspect $) *$ Canopy cover & 7 & 3.91 & 0.03 & 0.92 \\
\hline Null & 2 & 4.11 & 0.03 & 0.95 \\
\hline \multicolumn{5}{|l|}{ Understory Cover 0-1 m } \\
\hline Model & $\mathrm{K}$ & $\Delta \mathrm{AIC}_{\mathrm{c}}$ & $\mathrm{AIC}_{\mathrm{c}} \mathrm{Wt}$ & Cumulative $\mathrm{Wt}$ \\
\hline TRMI & 3 & - & 0.33 & 0.33 \\
\hline Null & 2 & 1.29 & 0.17 & 0.51 \\
\hline TRMI * Canopy cover & 5 & 1.43 & 0.16 & 0.67 \\
\hline Beers aspect $*$ Canopy cover & 5 & 2.99 & 0.07 & 0.74 \\
\hline SPI & 3 & 3.30 & 0.06 & 0.80 \\
\hline Beers aspect & 3 & 3.31 & 0.06 & 0.86 \\
\hline \multicolumn{5}{|l|}{ Understory Cover $>1-2 \mathrm{~m}$} \\
\hline Model & $\mathrm{K}$ & $\Delta \mathrm{AIC}_{\mathrm{c}}$ & $\mathrm{AIC}_{\mathrm{c}} \mathrm{Wt}$ & Cumulative $\mathrm{Wt}$ \\
\hline SPI $*$ Canopy cover & 5 & - & 0.40 & 0.40 \\
\hline SPI & 3 & 1.23 & 0.22 & 0.62 \\
\hline Null & 2 & 3.09 & 0.09 & 0.71 \\
\hline SPI + Beers aspect & 4 & 3.18 & 0.08 & 0.79 \\
\hline$($ SPI + Beers aspect $) *$ Canopy cover & 7 & 3.63 & 0.07 & 0.85 \\
\hline HLI & 3 & 4.21 & 0.05 & 0.90 \\
\hline \multicolumn{5}{|l|}{ Midstory Stems 0-5.1 cm DBH } \\
\hline Model & $\mathrm{K}$ & $\Delta \mathrm{AIC}_{\mathrm{c}}$ & $\mathrm{AIC}_{\mathrm{c}} \mathrm{Wt}$ & Cumulative $\mathrm{Wt}$ \\
\hline SPI $*$ Canopy cover & 5 & - & 0.73 & 0.73 \\
\hline$($ SPI + Beers aspect $) *$ Canopy cover & 7 & 2.03 & 0.27 & 1.00 \\
\hline TRMI * Canopy cover & 5 & 14.84 & 0.00 & 1.00 \\
\hline Beers aspect $*$ Canopy cover & 5 & 16.98 & 0.00 & 1.00 \\
\hline HLI $*$ Canopy cover & 5 & 17.75 & 0.00 & 1.00 \\
\hline Null & 2 & 18.28 & 0.00 & 1.00 \\
\hline \multicolumn{5}{|l|}{ Midstory Stems $>5.1-11.3 \mathrm{~cm}$ DBH } \\
\hline Model & $\mathrm{K}$ & $\Delta \mathrm{AIC}_{\mathrm{c}}$ & $\mathrm{AIC}_{\mathrm{c}} \mathrm{Wt}$ & Cumulative $\mathrm{Wt}$ \\
\hline SPI & 3 & - & 0.25 & 0.25 \\
\hline HLI & 3 & 0.16 & 0.23 & 0.48 \\
\hline Null & 2 & 0.65 & 0.18 & 0.66 \\
\hline SPI + Beers aspect & 4 & 2.01 & 0.09 & 0.75 \\
\hline TRMI & 3 & 2.47 & 0.07 & 0.83 \\
\hline Beers aspect & 3 & 2.52 & 0.07 & 0.90 \\
\hline
\end{tabular}


Appendix 2-F. Vegetation summary statistics (mean \pm standard error) in cut-back border treatments over time.

\begin{tabular}{|c|c|c|c|c|c|c|c|}
\hline & Control & $\begin{array}{c}15 \mathrm{~m}, \\
14 \mathrm{~m}^{2} / \mathrm{ha}\end{array}$ & $\begin{array}{c}15 \mathrm{~m}, \\
4.5 \mathrm{~m}^{2} / \mathrm{ha}\end{array}$ & $\begin{array}{c}30 \mathrm{~m}, \\
14 \mathrm{~m}^{2} / \mathrm{ha}\end{array}$ & $\begin{array}{c}30 \mathrm{~m}, \\
4.5 \mathrm{~m}^{2} / \mathrm{ha}\end{array}$ & $\begin{array}{c}45 \mathrm{~m}, \\
14 \mathrm{~m}^{2} / \mathrm{ha}\end{array}$ & $\begin{array}{c}45 \mathrm{~m}, \\
4.5 \mathrm{~m}^{2} / \mathrm{ha}\end{array}$ \\
\hline \multicolumn{8}{|l|}{ Basal area $\left(\mathrm{m}^{2} / \mathrm{ha}\right)$} \\
\hline Pre-treatment & $16.3 \pm 1.9$ & $16.7 \pm 1.9$ & $14.8 \pm 1.4$ & $20.00 \pm 1.5$ & $15.8 \pm 2.0$ & $19.7 \pm 1.2$ & $18.3 \pm 1.6$ \\
\hline One-year Post-treatment & $16.3 \pm 1.9$ & $9.4 \pm 1.1$ & $10.5 \pm 1.0$ & $10.9 \pm 1.5$ & $7.4 \pm 1.7$ & $11.4 \pm 1.1$ & $5.2 \pm 1.2$ \\
\hline Two-year Post-treatment & $15.6 \pm 2.3$ & $7.5 \pm 1.3$ & $9.3 \pm 1.3$ & $8.5 \pm 1.3$ & $4.0 \pm 1.0$ & $9.7 \pm 1.2$ & $4.5 \pm 1.0$ \\
\hline \multicolumn{8}{|l|}{ Percent overstory cover } \\
\hline Pre-treatment & $88.86 \pm 3.6$ & $95.5 \pm 2.7$ & $96.6 \pm 1.5$ & $84.4 \pm 5.6$ & $87.2 \pm 5.7$ & $94.6 \pm 3.1$ & $96.1 \pm 1.3$ \\
\hline One-year Post-treatment & $88.86 \pm 3.6$ & $64.2 \pm 6.0$ & $72.5 \pm 5.4$ & $70.7 \pm 6.3$ & $30.7 \pm 6.8$ & $67.2 \pm 6.4$ & $19.6 \pm 5.4$ \\
\hline Two-year Post-treatment & $87.83 \pm 4.3$ & $73.4 \pm 8.5$ & $73.7 \pm 7.5$ & $67.8 \pm 8.1$ & $39.5 \pm 8.4$ & $64.1 \pm 7.5$ & $25.9 \pm 8.0$ \\
\hline \multicolumn{8}{|c|}{ Midstory stems 0-5.1 cm DBH (stems/ha) } \\
\hline Pre-treatment & $276.1 \pm 57.9$ & $297.6 \pm 54.6$ & $325.0 \pm 117.6$ & $262.5 \pm 47.2$ & $363.6 \pm 70.1$ & $203.6 \pm 51.4$ & $232.5 \pm 54.6$ \\
\hline One-year Post-treatment & $276.1 \pm 57.9$ & $228.4 \pm 64.7$ & $250.0 \pm 120.3$ & $278.4 \pm 98.5$ & $150.0 \pm 36.7$ & $120.5 \pm 44.5$ & $107.9 \pm 41.5$ \\
\hline Two-year Post-treatment & $308.3 \pm 68.0$ & $394.4 \pm 81.8$ & $415.3 \pm 145.7$ & $345.8 \pm 99.1$ & $373.6 \pm 76.3$ & $212.5 \pm 44.3$ & $308.8 \pm 86.2$ \\
\hline \multicolumn{8}{|c|}{ Midstory stems $>5.1-11.3 \mathrm{~cm}$ DBH $($ stems/ha) } \\
\hline Pre-treatment & $122.7 \pm 14.5$ & $139.3 \pm 18.6$ & $140.9 \pm 25.7$ & $118.2 \pm 21.3$ & $164.8 \pm 25.0$ & $108.3 \pm 16.8$ & $78.8 \pm 12.7$ \\
\hline One-year Post-treatment & $122.7 \pm 14.5$ & $81.8 \pm 16.0$ & $108.0 \pm 26.5$ & $69.3 \pm 13.0$ & $36.4 \pm 9.6$ & $50.0 \pm 12.5$ & $19.3 \pm 5.9$ \\
\hline Two-year Post-treatment & $123.6 \pm 15.2$ & $98.6 \pm 20.6$ & $102.8 \pm 30.4$ & $93.1 \pm 25.1$ & $33.3 \pm 8.6$ & $76.4 \pm 22.5$ & $32.4 \pm 7.7$ \\
\hline \multicolumn{8}{|l|}{ Percent ground cover } \\
\hline Pre-treatment & $52.7 \pm 5.2$ & $50.5 \pm 6.0$ & $46.4 \pm 4.2$ & $50.9 \pm 5.5$ & $45.5 \pm 5.8$ & $41.9 \pm 4.6$ & $42.0 \pm 4.1$ \\
\hline One-year Post-treatment & $52.7 \pm 5.2$ & $48.2 \pm 4.9$ & $43.6 \pm 4.1$ & $44.5 \pm 4.7$ & $46.4 \pm 5.8$ & $47.3 \pm 6.0$ & $46.4 \pm 5.8$ \\
\hline Two-year Post-treatment & $55.6 \pm 5.5$ & $72.2 \pm 5.4$ & $73.3 \pm 5.8$ & $67.8 \pm 4.6$ & $75.6 \pm 6.2$ & $62.2 \pm 6.4$ & $85.9 \pm 4.8$ \\
\hline \multicolumn{8}{|c|}{ Percent understory cover $0-1$ m } \\
\hline Pre-treatment & $80.0 \pm 6.2$ & $91.4 \pm 4.9$ & $91.8 \pm 4.1$ & $80.9 \pm 5.2$ & $86.4 \pm 4.8$ & $69.5 \pm 6.6$ & $78.0 \pm 6.8$ \\
\hline One-year Post-treatment & $80.0 \pm 6.2$ & $93.6 \pm 3.3$ & $94.5 \pm 3.0$ & $94.5 \pm 3.3$ & $95.5 \pm 3.2$ & $85.5 \pm 5.6$ & $89.1 \pm 4.9$ \\
\hline Two-year Post-treatment & $83.3 \pm 6.1$ & $97.8 \pm 2.2$ & $100.0 \pm 0.0$ & $97.8 \pm 2.2$ & $97.8 \pm 2.2$ & $96.7 \pm 2.4$ & $100.0 \pm 0.0$ \\
\hline \multicolumn{8}{|c|}{ Percent understory cover $>1-2 \mathrm{~m}$} \\
\hline Pre-treatment & $58.2 \pm 7.1$ & $80.0 \pm 5.9$ & $74.5 \pm 5.9$ & $68.2 \pm 6.5$ & $73.6 \pm 6.4$ & $58.1 \pm 6.9$ & $62.0 \pm 6.6$ \\
\hline One-year Post-treatment & $58.2 \pm 7.1$ & $76.4 \pm 7.3$ & $68.2 \pm 6.5$ & $76.4 \pm 6.4$ & $73.6 \pm 7.7$ & $63.6 \pm 7.9$ & $64.5 \pm 7.0$ \\
\hline Two-year Post-treatment & $57.8 \pm 8.2$ & $85.6 \pm 6.4$ & $98.9 \pm 1.1$ & $84.4 \pm 6.8$ & $93.3 \pm 4.0$ & $75.6 \pm 7.7$ & $90.6 \pm 5.5$ \\
\hline
\end{tabular}


Appendix 2-G. Model posterior predictive check (Bayesian $p$-value) and model performance (deviance information criterion [DIC]; lower is better) for focal bird species, avian guild, and eastern red-backed salamander (Plethodon cinereus) treatment-time interaction and main effects model analyses. Bayesian $p$-value is the probability to obtain a Chi-square test statistic that is at least as extreme as the observed Chi-square test statistic. We assumed reasonable model fit with a Bayesian $p$-value $>0.1$ and $<0.9$.

\begin{tabular}{|c|c|c|c|c|c|}
\hline \multirow{2}{*}{$\begin{array}{l}\text { Focal birds } \\
\text { Common name }\end{array}$} & \multirow[b]{2}{*}{ Scientific name } & \multicolumn{2}{|c|}{ Bayesian $p$-value } & \multicolumn{2}{|c|}{ DIC } \\
\hline & & $\begin{array}{l}\text { Treatment- } \\
\text { Time }\end{array}$ & $\begin{array}{c}\text { Main } \\
\text { Effects }\end{array}$ & $\begin{array}{l}\text { Treatment- } \\
\text { Time }\end{array}$ & $\begin{array}{c}\text { Main } \\
\text { Effects }\end{array}$ \\
\hline American goldfinch & Spinus tristis & 0.305 & 0.303 & 8073.4 & 8181.1 \\
\hline American redstart & Setophaga ruticilla & 0.407 & 0.413 & 8138.3 & 8158.2 \\
\hline Black-and-white warbler & Mniotilta varia & 0.420 & 0.437 & 8341.3 & 8412.5 \\
\hline Black-throated green warbler & Setophaga virens & 0.412 & 0.338 & 7776.1 & 7845.1 \\
\hline Blue-gray gnatchatcher & Polioptila caerulea & 0.343 & 0.323 & 8195.6 & 8180.8 \\
\hline Carolina wren & Thryothorus ludovicianus & 0.300 & 0.247 & 8021.5 & 8178.5 \\
\hline Cerulean warbler & Setophaga cerulean & 0.517 & 0.533 & 7741.7 & 7760.2 \\
\hline Common yellowthroat & Geothlypis trichas & 0.313 & 0.338 & 7970.3 & 7966.9 \\
\hline Eastern towhee & Pipilo erythrophthalmus & 0.373 & 0.403 & 8872.6 & 8892.3 \\
\hline Eastern wood-pewee & Contopus virens & 0.410 & 0.383 & 8020.4 & 8022.2 \\
\hline Hooded warbler & Setophaga citrina & 0.472 & 0.410 & 8681.3 & 8590.3 \\
\hline Indigo bunting & Passerina cyanea & 0.528 & 0.547 & 8934.2 & 9029.0 \\
\hline Northern cardinal & Cardinalis cardinalis & 0.352 & 0.453 & 8098.0 & 8062.5 \\
\hline Ovenbird & Seiurus aurocapilla & 0.368 & 0.363 & 8617.9 & 8589.9 \\
\hline Red-eyed vireo & Vireo olivaceus & 0.403 & 0.413 & 9327.7 & 9098.1 \\
\hline Ruffed grouse & Bonasa umbellus & 0.528 & 0.547 & 4935.8 & 4941.9 \\
\hline Wood thrush & Hylocichla mustelina & 0.323 & 0.340 & 8023.6 & 8003.9 \\
\hline \multicolumn{6}{|l|}{ Avian guilds } \\
\hline Spring stopover & & 0.742 & 0.733 & 4568.2 & 1692.7 \\
\hline Young forest habitat guild & & 0.560 & 0.610 & 9946.7 & 9853.3 \\
\hline Interior-edge habitat guild & & 0.732 & 0.803 & 1465.4 & 1464.9 \\
\hline Forest gap habitat guild & & 0.600 & 0.658 & 9566.6 & 9575.0 \\
\hline Forest interior habitat guild & & 0.447 & 0.452 & 9669.2 & 9734.2 \\
\hline Aerial insectivore foraging guild & & 0.573 & 0.593 & 587.2 & 604.3 \\
\hline Cavity nesting guild & & 0.335 & 0.343 & 1079.9 & 1089.9 \\
\hline
\end{tabular}


Appendix 2-G continued.

\begin{tabular}{lcccc}
\hline & \multicolumn{2}{c}{ Bayesian $\boldsymbol{p}$-value } & \multicolumn{2}{c}{ DIC } \\
\hline \multirow{2}{*}{ Avian guild } & Treatment- & Main & Treatment- & Main \\
& Time & Effects & Time & Effects \\
\hline Predator/parasite guild & 0.353 & 0.340 & 498.3 & 486.5 \\
Species of Conservation Priority & 0.580 & 0.585 & 100021.9 & 10020.1 \\
\hline Eastern red-backed salamander & & & & \\
\hline Relative abundance & 0.510 & 0.410 & 705.7 & 682.8 \\
Body condition index & 0.550 & 0.520 & 206.2 & 203.7 \\
\hline
\end{tabular}


Appendix 2-H. Output table from canonical correspondence analysis (CCA) assessing avian species correlations with vegetation variables in cut-back borders. Numeric values in each column (CCA1, CCA2, etc.) indicate correlation with that canonical axis, with higher absolute numbers (positive or negative) being more strongly associated within that axis (e.g., CCA1 is strongly influenced by elevation, hence "Elevation" has the highest absolute value of vegetation variables in CCA1, and is correlated with CSWA, COYE, RUGR, etc. which have the highest absolute value of species). Positive correlations between vegetation variables and species are indicated with similar signs ("+" or "_") within each column.

\begin{tabular}{|c|c|c|c|c|c|c|c|}
\hline \multicolumn{2}{|c|}{ Predictor Variables } & CCA1 & CCA2 & CCA3 & CCA4 & CCA5 & CCA6 \\
\hline \multicolumn{2}{|c|}{ Elevation } & -0.97 & 0.02 & 0.05 & 0.04 & 0.06 & -0.12 \\
\hline \multicolumn{2}{|c|}{ Topographic Relative Moisture Index (TRMI) } & -0.35 & 0.67 & -0.18 & -0.08 & 0.49 & -0.33 \\
\hline \multicolumn{2}{|c|}{ Understory cover $>1-2 \mathrm{~m}$} & 0.05 & 0.60 & 0.32 & 0.15 & -0.02 & 0.48 \\
\hline \multicolumn{2}{|c|}{ Counts of trees $<28.0 \mathrm{~cm} \mathrm{DBH}$} & -0.31 & 0.08 & -0.64 & 0.24 & -0.27 & 0.31 \\
\hline \multicolumn{2}{|c|}{ Basal Area } & 0.00 & -0.47 & -0.41 & 0.40 & 0.37 & 0.25 \\
\hline \multicolumn{2}{|c|}{ Midstory stems $>5.1-<11.3 \mathrm{~cm} \mathrm{DBH}$} & -0.34 & 0.23 & -0.04 & 0.32 & -0.01 & 0.37 \\
\hline \multicolumn{2}{|c|}{ Snags } & -0.01 & 0.22 & -0.72 & -0.13 & -0.11 & 0.24 \\
\hline \multicolumn{2}{|l|}{ Overstory cover } & 0.10 & -0.12 & -0.44 & 0.83 & 0.19 & 0.00 \\
\hline \multicolumn{2}{|l|}{ Ground cover } & 0.22 & 0.48 & 0.23 & 0.18 & -0.57 & -0.25 \\
\hline Habitat Guild & Species & CCA1 & CCA2 & CCA3 & CCA4 & CCA5 & CCA6 \\
\hline \multirow{10}{*}{ Young Forest } & AMGO & 0.00 & 0.20 & -0.20 & -0.09 & -0.07 & 0.13 \\
\hline & BWWA & 0.76 & 0.62 & 0.29 & -0.19 & -0.23 & 0.13 \\
\hline & CARW & 0.46 & 0.23 & -0.04 & 0.09 & -0.26 & 0.18 \\
\hline & CSWA & -1.43 & 0.48 & 0.00 & -0.08 & -0.29 & 0.05 \\
\hline & COYE & -0.95 & 0.29 & 0.04 & 0.05 & -0.10 & 0.02 \\
\hline & EATO & -0.11 & 0.12 & 0.26 & -0.14 & -0.06 & -0.16 \\
\hline & FISP & 0.55 & -0.13 & 0.31 & 0.11 & -0.07 & -0.08 \\
\hline & GRCA & 0.04 & -0.22 & -0.17 & -0.35 & 0.46 & -0.02 \\
\hline & INBU & 0.39 & 0.04 & 0.22 & -0.11 & -0.05 & 0.06 \\
\hline & RUGR & -0.82 & 0.30 & 0.01 & -0.34 & 0.08 & -0.04 \\
\hline \multirow{11}{*}{ Interior-edge } & AMRE & 0.34 & 0.34 & 0.02 & 0.25 & 0.14 & -0.13 \\
\hline & AMRO & 0.18 & -0.59 & -0.09 & 0.12 & -0.12 & 0.19 \\
\hline & BGGN & 0.57 & 0.48 & -0.11 & -0.11 & 0.14 & -0.08 \\
\hline & CAWA & -1.74 & 0.14 & 0.44 & -0.38 & 0.24 & 0.31 \\
\hline & CEDW & -0.14 & -0.19 & 0.06 & -0.32 & -0.12 & 0.09 \\
\hline & DEJU & -1.06 & 0.01 & -0.12 & -0.52 & 0.09 & -0.26 \\
\hline & DOWO & 0.62 & 0.21 & -0.47 & -0.13 & -0.27 & 0.34 \\
\hline & EAWP & 0.33 & -0.69 & -0.10 & -0.03 & -0.13 & -0.05 \\
\hline & NOCA & 0.63 & 0.65 & -0.19 & 0.03 & -0.18 & 0.12 \\
\hline & RBWO & 0.41 & -0.51 & 0.00 & 0.23 & -0.12 & -0.19 \\
\hline & YTVI & -0.16 & 0.02 & 0.08 & 0.22 & -0.18 & -0.35 \\
\hline \multirow{7}{*}{ Forest Gap } & ACFL & 0.55 & 0.38 & -0.18 & 0.09 & 0.84 & 0.20 \\
\hline & BTNW & -1.45 & 0.32 & -0.07 & 0.27 & 0.15 & -0.22 \\
\hline & CERW & 0.36 & 0.06 & 0.43 & 0.02 & 0.17 & 0.01 \\
\hline & HOWA & 0.17 & -0.28 & 0.35 & 0.20 & 0.13 & 0.16 \\
\hline & KEWA & -0.06 & 0.18 & 0.04 & 0.20 & 0.00 & -0.06 \\
\hline & REVI & 0.10 & -0.06 & -0.12 & 0.05 & -0.05 & -0.09 \\
\hline & WBNU & 0.50 & -0.17 & 0.21 & -0.10 & 0.19 & 0.05 \\
\hline \multirow{10}{*}{ Forest Interior } & BAWW & -0.03 & -0.27 & 0.34 & 0.00 & 0.00 & 0.06 \\
\hline & BTBW & -1.55 & 0.53 & 0.03 & 0.62 & 0.02 & 0.45 \\
\hline & BHVI & -0.38 & -0.57 & -0.14 & 0.14 & 0.13 & 0.03 \\
\hline & HAWO & 0.04 & -0.32 & -0.14 & -0.21 & 0.26 & 0.38 \\
\hline & OVEN & -0.53 & -0.32 & -0.29 & 0.01 & -0.06 & 0.04 \\
\hline & PIWO & 0.52 & 0.01 & -0.25 & 0.21 & 0.50 & 0.00 \\
\hline & SCTA & 0.18 & -0.01 & -0.10 & 0.21 & 0.03 & -0.24 \\
\hline & TUTI & 0.50 & -0.10 & -0.16 & 0.13 & -0.25 & 0.00 \\
\hline & WEWA & 0.43 & 0.00 & -0.84 & -0.23 & 0.10 & 0.09 \\
\hline & WOTH & 0.20 & -0.26 & -0.04 & -0.13 & 0.19 & -0.14 \\
\hline \multirow{2}{*}{ Predator/Parasite } & $\mathrm{BHCO}$ & 0.35 & 0.23 & -0.06 & -0.10 & 0.24 & -0.18 \\
\hline & BLJA & 0.10 & -0.12 & 0.01 & -0.04 & -0.08 & 0.24 \\
\hline
\end{tabular}


Appendix 2-I. Capture breakdown of salamander species by cut-back border treatment over the study period. Table excludes recaptures.

\begin{tabular}{|c|c|c|c|c|c|}
\hline & Control & $\begin{array}{c}30 \mathrm{~m} \\
14 \mathrm{~m}^{2} / \mathrm{ha}\end{array}$ & $\begin{array}{c}30 \mathrm{~m} \\
4.5 \mathrm{~m}^{2} / \mathrm{ha}\end{array}$ & $\begin{array}{c}45 \mathrm{~m} \\
14 \mathrm{~m}^{2} / \mathrm{ha}\end{array}$ & $\begin{array}{c}45 \mathrm{~m} \\
4.5 \mathrm{~m}^{2} / \mathrm{ha} \\
\end{array}$ \\
\hline \multicolumn{6}{|c|}{$\begin{array}{l}\text { Eastern Red-backed Salamander } \\
\text { (Plethodon cinereus) }\end{array}$} \\
\hline Pre-treatment & 12 & 5 & 7 & 7 & 13 \\
\hline One-year Post-treatment & 14 & 4 & 9 & 13 & 21 \\
\hline Two-year Post-treatment & 27 & 9 & 17 & 11 & 18 \\
\hline \multicolumn{6}{|c|}{$\begin{array}{l}\text { Mountain Dusky Salamander } \\
\text { (Desmognathus ochrophaeus) }\end{array}$} \\
\hline Pre-treatment & 0 & 0 & 1 & 0 & 0 \\
\hline One-year Post-treatment & 0 & 0 & 0 & 0 & 0 \\
\hline Two-year Post-treatment & 0 & 0 & 2 & 0 & 0 \\
\hline \multicolumn{6}{|l|}{$\begin{array}{l}\text { Northern Red Salamander } \\
\text { (Pseudotriton ruber) }\end{array}$} \\
\hline Pre-treatment & 0 & 0 & 0 & 0 & 0 \\
\hline One-year Post-treatment & 0 & 0 & 0 & 0 & 0 \\
\hline Two-year Post-treatment & 1 & 0 & 0 & 0 & 0 \\
\hline \multicolumn{6}{|l|}{$\begin{array}{l}\text { Slimy Salamander } \\
(P . \text { glutinosus })\end{array}$} \\
\hline Pre-treatment & 0 & 0 & 3 & 2 & 5 \\
\hline One-year Post-treatment & 5 & 1 & 3 & 0 & 0 \\
\hline Two-year Post-treatment & 1 & 1 & 1 & 3 & 2 \\
\hline \multicolumn{6}{|l|}{$\begin{array}{l}\text { Wehrle's Salamander } \\
(P . \text { wehrlei) }\end{array}$} \\
\hline Pre-treatment & 0 & 0 & 0 & 1 & 2 \\
\hline One-year Post-treatment & 1 & 3 & 1 & 0 & 0 \\
\hline Two-year Post-treatment & 1 & 1 & 0 & 0 & 1 \\
\hline
\end{tabular}


Appendix 2-J. Total number annual detections in cut-back border treatments for species of conservation concern in the Appalachian region (Bird Conservation Region 28; PIF 2019) that did not meet the detection count criteria ( $\geq 40$ detections) or the detection probability criteria ( $\geq 0.200$ probability of detection).

\begin{tabular}{|c|c|c|c|c|c|c|c|}
\hline & Control & $\begin{array}{c}15 \mathrm{~m} \\
14 \mathrm{~m}^{2} / \mathrm{ha} \\
\end{array}$ & $\begin{array}{c}15 \mathrm{~m} \\
4.5 \mathrm{~m}^{2} / \mathrm{ha} \\
\end{array}$ & $\begin{array}{c}30 \mathrm{~m} \\
14 \mathrm{~m}^{2} / \mathrm{ha} \\
\end{array}$ & $\begin{array}{c}30 \mathrm{~m} \\
4.5 \mathrm{~m}^{2} / \mathrm{ha} \\
\end{array}$ & $\begin{array}{c}45 \mathrm{~m} \\
14 \mathrm{~m}^{2} / \mathrm{ha} \\
\end{array}$ & $\begin{array}{c}45 \mathrm{~m} \\
4.5 \mathrm{~m}^{2} / \mathrm{ha} \\
\end{array}$ \\
\hline \multicolumn{8}{|l|}{ Acadian Flycatcher } \\
\hline Pre-treatment & 1 & 1 & 1 & 4 & 1 & 0 & 3 \\
\hline One-year Post-treatment & 4 & 3 & 0 & 1 & 0 & 4 & 3 \\
\hline Two-year Post-treatment & 1 & 0 & 1 & 6 & 0 & 0 & 2 \\
\hline \multicolumn{8}{|c|}{ Black-throated Blue Warbler } \\
\hline Pre-treatment & 3 & 3 & 6 & 6 & 5 & 2 & 3 \\
\hline One-year Post-treatment & 0 & 1 & 1 & 1 & 1 & 0 & 2 \\
\hline Two-year Post-treatment & 0 & 2 & 0 & 1 & 1 & 0 & 1 \\
\hline \multicolumn{8}{|l|}{ Blue-winged Warbler } \\
\hline Pre-treatment & 0 & 0 & 2 & 1 & 2 & 1 & 0 \\
\hline One-year Post-treatment & 0 & 0 & 1 & 1 & 3 & 3 & 1 \\
\hline Two-year Post-treatment & 1 & 1 & 6 & 1 & 3 & 3 & 1 \\
\hline \multicolumn{8}{|l|}{ Canada Warbler } \\
\hline Pre-treatment & 0 & 0 & 2 & 1 & 1 & 0 & 2 \\
\hline One-year Post-treatment & 0 & 4 & 4 & 0 & 2 & 1 & 3 \\
\hline Two-year Post-treatment & 0 & 0 & 1 & 1 & 1 & 2 & 2 \\
\hline \multicolumn{8}{|l|}{ Chipping Sparrow } \\
\hline Pre-treatment & 1 & 2 & 3 & 0 & 2 & 0 & 0 \\
\hline One-year Post-treatment & 1 & 0 & 0 & 1 & 0 & 0 & 2 \\
\hline Two-year Post-treatment & 0 & 0 & 0 & 0 & 0 & 1 & 0 \\
\hline \multicolumn{8}{|l|}{ Field Sparrow } \\
\hline Pre-treatment & 2 & 3 & 2 & 0 & 2 & 0 & 3 \\
\hline One-year Post-treatment & 0 & 3 & 1 & 2 & 1 & 2 & 2 \\
\hline Two-year Post-treatment & 3 & 0 & 1 & 3 & 5 & 1 & 0 \\
\hline \multicolumn{8}{|l|}{ Least Flycatcher } \\
\hline Pre-treatment & 0 & 0 & 0 & 0 & 0 & 0 & 0 \\
\hline One-year Post-treatment & 0 & 0 & 0 & 0 & 1 & 0 & 0 \\
\hline Two-year Post-treatment & 0 & 1 & 0 & 0 & 0 & 0 & 0 \\
\hline
\end{tabular}


Appendix 2-J continued.

\begin{tabular}{|c|c|c|c|c|c|c|c|}
\hline & Control & $\begin{array}{c}15 \mathrm{~m} \\
14 \mathrm{~m}^{2} / \mathrm{ha} \\
\end{array}$ & $\begin{array}{c}15 \mathrm{~m} \\
4.5 \mathrm{~m}^{2} / \mathrm{ha}\end{array}$ & $\begin{array}{c}30 \mathrm{~m} \\
14 \mathrm{~m}^{2} / \mathrm{ha} \\
\end{array}$ & $\begin{array}{c}30 \mathrm{~m} \\
4.5 \mathrm{~m}^{2} / \mathrm{ha} \\
\end{array}$ & $\begin{array}{c}45 \mathrm{~m} \\
14 \mathrm{~m}^{2} / \mathrm{ha} \\
\end{array}$ & $\begin{array}{c}45 \mathrm{~m} \\
4.5 \mathrm{~m}^{2} / \mathrm{ha} \\
\end{array}$ \\
\hline \multicolumn{8}{|l|}{ Louisiana Waterthrush } \\
\hline Pre-treatment & 0 & 0 & 0 & 1 & 0 & 0 & 0 \\
\hline One-year Post-treatment & 0 & 1 & 0 & 1 & 0 & 0 & 0 \\
\hline Two-year Post-treatment & 1 & 1 & 0 & 1 & 0 & 0 & 1 \\
\hline \multicolumn{8}{|l|}{ Prairie Warbler } \\
\hline Pre-treatment & 0 & 0 & 0 & 0 & 0 & 0 & 0 \\
\hline One-year Post-treatment & 0 & 0 & 0 & 0 & 0 & 0 & 0 \\
\hline Two-year Post-treatment & 0 & 1 & 1 & 0 & 0 & 0 & 0 \\
\hline \multicolumn{8}{|l|}{ Rose-breasted Grosbeak } \\
\hline Pre-treatment & 1 & 0 & 4 & 2 & 1 & 1 & 1 \\
\hline One-year Post-treatment & 0 & 0 & 0 & 1 & 1 & 0 & 0 \\
\hline Two-year Post-treatment & 1 & 0 & 1 & 1 & 0 & 1 & 0 \\
\hline \multicolumn{8}{|l|}{ Scarlet Tanager } \\
\hline Pre-treatment & 6 & 5 & 2 & 3 & 6 & 2 & 4 \\
\hline One-year Post-treatment & 7 & 10 & 3 & 3 & 4 & 4 & 5 \\
\hline Two-year Post-treatment & 6 & 7 & 3 & 9 & 5 & 5 & 5 \\
\hline \multicolumn{8}{|l|}{ Worm-eating Warbler } \\
\hline Pre-treatment & 0 & 2 & 1 & 4 & 3 & 2 & 2 \\
\hline One-year Post-treatment & 3 & 0 & 5 & 1 & 1 & 1 & 3 \\
\hline Two-year Post-treatment & 1 & 2 & 1 & 1 & 0 & 0 & 1 \\
\hline \multicolumn{8}{|l|}{ Yellow-breasted Chat } \\
\hline Pre-treatment & 1 & 0 & 0 & 0 & 1 & 0 & 1 \\
\hline One-year Post-treatment & 0 & 0 & 0 & 0 & 1 & 0 & 1 \\
\hline Two-year Post-treatment & 1 & 1 & 2 & 0 & 3 & 1 & 0 \\
\hline \multicolumn{8}{|l|}{ Yellow-throated Warbler } \\
\hline Pre-treatment & 0 & 1 & 0 & 0 & 0 & 0 & 0 \\
\hline One-year Post-treatment & 0 & 2 & 1 & 0 & 0 & 0 & 0 \\
\hline Two-year Post-treatment & 0 & 0 & 0 & 0 & 0 & 0 & 0 \\
\hline
\end{tabular}




\title{
CHAPTER 3
}

\section{AVIAN AND SALAMANDER RESPONSE TO NON-COMMERCIAL YOUNG FOREST MANAGEMENT TECHNIQUES}

\begin{abstract}
Current forest conditions throughout West Virginia and the central Appalachian region indicate a young forest deficit which has negatively affected wildlife species associated with forest disturbance. Due to the prominence of commercial logging as a means to create young forest, forests of low- or poor-quality stocking are often overlooked and thus limit the management and conservation of young forest wildlife species. In order to promote habitat for young forest wildlife species, more opportunities for creating young forest habitat via forest management are greatly needed. In this chapter, we assessed three non-commercial young forest management treatments (clearcut-and-leave [CL], clearcut-and-windrow [CW], and hack-and-spray [HS]) for promoting young forest habitat. Similar to Chapter 2, the objectives of this chapter were to examine whether the non-commercial young forest management treatments increased habitat suitability for young forest wildlife species and to determine which treatments optimized the tradeoff between maximizing positive responses of disturbance-dependent species (i.e., young forest songbirds) and minimizing negative responses of disturbance-avoidant species (i.e., forest interior songbirds and woodland salamanders). Additionally, we included a cost-benefit analysis to quantify the tradeoffs between maximizing songbird richness (cavity nesting guild, forest gap habitat guild, forest interior habitat guild, and young forest habitat guild) and minimizing cost of forest management. Implementation of regeneration treatments induced a dichotomous response from the avian community. Young forest songbird species responded positively to the CL treatment and negatively to the HS treatment, while forest interior songbirds responded positively to the HS treatment and negatively to the CL treatment. Eastern red-backed salamander (Plethodon cinereus), a terrestrial salamander most suited to forest interiors, responded positively to the HS treatment immediately following treatment. Based on our costbenefit analysis, the CL treatment was the optimum treatment for maximizing songbird species richness and minimizing cost of habitat management followed by the control, the HS treatment, and the $\mathrm{CW}$ treatment. These results suggest that non-commercial forest management can provide suitable habitat conditions for young forest songbirds but can negatively affect forest
\end{abstract}


interior songbirds, while other treatments retain suitable habitat conditions for forest interior species but do not provide immediate suitable habitat for young forest species.

\section{Introduction}

\subsection{Introduction}

Young forest wildlife species are experiencing precipitous population declines across the eastern US due to human-induced land-use modifications (e.g., farm abandonment, wildfire suppression, shifting disturbance regimes, urbanization) over the past century (Lorimer 2001, Trani et al. 2001). These anthropogenic modifications have resulted in the loss or conversion of young forest areas, primarily through the suppression of forest canopy disturbances such as tree cutting. However, canopy disturbances are an essential component of forest systems as they provide developmental stimuli to promote diverse plant species growth and resources to animals (McDermott and Wood 2010, Dey 2014). Without canopy disturbances, young forests will eventually mature into a later successional stage thereby eliminating breeding cover and foraging opportunities vital to young forest wildlife, a high conservation priority group in West Virginia and the central Appalachian region (King and Schlossberg 2014). Currently, West Virginia and much of the central Appalachian region is in a young forest deficit relative to historical conditions (Oswalt et al. 2010, Shifley and Thompson III 2011). Relative to conditions from the mid-century (ca. 1949), young forest area in West Virginia is down from 19\% of all forestlands to $7 \%$ today (Morin et al. 2016). However, Lorimer (2001) states that due to exploitation logging, farm abandonment, and wildfires during the late nineteenth century young forests likely reached a peak of $55-60 \%$ of forestlands during this period but has since declined to $20 \%$ or less in many parts of eastern North America. Contemporary expectations of young forest levels are unlikely to be met using these historical baselines because they were outcomes of larger societal pressures which have changed over time. However, considering the scenario from Shifley and Thompson (2011) where forest age classes from 0-120 years old are evenly distributed, young forests (0-10 years old) would comprise $7.1 \%$ of all forestland (Note: Morin et al. 2016 used a different criterion than Shifley and Thompson III 2011 to categorize young forest). Using the $7.1 \%$ as a contemporary baseline for young forest area, West Virginia is currently in a young forest deficit with only $2.4 \%$ of forestland in this age class (or a 226,255-ha state-wide deficit).

While young forest area in West Virginia remains low, timber volume is concurrently increasing at twice the rate than what is being removed via harvesting. However, despite the 
prominence of forests comprised of older, larger trees in West Virginia (93\% of all forestland), only $38 \%$ of these forestlands are well stocked with trees of commercial importance (Morin et al. 2016). The lack of young forests and predominance of mature forests demonstrates the need for increased opportunities for young forest management in order to reduce the young forest deficit in the region (DeGraaf and Yamasaki 2003, Shifley and Thompson III 2011). Implementation of tree cutting, the major canopy disturbance agent in the region, will likely need to be expanded to reduce the young forest deficit currently present in West Virginia and throughout the central Appalachian region.

Numerous options exist for creating and managing young forest habitat, but commercial tree-cutting is the primary contemporary disturbance agent in the central Appalachian region (Cohen et al. 2016). Commercial logging is largely driven by the economic value of timber and thus, management and conservation of young forest species is greatly affected by the commercial logging industry (King and Schlossberg 2014, Demarais et al. 2017). However, in forested areas with poorly stocked or low-quality timber, forest management is often cost prohibitive for many commercial loggers. Without an economic incentive to cut trees, low-quality forestlands that would have otherwise increased the amount of young forest area remains in a forest stage that is unsuitable for young forest wildlife. Despite this limitation for conserving and managing young forest wildlife, non-commercial wildlife stand improvement (WSI) strategies can provide alternative approaches to managing wildlife habitat (Wilson et al. 1995, Masters et al. 1998). Wildlife stand improvement strategies focus on ecological capital rather than economic capital with the specific goal of managing forestlands for specific wildlife habitats, primarily those of high conservation value with limited regional distribution. However, economic costs of noncommercial WSI treatments need to be considered as no short-term economic output is produced (Shwiff et al. 2013). Land managers need to consider this aspect in order to implement WSI treatment as a stand-alone management technique or to potentially incorporate WSI treatments along with commercial timber sales.

Silviculture provides relevant land management applications and documented wildlife responses for WSI prescriptions to mimic in order to meet the objective of creating young forest wildlife habitat. Clearcutting removes all canopy trees and induces a complete turnover of the wildlife community, replacing mature forest species with young forest species (Duguay et al. 2001, Gram et al. 2003). Shelterwood harvest removes a portion of canopy trees which benefits 
young forest wildlife while retaining enough canopy for mature forest species (Newell and Rodewald 2012, Sheehan et al. 2014, Perry et al. 2018). While these even-aged techniques create canopy openness by felling trees, recent emphasis has been placed on ecological forestry measures, where poor-quality or low-value trees are girdled or sprayed with herbicide then left standing, thereby creating snags, as opposed to cutting (Bütler et al. 2013). This technique benefits young forest species but maintains snags for ecologically important avian groups (e.g., cavity nesters; Cockle et al. 2012, Nappi et al. 2015). Both forest management techniques create habitat for young forest species. However, both incur different costs related to treatment implementation, where clearcutting techniques rely on heavy machinery and herbicide techniques via girdling and spraying rely on expensive herbicide.

Little has been explored on the most cost-effective means for creating young forest with a focus on wildlife habitat. In order to reduce the young forest deficit in West Virginia and the central Appalachian region, non-commercial approaches need further examination. Considering the dependence of young forest wildlife species on forest management, efforts to expand young forest habitat creation beyond the commercial realm is greatly needed.

\section{2. $\quad$ Chapter objectives and hypotheses}

The primary objective of this chapter was to assess avian and salamander individual species and community responses to three different non-commercial young forest management treatments. We used a before-after-control-impact (BACI) framework to examine two cutting treatments and one herbicide treatment to inform our inferences about avian and salamander responses to treatments over time. Additionally, we examined the tradeoffs between minimizing cost of treatment and maximizing avian community richness to inform management decisions using a cost-benefit analysis. For avifauna responses to treatments, we hypothesized that (1) young forest avifauna would respond positively to all regeneration treatments with greatest responses in the cutting treatments and smallest responses in the herbicide treatment, (2) forest interior avifauna would respond negatively to all regeneration treatments with greatest responses in the cutting treatments and smallest responses in the herbicide treatment, and (3) forest gap, cavity nesting, and bark foraging avifauna would respond positively to the herbicide treatment and negatively to the cutting treatments. For our cost-benefit analysis, we hypothesized that the herbicide treatment would score highest among the three treatments due to the low cost of implementation and the positive responses by young forest species while minimizing the 
negative responses by forest interior species. The cutting treatments would score lower than the herbicide treatment due to the expected negative responses from the forest interior species as well as a higher cost of implementation. For woodland salamanders, we hypothesized that the herbicide treatment would negatively influence their relative abundance.

\section{Methods}

\subsection{Study area}

West Virginia lies within the Appalachian region, which is characterized by extensive forests, comprised of mixed mesophytic, Appalachian oak, transition Appalachian oak-northern hardwood, and oak-hickory-pine forest types (Küchler 1964). Elevations at study sites ranged from 300-1132 m. West Virginia's humid continental climate is characterized by hot summers and cool to cold winters with average spring and fall temperatures of $10.0^{\circ} \mathrm{C}$ and an average summer temperature of $28.0^{\circ} \mathrm{C}$. Annual precipitation levels are 76,127 , and $102 \mathrm{~cm}$ in the western, central, and eastern portions of the state, respectively, distributed uniformly throughout the year (NOAA 2019).

\subsection{Study design}

This study was conducted on six West Virginia Division of Natural Resources' (WVDNR) wildlife management areas (WMA) located throughout central and eastern West Virginia (Figure 3-1; see Figures 1-7, 1-10, 1-12, 1-13, 1-14, and 1-15 for site-level maps). The six study sites included 16 block replicates (Table 3-1) located within mature forests. A single block replicate consisted of four independent experimental units with each randomly assigned to one of four experimental treatments. Wildlife stand improvement treatments (hereafter "regeneration stands") included clearcut-and-leave (hereafter "CL"), clearcut-and-windrow (hereafter "CW"), hack-and-spray (hereafter "HS"), and a control with no canopy manipulation. All blocks contained all four treatments except for the three blocks at CBWMA which did not have any HS treatments (Appendix 3-A). Each regeneration stand was 4 ha (200 m x $200 \mathrm{~m}$ ) in size and roughly square in shape, and all were $\geq 200 \mathrm{~m}$ apart to ensure sampling independence. Regeneration stands within a single block replicate were presumed to be subjected to similar biotic and abiotic environmental constraints.

Within the CL treatment, all trees $\geq 5 \mathrm{~cm}$ diameter-at-breast height (DBH) were cut and left on the ground where they fell within the plot. Within the $\mathrm{CW}$ treatment, all trees $\geq 5 \mathrm{~cm}$ 
DBH) were cut and placed into linear piles (i.e., windrows) perpendicular to contours. Tree cutting was accomplished using a feller-buncher in both CL and CW treatments, and cutting began 1 September if a study site was $>8 \mathrm{~km}$ from an Indiana bat (Myotis sodalis) roosting area, or 15 November if the study site was $<8 \mathrm{~km}$ from an Indiana bat roosting area and was completed by 31 March.

Within the HS treatment, herbicide treatments of either stem injection or cut-stump were applied to non-desirable trees $\geq 5 \mathrm{~cm} \mathrm{DBH}$ to mimic crop tree or shelterwood conditions (i.e., 9$14 \mathrm{~m}^{2} /$ ha target basal area retention). Non-desirable tree species were considered to have low wildlife value (i.e., species with low mast production) and varied depending on species composition at each study site. WVDNR managers/foresters cruised HS treatments and selected leave trees based on species desirability. The stem injection treatment was applied to nondesirable tree species using 6\% solution of Arsenal $^{\circledR}$ (active ingredient Imazapyr, 28.7\% a.i.) or $3 \%$ solution of Arsenal $^{\circledR}$ AC (active ingredient Imazapyr 53.1\% a.i.) in a water carrier. For Arsenal $^{\circledR}$, one, one-inch incision was made per $2.5 \mathrm{~cm} \mathrm{DBH}$ spaced evenly around the stem. For Arsenal $^{\circledR} \mathrm{AC}$, one, one-inch incision was made per $7.5 \mathrm{~cm}$ DBH spaced evenly around the stem. For Arsenal ${ }^{\circledR}$ or Arsenal ${ }^{\circledR}$ AC, $1.5 \mathrm{ml}$ of solution was applied to each incision. The cut-stump treatment was applied to all American beech (Fagus grandifolia) $\geq 5 \mathrm{~cm} \mathrm{DBH}$ within the stand. American beech were cut down and the outer $5 \mathrm{~cm}$ of the stump surface were applied with $50 \%$ solution of Razor $^{\circledR}$-Pro, Glyphosate ${ }^{\circledR} 41$, or Roundup ${ }^{\circledR}$-Pro (all containing $41 \%$ Glyphosate a.i.) in a water carrier. The stem injection treatment was applied beginning 31 August and was completed by 1 November of each year, and the cut-stump treatment was applied beginning 31 August and was completed by 31 December of each year.

We used a before-after-control-impact (BACI) framework to infer causal relations between regeneration stand treatments and the response of avian and salamander communities through time (Eberhardt 1976). At each regeneration stand, we collected one-year of pretreatment data and one- or two-years of post-treatment data on the vegetation, avian, and salamander communities (Table 3-1). A single vegetation and avian sampling point was placed at the center of each regeneration stand, $100 \mathrm{~m}$ from the stand edge (Figure 3-2). Four vegetation and salamander sampling points were spaced at the corners of a $100 \mathrm{~m}$ X $100 \mathrm{~m}$ square grid with the grid centered on the avian point count. Each vegetation and salamander sampling point was located 50-m from the stand edge (Figure 3-2). 


\subsection{Vegetation assessment}

We measured vegetation characteristics at five sampling points within each regeneration stand (Figure 3-2) each year using an $11.3 \mathrm{~m}$ radius (0.04 ha) circular plot design. This vegetation protocol followed previous young forest wildlife studies in the central Appalachian region (Fettinger 2002, Schumacher 2002). Within this plot, we measured diameter-at-breast height $(\mathrm{DBH})$ of all trees $\geq 11.4 \mathrm{~cm}$ DBH to the nearest $0.1 \mathrm{~cm}$ using DBH tapes and recorded status ("live" or "dead"). All trees (live and dead) were placed into one of five decay stage classes modified from Backhouse and Louiser (1991; Table 3-2). Within each respective decay stage class, individual tree DBH data were converted to tree basal area $\left(\mathrm{m}^{2} / \mathrm{ha}\right)$ then summed for each $11.3 \mathrm{~m}$ circular plot. Additionally, we summed basal area for all live and dead trees to generate a single live tree and a single dead tree basal area value for each $11.3 \mathrm{~m}$ circular plot.

We estimated the amount of live foliage understory cover within two vertical zones $(0-$ $1.0 \mathrm{~m}$ and $>1.0-2.0 \mathrm{~m}$ ) with a modified Nudds (1977) profile board (hereafter "understory 0-1 $\mathrm{m}$ " and "understory >1-2 m", respectively) placed 15-m from plot center in the four cardinal directions. Observers kneeled at the vegetation plot center, to reduce variation due to differing observer heights, and estimated understory cover into one of five categories $(0-20 \%,>20-40 \%$, $>40-60 \%,>60-80 \%$, or $>80-100 \%$ ) for each of the two zones. Standing at the vegetation plot center, we measured the percentage of live overstory cover (delineated at $\geq 5 \mathrm{~m}$ above ground) using a $25 \mathrm{~cm}$ x $25 \mathrm{~cm}$ transparent plexiglass panel, divided into a 5 x 5 grid, held overhead (Hachè et al. 2013; hereafter “overstory cover”).

We derived five topographic variables using 3-m scale digital elevation model (DEM) data (WVGIS 2019) within ArcGIS (ESRI 2014). They included slope percent, slope aspect, slope position (Weiss 2001), slope configuration, and elevation and were calculated using zonal statistics to generate a mean value within a 50-m radius surrounding each of the five vegetation sampling points. Slope percent, slope aspect, slope position, and slope configuration were combined using ModelBuilder in ArcGIS (ESRI 2014) to derive a topographic relative moisture index (TRMI) ranging from 0 (xeric soil) to 60 (mesic soil; Parker 1982).

\subsection{Avian sampling}

We quantified ruffed grouse and songbird responses to regeneration stands at one pointcount location in each regeneration stand treatment (Figure 3-2) during 2016 - 2019 on days that were considered optimal for sampling (e.g., no rain, no heavy or gusty winds, and minimal 
peripheral noise). Survey-level data collected during each visit included time of survey and ordinal day. Prior to surveys, observers were trained in survey protocols, distance estimation, and to independently identify all species visually and aurally while simultaneously recording distance and time interval. Surveyor skill was assessed based on their previous experience conducting point counts in the region and identification skills of avian species of the region and ranged from 1-5, where a score of 5 indicated thorough knowledge of species with extensive experience conducting point counts, a score of 1 indicated no knowledge of species with no previous experience conducting point counts, and a score of 3 indicated introductory knowledge of species with minimal experience conducting point counts (most technicians that lacked previous point count experience were scored as 3 following training).

Ruffed grouse.-We assessed ruffed grouse response during 5-minute drumming surveys (McBurney 1989) twice at each point between 12 April and 20 May during 0530-1000 (EST). Observers recorded presence or absence of drumming grouse during each survey and if present, placed detected individuals into one of five distance intervals $(0-25 \mathrm{~m},>25-50 \mathrm{~m},>50-75 \mathrm{~m}$, $>75-100 \mathrm{~m}$, or $>100 \mathrm{~m})$.

Songbird.-We quantified breeding songbird response using 10-minute standardized fixed-radius point counts (Ralph et al. 1993, Bibby et al. 2002). We conducted two visits during 19 May-27 June after 0530 and before 1000 (EST). Observers recorded species of each individual bird detected, type of detection (song, call, visual, or flyover), demographic information (male, female, juvenile, or unknown), distance from observer placed into one of five distance intervals $(0-25 \mathrm{~m},>25-50 \mathrm{~m},>50-75 \mathrm{~m},>75-100 \mathrm{~m}$, or $>100 \mathrm{~m})$, and time interval the individual was first detected (0-2 $\mathrm{min},>2-4 \mathrm{~min},>4-6 \mathrm{~min},>6-8 \mathrm{~min}$, and >8-10 $\mathrm{min}$ ).

For all songbird data analyses, we used only detections within 100-m of the sampling point. We chose $100 \mathrm{~m}$ as a sampling radius because it provided greater coverage of the entire stand area compared with a $50 \mathrm{~m}$ sampling radius. We included birds detected by sight and sound (excluding flyovers) for individual species and community statistical analyses. See Appendix 3-B for detection types used for each species.

\subsection{Salamander sampling}

We quantified salamander response to regeneration stands using a combination of artificial and natural cover objects on five block replicates at Beury Mountain WMA 
(BMWMA). We sampled at four points (Figure 3-2) within the control and HS treatments, the $\mathrm{CL}$ and $\mathrm{CW}$ treatments were not sampled for salamanders. We conducted three survey visits annually during 2017-2019. Visit 1 was 18 April-6 May, visit 2 was 6-16 May, and visit 3 was 17 June-2 August. Artificial coverboards at each point consisted of nine $(3 \times 3$ arrangement spaced $\sim 1 \mathrm{~cm}$ apart), $20.0 \times 10.0 \times 2.5 \mathrm{~cm}$ wooden boards cut from hardwood species from the region (American basswood [Tilia americana], American sycamore [Platanus occidentalis], and yellow poplar [Liriodendron tulipifera]). Coverboards were placed at points at least one month prior to sampling to allow them to weather (Hesed 2012). Natural cover objects included for sampling were logs or rocks that measured $\geq 40 \mathrm{~mm}$ at the narrowest dimension and occurred within a 5-m radius of each artificial coverboard location. All eligible natural cover object dimensions (length and width, in $\mathrm{mm}$ ) were measured prior to salamander sampling during the pre-harvest period. We marked natural cover objects with stake flags to maintain consistent sampling effort across visits and years. Use of a combination of artificial and natural cover objects for sampling can produce valid indices of terrestrial salamander populations (Smith and Petranka 2000).

We recorded species of each captured individual and measured snout-vent length (SVL, anterior edge of the snout to the distal end of the cloaca) to the nearest $0.1 \mathrm{~mm}$ using a dial caliper. We recorded body mass to the nearest $0.1 \mathrm{~g}$ using a Pesola spring scale. We clipped their tail to identify recaptures in subsequent sampling visits. We sprayed an antiseptic to the clipped tail to reduce risk of infection. We clipped the tail of each individual to identify recaptures in subsequent sampling visits and sprayed an antiseptic to the clipped tail to minimize risk of infection. Clippers were flame-sterilized with $95 \%$ ethanol to reduce potential disease transmission between captures. Salamanders were released at their original point of capture. Salamander sampling was conducted under methods approved by the WVDNR (permits 2016.143, 2017.104, 2018.110, and 2019.110) and the West Virginia University Institutional Animal Care and Use Committee (protocol 1602000305).

\subsection{Statistical analyses}

Ruffed grouse.-We provide summary statistics for ruffed grouse responses to regeneration stands because we had insufficient detections (20 total detections) to complete a statistical analysis with enough predictive power to warrant analyzing these data further. Sampling effort and a descriptive summary of ruffed grouse data are provided in results. 
Focal songbird abundance.-We estimated abundance of breeding songbird species in regeneration stands over time using a stacked Bayesian $N$-mixture model (Kéry and Royle 2016). This modeling approach estimates abundances for each species using count data while accounting for imperfect detection. Additionally, estimated abundances of species are allowed to vary from year-to-year making this a dynamic modeling approach. We included species with $\geq 40$ detections within $100-\mathrm{m}$ of the sampling point and $\geq 0.200$ estimated effective detection probability (i.e., probability of detecting an individual at least once across two annual survey visits). We fit two models for each songbird species. Model \#1 incorporated a regeneration stand treatment and time interaction and model \#2 incorporated a regeneration stand treatment main effect. Both models used the same detection-level sub-model but a different biological-level submodel. In our detection-level sub-model, we modeled probability of detecting an individual, conditional on true presence, using a Binomial process model. We modeled survey-level covariates (e.g., ordinal day, surveyor skill, and time since sunrise) thought to influence an observer's probability of detecting an individual on the logit-linear scale.

In our biological-level sub-model for both model \#1 and \#2, we modeled species abundance using a Poisson process model. For model \#1, we modeled expected abundance, $y_{i k}$, as a function of regeneration stand treatments with time and nuisance variables on the log-linear scale (Equation 1).

$$
\begin{aligned}
\log \left(y_{i k}\right)= & \beta_{0}+\beta_{1} \times t r t_{i k}+\beta_{2} \times C W_{i k}+\beta_{3} \times H S_{i k}+ \\
& \beta_{4} \times\left(\text { trt }_{i k} \times \text { time }_{i k}\right)+\beta_{5} \times\left(C W_{i k} \times \text { time }_{i k}\right)+ \\
& \beta_{6} \times\left(H S_{i k} \times \text { time }_{i k}\right)+\beta_{7} \times \text { elev }_{i}+ \\
& \beta_{8} \times \text { TRMI }_{i}+\text { rand.point }_{i}
\end{aligned}
$$

For model \#2, we modeled expected abundance, $\mathrm{y}_{\mathrm{ik}}$, as a function of regeneration stand treatments and nuisance variables. In model \#2, the variable time interacts the same with all regeneration stand treatments (Equation 2).

$$
\begin{aligned}
& \log \left(y_{i k}\right)= \beta_{0}+\beta_{1} \times \operatorname{trt}_{i k}+\beta_{2} \times C W_{i k}+\beta_{3} \times H S_{i k}+ \\
& \beta_{4} \times\left(\operatorname{trt}_{i k} \times \text { time }_{i k}\right)+\beta_{5} \times+ \text { elev }_{i} \\
& \beta_{6} \times \text { TRMI }_{i}+\text { rand.point } \\
&
\end{aligned}
$$


For both equations, $i$ references each sampling point location (i.e., individual regeneration stand) and $k$ references year. On the right-hand side of the equation, the pre-treatment period is included in the intercept $\left(\beta_{0}\right)$. This approach allows the control treatment across all years and the pretreatment year for all regeneration treatments (CL, CW, and HS) to be used as baseline values for comparison with one-year and two-year post-treatment data. The term $t_{t} t_{i k}$, corresponds to the $\mathrm{CL}$ treatment that was used as a reference treatment. The term $C W_{i k}$, corresponds to $\mathrm{CW}$ treatment, $H S_{i k}$ corresponds to HS treatment. The term $t_{i m e} e_{i k}$ was included as an interactive term with each treatment in model \#1 to allow the effect of time to vary for each treatment. In model \#2, time $_{i k}$ was included as an interactive term applied the same to all treatments. All factor levels were dummy coded with " 0 " or " 1 " depending on whether that factor level occurred at each point, except for the reference ( $\operatorname{trt}_{i k}$; i.e., CL treatment) which was dummy coded with a " 1 " unless it was the control treatment. Time was treated as a continuous variable with 0 , 1 , or 2 corresponding to pre-treatment, one-year post-treatment, or two-year post-treatment, respectively. Elevation $\left(e l e v_{i}\right)$ and TRMI $\left(T R M I_{i}\right)$ were included as nuisance predictor variables. We included a random point-count effect (rand.point $t_{i}$ ) to account for heterogeneity among points and repeated observations at the same point. Continuous variables were standardized to have a mean of 0 and standard deviation of one prior to analysis.

We used diffuse prior distributions for detection-level covariates (Gaussian distribution $[$ mean $=0$, variance $=100]$ ) and biological-level and nuisance covariates (Gaussian distribution $[$ mean $=0$, variance $=10]$ ). Diffuse covariate priors were used because we were uncertain of the relationships between treatments and songbird species. For our random point-count effect, we used a Gaussian distribution (mean $=0$, variance $=\tau$ ) prior with a hyperparameter $\tau$ from an inverse Gamma distribution $(\alpha=1, \beta=1)$. We obtained posterior distributions of model parameters by running three parallel MCMC simulations of 40000 iterations with a burn-in of 20000 iterations at a thinning rate of 100, yielding 600 samples for posterior distributions. We assessed model fit with a posterior check, where we compared Chi-square goodness-of-fit tests between an observed posterior predictive distribution and a simulated posterior predictive distribution. We calculated a Bayesian $p$-value, $p_{B}$, as the probability to obtain a simulated Chisquare test statistic that is at least as extreme as the observed Chi-square test statistic and assumed reasonable fit if $0.1<p_{B}<0.9$ (Gelman et al. 2014). Model convergence was assessed using the Brooks-Gelman-Rubin statistic and assumed adequate convergence when all parameter 
Rhat values <1.1 (Brooks and Gelman 1998). Data analyses were performed in R (R Core Team 2020) using a Bayesian framework in JAGS (Plummer 2017) called from the package jagsUI (Kellner 2015). We assessed model performance between the treatment-time interaction model (model \#1) and the main effects model (model \#2) using deviance information criterion (DIC).

For model \#1, we transformed model outputs using an inverse log-link and calculated expected abundance in each regeneration treatment in each year using Equation 1 terms. We calculated the log of the proportional change of abundance within each respective regeneration treatment at one-year post-treatment period and two-year post-treatment period against the pretreatment period and between cut-back border treatments within each time period, and assessed differences based on $95 \%$ credible intervals not overlapping 0. For model \#2, we transformed model outputs using an inverse log-link and calculated expected abundance in each regeneration treatment using Equation 2 terms. We calculated the log proportional change of expected abundance among regeneration treatments and assessed differences based on $95 \%$ credible intervals not overlapping 0.

Avian community richness. - We used a Bayesian generalized linear mixed-effects model (GLMM) to assess apparent species richness (species richness not accounting for imperfect detection of species) of avian guilds to regeneration stands through time. Richness was the total number of species detected at a point across the two visits annually. We categorized avian species into ecological guilds based on habitat (forest gap, forest interior, and young forest), nesting (primary cavity and secondary cavity), foraging substrate (bark), and conservation status (i.e., species of conservation priority). Species groupings were based on breeding biology of regional bird species and previous guild studies from the region (McDermott and Wood 2009, Farwell et al. 2016). We considered a species as conservation priority if it was listed by Appalachian Mountains Joint Venture (AMJV 2018), Partners-in-Flight Appalachian region Bird Conservation Region 28 (PIF 2019), or WVDNR State Wildlife Action Plan (WVDNR 2015; see Appendix 3-B for species status and guild association).

We modeled expected apparent species richness using Equation 1 (model \#1) and Equation 2 (model \#2), with the log expected apparent richness, $y_{i k}$, specified with a Poisson process model. We used diffuse prior distributions for the treatment levels and nuisance covariates (Gaussian distribution $[$ mean $=0$, variance $=10]$ ). Diffuse covariate priors were used because we were uncertain of the relationships between treatments and avian guilds. For our 
random point-count effect, we used a Gaussian distribution (mean $=0$, variance $=\tau)$ prior with a hyperparameter $\tau$ from an inverse Gamma distribution $(\alpha=1, \beta=1)$. We obtained posterior distributions of model parameters by running three parallel MCMC simulations of 40000 iterations with a burn-in of 20000 iterations at a thinning rate of 100, yielding 600 samples for posterior distributions. We assessed model fit with a posterior check, where we compared Chisquare goodness-of-fit tests between an observed posterior predictive distribution and a simulated posterior predictive distribution. We calculated a Bayesian $p$-value, $p_{B}$, as the probability to obtain a simulated Chi-square test statistic that is at least as extreme as the observed Chi-square test statistic and assumed reasonable fit if $0.1<p_{B}<0.9$ (Gelman et al. 2014). Model convergence was assessed using the Brooks-Gelman-Rubin statistic and assumed adequate convergence when all parameter Rhat values <1.1 (Brooks and Gelman 1998). Data analyses were performed in R (R Core Team 2020) using a Bayesian framework in JAGS (Plummer 2017) called from the package jagsUI (Kellner 2015). We assessed model performance between the treatment-time interaction model (model \#1) and the main effects model (model \#2) using DIC.

For model \#1, we transformed model outputs using an inverse log-link and calculated expected apparent species richness in each regeneration treatment in each year using Equation 1 terms. We calculated the log of the proportional change of richness within each respective regeneration treatment at one-year post-treatment period and two-year post-treatment period against the pre-treatment period and between cut-back border treatments within each time period, and assessed differences based on $95 \%$ credible intervals not overlapping 0. For model \#2, we transformed model outputs using the inverse log-link and calculated apparent species richness in each regeneration treatment using Equation 2 terms. We calculated the log proportional change of expected richness among regeneration treatments and assessed differences based on $95 \%$ credible intervals not overlapping 0 .

Salamander surface relative abundance.-We estimated surface relative abundance of eastern red-backed salamanders (Plethodon cinereus) in regeneration stands over time using a Bayesian GLMM. We estimated surface relative abundance because terrestrial salamanders spend the majority of their time underground and we did not incorporate detection probability into the analysis. We performed analysis only on eastern red-backed salamanders because they comprised the majority of captures $(78 \%)$ during the study. We treated capture data at the four 
sampling plots within a single regeneration stand as independent because of the small home range size of terrestrial salamanders (Kleeberger and Werner 1982). We used total captures across the three visits (excluding recaptures) at each sampling plot within a sampling year in analysis.

We modeled expected relative abundance using a Poisson process model. We modeled expected abundance, $y_{i k}$, as a function of regeneration stand treatments with time and nuisance variables on the log-linear scale (Equation 3),

$$
\begin{aligned}
\log \left(y_{i k}\right)= & \beta_{0}+\beta_{1} \times H S_{i k}+\beta_{3} \times\left(H S_{i k} \times \text { time }_{i k}\right)+ \\
& \beta_{4} \times \text { elev }_{i}+\beta_{5} \times \text { TRMI }_{i}+\beta_{6} \times \text { Cover }_{i}+ \\
& \text { rand.point }
\end{aligned}
$$

where $i$ references each sampling point location (i.e., individual regeneration stand) and $k$ references year. On the right-hand side of the equation, the pre-treatment period is included in the intercept $\left(\beta_{0}\right)$. This approach allows the control treatment across all years and the pretreatment year for the HS treatment to be used as baseline values for comparison with one-year and two-year post-treatment data. The term $H S_{i k}$ corresponds to HS treatment. The term time $i k$ was included as an interactive term to limit the effect of time to the HS treatment. Factor levels were dummy-coded with " 0 " or " 1 " depending on whether that factor level occurred at each point. Time was treated as a continuous variable with 0,1 , or 2 corresponding to pre-treatment, one-year post-treatment, or two-year post-treatment, respectively. Elevation $\left(e l e v_{i}\right)$, TRMI $\left(T R M I_{i}\right)$, and number of cover objects $\left(\right.$ Cover $\left._{i}\right)$ were included as nuisance predictor variables. We included a random sampling point effect (rand.point ${ }_{i}$ ) to account for heterogeneity among points. Continuous variables were standardized to have a mean of 0 and standard deviation of one prior to analysis.

We used diffuse prior distributions for factor levels and nuisance covariates (Gaussian $[$ mean $=0$, variance $=10])$. Diffuse covariate priors were used because we were uncertain of the relationships between treatments, topography, and elevation variables and eastern red-backed salamanders. For our random point effect, we used a Gaussian distribution ( $m e a n=0$, variance $=$ $\tau)$ prior with a hyperparameter $\tau$ from an inverse Gamma distribution $(\alpha=1, \beta=1)$. We obtained posterior distributions of model parameters by running three parallel MCMC simulations of 20000 iterations with a burn-in of 10000 iterations at a thinning rate of 100, yielding 300 
samples for posterior distributions. We assessed model fit with a posterior predictive check, where we compared Chi-square goodness-of-fit tests between an observed posterior distribution and a simulated posterior predictive distribution. We calculated a Bayesian $p$-value, $p_{B}$, as the probability to obtain a simulated Chi-square test statistic that is at least as extreme as the observed Chi-square test statistic and assumed reasonable fit if $0.1<p_{B}<0.9$ (Gelman et al. 2014). Model convergence was assessed using the Brooks-Gelman-Rubin statistic and assumed adequate convergence when all parameter Rhat values <1.1 (Brooks and Gelman 1998). Data analyses were performed in $\mathrm{R}$ (R Core Team 2020) using a Bayesian framework in JAGS (Plummer 2017) called from the package jagsUI (Kellner 2015).

We transformed model outputs using an inverse log-link and calculated expected relative abundance in each regeneration treatment in each year using Equation 2 terms. We calculated the $\log$ of the proportional change of relative abundance values within the HS treatment at one-year post-treatment period and two-year post-treatment period against the pre-treatment period, and assessed differences based on $95 \%$ credible intervals not overlapping 0 .

Salamander body condition.-We assessed body condition index (BCI) of eastern redbacked salamanders in the control and HS treatments over time using a Bayesian GLMM. We calculated BCI by regressing the natural logarithm of body mass on the natural logarithm of SVL and using the residuals as the BCI values for each individual following Gabor (1995).

We modeled expected BCI with a Gaussian process model using Equation 3. We used diffuse prior distributions for the process model variance (variance $=\tau$ ) and the factor levels and nuisance variables (Gaussian distribution $[$ mean $=0$, variance $=10]$ ). For our random point effect, we used an inverse Gaussian distribution $($ mean $=0$, variance $=\tau)$ prior with a hyperparameter $\tau$ from a Gamma distribution $(\alpha=1, \beta=1)$. We obtained posterior distributions of model parameters by running three parallel MCMC simulations of 20000 iterations with a burn-in of 10000 iterations at a thinning rate of 100, yielding 300 samples for posterior distributions. We assessed model fit with a posterior predictive check, where we compared Chisquare goodness-of-fit tests between an observed posterior distribution and a simulated posterior predictive distribution. We calculated a Bayesian $p$-value, $p_{B}$, as the probability to obtain a simulated Chi-square test statistic that is at least as extreme as the observed Chi-square test statistic and assumed reasonable fit if $0.1<p_{B}<0.9$ (Gelman et al. 2014). Model convergence was assessed using the Brooks-Gelman-Rubin statistic and assumed adequate convergence when 
all parameter Rhat values <1.1 (Brooks and Gelman 1998). Data analyses were performed in $\mathrm{R}$ (R Core Team 2019) using a Bayesian framework in JAGS (Plummer 2017) called from the package jagsUI (Kellner 2015).

We calculated the change of expected BCI values in each regeneration treatment in each year using Equation 2 terms. We calculated the change of expected BCI values within the HS treatment at one-year and two-year post-treatment period against the pre-treatment period, and assessed differences based on $95 \%$ credible intervals not overlapping 0 .

Cost-benefit analysis. - We used a weighted analysis to define management objectives in order to evaluate the cost of treatment versus the benefit of maximizing songbird richness in regeneration stand treatments. The management objectives for the weighted analysis were to maximize young forest habitat guild species richness, maximize forest interior habitat guild species richness, maximize cavity (primary and secondary) nesting guild species richness, maximize richness of species of conservation priority, and minimize cost. We did not include bark foragers into the objectives because of the overlap this guild has with the cavity nesting guild. A salamander objective was not included for this analysis because sampling only occurred in the control and HS treatments.

In our cost-benefit analysis, we scored the benefit of maximizing species richness of multiple avian guilds objective and the cost of implementing treatment objective for each regeneration treatment and compared each treatment with other regeneration treatments. This approach is different from a traditional cost-benefit analysis, where we would measure and score the benefits of a single decision/action minus the costs associated with that decision/action and then compare each respective score with other decisions/actions under consideration. Our costbenefit analysis approach follows other wildlife studies that have compared multiple mitigation strategies and their effects on some index (e.g., species richness, number of mortalities) as a benefit for multiple species while minimizing cost of implementation (Huijser et al. 2009, Siemers et al. 2015). We used this approach for the cost-benefit analysis because it allows for multiple benefits and/or costs objectives to generate a score for comparison with other regeneration treatments. For each regeneration stand treatment, we evaluated guild responses and cost. Guild richness (i.e., performance scores) within each regeneration treatment across both post-treatment years (Table 3-3) were calculated from 300 posterior draws using Equation 2 terms. Cutting and herbicide costs per ha (Table 3-3) were provided by WVDNR and the 
Wildlife Management Institute (WMI). We used a generalized multi-method tradeoffs approach to rank and weight each management objective in order to compare regeneration stand treatments (Gregory et al. 2012). We assigned weights for each objective as young forest species richness = 0.28 , species of conservation priority species richness $=0.21$, cost $=0.20$, forest interior species richness $=0.18$, and cavity nesting species richness $=0.14$. We derived weight values of objectives using a three-step process, where in step 1 we assigned initial objective ranking priority from 1 to 6 , with rankings $1-5$ being the objectives from highest to lowest importance and $6=$ hypothetical baseline where no management objectives are maximized. Rankings were as follows: 1 = young forest species richness, 2 = species of conservation priority species richness, 3 = cost, 4 = forest interior species richness, and $5=$ cavity nesting species richness. In step 2 we used priority rankings to assign relative swing weights to each management objective, giving " 100 " to rank 1 and " 0 " to rank 6 with all other rankings receiving a value between 1 and 99 based on relative importance. Relative swing weights were as follows: young forest species = 100 , species of conservation priority $=75$, cost $=70$, forest interior species $=65$, cavity nesting species $=50$, and hypothetical baseline $=0$. Lastly, in step 3 we normalized relative swing weights to obtain weight values. We calculated the normalized performance score (NPS) of each cell in row $x$ and column $y$ (Table 3-4) using Equation 4,

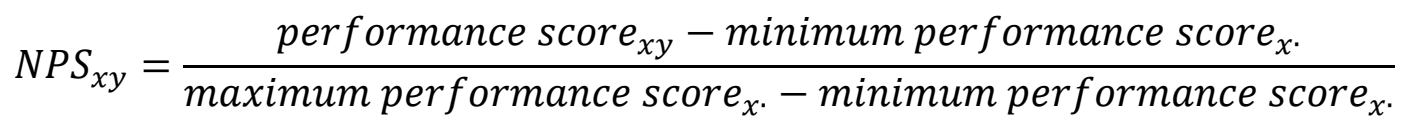

for each of the 300 posterior draws where performance scores are referenced by row $x$ and column $y$ in Table 3-3. The weighted utility sum (WUS) for each posterior draw of each regeneration stand treatment was the sum of the product of normalized performance scores in Table 3-4 and weights.

\section{Results}

\subsection{Vegetation}

Following treatment, live and dead basal area and overstory cover were negligible in CL and CW treatments (Table 3-5). In the HS treatment, mean live basal area was reduced from 19

$\mathrm{m}^{2} /$ ha at pre-treatment to $11 \mathrm{~m}^{2} /$ ha at two-year post-treatment and mean dead basal area increased from $1 \mathrm{~m}^{2} /$ ha at pre-treatment to $4 \mathrm{~m}^{2} /$ ha at two-year post-treatment. Overstory cover in the HS treatment was reduced from $93 \%$ at pre-treatment to $66 \%$ and $65 \%$ at one-year and 
two-year post-treatment, respectively. Understory cover 0-1 m increased annually at similar levels from pre-treatment to two-year post-treatment in CL, CW, and HS treatments (77 to 96\%, 70 to $97 \%$, and 75 to $92 \%$ in CL, CW, and HS, respectively). However, understory cover $>1-2 \mathrm{~m}$ only increased in the CL and CW treatments by two-year post-treatment (60 to 87\%, 54 to $82 \%$, and 63 to $66 \%$ in the CL, CW, and HS, respectively).

\subsection{Ruffed grouse}

We conducted 340 grouse drumming surveys during the study and detected 20 grouse. Mean number of detections varied little across time for three of the treatments (Table 3-6). Mean detections increased over time in the HS treatment, with 0.1 detections/plot during pre-treatment and 0.4 detections/plot during two-year post-treatment.

\subsection{Focal songbird abundance}

We conducted a total of 338 avian point-counts over the course of the study period and detected a total of 98 species. Of the 21 species that met the detection criteria ( $\geq 40$ detections), 13 species also met the estimated effective detection probability criteria ( $\geq 0.200$; Appendix 3-B).

Of these 13 species, four were from the young forest guild (chestnut-sided warbler, common yellowthroat, eastern towhee, and indigo bunting), three were from the forest gap guild (blackthroated green warbler, hooded warbler, and red-eyed vireo), and four were from the forest interior guild (black-and-white warbler, blue-headed vireo, ovenbird, and tufted titmouse). Our posterior predictive checks indicated all individual species models were a reasonable fit (Appendix 3-C).

Of the 13 species analyzed, six responded positively to one regeneration stand treatment and four responded negatively to one regeneration stand treatment. Abundances of all four young forest species analyzed increased in the CL from pre-treatment to one-year or two-year posttreatment (Figure 3-3) while blue-headed vireo and ovenbird (both forest interior species) abundances decreased from pre-treatment to two-year post-treatment (Figure 3-4). In the HS treatment, blue-headed vireo and ovenbird (both forest interior species,) abundances increased from pre-treatment to one-year or two-year post-treatment (Figure 3-4) while eastern towhee and indigo bunting (both young forest species) abundances decreased from pre-treatment to one-year and two-year post-treatment (Figure 3-3). No forest gap species responded positively or negatively to regeneration stand treatments (Figure 3-5). 
The main effect of regeneration treatments had a strong influence on four species. Eastern towhee and indigo bunting abundances were higher in the CL than the HS and control, and abundances in the CW where higher than HS treatment (Figure 3-6). Abundance of common yellowthroat was higher in the CW than control (Figure 3-6). Ovenbird abundance was higher in the HS than the CL, CW, and control, while abundance in the control was higher than the CL (Figure 3-6). No forest gap species were strongly influenced by regeneration treatment main effects.

\subsection{Avian community richness}

Our posterior predictive checks indicated all avian guild models were a reasonable fit (Appendix 3-C). Species richness of two of the three habitat guilds, the primary and secondary cavity nesting guilds, and the bark foraging guild were strongly influenced by regeneration stand treatment. In the CL treatment, richness of the young forest guild increased from pre-treatment to one-year and two-year post-treatment (Figure 3-7) while richness of forest interior habitat guild (Figure 3-7) and secondary cavity nesting guild (Figure 3-8) decreased by two-year posttreatment. In the HS treatment, species richness of the forest interior habitat guild, primary and secondary cavity nesting guilds, and bark foraging guild increased from pre-treatment to twoyear post-treatment (Figures 3-7 and 3-8). Species richness of the young forest habitat guild decreased in the HS treatment from pre-treatment to one-year and two-year post-treatment (Figure 3-7). Species richness of the forest gap habitat guild (Figure 3-7) and species of conservation priority group (Figure 3-8) were not strongly influenced by regeneration stand treatments over time.

The main effect of regeneration treatments had a strong influence on one habitat guild and two avian guilds. Species richness of the young forest habitat guild was higher in the CL treatment than the HS and control treatments, and higher in the CW treatment than the HS treatment (Figure 3-9). Species richness of the primary cavity nesting guild and bark foraging guild were higher in the HS treatment than the control treatment (Figure 3-9), while richness of the bark foraging guild was also higher in the HS treatment than the CL treatment (Figure 3-9).

\subsection{Salamander surface relative abundance and body condition index}

We captured a total of 274 salamanders of six species during the study period (Appendix 3-D), with 213 (78\%) being eastern red-backed salamanders. Our posterior predictive check 
indicated our relative abundance and body condition index models were a reasonable fit (Appendix 3-C). Relative abundance of eastern red-backed salamanders increased in the HS treatment from pre-treatment to one-year post-treatment but was not different from pre-treatment to two-year post-treatment (Figure 3-10). Body condition index of eastern red-backed salamanders decreased in the HS treatment from pre-treatment to one-year post-treatment then increased at two-year post-treatment (Figure 3-11).

\subsection{Cost-benefit analysis}

Species richness of the young forest habitat guild and species of conservation concern was maximized in the CL treatment. The HS treatment maximized forest interior habitat guild and cavity nesting guild species richness. Performance of cost was maximized in the control treatment and minimized in the CW (Table 3-4). Based on the cost-benefit analysis, weighted utility sum (WUS) for CL was the optimum treatment (WUS [lower and upper 95\% credible intervals $]=0.63[0.33,0.85])$, followed by control (WUS $=0.52[0.37,0.67])$, HS $($ WUS $=0.33$ $[0.11,0.54]$ ), and CW (WUS = $0.30[0.06,0.57]$; Table 3-4).

\section{Discussion}

Based on a scenario of evenly distributed forest age classes, current forest conditions throughout much of West Virginia and the central Appalachian region indicate young forest deficit throughout the region (Shifley and Thompson III 2011). Due to young forest habitat being largely created via commercial logging, management and conservation of young forest wildlife relies heavily on forest stands of high economic value. Measures that incorporate poor quality forestlands into timber sales and habitat management plans will be needed in order to reduce the young forest deficit and meet conservation objectives for young forest wildlife. Here we have assessed three non-commercial young forest management treatments and their effects on birds and salamanders. Additionally, we examined the tradeoffs between maximizing bird responses and minimizing cost of young forest treatments to assist managers in their decision-making when developing wildlife management guidelines.

\subsection{Wildlife response to regeneration stands}

Implementation of regeneration treatments induced a dichotomous response from the avian community. Young forest species responded positively to the CL treatment and negatively 
to the HS treatment, while forest interior and cavity nesting species generally responded positively to the HS treatment and negatively to the CL treatment. Guild richness responses followed similar trends. Additionally, the eastern red-backed salamander, a terrestrial salamander most suited to forest interiors, responded positively to the HS treatment immediately following treatment although BCI was reduced during this period.

Abundance and species richness of the young forest guild increased in the CL and decreased in the HS following treatment from both the treatment-time interaction model (model \#1) and main effects model (model \#2). Positive responses by young forest species in the CL were likely driven by the complete removal of live and dead basal area, which stimulated vegetation growth in the understory, particularly for understory vegetation $>1-2 \mathrm{~m}$, and created habitat conditions favorable for foraging and breeding. Vegetation response to treatment was not immediate however, as understory vegetation $>1-2 \mathrm{~m}$ had generally similar amounts across CL, $\mathrm{CW}$, and HS treatments at one-year post-treatment likely reflecting a stronger time effect than treatment effect. The deviation of understory vegetation levels among treatments was more noticeable at two-year post-treatment, likely due to treatment differences (Table 3-5). The partial harvest of live basal area in the HS elicited vegetation growth in the understory at two-year posttreatment, but not to the extent we observed in the CL treatment (Table 3-5). The differences in the understory vegetation, particularly for the >1-2 m stratum, between CL and HS likely contributed to the differences in responses of young forest species in these two treatments. Partial harvesting approaches similar to the HS (e.g., shelterwood) do create vegetation conditions suitable for young forest species immediately following treatment and we expected similar responses to occur in our study (Duguay et al. 2001, Perry et al. 2013, Sheehan et al. 2014, Greenberg et al. 2014). However, the HS treatment may not have created enough canopy openness to induce immediate understory vegetation growth and create suitable habitat conditions for young forest species at one-year and two-year post-treatment. Another possible explanation for the lack of response from young forest species to the HS may be the lack of coarse woody debris (CWD) following treatment, which can provide cover for many young forest species (Lohr et al. 2002).

Arrangement of CWD can also affect the distribution of young forest species within a stand (Grodsky et al. 2016). The CL and CW treatments both received complete removal of live and dead basal area and understory vegetation levels were comparable at one-year and two-year 
post-treatment. However, our main effects analyses indicated only the common yellowthroat had higher abundances in the $\mathrm{CW}$ while eastern towhee and indigo bunting abundances and young forest habitat guild richness were higher in the CL. Our treatment-time interaction results (Figures 3-3 and 3-9) were consistent with these findings, indicating habitat suitability increased in the $\mathrm{CL}$ and remained consistent in the $\mathrm{CW}$ following treatment, relative to the control. Creating large CWD piles or windrows, like in the CW treatment, can create suitable nesting areas for a suite of young forest species that nest in brush piles (e.g., Carolina wren, eastern towhee; Grodsky et al. 2016). However, wood piles can also attract avian nest predators (e.g., snakes, rodents) which may reduce reproductive output of species and the concentration of wood piles likely reduces plant regeneration throughout the stand via greater browse pressure (Murray et al. 2016, Sullivan et al. 2017). Additionally, construction of wood piles via heavy machinery likely damaged understory vegetation which could negatively affect young forest species. Contrary to the CW treatment, CWD in the CL treatment was evenly distributed throughout the stand.

Live basal area in HS treatments was reduced on average from $19 \mathrm{~m}^{2} /$ ha at pre-treatment to $11 \mathrm{~m}^{2} /$ ha at two-year post-treatment (Table 3-5) but this did not appear to significantly reduce habitat suitability, relative to the control, for forest interior species. Further, some forest interior species responded positively to this treatment likely due to the retention of canopy trees. While live basal area was reduced in the HS treatment, all canopy trees (both live and dead) were retained in this treatment. This may help lessen the negative effects of forest disturbances on forest interior species. Additionally, partial canopy removal treatments (e.g., shelterwood) typically retain some level of forest interior species following harvest (Newell and Rodewald 2012, Greenberg et al. 2014), particularly those that use canopy gaps (Sheehan et al. 2014). Consequently, we had expected to see a positive response from gap-associated species to the HS, but this treatment did not appear to strongly, positively influence abundances or species richness of this group. This could be due to the small reduction of live basal area in the HS following treatment not creating sufficiently-sized canopy gaps (Sheehan et al. 2014). Nareff et al. (2019) reported cerulean warbler, a forest gap species, exhibited more rapid decreases in abundance in lighter intensity silviculture harvests than heavier intensity harvests, likely due to the smallersized canopy gaps in lighter intensity stands limiting habitat suitability for this species. A similar response may be occurring in the HS treatments, indicating more extensive tree kill in the HS is 
necessary to increase habitat suitability for forest gap species. Interestingly, forest interior species responded negatively to the CL but not the $\mathrm{CW}$ at the two-year post-treatment period. Both CL and CW removed all live and dead basal area within their stands, thus eliminating canopy trees and mature forest conditions for this group of species (Table 3-5). One factor that could affect species responses is the peripheral mature forest at CL and CW stand edges (Duguay et al. 2001) but we did not assess this effect. To capture influence of edge habitats, we used species detections $<100 \mathrm{~m}$ from surveyor. Therefore, responses we observed in the CL and CW treatments on forest interior species may be due to factors in the mature forest beyond the stand boundary. Regardless, the HS was the most effective treatment, besides the control, that we evaluated for increasing abundance and richness of forest interior avian species.

Similar to the forest interior avifauna, eastern red-backed salamander relative abundance responded positively to the HS treatment at one-year post-treatment (no salamander sampling occurred in the CL or CW treatments). This is surprising considering canopy cover was reduced in the HS without any habitat mitigation via CWD input. Canopy openness inhibits drier forest floor microclimate conditions which conflicts with terrestrial salamander physiology (Brooks and Kyker-Snowman 2008, Hillman et al. 2009). However, partial harvesting techniques (e.g., shelterwood) typically retain some level of forest floor CWD, which constitutes important surface refugia, to help salamanders cope with changes at the forest floor microclimate following harvest (Peele et al. 2017). Despite mitigation via CWD, terrestrial salamanders are often negatively affected by shelterwood harvests (Harpole and Haas 1999, Duguay and Wood 2002). It would follow that in the HS, which did not create any CWD, eastern red-backed salamanders would decrease in relative abundance following treatment. This was not the case however, as relative abundance increased in the HS following treatment, although relative abundance returned to levels similar to pre-treatment at the two-year post-treatment period. Abundance of eastern red-backed salamanders was inversely related to $\mathrm{BCI}$ at the one-year and two-year posttreatment periods. This indicates that while there were more individuals at the surface for capture in the HS at one-year post-treatment, these individuals had poor body condition relative to individuals captured during pre-treatment and in the control. Lower BCI in individuals could result from reduced food availability at the surface, which forces individuals to remain at the surface for longer periods in order to meet their energy demands. This could be from increased canopy openness following treatment which dried out the leaf litter and soil where this species 
primarily forages. The decrease in relative abundance and increase in BCI in the HS at two-year post-treatment could indicate an increase in habitat suitability during this period, which could be due to understory vegetation growth shading the forest floor and retaining leaf litter and soil moisture. Future monitoring could elucidate these questions to determine whether this partial harvesting approach is suitable for eastern red-backed salamander populations.

Primary and secondary cavity nesters and bark foragers responses to regeneration treatments for this study were of high priority, particularly the HS treatment. One factor for this is that snags constitute important foraging and nesting substrate for cavity nesting and bark foraging species but also provide habitat structures for small mammals, invertebrates, and fungi (Cockle et al. 2011, Garrick et al. 2019). Further, woodpeckers, which make up the majority of primary cavity nesters and bark foragers, are good indicators of forest bird diversity (Mikusiński et al. 2001, Drever et al. 2008). We observed increased species richness of the primary and secondary cavity nesting guilds and bark foraging guild in the HS treatment at the two-year posttreatment period, likely due to the increase in snag basal area (Table 3-5). The increase in snags in the HS (4\% of canopy trees at pre-treatment and 38\% at two-year post-treatment) likely increased food resources for bark foragers and nesting trees for cavity nesters. The increase in snags in HS treatment also likely created important habitat for small mammals, invertebrates, fungi, and other taxa, although we did not test this and thus can make no definitive conclusions (Payer and Harrison 2005, Wermelinger et al. 2017). Further monitoring of the HS treatment to assess snag dynamics for cavity nesting and bark foraging species and to assess understory vegetation growth for young forest species will help managers determine if the HS technique offers a long-term suitable approach for managing forest avifauna with different vegetation requirements.

Based on our cost-benefit analysis, the CL treatment (weighted utility sum [WUS] = 0.70) was the optimum regeneration treatment to meet our management objectives of maximizing species richness and minimizing cost of habitat management. High WUS in the CL was due to high performance of young forest species and species of conservation priority (Table 3-3). The control treatment performed well meeting the cost and species of conservation priority management objectives and received a WUS $=0.48$, indicating that no forest manipulation can still meet objectives set by managers. The HS treatment performed well meeting the forest interior and cavity nesting objectives (Table 3-4), however these were given lower weights and 
therefore HS received a WUS $=0.38$. The CW (WUS $=0.28)$ met the cavity nesting species objective well, most likely due to secondary cavity nesting species responding to this treatment (Figure 3-7).

\section{Management Implications}

Avian species responses to regeneration treatments were dichotomous and followed predictable patterns. Young forest species were positively influenced by the CL treatment and negatively influenced by the HS treatment, while forest interior and cavity nesting species were positively influenced by the HS treatment and negatively influenced by the CL treatment. Managing for young forest species can negatively affect species associated with mature, undisturbed forests and this was evident in the CL treatment. However, partial harvest techniques, like shelterwood harvests, have been shown to reduce species composition turnover by retaining some level of forest interior species while creating understory vegetation features suitable for young forest species (Sheehan et al. 2014, Perry et al. 2018). We hypothesized that young forest and forest gap species would positively respond to the canopy openness created in the HS treatment, but individual young forest species and the community responded negatively to treatment and forest gap response was negligible. Increased understory vegetation growth via greater reduction of live basal area in the HS will likely increase understory cover for young forest species while providing larger canopy gaps for forest gap species and higher snag densities for cavity nesting species. However, this measure will likely reduce the habitat suitability of the HS for forest interior species. Future monitoring of the HS will provide interesting insight into whether managers can simultaneously promote vegetation features suitable for young forest, forest gap, forest interior, and cavity nesting/bark foraging avian species.

Determining appropriate non-commercial young forest management measures is something that needs to be considered on poor quality sites to ensure future forest resiliency and promote diversity (Gunn et al. 2019). Non-commercial wildlife habitat management is used by agencies, but little empirical evidence exists on a most appropriate and cost-effective approach for creating habitat. The CL treatment benefitted young forest species and retained all CWD to provide better growing conditions and fewer plant regeneration barriers (i.e., deer browse) than treatments like the HS, but also displaced forest interior and cavity nesting species. The CW did not perform well in maximizing species richness and was the most expensive treatment to implement. The $\mathrm{CW}$ appears to be the least effective regeneration stand treatment for meeting 
our management objectives. Ultimately, it depends on the short- and long-term objectives of the manager. The CL provided short-term benefits to young forest species, a group of high conservation interest, and may produce merchantable timber in the long-term. The HS provides short-term and likely long-term benefits to cavity nesting/bark foraging species and forest interior birds and salamanders. Higher costs of the CL treatment should certainly be considered when deciding what non-commercial approach to use, but incorporating small, non-commercial management stands into larger commercial timber sales may alleviate these expenditures. The incorporation of poor-quality forestlands into management plans will help reduce the young forest deficit in West Virginia and the central Appalachian region and provide important habitat for young forest wildlife communities.

Despite the usefulness of cost-benefit analysis for evaluating multiple benefit/cost objectives for managers, there are limitations to this approach. We simplified the management objectives into four biological and one economic objective but there are often a myriad of objectives that managers need to consider (e.g., retaining biological legacies, other taxa responses to management). Further, we did not incorporate the cost of non-native, invasive plant management into the cost of management, which will likely affect the long-term management goals of these treatments. When managers are confronted with a higher likelihood of invasive species spread following treatment further assessment is needed to incorporate the necessary long-term maintenance of invasive species into the cost-benefit analysis. If consideration is not given to potential invasive species spread following treatment (something that was not done here because we did not have the necessary information) then cost of treatment is likely to be underestimated and will limit the effectiveness of a cost-benefit analysis for assessing management objectives. Another limitation of the cost-benefit analysis is that some performance measures are not easily quantified and therefore are difficult to put into any analysis (e.g., public response, future stand value). There is also a level of subjectivity when ranking the importance weights of each management objective. These weights are likely to vary across space (e.g., different wildlife management areas) and time (e.g., invasive plant spread and subsequent wildlife response), and among natural resource experts. To fix this, greater involvement of agency personnel and interest groups to help in developing importance weights is likely to ensure any subjectivity is reduced to some extent. 
Continued monitoring of treatments will provide important information about the effectiveness of regeneration stands to manage wildlife populations. Notably, continued monitoring of the HS treatment to determine whether this regeneration technique can simultaneously provide habitat for young forest species while retaining key habitat features for cavity nesting and bark foraging species will assist managers conserve both groups of species. Future research studies evaluating different non-commercial, young forest habitat management treatments and their associated costs and wildlife responses will be necessary to continue to reduce the young forest deficit in the region. This information will provide a broader range of options for land managers to suit their site-specific needs. Additionally, assessing the effectiveness of other non-commercial treatments to replicate or retain habitat features (e.g., snags, high stem densities) considered important for species or groups of interest (similar to our HS treatment) will be important when managing poorly-stocked forest stands for wildlife populations. 


\section{Literature Cited}

AMJV (Appalachian Mountains Joint Venture). 2018. AMJV Priority Landbirds. https://amjv.org/priority-species/

Backhouse, F., and J.D. Louiser. 1991. Silviculture systems research: wildlife tree problem analysis. B.C. Ministry of Forests and B.C. Ministry of Environment, Wildlife Tree Committee, Victoria, B.C.

Bibby, C.J., N.D. Burgess, D.A. Hill, and S.H. Mustoe. 2002. Bird Census Techniques, $2^{\text {nd }}$ edition. Academic Press, London, UK. 302 p.

Brooks, S.P., and A. Gelman. 1998. General methods of monitoring convergence of iterative simulations. Journal of Computational and Graphical Statistics 7 (4): 434-455.

Brooks, R.T., and T.D. Kyker-Snowman. 2008. Forest floor temperature and relative humidity following timber harvesting in southern New England, USA. Forest Ecology and Management 254:65-73. http://doi.org/10.1016/j.foreco.2007.07.028

Bütler, R., T. Lachat, L. Larrieu, and Y. Paillet. 2013. Habitat trees: key elements for forest biodiversity. Pages 84-91 in D. Kraus and F. Krumm (eds.) Integrate approaches as an opportunity for the conservation of forest biodiversity.

Cockle, K.L., K. Martin, and G. Robledo. 2012. Linking fungi, trees, and hole-using birds in a Neotropical tree-cavity network: pathways of cavity production and implications for conservation. Forest Ecology and Management 264: 210-219. http://doi.org/10.1016/j.foreco.2011.10.015

Cockle, K.L., K. Martin, and T. Wesolowski. 2011. Woodpeckers, decay, and the future of cavity-nesting vertebrate communities worldwide. Frontiers in Ecology and the Environment 9 (7): 377-382. http://doi.org/10.1890/110013

Cohen, W.B., Z. Yang, S.V. Stehman, T.A. Schroeder, D.M. Bell, J.G. Masek, C. Huang, and G.W. Meigs. 2016. Forest disturbance across the conterminous United States from 19852012: the emerging dominance of forest decline. Forest Ecology and Management 360: 242-252. http://doi.org/10.1016/j.foreco.2015.10.042

DeGraaf, R.M., and M. Yamasaki. 2003. Options for managing early-successional forest and shrubland bird habitats in the northeastern United States. Forest Ecology and Management 185: 179-191. http://doi.org/10.1016/S0378-1127(03)00254-8

Demarais, S., J.P. Verschuyl, G.J. Roloff, D.A. Miller, and T.B. Wigley. 2017. Tamm review: Terrestrial vertebrate biodiversity and intensive forest management in the U.S.. Forest Ecology and Management 385: 308-330. http://doi.org/10.1016/j.foreco.2016.10.006 
Dey, D.C. 2014. Sustaining oak forests in eastern North America: Regeneration and recruitment, the pillars of sustainability. Forest Science 60 (5): 926-942.

http://doi.org/10.5849/forsci.13-114

Drever, M.C., K.E.H. Aitken, A.R. Norris, and K. Martin. 2008. Woodpeckers as reliable indicators of bird richness, forest health and harvest. Biological Conservation 141 (3): 624-634. http://doi.org/10.1016/j.biocon.2007.12.004

Duguay, J.P., and P.B. Wood. 2002. Salamander abundance in regenerating forest stands on the Monongahela National Forest, West Virginia. Forest Science 48 (2): 331-335. http://doi.org/10.1093/forestscience/48.2.331

Duguay, J.P., P.B. Wood, and J.V. Nichols. 2001. Songbird abundance and avian nest survival rates in forests fragmented by different silvicultural treatments. Conservation Biology 15 (5): 1405-1415. http://doi.org/10.1111/j.1523-1739.2001.99023.x

ESRI (Environmental Systems Research Institute). 2014. ArcGIS Desktop: Release 10.3. Redlands, CA.

Eberhardt, L.L. 1976. Quantitative ecology and impact assessment. Journal of Environmental Management 4 (1).

Farwell, L.S., P.B. Wood, J. Sheehan, and G.A. George. 2016. Shale gas development effects on the songbird community in a central Appalachian forest. Biological Conservation 201: 78-91. http://doi.org/10.1016/j.biocon.2016.06.019

Fettinger, J.L. 2002. Ruffed grouse nesting ecology and brood habitat in western North Carolina. Thesis. University of Tennessee, Knoxville, Tennessee, USA.

Harpole, D.N., and C.A. Haas. 1999. Effects of seven silvicultural treatments on terrestrial salamanders. Forest Ecology and Management 114: 349-356. http://doi.org/10.1016/S0378-1127(98)00365-X

Hachè, S., T. Pètry, and M.-A. Villard. 2013. Numerical response of breeding birds following experimental selection harvesting in northern hardwood forests. Avian Conservation and Ecology 8 (1): 4. http://doi.org/10.5751/ACE-00584-080104

Hesed, K.M. 2012. Uncovering salamander ecology: a review of coverboard design. Journal of Herpetology 46 (4): 442-450. http://doi.org/10.1670/10-220

Hillman, S.S., P.C. Withers, R.C. Drewers, and S.D. Hillyard. 2009. Ecological and Environmental Physiology of Amphibians. Oxford University Press, New York, NY, USA. 469 p. 
Huijser, M.P., J.W. Duffield, A.P. Clevenger, R.J. Ament, and P.T. McGowen. 2009. Costbenefit analysis of mitigation measures aimed at reducing collisions with large ungulates in the United States and Canada: a decision support tool. Ecology and Society 14 (2): 15.

Gabor, C.R. 1995. Correlational test of Mathis' hypothesis that bigger salamanders have better territories. Copeia 3: 729-735.

Garrick, R.C., D.K. Reppel, J.T. Morgan, S. Burgess, C. Hyseni, R.J. Worthington, and M.D. Ulyshen. 2019. Trophic interactions among dead-wood-dependent forest arthropods in the southern Appalachian Mountains, USA. Food Webs 18: e00112.

Gelman, A., J.B. Carlin, H.S. Stern, D.B. Dunson, A. Vehtari, and D.B. Rubin. 2014. Bayesian data analysis. Third edition. CRC Press, Boca Raton, Florida, USA, 661 p.

Gram, W.K., P.A. Porneluzi, R.L. Clawson, J. Faaborg, and S.C. Richter. 2003. Effects of experimental forest management on density and nesting success of bird species in Missouri Ozark forests. Conservation Biology 17 (5): 1324-1337. http://doi.org/10.1046/j.1523-1739.2003.02171.x

Greenberg, C.H., K.E. Franzreb, T.L. Keyser, S.J. Zarnoch, D.M. Simon, and G.S. Warburton. 2014. Short-term response of breeding birds to oak regeneration treatments in upland hardwood forests. Natural Areas Journal 34 (4): 409-422.

Gregory, R., L. Failing, M. Harstone, G. Long, T. McDaniels, and D. Ohlson. 2012. Structured Decision Making: A Practical Guild to Environmental Management Choices. WileyBlackwell. 312 pp.

Grodsky, S.M., C.E. Moorman, S.R. Fritts, S.B. Castleberry, and T.B. Wigley. 2016. Breeding, early-successional bird response to forest harvests for bioenergy. PLoS ONE 11 (10). http://doi.org/10.1371/journal.pone.0165070

Gunn, J.S., M.J. Ducey, and E. Belair. 2019. Evaluating degradation in a North American temperate forest. Forest Ecology and Management 432: 415-426. http://doi.org/10.1016/j.foreco.2018.09.046

Kellner, K.F. 2015. jagsUI: a wrapper around rjags to streamline JAGS analyses. R package version 1.4.1.

Kéry, M., and J.A. Royle. 2016. Applied Hierarchical Modeling in Ecology: Analysis of distribution, abundance and species richness in R and BUGS, Volume 1. Academic Press. $783 \mathrm{pp}$.

King, D.I., and S. Schlossberg. 2014. Synthesis of the conservation value of the earlysuccessional stage in forests of eastern North America. Forest Ecology and Management 324: 186-195. http://doi.org/10.1016/j.foreco.2013.12.001 
Kleeberger, S.R., and J.K. Werner. 1982. Home range and homing behavior of Plethodon cinereus in northern Michigan. Copeia 2: 409-415.

Küchler, A.W. 1964. Potential natural vegetation of the conterminous United States (map). Special Publication 36. American Geographic Society, New York.

Lohr, S.M., S.A. Gauthreaux, and J.C. Kilgo. 2002. Importance of coarse woody debris to avian communities in loblolly pine forests. Conservation Biology 16 (3): 767-777. http://doi.org/10.1046/j.1523-1739.2002.01019.x

Lorimer, C.G. 2001. Historical and ecological roles of disturbance in eastern North American forests: 9,000 years of change. Wildlife Society Bulletin 29 (2): 425-439.

Masters, R.E., R.L. Lochmiller, S.T. McMurray, and G.A. Bukenhofer. 1998. Small mammal response to pine-grassland restoration for red-cockaded woodpeckers. Wildlife Society Bulletin 26 (1): 148-158.

McBurney, R.S. 1989. Drumming. Pages 176-197 in S. Atwater and J. Schnell (eds.). The Wildlife Series: Ruffed Grouse. Stackpole Books, Harrisburg, Pennsylvania, USA.

McDermott, M.E., and P.B. Wood. 2009. Short- and long-term implications of clearcut and twoage silviculture for conservation of breeding forest birds in the central Appalachians, USA. Biological Conservation 142 (1): 212-220. http://doi.org/10.1016/j.biocon.2008.10.016

McDermott, M.E, and P.B. Wood. 2010. Influence of cover and food resource variation on postbreeding bird use of timber harvests with residual canopy trees. The Wilson Journal of Ornithology 122 (3): 545-555. http://doi.org/10.1676/09-050.1

Mikusiński, G., M. Gromadzki, and P. Chylarecki. 2001. Woodpeckers as indicators of forest bird diversity. Conservation Biology 15 (1): 208-217. http://doi.org/10.1111/j.1523$\underline{1739.2001 .99236 . x}$

Morin, R.S., G.W. Cook, C.J. Barnett, B.J. Butler, S.J. Crocker, M.A. Hatfield, C.M. Kurtz, T.W. Lister, W.G. Luppold, W.H. McWilliams, P.D. Miles, M.D. Nelson, C.H. Perry, R.J. Piva, J.E. Smith, J.A. Westfall, R.H. Widmann, C.W. Woodall. 2016. West Virginia Forests 2013. Resource Bulletin. NRS-105. Newtown Square, PA: U.S. Department of Agriculture, Forest Service, Northern Research Station. 128 p. https://doi.org/10.2737/NRS-RB-105

Murray, B.D., C.R. Webster, M.A. Jenkins, M.R. Saunders, and G.S. Haulton. 2016. Ungulate impacts on herbaceous-layer plant communities in even-aged and uneven-aged managed forests. Ecosphere 7(6). http://doi.org/10.1002/ecs2.1378 
Nappi, A., P. Drapeau, and A. Leduc. 2015. How important is dead wood for woodpeckers foraging in eastern North American boreal forests? Forest Ecology and Management 346: 10-21. http://doi.org/10.1016/j.foreco.2015.02.028

Nareff, G.E., P.B. Wood, D.J. Brown, T. Fearer, J.L. Larkin, and W.M. Ford. 2019. Cerulean warbler (Setophaga cerulea) response to operational silviculture in the central Appalachian region. Forest Ecology and Management 448: 409-423. http://doi.org/10.1016/j.foreco.2019.05.062

Newell, F.L., and A.D. Rodewald. 2012. Management for oak regeneration: short-term effects on the bird community and suitability of shelterwood harvests for canopy songbirds. The Journal of Wildlife Management 76 (4): 683-693. http://doi.org/10.1002/jwmg.314

NOAA (National Oceanic and Atmospheric Administration). 2019. National Weather Service Forecast Office, Charleston, WV. https://w2.weather.gov/climate/xmacis.php?wfo=rlx

Nudds, T.D. 1977. Quantifying the vegetative structure of wildlife cover. Wildlife Society Bulletin 5 (3): 113-117.

Oswalt, S.J., K.E. Franzreb, and D.A. Buehler. 2010. Changes in early-successional hardwood forest area in four bird conservation regions across four decades. Joint Meeting of the Forest Inventory and Analysis (FIA) Symposium and the Southern Mensurationists, 8793.

Parker, A.J. 1982. The topographic relative moisture index: An approach to soil-moisture assessment in mountain terrain. Physical Geography 3 (2): 160-168.

Payer, D., and D. Harrison. 2005. Relationships between forest structure and habitat use by American martens in Maine, USA. Pages 173-186 in Martens and fishers (Martes) in human-altered environments.

Peele, J., C. Nix, P. Ruhl, R. Chapman, P. Zollner, and M.R. Saunders. 2017. Effects of woody biomass harvests on populations of Plethodontid salamanders in southeast Indiana. The American Midland Naturalist 178 (1): 132-143. http://doi.org/10.1674/0003-0031$\underline{178.1 .132}$

Perry, R.W., J.M.A. Jenkins, R.E. Thill, and F.R. Thompson III. 2018. Long-term effects of different forest regeneration methods on mature forest birds. Forest Ecology and Management 408: 183-194. http://doi.org/10.1016/j.foreco.2017.10.051

Perry, R.W., and R.E. Thill. 2013. Long-term responses to disturbance-associated birds after different timber harvests. Forest Ecology and Management 307: 274-283. http://doi.org/10.1016/j.foreco.2013.07.026

Plummer, M. 2017. JAGS Version 4.3.0 user manual. 
R Core Team. 2020. R: A language and environment for statistical computing. R Foundation for Statistical Computing, Vienna, Austria. https://www.R-project.org/

Ralph, C.J., G.R. Geupel, P. Pyle, T.E. Martin, and D.F. DeSante. 1993. Handbook of Field Methods for Monitoring Landbirds. General Technical Report PSW-GTR 144-www. U.S. Department of Agriculture, Forest Service, Pacific Southwest Research Station, Albany, California, USA. http://doi.org/10.2737/PSW-GTR-144

Schumacher, C.L. 2002. Ruffed grouse habitat use in western North Carolina. Thesis. University of Tennessee, Knoxville, Tennessee, USA.

Sheehan, J., P.B. Wood, D.A. Buehler, P.D. Keyser, J.L. Larkin, A.D. Rodewald, T.B. Wigley, T.J. Boves, G.A. George, M.H. Bakermans, T.A. Beachy, A. Evans, M.E. McDermott, F.L. Newell, K.A. Perkins, and M. White. 2014. Avian response to timber harvesting applied experimentally to manage Cerulean Warbler breeding populations. Forest Ecology and Management 321: 5-18. http://doi.org/10.1016/j.foreco.2013.07.037

Shifley, S.R.., and F.R. Thompson III. 2011. Spatial and temporal patterns in the amount of young forests and implications for biodiversity. Pages 73-95 in C.H. Greenberg, B.S. Collins, and F.R. Thompson III (eds.). Sustaining Young Forest Communities, Managing Forest Ecosystems 21. http://doi.org/10.1007/978-94-007-1620-9_6

Shwiff, S.A., A. Anderson, R. Cullen, P.C.L. White, and S.S. Shwiff. 2013. Assignment of measureable costs and benefits to wildlife conservation projects. Wildlife Research 40 (2): 134-141. http://doi.org/10.1071/WR12102

Siemers, J.L., K.R. Wilson, and S. Baruch-Mordo. 2015. Monitoring wildlife-vehicle collisions: analysis and cost-benefit of escape ramps for deer and elk on US highway 550. Colorado Department of Transportation, Applied Research and Innovation Branch (No. CDOT2015-05).

Smith, C.K., and J.W. Petranka. 2000. Monitoring terrestrial salamanders: repeatability and validity of area-constrained cover object searches. Journal of Herpetology 34: 547-557.

Sullivan, T.P., D.S. Sullivan, and J. Hazel-rah Sullivan. 2017. Mammalian responses to windrows of woody debris on clearcuts: Abundance and diversity of forest-floor small mammals and presence of small mustelids. Forest Ecology and Management 399: 143154. http://doi.org/10.1016/j.foreco.2017.05.028

Trani, M.K., R.T. Brooks, T.L. Schmidt, V.A. Rudis, and C.M. Gabbard. 2001. Patterns and trends of early successional forests in the eastern United States. Wildlife Society Bulletin 29 (2): 413-424.

Weiss, A.D. 2001. Topographic position and landforms analysis. Poster Presentation, ESRI Users Conference, San Diego, CA. 
Wermelinger, B., M. Moretti, P. Duelli, T. Lachat, G.B. Pezzatti, and M.K. Obrist. 2017. Impact of windthrow and salvage-logging on taxonomic and functional diversity of forest arthropods. Forest Ecology and Management 391: 9-18.

http://doi.org/10.1016/j.foreco.2017.01.033

Wilson, C.W., R.E. Masters, and G.A. Bukenhofer. 1995. Breeding bird response to pinegrassland community restoration for red-cockaded woodpeckers. The Journal of Wildlife Management 59 (1): 56-67.

WVGIS (West Virginia GIS Technical Center). 2019. WV State GIS Data Clearinghouse. http://wvgis.wvu.edu/about/about.php 


\section{Tables}

Table 3-1. Data collection time-table for 16 regeneration stand blocks at six West Virginia Division of Natural Resource (WVDNR) wildlife management areas (WMA). "Blocks" in the table refers to number of block replicates at each site.

\begin{tabular}{l|c|c|c|c|}
\hline \multicolumn{2}{c}{2016} & 2017 & 2018 & 2019 \\
\hline Little Canaan WMA (4 blocks) & $\begin{array}{c}\text { 1 Year Pre- } \\
\text { treatment }\end{array}$ & $\begin{array}{c}\text { 1 Year Post- } \\
\text { treatment }\end{array}$ & $\begin{array}{c}2 \text { Year Post- } \\
\text { treatment }\end{array}$ & \\
\hline $\begin{array}{l}\text { Beury Mountain WMA (5 blocks) } \\
\text { Center Branch WMA (3 blocks) }\end{array}$ & & $\begin{array}{c}1 \text { Year Pre- } \\
\text { treatment } \\
\text { Moncove Lake WMA (2 blocks) }\end{array}$ & $\begin{array}{c}1 \text { Year Post- } \\
\text { treatment }\end{array}$ & $\begin{array}{c}2 \text { Year Post- } \\
\text { treatment }\end{array}$ \\
\hline $\begin{array}{l}\text { Short Mountain WMA (1 block) } \\
\text { Sleepy Creek WMA (1 block) }\end{array}$ & & $\begin{array}{c}1 \text { Year Pre- } \\
\text { treatment }\end{array}$ & $\begin{array}{c}1 \text { Year Post- } \\
\text { treatment }\end{array}$ \\
\hline
\end{tabular}

Table 3-2. Decay stage classifications used to assess canopy trees in regeneration stands. We condensed the eight Backhouse and Louiser (1991) classes into five (in parentheses) by combining classes $4-5$ into a single decay class and classes $6-8$ into a single decay class.

\begin{tabular}{cl}
\hline Decay Class & Description \\
\hline $1(1)$ & Live, healthy \\
$2(2)$ & Live, unhealthy (e.g., broken top, shelf fungus, boring insects, trunk gall) \\
$3(3)$ & Recently dead, most branches/twigs, possible broken top, stable \\
$4(4)$ & No needles/twigs, 50\% branches lost, possible broken top, 25-50\% bark lost, \\
& wood mostly hard \\
$5(4)$ & Most branches gone, possible broken top, 51-75\% bark lost, wood hard and \\
$6(5)$ & Noft \\
$7(5)$ & No branches, some stubs, broken top, 76-100\% bark lost, wood mostly soft \\
$8(5)$ & No branches, broken top, no bark, wood soft \\
\hline
\end{tabular}


Table 3-3. Posterior means with 95\% confidence intervals (in parentheses) of guild richness and cost (i.e., estimated performance scores) of regeneration stand treatments ("Cost" score was not generated via posterior mean). Guild richness values for each treatment were derived from Equation 1 and cost information was provided from the West Virginia Division of Natural Resources and the Wildlife Management Institute.

\begin{tabular}{lcccc}
\hline & \multicolumn{4}{c}{ Treatment } \\
\cline { 2 - 5 } Performance measure & Control & Clearcut-Leave & Clearcut-Windrow & Hack-Spray \\
\hline Guild Richness (species/plot) & & & & \\
$\quad$ Young Forest & $1.36(1.09,1.64)$ & $2.89(2.07,3.92)$ & $1.42(0.80,2.29)$ & $0.63(0.31,1.11)$ \\
$\quad$ Forest Interior & $3.44(2.96,3.91)$ & $3.43(2.60,4.40)$ & $3.05(1.97,4.61)$ & $3.80(2.34,5.96)$ \\
Cavity nesting & $1.42(1.16,1.75)$ & $1.58(1.09,2.27)$ & $1.59(0.84,2.84)$ & $1.72(0.93,2.90)$ \\
Species of Conservation Priority & $3.92(3.44,4.41)$ & $4.21(3.33,5.40)$ & $3.75(2.41,5.34)$ & $3.47(2.31,5.04)$ \\
Cost $(\$ /$ ha) & 0 & 1410 & 1776 & 1218 \\
\hline
\end{tabular}


Table 3-4. Normalized performance scores (i.e., utility values) and 95\% confidence intervals (in parenthesis) of regeneration stand treatments. Scores are derived by taking the quotient of the cell-level performance score in Table 3-3 minus the maximum row-level performance score (numerator) and minimum row-level performance score minus the maximum row-level performance score (denominator). Scores range $0-1(0=$ low performance, $1=$ high performance). Weighted utility scores (WUS) of each regeneration stand treatment is the sum of the product of normalized performance scores and weights. Weights are as follows: young forest richness $=0.28$, species of conservation priority richness $=0.21$, cost $=0.20$, forest interior richness $=0.18$, and cavity nesting richness $=0.14$.

\begin{tabular}{lcccc}
\hline & \multicolumn{4}{c}{ Treatment } \\
\cline { 2 - 5 } Performance measure & Control & Clearcut-Leave & Clearcut-Windrow & Hack-Spray \\
\hline Avian Guilds & & & & \\
$\quad$ Young Forest & $0.32(0.17,0.47)$ & $0.99(0.99,1.00)$ & $0.39(0.11,0.99)$ & $0.00(0.00,0.00)$ \\
$\quad$ Forest Interior & $0.53(0.03,1.00)$ & $0.52(0.00,1.00)$ & $0.21(0.00,1.00)$ & $0.75(0.00,1.00)$ \\
Cavity nesting & $0.23(0.00,0.69)$ & $0.53(0.00,1.00)$ & $0.44(0.00,1.00)$ & $0.60(0.00,1.00)$ \\
$\quad$ Species of Conservation Priority & $0.54(0.00,1.00)$ & $0.70(0.00,1.00)$ & $0.45(0.00,1.00)$ & $0.24(0.00,1.00)$ \\
Cost & 1.00 & 0.21 & 0.00 & 0.31 \\
\hline Weighted Utility Score (WUS) & $0.52(0.36,0.67)$ & $0.63(0.33,0.85)$ & $0.30(0.06,0.57)$ & $0.33(0.11,0.54)$ \\
\hline
\end{tabular}


Table 3-5. Vegetation summary statistics (mean \pm standard error) in regeneration treatments over time. Treatment abbreviations include $\mathrm{CL}=$ clearcut-and-leave, $\mathrm{CW}=$ clearcut-and-windrow, and $\mathrm{HS}=$ hack-and-spray. Live and dead tree decay stages are defined in Table 3-2.

\begin{tabular}{|c|c|c|c|c|}
\hline & Control & $\mathbf{C L}$ & $\mathbf{C W}$ & HS \\
\hline \multicolumn{5}{|c|}{ Live basal area $\left(\mathrm{m}^{2} / \mathrm{ha}\right):$ Decay stage 1} \\
\hline Pre-treatment & $15.0 \pm 1.4$ & $15.0 \pm 1.2$ & $15.4 \pm 1.0$ & $16.4 \pm 1.7$ \\
\hline One-year Post-treatment & $15.0 \pm 1.4$ & $0.2 \pm 0.2$ & $0.4 \pm 0.2$ & $10.4 \pm 1.2$ \\
\hline Two-year Post-treatment & $14.5 \pm 1.5$ & $0.0 \pm 0.0$ & $0.3 \pm 0.2$ & $7.9 \pm 1.2$ \\
\hline \multicolumn{5}{|c|}{ Live basal area $\left(\mathrm{m}^{2} / \mathrm{ha}\right):$ Decay stage 2} \\
\hline Pre-treatment & $0.2 \pm 0.1$ & $0.1 \pm 0.1$ & $0.3 \pm 0.1$ & $0.1 \pm 0.0$ \\
\hline One-year Post-treatment & $0.2 \pm 0.1$ & $0.0 \pm 0.0$ & $0.1 \pm 0.1$ & $3.2 \pm 0.7$ \\
\hline Two-year Post-treatment & $0.2 \pm 0.1$ & $0.0 \pm 0.0$ & $0.1 \pm 0.0$ & $2.6 \pm 0.4$ \\
\hline \multicolumn{5}{|c|}{ Dead basal area $\left(\mathrm{m}^{2} / \mathrm{ha}\right):$ Decay stage 3} \\
\hline Pre-treatment & $0.4 \pm 0.1$ & $0.4 \pm 0.1$ & $0.5 \pm 0.1$ & $0.5 \pm 0.1$ \\
\hline One-year Post-treatment & $0.4 \pm 0.1$ & $0.0 \pm 0.0$ & $0.0 \pm 0.0$ & $2.3 \pm 0.5$ \\
\hline Two-year Post-treatment & $0.4 \pm 0.1$ & $0.0 \pm 0.0$ & $0.0 \pm 0.0$ & $3.0 \pm 0.6$ \\
\hline \multicolumn{5}{|c|}{ Dead basal area $\left(\mathrm{m}^{2} / \mathrm{ha}\right):$ Decay stage 4} \\
\hline Pre-treatment & $0.3 \pm 0.1$ & $0.3 \pm 0.01$ & $0.3 \pm 0.1$ & $0.3 \pm 0.1$ \\
\hline One-year Post-treatment & $0.3 \pm 0.1$ & $0.0 \pm 0.0$ & $0.0 \pm 0.0$ & $0.4 \pm 0.1$ \\
\hline Two-year Post-treatment & $0.3 \pm 0.1$ & $0.0 \pm 0.0$ & $0.3 \pm 0.2$ & $0.4 \pm 0.1$ \\
\hline \multicolumn{5}{|c|}{ Dead basal area $\left(\mathrm{m}^{2} / \mathrm{ha}\right):$ Decay stage 5} \\
\hline Pre-treatment & $0.5 \pm 0.2$ & $0.4 \pm 0.2$ & $0.4 \pm 0.2$ & $0.3 \pm 0.1$ \\
\hline One-year Post-treatment & $0.5 \pm 0.2$ & $0.0 \pm 0.0$ & $0.0 \pm 0.0$ & $0.6 \pm 0.2$ \\
\hline Two-year Post-treatment & $0.5 \pm 0.2$ & $0.0 \pm 0.0$ & $0.0 \pm 0.0$ & $0.3 \pm 0.1$ \\
\hline \multicolumn{5}{|c|}{ Total live basal area $\left(\mathrm{m}^{2} / \mathrm{ha}\right)$ : Decay stages $1-2$} \\
\hline Pre-treatment & $15.2 \pm 1.4$ & $15.1 \pm 1.3$ & $15.7 \pm 0.9$ & $16.5 \pm 1.7$ \\
\hline One-year Post-treatment & $15.2 \pm 1.4$ & $0.2 \pm 0.2$ & $0.5 \pm 0.3$ & $13.6 \pm 1.5$ \\
\hline Two-year Post-treatment & $14.7 \pm 1.5$ & $0.1 \pm 0.0$ & $0.3 \pm 0.2$ & $10.4 \pm 1.5$ \\
\hline \multicolumn{5}{|c|}{ Total dead basal area $\left(\mathrm{m}^{2} / \mathrm{ha}\right)$ : Decay stages $3-5$} \\
\hline Pre-treatment & $1.2 \pm 0.3$ & $1.1 \pm 0.2$ & $1.2 \pm 0.2$ & $1.1 \pm 0.2$ \\
\hline One-year Post-treatment & $1.2 \pm 0.3$ & $0.1 \pm 0.0$ & $0.0 \pm 0.0$ & $3.3 \pm 0.5$ \\
\hline Two-year Post-treatment & $1.2 \pm 0.3$ & $0.0 \pm 0.0$ & $0.3 \pm 0.2$ & $3.7 \pm 0.5$ \\
\hline \multicolumn{5}{|l|}{ Percent overstory cover } \\
\hline Pre-treatment & $93.0 \pm 1.5$ & $86.4 \pm 2.3$ & $89.7 \pm 2.8$ & $92.9 \pm 1.4$ \\
\hline One-year Post-treatment & $93.0 \pm 1.5$ & $2.1 \pm 1.4$ & $3.2 \pm 1.8$ & $65.9 \pm 8.7$ \\
\hline Two-year Post-treatment & $93.3 \pm 1.6$ & $1.2 \pm 1.2$ & $3.2 \pm 1.8$ & $64.8 \pm 9.5$ \\
\hline \multicolumn{5}{|c|}{ Percent understory cover $\mathbf{0}-1$ m } \\
\hline Pre-treatment & $85.5 \pm 4.3$ & $77.3 \pm 5.1$ & $70.3 \pm 5.5$ & $75.2 \pm 6.2$ \\
\hline One-year Post-treatment & $85.5 \pm 4.3$ & $87.5 \pm 4.7$ & $85.5 \pm 5.9$ & $85.9 \pm 2.7$ \\
\hline Two-year Post-treatment & $83.4 \pm 4.7$ & $96.0 \pm 2.8$ & $97.4 \pm 1.4$ & $92.0 \pm 2.6$ \\
\hline \multicolumn{5}{|c|}{ Percent understory cover $>1-2 \mathrm{~m}$} \\
\hline Pre-treatment & $68.2 \pm 5.7$ & $60.3 \pm 7.2$ & $54.3 \pm 7.1$ & $62.5 \pm 6.7$ \\
\hline One-year Post-treatment & $68.2 \pm 5.7$ & $69.5 \pm 6.7$ & $59.8 \pm 6.5$ & $58.2 \pm 6.2$ \\
\hline Two-year Post-treatment & $67.4 \pm 6.5$ & $86.9 \pm 6.4$ & $82.4 \pm 8.1$ & $65.8 \pm 6.8$ \\
\hline
\end{tabular}


Table 3-6. Total and mean (detections/plot) ruffed grouse (Bonasa umbellus) detections in regeneration stands over the study period. Mean values account for uneven sampling because Sleepy Creek WMA and Short Mountain WMA received no two-year post-treatment sampling and Center Branch WMA had no hack-and-spray (HS) treatments. Treatment abbreviations include $\mathrm{CL}=$ clearcut-and-leave, $\mathrm{CW}=$ clearcut-and-windrow, and $\mathrm{HS}$ = hack-and-spray.

\begin{tabular}{lcc|cc|cc|cc}
\hline & \multicolumn{2}{c|}{ Control } & \multicolumn{2}{c|}{$\underline{\mathbf{C L}}$} & \multicolumn{2}{c|}{$\underline{\mathbf{C W}}$} & \multicolumn{2}{c}{$\underline{\text { HS }}$} \\
& Total & Mean & Total & Mean & Total & Mean & Total & Mean \\
\hline Pre-treatment & 0 & 0.0 & 1 & 0.1 & 3 & 0.2 & 1 & 0.1 \\
One-year Post-treatment & 1 & 0.1 & 4 & 0.2 & 1 & 0.1 & 4 & 0.3 \\
Two-year Post-treatment & 1 & 0.1 & 1 & 0.1 & 2 & 0.1 & 1 & 0.4 \\
\hline
\end{tabular}




\section{Figures}

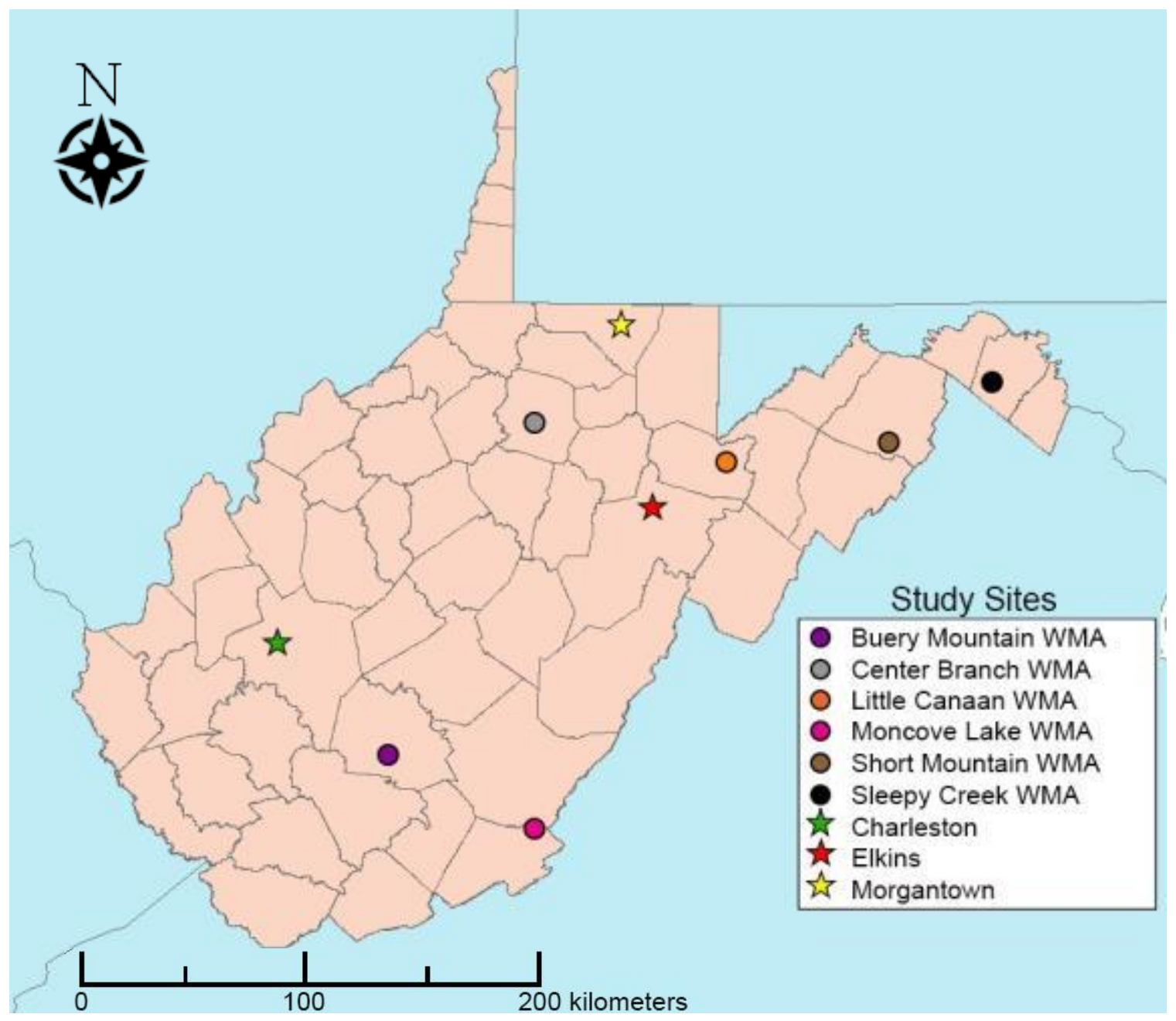

Figure 3-1. County map of West Virginia showing locations of wildlife management areas (WMA) where regeneration stands were located (circles) as well as major cities (stars). 


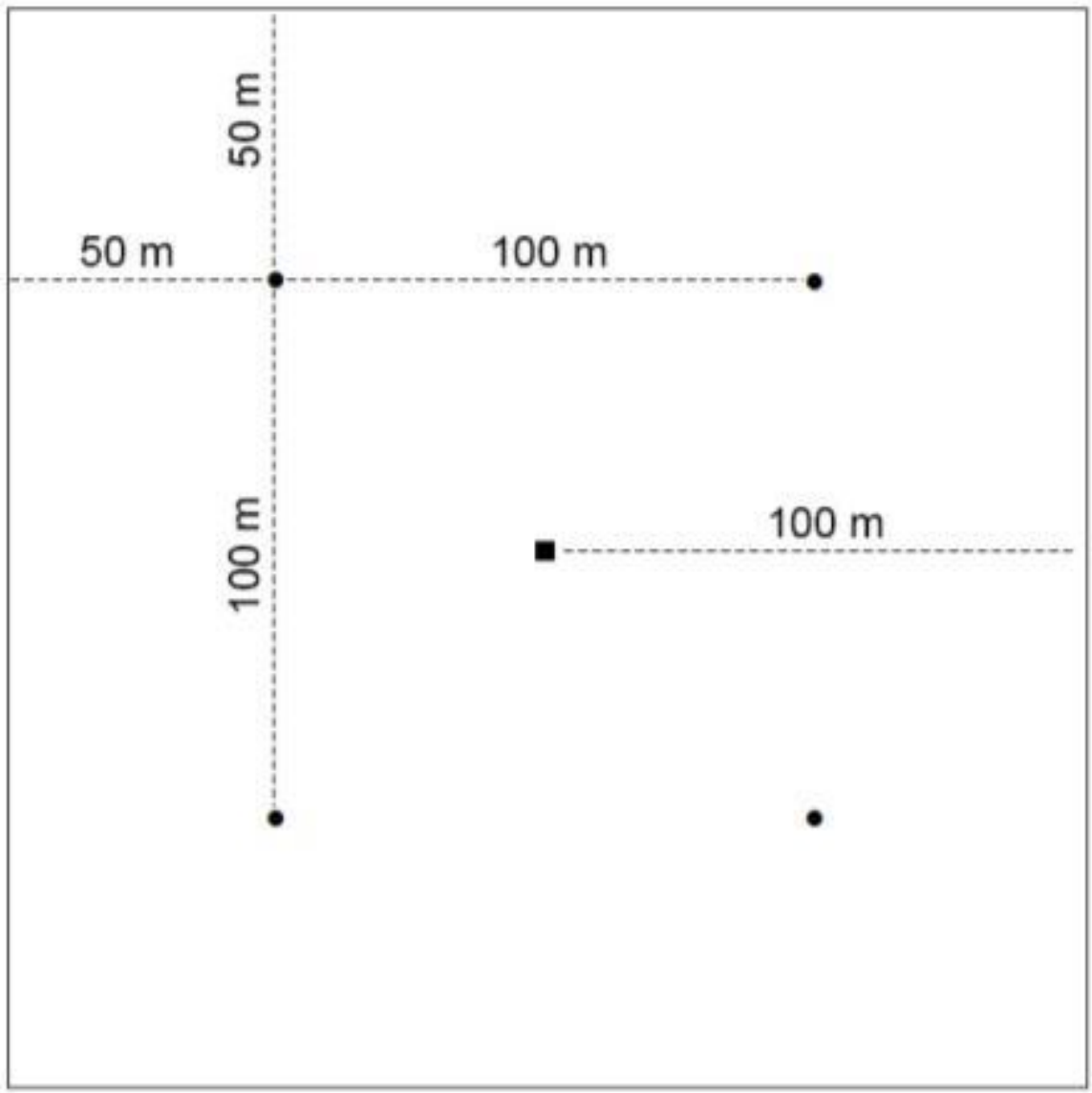

Figure 3-2. Regeneration stand layout with avian sampling point (black square) and salamander sampling point (black dot) placements. Vegetation sampling points were located at each avian and salamander sampling point. 

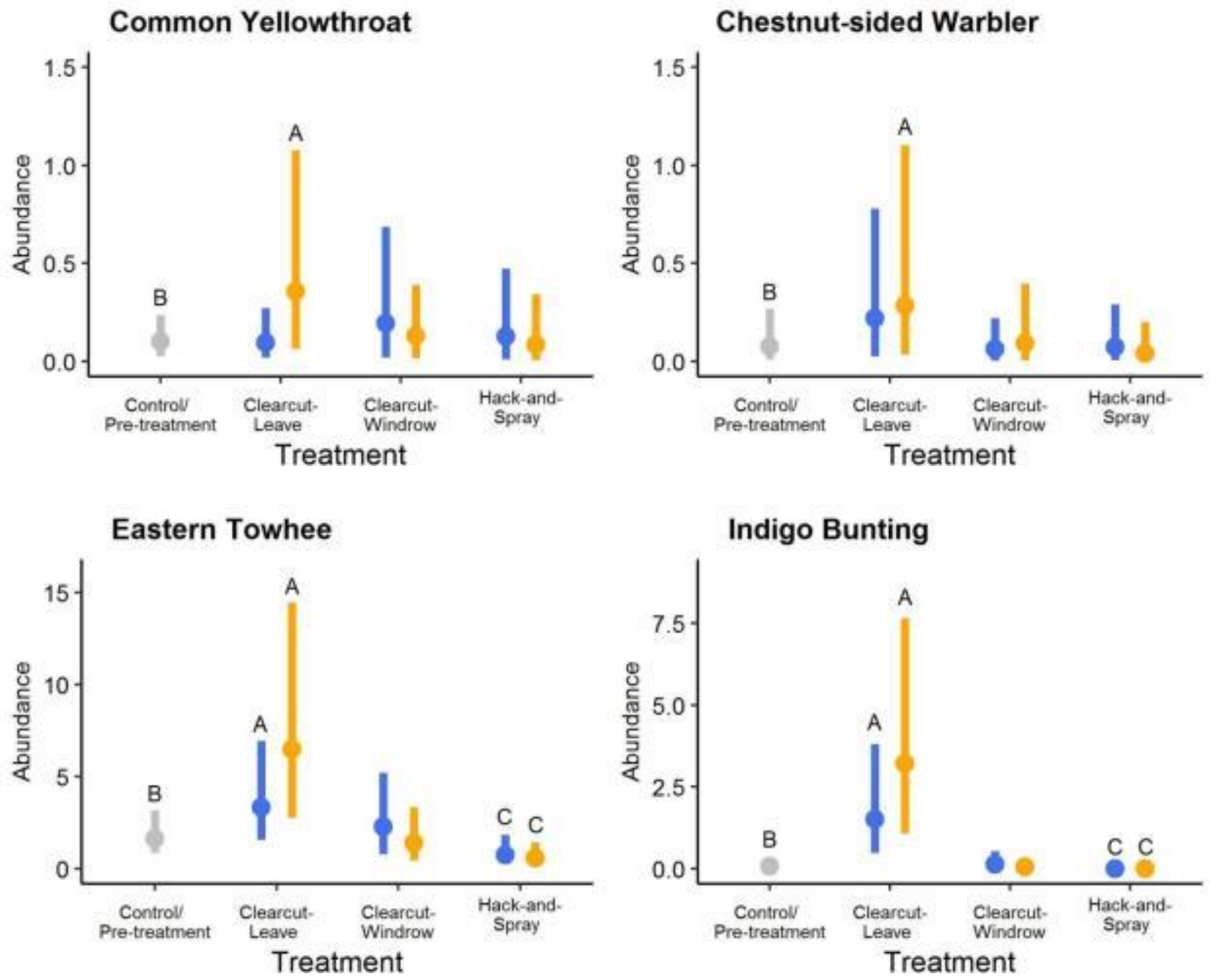

Year $\leadsto$ 1-yr Post-treatment $=2$-yr Post-treatment

Figure 3-3. Plot-level estimated abundance and 95\% confidence intervals of young forest focal songbird species during the breeding season. Differences in abundance within regeneration treatments between pre-treatment/control and one-year or two-year post-treatment are indicated by alphabetical notation based on non-overlapping $95 \%$ credible intervals. 

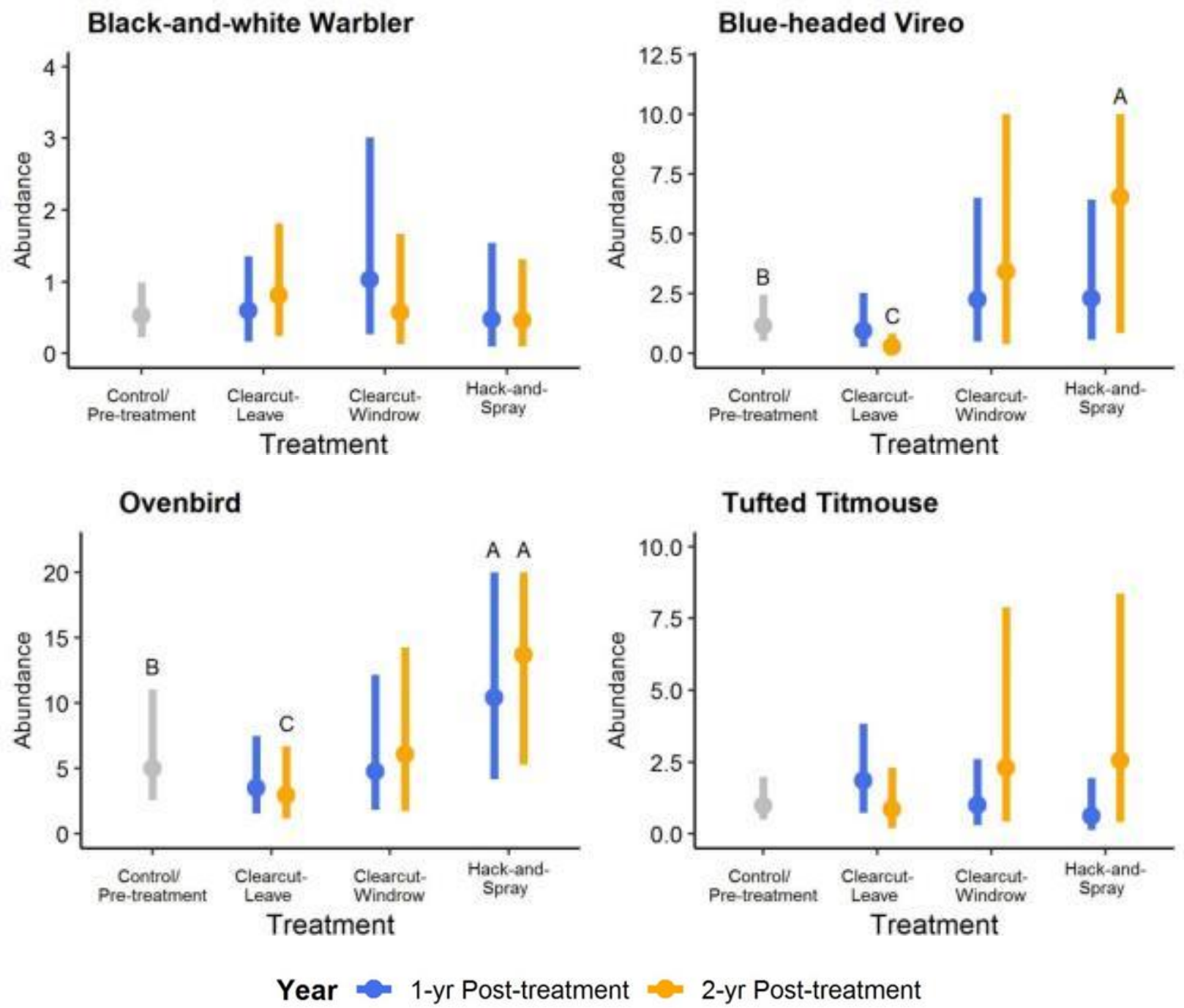

Figure 3-4. Plot-level estimated abundance and 95\% confidence intervals of forest interior focal songbird species during the breeding season. Differences in abundance within regeneration treatments between pre-treatment/control and one-year or two-year post-treatment are indicated by alphabetical notation based on $95 \%$ credible intervals. 

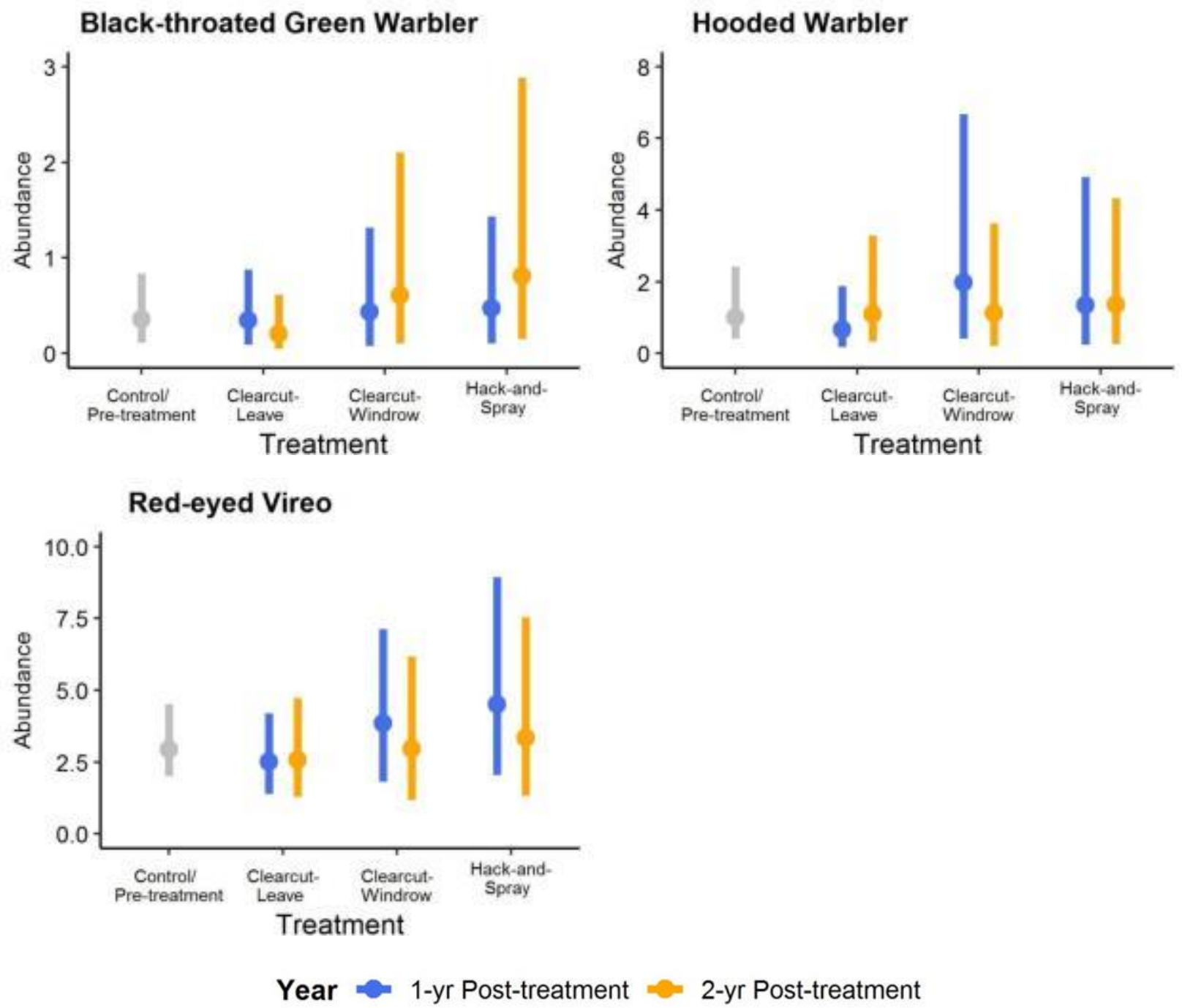

Figure 3-5. Plot-level estimated abundance and 95\% confidence intervals of forest gap focal songbird species during the breeding season. Differences in abundance within regeneration treatments between pre-treatment/control and one-year or two-year post-treatment are indicated by alphabetical notation based on non-overlapping $95 \%$ credible intervals. 

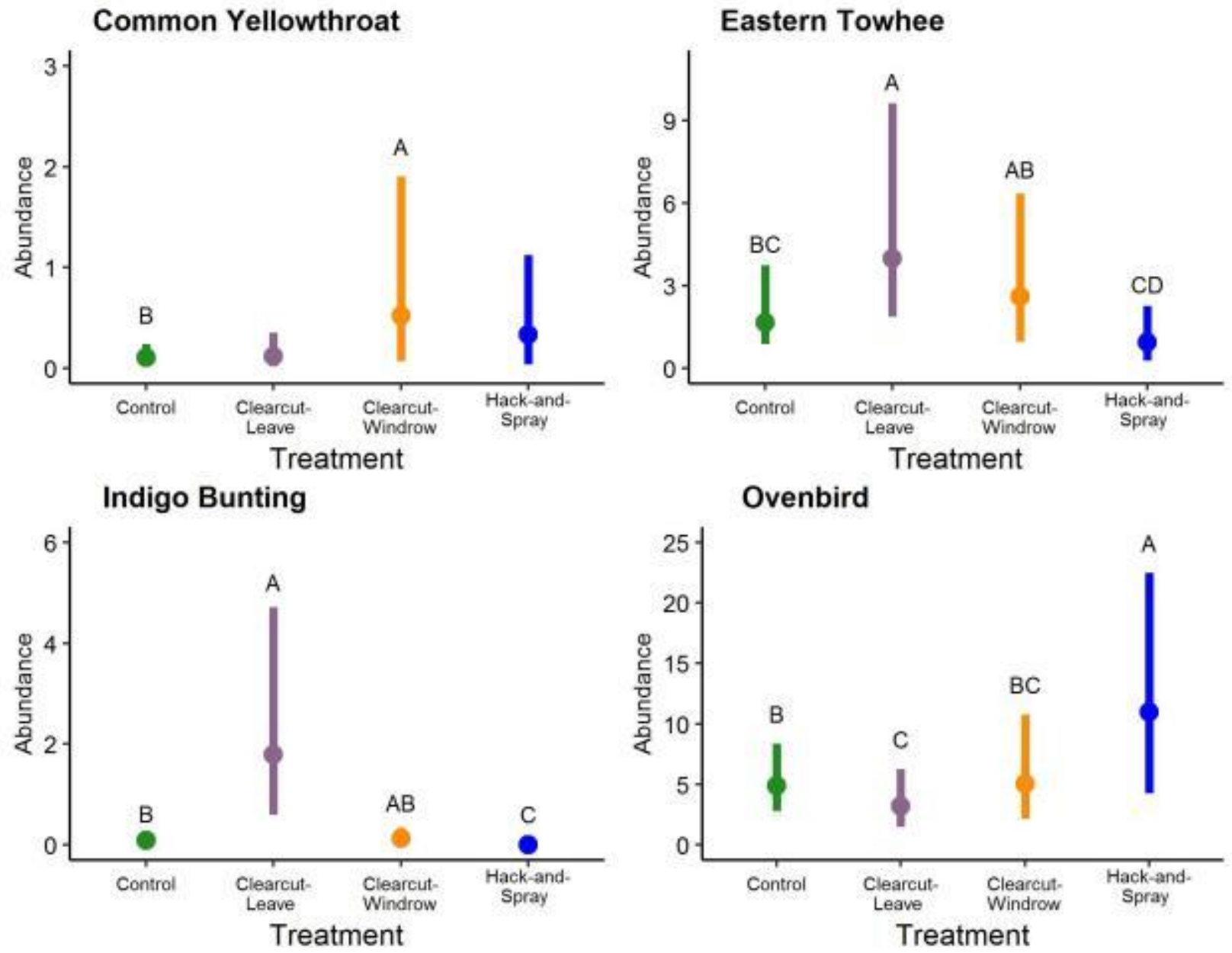

Figure 3-6. Plot-level estimated abundance and 95\% confidence intervals of focal songbird species during the breeding season. Differences in abundance between regeneration treatments are indicated by alphabetical notation based on non-overlapping $95 \%$ credible intervals. 

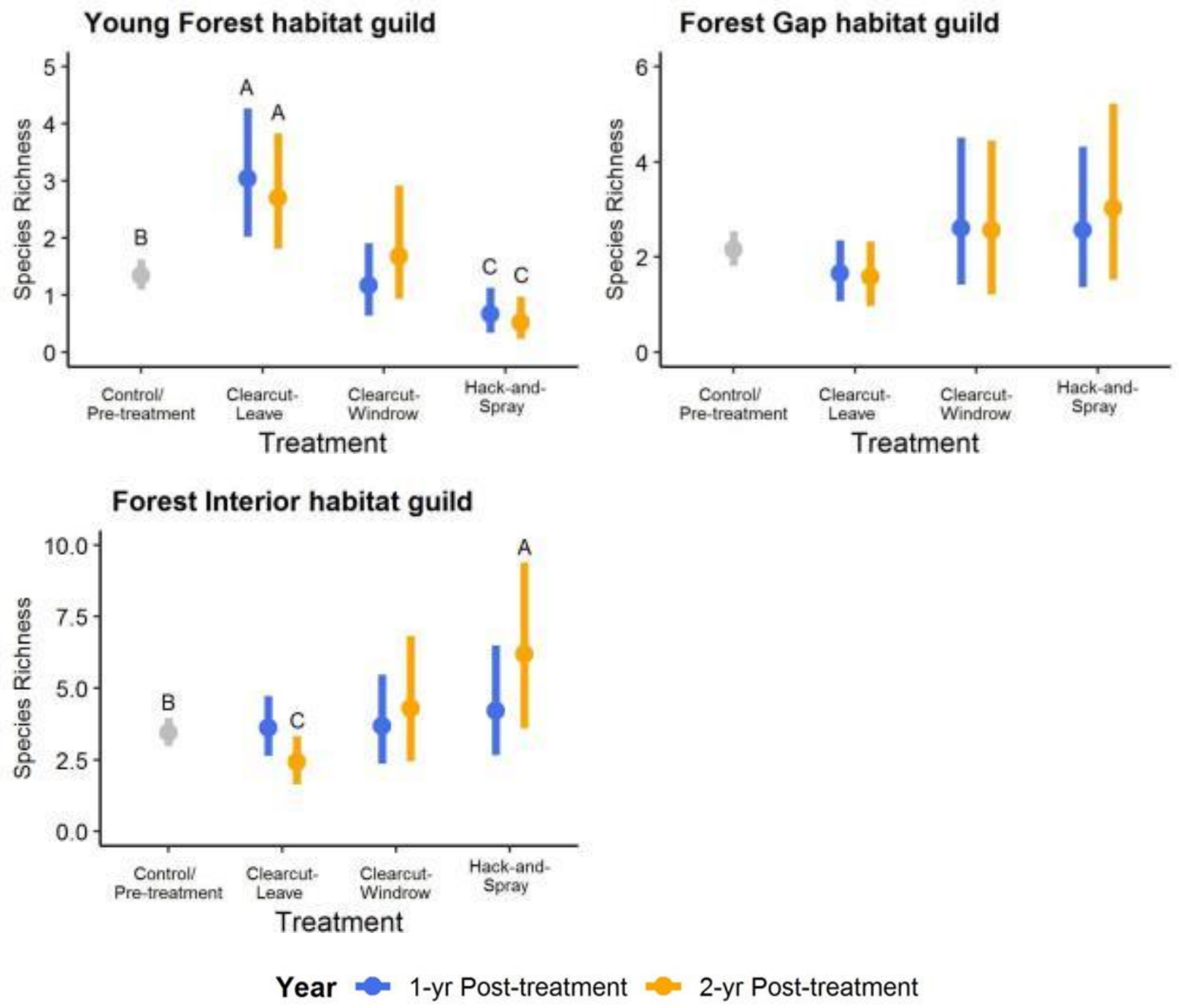

Figure 3-7. Plot-level species richness and 95\% confidence intervals of avian habitat guilds during the breeding season. Differences in richness within regeneration treatments between pretreatment/control and one-year or two-year post-treatment are indicated by alphabetical notation based on non-overlapping $95 \%$ credible intervals. 

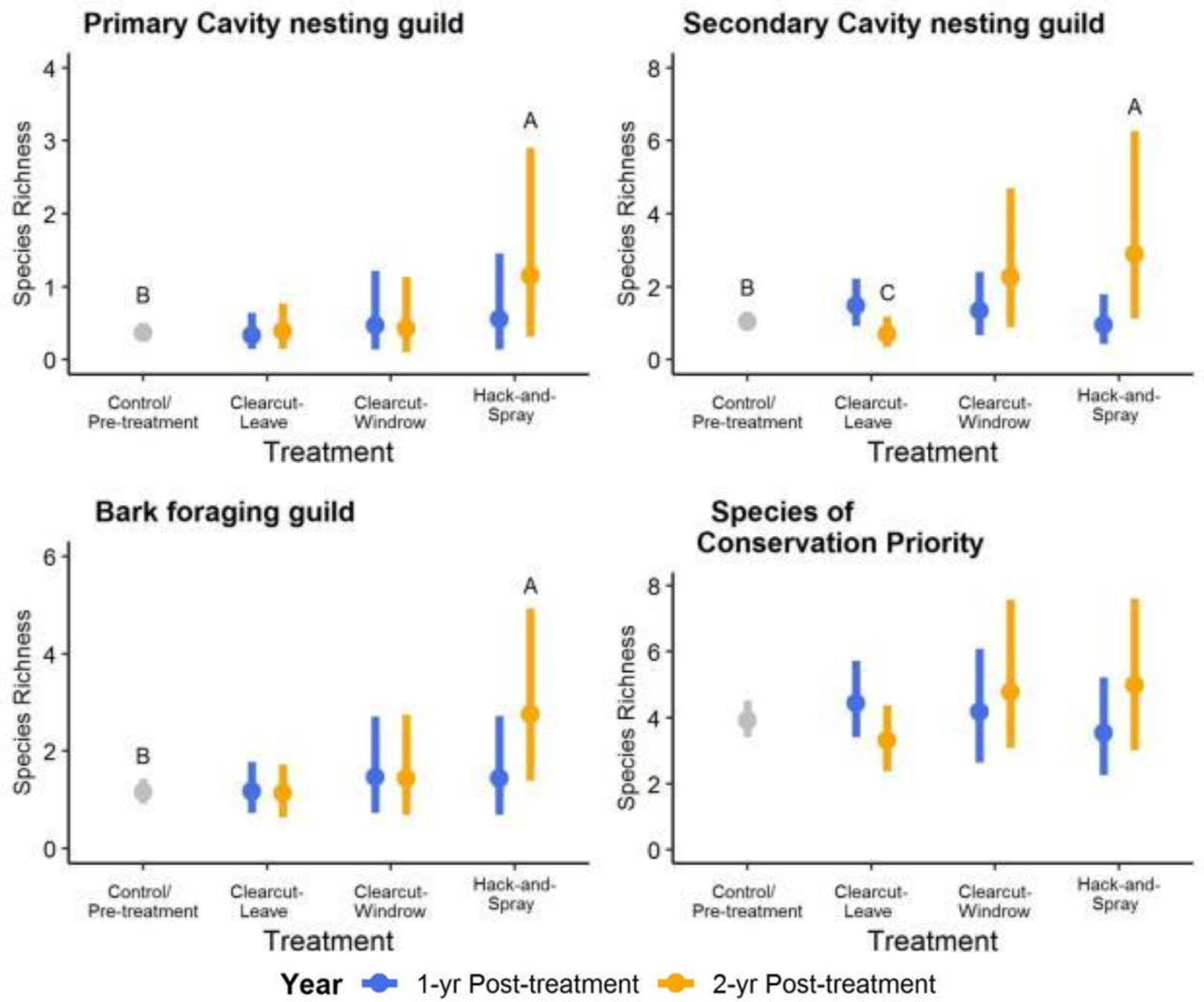

Figure 3-8. Plot-level species richness and 95\% confidence intervals of avian guilds during the breeding season. Differences in richness within regeneration treatments between pretreatment/control and one-year or two-year post-treatment are indicated by alphabetical notation based on non-overlapping $95 \%$ credible intervals. 

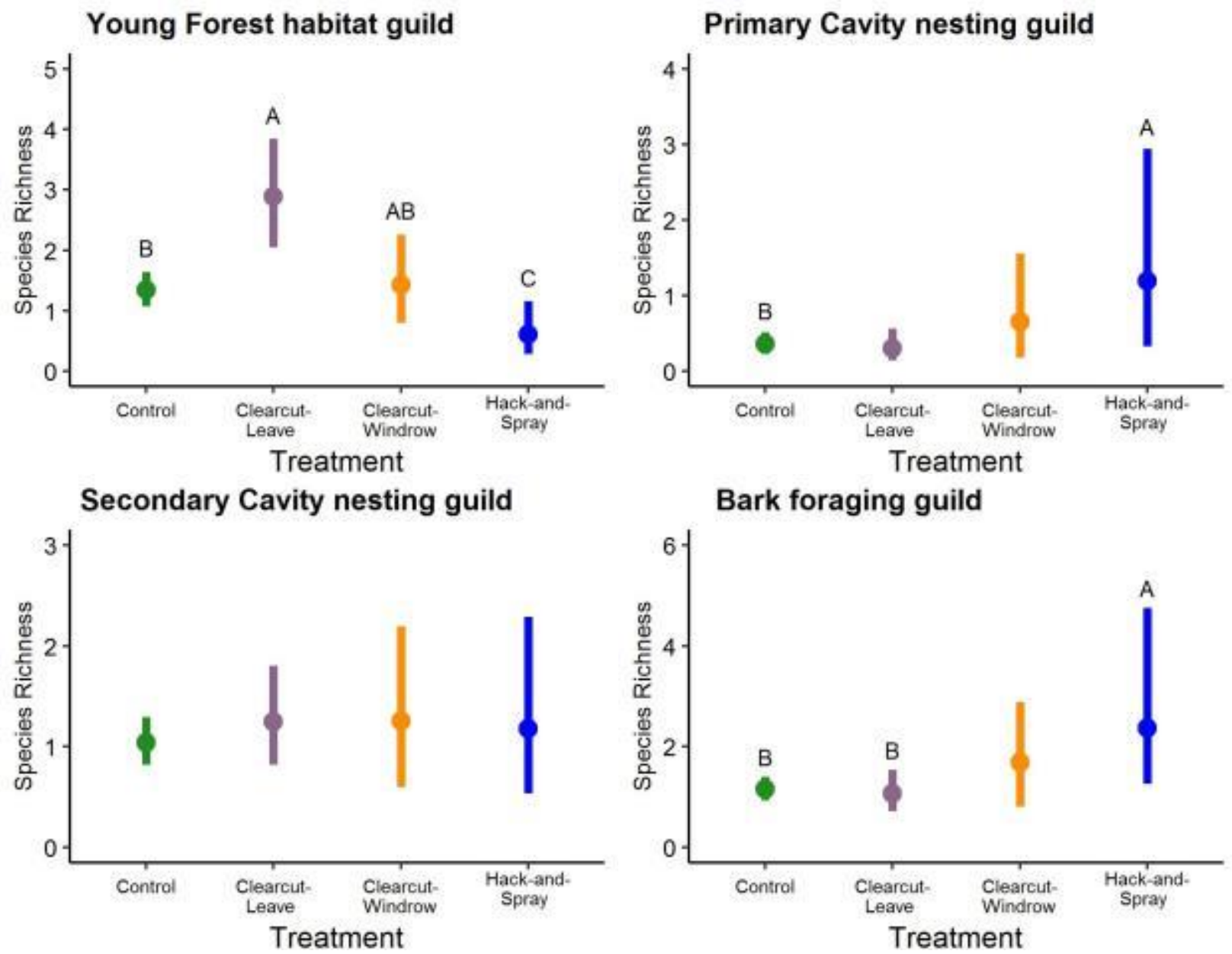

Figure 3-9. Plot-level estimated species richness and 95\% confidence intervals of avian guilds during the breeding season. Differences in species richness between regeneration treatments are indicated by alphabetical notation based on non-overlapping 95\% credible intervals. 


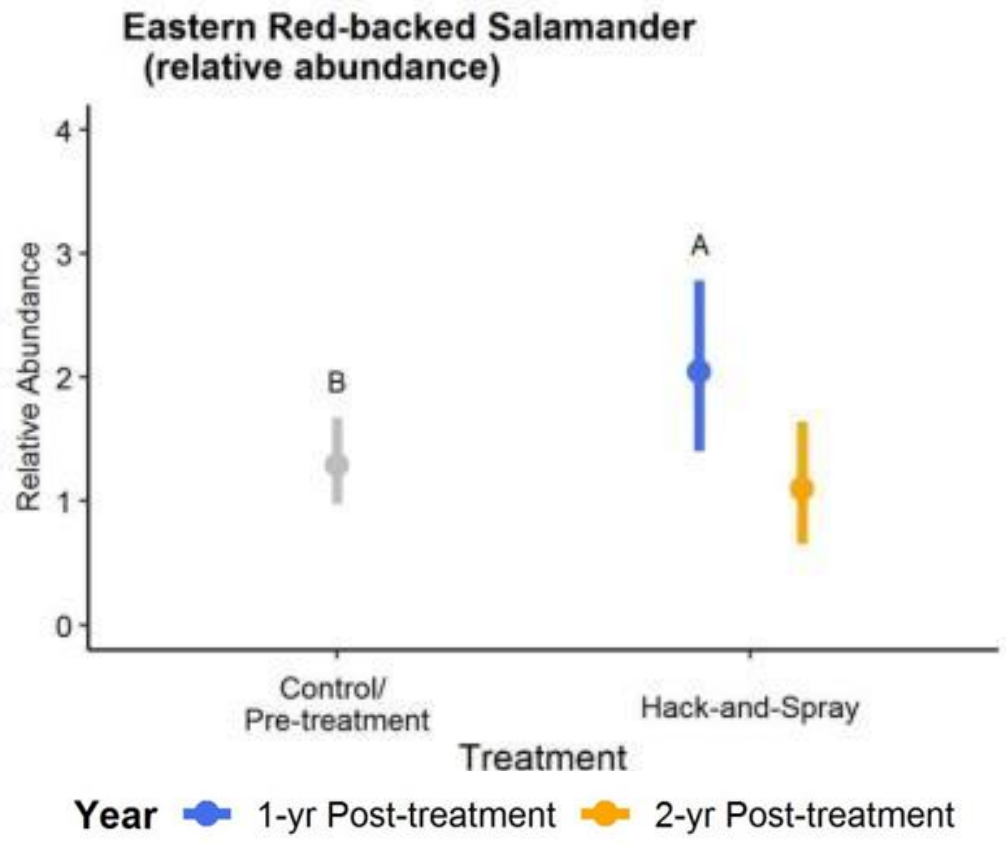

Figure 3-10. Plot-level relative abundance and 95\% confidence intervals of eastern red-backed salamanders (Plethodon cinereus). Differences in relative abundance within the HS treatment between pre-treatment/control and one-year or two-year post-treatment are indicated by alphabetical notation based on non-overlapping $95 \%$ credible intervals.

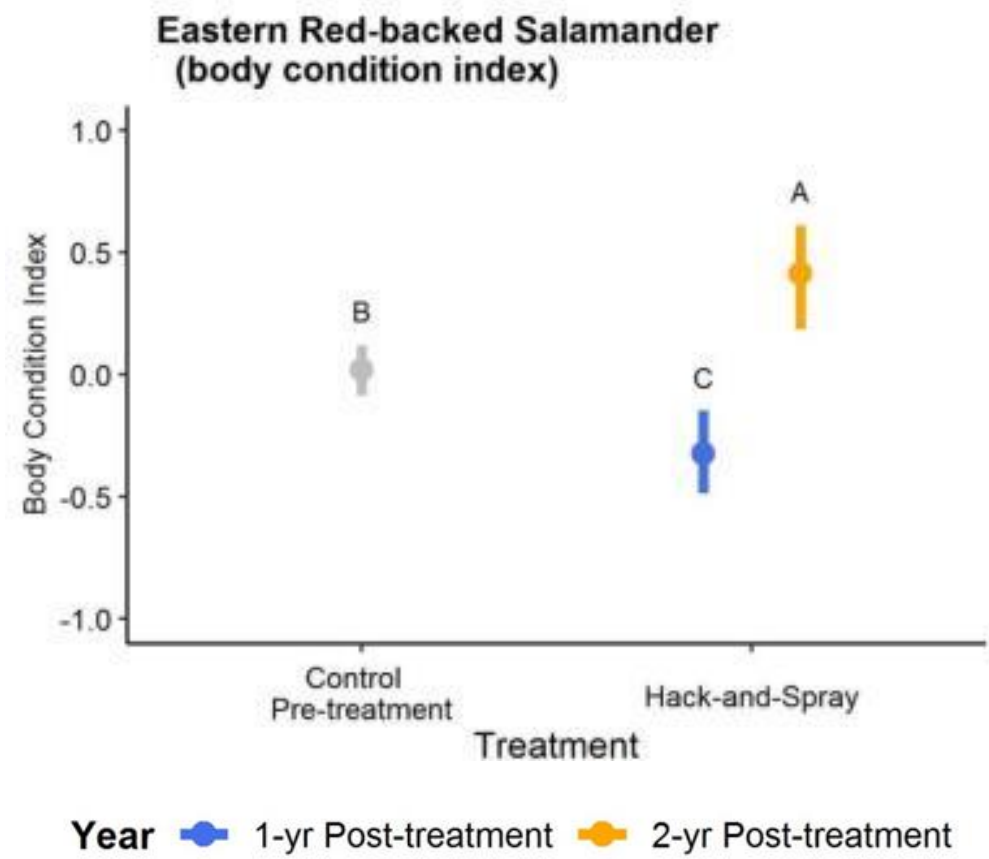

Figure 3-10. Plot-level body condition index (BCI) and 95\% confidence intervals of eastern redbacked salamanders (Plethodon cinereus). Differences in BCI within the HS treatment between pre-treatment/control and one-year or two-year post-treatment are indicated by alphabetical notation based on non-overlapping $95 \%$ credible intervals. 


\section{Appendices}

Appendix 3-A. Acreage managed by wildlife management area and year.

\begin{tabular}{lcrr}
\hline Wildlife Management Area & Year & Cutting Acreage & Herbicide Acreage \\
\hline Beury Mountain & Winter $2017-18$ & $100 \mathrm{ac}(40.5 \mathrm{ha})$ & $50 \mathrm{ac}(20.2 \mathrm{ha})$ \\
Center Branch & Winter $2017-18$ & $60 \mathrm{ac}(24.3 \mathrm{ha})$ & $0 \mathrm{ac}(0 \mathrm{ha})$ \\
Little Canaan & Winter $2016-17$ & $80 \mathrm{ac}(32.4 \mathrm{ha})$ & $40 \mathrm{ac}(16.2 \mathrm{ha})$ \\
Moncove Lake & Winter $2017-18$ & $40 \mathrm{ac}(16.2 \mathrm{ha})$ & $20 \mathrm{ac}(8.1 \mathrm{ha})$ \\
Short Mountain & Winter $2018-19$ & $20 \mathrm{ac}(8.1 \mathrm{ha})$ & $10 \mathrm{ac}(4 \mathrm{ha})$ \\
Sleepy Creek & Winter $2018-19$ & $20 \mathrm{ac}(8.1 \mathrm{ha})$ & $10 \mathrm{ac} \mathrm{(4} \mathrm{ha)}$ \\
\hline
\end{tabular}

\begin{tabular}{|c|c|c|}
\hline Year & Cutting Acreage & Herbicide Acreage \\
\hline Winter 2016-17 & $80 \mathrm{ac}(32.4 \mathrm{ha})$ & $40 \mathrm{ac}(16.2 \mathrm{ha})$ \\
\hline Winter 2017-18 & 200 ac (80.9 ha) & 70 ac (28.3 ha) \\
\hline Winter 2018-19 & 40 ac (16.2 ha) & $20 \mathrm{ac}$ (8.1 ha) \\
\hline & 320 ac (129.5 ha) & $130 \mathrm{ac}(52.6 \mathrm{ha})$ \\
\hline
\end{tabular}


Appendix 3-B. Total detections for bird species in regeneration stands heard within 100-m of point count and used in analyses for this chapter. Auditory detection type indicates which vocalizations were used to determine species presence. An "** indicates species was included in species-specific analysis. See Appendix 1-A for scientific names of species and guild assignments. Species of conservation priority (SCP) include those identified by Appalachian Mountains Joint Venture, Partners-in-Flight Appalachian region, or the West Virginia Division of Natural Resources State Wildlife Action Plan. Guild codes are: BF = bark foraging, $\mathrm{FG}=$ forest gap, FI = forest interior, $\mathrm{IE}=$ interior-edge, $\mathrm{PC}=$ primary cavity nester, $\mathrm{SC}=$ secondary cavity nester, $\mathrm{YF}=$ young forest.

\begin{tabular}{|c|c|c|c|c|c|}
\hline Common Name & Guild & $\begin{array}{c}\text { Auditory } \\
\text { Detection Type }\end{array}$ & SCP & Count & $\begin{array}{c}\text { Detection } \\
\text { Probability }\end{array}$ \\
\hline Acadian Flycatcher & FG & Song/Call & $\mathrm{X}$ & 25 & \\
\hline American Goldfinch & YF & Song/Call & & 44 & 0.126 \\
\hline Black-and-white Warbler* & FI, BF & Song & $\mathrm{X}$ & 91 & 0.327 \\
\hline Black-billed Cuckoo & IE & Song/Call & $\mathrm{X}$ & 2 & \\
\hline Black-capped Chickadee & $\mathrm{IE}, \mathrm{SC}, \mathrm{BF}$ & Song & & 29 & \\
\hline Black-throated Blue Warbler & FI & Song & $X$ & 39 & \\
\hline Black-throated Green Warbler* & FG & Song & & 104 & 0.267 \\
\hline Blue-headed Vireo* & FI & Song & & 94 & 0.209 \\
\hline Blue-winged Warbler & YF & Song & $\mathrm{X}$ & 14 & \\
\hline Brown Creeper & FI, SC, BF & Song & $X$ & 10 & \\
\hline Brown Thrasher & YF & Song & & 2 & \\
\hline Canada Warbler & $\mathrm{IE}$ & Song & $X$ & 17 & \\
\hline Carolina Chickadee & IE, SC & Song & & 17 & \\
\hline Carolina Wren & YF, SC & Song & & 12 & \\
\hline Cerulean Warbler & FG & Song & $X$ & 22 & \\
\hline Chestnut-sided Warbler* & YF & Song & & 62 & 0.212 \\
\hline Chipping Sparrow & YF & Song & $\mathrm{X}$ & 10 & \\
\hline Common Yellowthroat* & YF & Song & & 55 & 0.320 \\
\hline Downy Woodpecker & IE, PC, BF & Call & & 23 & \\
\hline Eastern Towhee* & YF & Song & $X$ & 160 & 0.242 \\
\hline Eastern Wood-pewee* & $\mathrm{IE}$ & Song & $\mathrm{X}$ & 79 & 0.355 \\
\hline Field Sparrow & YF & Song & $X$ & 13 & \\
\hline Gray Catbird & YF & Song/Call & & 16 & \\
\hline Great Crested Flycatcher & IE, SC & Song/Call & & 12 & \\
\hline Hairy Woodpecker & FI, PC, BF & Call & & 14 & \\
\hline Hooded Warbler* & FG & Song & $\mathrm{X}$ & 87 & 0.239 \\
\hline House Wren & IE, SC & Song & & 3 & \\
\hline Indigo Bunting* & YF & Song & & 62 & 0.241 \\
\hline Kentucky Warbler & FG & Song & $X$ & 16 & \\
\hline Least Flycatcher & FI & Song/Call & $X$ & 2 & \\
\hline Louisiana Waterthrush & FI & Song & $\mathrm{X}$ & 2 & \\
\hline
\end{tabular}


Appendix 3-B continued.

\begin{tabular}{lccrrr}
\hline Common Name & Guild & $\begin{array}{c}\text { Auditory } \\
\text { Detection Type }\end{array}$ & SCP & Count & $\begin{array}{c}\text { Detection } \\
\text { Probability }\end{array}$ \\
\hline Magnolia Warbler & FI & Song & & 8 & \\
Northern Flicker & IE, PC & Call & X & 5 & \\
Ovenbird & FI & Song & & 286 & 0.260 \\
Pileated Woodpecker & FI, PC, BF & Call & & 18 & \\
Pine Warbler & FI & Song & & 11 & \\
Prairie Warbler & YF & Song & X & 1 & \\
Red-bellied Woodpecker & IE, PC, BF & Call & & 30 & \\
Red-breasted Nuthatch & FI, SC, BF & Song/Call & & 3 & \\
Red-eyed Vireo & FG & Song & & 265 & 0.378 \\
Rose-breasted Grosbeak & IE & Song & X & 18 & \\
Scarlet Tanager & FI & Song & X & 137 & 0.198 \\
Swainson's Thrush & FI & Song & & 3 & \\
Tufted Titmouse & FI, SC & Song/Call & & 97 & 0.260 \\
Veery & IE & Song & X & 23 & \\
White-breasted Nuthatch & FG, SC & Song/Call & & 63 & 0.162 \\
White-eyed Vireo & YF & Song & & 8 & \\
Winter Wren & FI, SC & Song & & 3 & \\
Wood Thrush & FI & Song & X & 82 & 0.171 \\
Worm-eating Warbler & FI & Song & X & 31 & \\
Yellow-bellied Sapsucker & IE, PC, BF & Call & X & 1 & \\
Yellow-billed Cuckoo & IE & Song/Call & X & 40 & 0.180 \\
Yellow-breasted Chat & YF & Song & X & 5 & \\
Yellow-throated Warbler & FI & Song & X & 10 & \\
Yellow Warbler & YF & Song & & 4 & \\
\hline
\end{tabular}


Appendix 3-C. Model posterior predictive check (Bayesian $p$-value) and model performance (deviance information criterion [DIC]; lower is better) for focal bird species, avian guild, and eastern red-backed salamander (Plethodon cinereus) treatment-time interaction and main effects model analyses. Bayesian $p$-value is the probability to obtain a Chi-square test statistic that is at least as extreme as the observed Chi-square test statistic. We assumed reasonable model fit with a Bayesian $p$-value $>0.1$ and $<0.9$.

\begin{tabular}{|c|c|c|c|c|c|}
\hline \multicolumn{2}{|l|}{ Songbird } & \multicolumn{2}{|c|}{ Bayesian $p$-value } & \multicolumn{2}{|c|}{ DIC } \\
\hline Common name & Scientific name & $\begin{array}{l}\text { Treatment- } \\
\text { Time }\end{array}$ & $\begin{array}{c}\text { Main } \\
\text { Effects }\end{array}$ & $\begin{array}{l}\text { Treatment- } \\
\text { Time }\end{array}$ & $\begin{array}{l}\text { Main } \\
\text { Effects }\end{array}$ \\
\hline Black-and-white warbler & Mniotilta varia & 0.643 & 0.653 & 3417.0 & 3376.6 \\
\hline Black-throated green warbler & Setophaga virens & 0.317 & 0.310 & 3397.6 & 3434.3 \\
\hline Blue-headed vireo & Vireo solitaries & 0.140 & 0.183 & 3538.4 & 3500.3 \\
\hline Chestnut-sided warbler & Setophaga pensylvanica & 0.385 & 0.387 & 3201.5 & 3217.6 \\
\hline Common yellowthroat & Geothlypis trichas & 0.708 & 0.710 & 3136.8 & 3142.5 \\
\hline Eastern towhee & Pipilo erythrophthalmus & 0.325 & 0.315 & 3865.4 & 3918.1 \\
\hline Hooded warbler & Setophaga citrina & 0.503 & 0.530 & 3542.5 & 3536.8 \\
\hline Indigo bunting & Passerina cyanea & 0.410 & 0.433 & 3182.9 & 3183.5 \\
\hline Ovenbird & Seiurus aurocapilla & 0.868 & 0.853 & 4085.9 & 4058.5 \\
\hline Red-eyed vireo & Vireo olivaceus & 0.457 & 0.507 & 4150.2 & 4200.6 \\
\hline Tufted titmouse & Baeolophus bicolor & 0.367 & 0.353 & 3606.9 & 2578.7 \\
\hline \multicolumn{6}{|c|}{ Eastern red-backed salamander } \\
\hline Relative abundance & & 0.673 & $N A$ & 374.7 & $N A$ \\
\hline Body condition index & & 0.460 & $N A$ & 310.6 & $N A$ \\
\hline
\end{tabular}


Appendix 3-D. Total number of individuals captured (excluding recaptures) of salamander species by regeneration stand treatment over the study period.

\begin{tabular}{lll}
\hline \multicolumn{1}{c}{ Control } & HS \\
\hline $\begin{array}{l}\text { Eastern Red-backed Salamander } \\
\text { (Plethodon cinereus) }\end{array}$ & \\
\hline Pre-treatment & 38 & 24 \\
One-year Post-treatment & 43 & 45 \\
Two-year Post-treatment & 39 & 24 \\
\hline Mountain Dusky Salamander & & \\
(Desmognathus ochrophaeus) & & 5 \\
\hline Pre-treatment & 1 & 2 \\
One-year Post-treatment & 0 & 5 \\
Two-year Post-treatment & 0 & \\
\hline Northern Red Salamander & & 0 \\
(Pseudotriton ruber) & & 0 \\
\hline Pre-treatment & 1 & 0 \\
One-year Post-treatment & 0 & \\
Two-year Post-treatment & 0 & 7 \\
\hline Slimy Salamander & & \\
$(\boldsymbol{P}$. glutinosus) & & 7 \\
\hline Pre-treatment & \\
One-year Post-treatment & 4 & 1 \\
Two-year Post-treatment & 5 & \\
\hline Wehrle's Salamander & & \\
$(\boldsymbol{P}$. wehrlei) & & \\
\hline Pre-treatment & 2 & \\
One-year Post-treatment & 0 & \\
Two-year Post-treatment & 3 & \\
\hline & & \\
\hline
\end{tabular}




\title{
CHAPTER 4
}

\section{EFFECTS OF LOCAL- AND LANDSCALE-LEVEL HABITAT FEATURES ON FOREST SONGBIRDS IN HUMAN-MODIFIED LANDSCAPES}

\begin{abstract}
Land managers must be able to assess the influence of habitat features across multiple spatial scales when developing management plans. Although stand-level habitat management measures have a profound effect on species presence, broader spatial habitat features may limit the effectiveness of local-level management if not fully considered. In this chapter, we assessed the influence of local- (100-m radius surrounding point counts) and landscape-level (500-m radius) habitat features on the forest songbird community in cut-back borders along rights-of-way (ROWS) and wildlife openings. We examined four local-level variables (stand-level canopy cover, proportion of maintained early-successional habitat, proportion of young forest/shrubland habitat, and ROW/wildlife opening width) and five landscape-level variables (proportion of young forest/shrubland, core forest, mature forest, distance to nearest young forest/shrubland patch, and size of nearest young forest/shrubland patch) surrounding point counts to determine which variables had the strongest influence on species abundances and guild richness in cut-back borders. Landscape-level variables had the strongest influence on abundances and richness of young forest, forest gap, forest interior, and conservation priority species. Carolina wren and eastern towhee were more likely to occur in cut-back borders and ovenbirds were less likely to occur in cut-back borders that were located closer to pre-existing young forest/shrubland patches (see Appendix 1-A for scientific names). Size of nearest young forest/shrubland patch positively influenced common yellowthroat abundance, and negatively influenced black-and-white warbler and indigo bunting abundances. Proportion of young forest/shrubland habitat at the landscapelevel positively influenced mature forest-associated species black-and-white warbler, cerulean warbler, and hooded warbler as well as the species of conservation priority guild. No local-level variables strongly influenced abundance or richness in cut-back borders. These results indicate that within forest dominated landscapes, cut-back borders located closer to pre-existing young forest/shrubland patches benefit young forest species while species responses to the size of nearest young forest/shrubland patch is likely species-specific. For mature forest species,
\end{abstract}


presence of small levels of young forest/shrubland area at the landscape level appears to increase abundances in cut-back borders.

\section{Introduction}

Wildlife habitat management often aims to manipulate vegetation features to meet the habitat needs of a particular species or group of interest. Stand-level management measures need to be cognizant of surrounding habitats across multiple spatial scales however, and how landscape matrices can affect species responses to local management in order to make effective management decisions (Askins et al. 2007, Desrochers et al. 2010, Grinde et al. 2017).

Management is often focused at the local level because this scale often has the most profound effect on species distributions relative to landscape-level features (McDermott et al. 2011, Smith et al. 2011, Adams and Matthews 2019). However, when local-level management measures are implemented in concert with the surrounding landscape, the likelihood of success of local management often increases. This multi-spatial decisional hierarchy exhibited by species is best described as a gradient from features with high importance to features with low importance, which provides land managers with a select few habitat features to focus management efforts towards. However, the decisional hierarchy of a species is often site-dependent or generalized based on data from studies elsewhere. Currently, few studies have examined decisional hierarchies of species or groups within forestlands where linear energy infrastructure footprints dominate (e.g., underground gas pipelines, overhead utility powerlines, and seismic lines; Bayne et al. 2005, Mutter et al. 2015, Farwell et al. 2016). Understanding species decisional hierarchies within these anthropogenic landscapes will give managers management recommendations specific to these human-modified landscapes.

Partial canopy disturbance typically creates local vegetation characteristics beneficial to songbird species from a diverse array of habitat association groups (Sheehan et al. 2014). Local vegetation change, via cut-back borders, along abrupt forest edges of rights-of-way (hereafter "ROWs") and wildlife openings can influence songbird species associated with young forest and forest interior habitats (see Chapter 2 for results). However, responses to local vegetation in ROWs and wildlife openings often depend on landscape-level features to some degree (Askins et al. 2012). This seems particularly likely when managing young forest wildlife habitats in association with ROWs and wildlife openings within forest-dominated landscapes. Rights-ofway are narrow and wildlife openings are small in size, and within forest-dominated landscapes 
both are often isolated from other young forest or early-successional areas (Askins 1994). This isolation likely influences the effectiveness of local habitat management measures for young forest species along ROWs or wildlife openings (Roberts and King 2017). Further, vegetation type and associated species composition (e.g., herbaceous material in early-successional areas or woody plant material in young forest areas) in ROW corridors or wildlife openings may affect how young forest species respond to local management measures, which likely affects the effectiveness of local habitat management along ROWs and wildlife openings (Schlossberg et al. 2010).

Young forest wildlife species continue to face threats related to habitat loss and conversion (Trani et al. 2001, Dettmers 2003, Pardieck et al. 2019). The use of ROWs for managing and conserving young forest species has increased as ROWs have become more prominent on the landscape in West Virginia and the central Appalachian region (HIFLD 2019, EIA 2020). While ROWs and wildlife openings can provide needed habitat for young forest species, active management to improve these areas and optimize conservation measures has been generally unexplored. Further, little empirical evidence exists regarding the importance of habitat variables across multiple spatial scales for effectively managing young forest avifauna and other forest-associated songbird species along ROW and wildlife opening landscapes. For land managers to be able to optimize ROW and wildlife opening areas for forest songbirds, knowledge of how species respond to local- and landscape-level habitat features will be necessary. In this chapter, we assessed the relative importance of local- and landscape-level habitat variables (as it relates to songbirds) surrounding cut-back borders, and evaluated how early-successional vegetation (e.g., maintained grasslands and hay fields, shrubland, young forest) surrounding ROWs or wildlife openings affect avian responses in cut-back borders.

\section{Methods}

\subsection{Study area}

West Virginia lies within the central Appalachian region, which is characterized by extensive forests and humid continental climate with warm summers (daily mean $=22{ }^{\circ} \mathrm{C}$ ) and cool to cold winters (daily mean $=1{ }^{\circ} \mathrm{C}$ ). Elevations at study sites range from 224-1132 $\mathrm{m}$. Annual mean precipitation levels are 76,127 , and $102 \mathrm{~cm}$ in the western, central, and eastern portions of the state, respectively, distributed relatively uniformly throughout the year but highest in spring and summer (NOAA 2019). This study was conducted on eight West Virginia 
Division of Natural Resources' (WVDNR) wildlife management areas (WMAs) located throughout central and eastern West Virginia (Figure 2-1). Powerlines and pipelines used in this study were narrow linear openings (9-39 $\mathrm{m}$ in width [mean $=25.7, \mathrm{SD}=17.9 \mathrm{~m}]$ ) with varying purposes (i.e., gathering pipelines and short- and long-distance powerlines). Vegetation in powerlines and pipelines consisted of grassland or low shrubland vegetation, was void of a midor over-story vegetation layer, and was distinct from adjacent forests. Pipelines and powerlines are hereafter referred to as "ROWs". Wildlife openings used in this study were fields planted with a row crop (e.g., corn, clover) or left fallow for harvesting hay. Wildlife openings ranged $0.3-11.5$ ha $($ mean $=3.1, \mathrm{SD}=3.1 \mathrm{ha})$ in size, ranged $19-97 \mathrm{~m}($ mean $=57.8, \mathrm{SD}=21.7)$ in width, and were of varying shapes. Uses of wildlife openings (e.g., hay field, row crop) were consistent across years.

\subsection{Study design}

The eight study sites included 11 block replicates located along underground gas pipelines $(n=4)$, overhead utility powerlines $(n=4)$, or wildlife openings $(n=3)$. Study plots within block replicates were presumed to be subjected to similar biotic and abiotic environmental constraints. Block replicates along ROWs were located along one or two ROWs of similar widths within the same WMA and block replicates along wildlife openings were within the same WMA. A single block replicate consisted of seven independent experimental units (hereafter referred to as "cut-back borders") with each assigned one of seven experimental treatments. Treatment designation for each cut-back border consisted of randomly selecting one of two target residual basal area levels $\left(4.5 \mathrm{~m}^{2} / \mathrm{ha}\right.$ or $14.0 \mathrm{~m}^{2} /$ ha basal area retention) and one of three cutting depths into the forest (15 $\mathrm{m}$ [0.5 ha total area], $30 \mathrm{~m}$ [0.9 ha], or $45 \mathrm{~m}$ [1.4 ha] perpendicular to forest edge) with one cut-back border designated as a control (i.e., no tree cutting). Each cut-back border was $300 \mathrm{~m}$ in linear distance along the forest edge and $\geq 200 \mathrm{~m}$ apart to ensure sampling independence.

Local vegetation change in each cut-back border was induced via tree cutting using a feller-buncher or hand crew to mimic forest management prescriptions for clearcuts with reserves $\left(\sim 4.5 \mathrm{~m}^{2} / \mathrm{ha}\right)$ or crop tree/shelterwood stands $\left(\sim 14.0 \mathrm{~m}^{2} / \mathrm{ha}\right)$. Residual trees were based on species desirability (i.e., species of high wildlife value, such as oaks [Quercus spp.] and hickories [Carya spp.]). All trees $\geq 5 \mathrm{~cm} \mathrm{DBH}$ were felled, excluding selected residual trees. Felled trees were dropped within the cut-back border and remained on the ground. Herbicide was 
applied to non-native shrub species (e.g., autumn olive [Elaeagnus umbellate], Tatarian honeysuckle [Lonicera tatarica], and multiflora rose [Rosa multiflora]) to reduce presence in cut-back borders. Herbicide was applied in the fall and tree cutting occurred in the winter after pre-treatment data collection.

In each cut-back border, two avian and vegetation sampling points were spaced $150 \mathrm{~m}$ apart, $75 \mathrm{~m}$ from cut-back border ends, and located $15 \mathrm{~m}$ into the forest away from the ROW/wildlife opening edge. At each sampling point, we collected one- or two-years of posttreatment data on the avian community (see Table 2-1).

\subsection{Avian sampling}

We assessed songbirds in cut-back borders during the summer breeding period using 10minute standardized fixed-radius point counts (Bibby et al. 2002). At each of the two point count locations within each cut-back border, we conducted two visits during 18 May-27 June in 20162019. Surveys began after 0530 and before 1000 (EST) on days with no rain, no heavy or gusty winds, and minimal peripheral noise. Observers recorded species of each individual bird detected, type of detection (song, call, visual, or flyover), demographic information (male, female, juvenile, or unknown), distance from observer placed into one of five distance intervals (0-25 m, > 25-50 m, >50-75 m, >75-100 m, or >100 m), and time interval the individual was first detected (0-2 $\mathrm{min},>2-4 \mathrm{~min},>4-6 \mathrm{~min},>6-8 \mathrm{~min}$, and >8-10 min). Survey-level data were collected during each visit and included time of survey and ordinal day. Prior to surveys, observers were trained to independently identify all species visually and aurally while simultaneously recording distance and time interval. The surveyor skill variable used for analyses ranged from 3-5 after training where a score of 5 indicated thorough knowledge of species with extensive experience conducting point counts and a score of 3 indicated introductory knowledge of species with minimal experience conducting point counts. For all songbird data analyses, we used only detections within 50-m of the sampling point. We used this detection radius because sound attenuation of songbird vocalizations is species-specific and highly variable, and using a larger sampling radius (e.g., 100-m radius) may reduce detection rates of certain species that have higher frequency vocalizations (Schieck 1997, Yip et al. 2017). We included birds detected by sight and sound (excluding flyovers) for individual species and community statistical analyses. 


\subsection{Local and landscape metric derivation}

We derived local- and landscape-level variables centered on each point count location from 1-m resolution leaf-on aerial imagery from 2018 National Agriculture Imagery Program (NAIP 2018) and 3-m resolution digital elevation models (DEMs) from West Virginia Statewide Addressing and Mapping Board (SAMB 2008; WVGIS 2020), as well as personal knowledge of the study sites. We manually digitized land cover classes (Table 4-1) in the program ArcGIS (ESRI 2014) then converted maps to 1-m resolution raster grids. Breaks in land classes (i.e., roads through mature forest) were determined when breaks were $>3 \mathrm{~m}$. Using raster grids, we calculated proportion of land cover for each local- and landscape-scale land class and core forest area in FRAGSTATS (version 4; McGarigal et al. 2012).

Local-level variables represented data collected at each point-count location or within a 100-m radius. A 100-m radius encompasses a 3.1 ha area and represents the local extent surrounding each point count location and roughly approximates the size of a songbird territory (Springborn and Meyers 2005, Stober and Krementz 2006, Frantz et al. 2016). We included percent canopy cover $(C C)$ at each point count location as a surrogate for cut-back border harvest intensity. We measured canopy cover using a $25 \mathrm{~cm}$ x $25 \mathrm{~cm}$ transparent plexiglass panel, divided into a 5 x 5 grid and held overhead (Haché et al. 2013). Within the 100-m radius surrounding each point-count location, we measured the proportion of young forest (even-aged timber harvest occurring within the past 10 years and included the cut-back border into calculation) or shrubland habitat (areas with dense woody understory growth and no overstory cover; $Y F 100$ ), proportion of maintained habitat (habitats subjected to period maintenance, including grassland, hay field, row crop, or agriculture field; MTN100), width of ROW corridor or wildlife opening (WID), elevation (ELEV), and topographic relative moisture index (TRMI). Width of ROW corridor or wildlife opening (WID) adjacent to each point count location was measured from NAIP aerial photos. Elevation ( $E L E V)$ data were derived from DEMs.

Topographic relative moisture index (TRMI) was derived from slope percent, slope aspect, slope position, and slope configuration data in DEMs and represents a moisture gradient from xeric to mesic soils (Parker 1982). We calculated continuous variables ELEV and TRMI using zonal statistics in the program ArcGIS (version 10.0; ESRI 2014) to generate a mean value within a 50-m radius surrounding each point count location. 
Landscape-level variables represented data within a 500-m radius surrounding each point-count location, which encompassed a 78.5 ha area. We chose 500-m as a landscape-level radius because previous studies have shown that the 500-m extent captures species responses to landscape-level variables in ROW landscapes (Farwell et al. 2016). We did not use a larger spatial extent because the proportion of landscape-level variables did not change drastically beyond 500-m extent. Landscape-level variables included proportion of mature forest (areas where the majority of woody stems are $\geq 28.0 \mathrm{~cm}$ DBH, as per USDA Forest Service's Forest Inventory and Analysis classification, and was ground-truthed with aerial imagery using personal knowledge of the study sites; $M F)$, proportion of core forest $(C F)$, proportion of young forest or shrubland habitat (which included cut-back borders; YF500), distance to nearest young forest/shrubland patch (DIST), and size of nearest young forest/shrubland patch (SIZE). Core forest $(C F)$ was defined as the amount of mature forest $\geq 100 \mathrm{~m}$ from any edge visible on NAIP aerial photos (Didham and Lawton 1999, Hofmeister et al. 2019). All variables were selected based on assumed importance to the songbird community, ease of measurement and conceptualization, and ability to implement by land managers.

\subsection{Statistical analyses}

We used a stacked Bayesian $N$-mixture model to evaluate the effects of local- and landscape-level factors on individual songbird species and avian guilds (Kéry and Royle 2016). For individual songbird analysis, we used the same detection criteria as in Chapter 2 and included species that had $\geq 40$ detections and $\geq 0.2$ cumulative detection probability (i.e., probability of detecting a species at least once across two annual survey visits; see Appendix 2-C for species-level detections, guild association, and conservation status). For avian guild richness analysis, we used the young forest habitat guild (18 total species detected), forest gap specialist guild (seven species), forest interior habitat guild (19 species), and species of conservation priority (27 species). We used post-treatment data only (one-year and two-year post-treatment) for analyses to reflect habitat changes from management in the local- and landscape-level covariates. We did not incorporate time as a covariate of interest in the analyses as habitat variables tested did not change over the 2-year time-span.

We fit a single model for each species or guild composed of a detection sub-model and an abundance/richness sub-model. We modeled conditional detection probability from two annual survey visits with a binomial process model using ordinal day, time since sunrise, and surveyor 
skill as covariates on the logit-linear scale. For individual songbird analyses, we used the count of unique individuals during each visit as our response variable in our detection sub-model. For avian guild analyses, we used the number of unique species during each visit as our response variable in our detection sub-model. We modeled expected species abundance or guild richness using a Poisson process model. We modeled expected abundance or richness $\lambda$ for each species or guild at point-count $i$ during year $k$ as a function of an intercept $\beta$, random effects of point count $(P C)$ and treatment plot $(T P)$, two nuisance variables (ELEV and TRMI), four local-level covariates, and five landscape-level covariates:

$$
\begin{aligned}
\log \left(\lambda_{i k}\right)= & \beta+P C+T P+E L E V+T R M I+M T N 100+Y F 100+C C+W I D+ \\
& Y F 500+C F+M F+D I S T+S I Z E
\end{aligned}
$$

We included a point count random effect $(P C)$ to account for heterogeneity among points and repeated observation at the same point and a treatment plot random effect (TP) to account for the lack of independence between points within the same cut-back border. All variables were standardized to have a mean of 0 and standard deviation of one prior to analysis. Variables were tested for collinearity prior to analysis. If two variables were collinear, we removed one of the variables to avoid potentially inflated variances of collinear variables and incorrect coefficient sign of variables. Initially, the variables patchiness and $C F$ were highly collinear and thus we removed patchiness.

We used diffuse prior distributions for all slope coefficients (Gaussian [mean $=0, \mathrm{SD}=$ 100]). For our random point count and treatment plot effects, we used a Gaussian distribution (mean $=0$, variance $=\tau)$ prior with a hyperparameter $\tau$ from an inverse Gamma distribution $(\alpha=$ $1, \beta=1)$. We obtained posterior distributions of model parameters by running three parallel Markov chain Monte Carlo (MCMC) simulations of 40000 iterations with a burn-in of 20000 iterations at a thinning rate of 100, yielding 600 samples for posterior distributions. We assessed model fit with a posterior predictive check, where we compared Chi-square goodness-of-fit tests between an observed posterior predictive distribution and a simulated posterior predictive distribution. We calculated a Bayesian $p$-value, $p_{B}$, as the probability to obtain a Chi-square test statistic that is at least as extreme as the observed Chi-square test statistic and assumed reasonable fit if $0.1<p_{B}<0.9$ (Gelman et al. 2014). Model convergence was assessed using the Brooks-Gelman-Rubin statistic and assumed adequate convergence when all parameter Rhat 
values <1.1 (Brooks and Gelman 1998). Data analyses were performed in R (R Core Team 2019) using a Bayesian framework in JAGS (Plummer 2017) called from the package jagsUI (Kellner 2015). We considered a variable to have an influential effect on abundance of a given species or guild richness when the $95 \%$ credible interval around the estimated coefficient did not overlap zero.

\section{Results}

Landscape-level land cover within 500-m radius varied across study sites but all were dominated by mature forest cover $($ mean $=86 \%)$ with an average of $27 \%$ of this being core forest area (Table 4-1). Young forest/shrubland habitat was the predominant early-successional vegetation type at the local-level (100-m radius) with $23 \%$ of all land cover. Maintained earlysuccessional habitats comprised $11 \%$ of all land cover within $100-\mathrm{m}$ of point counts.

Our posterior predictive check indicated all individual species and avian guild models were a reasonable fit (Table 4-2). Eleven species from the young forest habitat guild, forest gap specialist habitat guild, forest interior habitat guild, or species of conservation priority met the detection criterion for species specific analyses (Table 4-3). The young forest habitat guild included five species (American goldfinch, Carolina wren, common yellowthroat, eastern towhee, and indigo bunting; scientific names for all species are provided in Table 4-3), the forest interior habitat guild included three species (black-and-white warbler, ovenbird, and wood thrush), and species of conservation priority included three species (cerulean warbler, eastern wood-pewee, and hooded warbler).

Of the variables tested, four landscape-level variables, YF500, CF, DIST, and SIZE, had a strong influence on abundance or richness of at least one of the 11 species and four guilds analyzed (Table 4-3; Figure 4-1). No local-level variables strongly influenced species responses. Three species (black-and-white warbler, cerulean warbler, and hooded warbler) and one guild (species of conservation priority) were positively influenced by YF500. Abundances of blackand-white warbler, cerulean warbler, and hooded warbler increased by $100.6 \%, 111.9 \%$, and $79.1 \%$, respectively, when YF500 increased by 3.8\% (2.9 ha). Richness of the species of conservation priority guild was also positively influenced by $Y F 500$ and increased by $21.5 \%$ when YF500 increased by $3.8 \%$. Core forest had a negative influence on cerulean warbler abundance; they decreased by $72.7 \%$ when $C F$ increased by $11.0 \%$ ( 8.6 ha increase). Distance to the nearest young forest/shrubland patch (DIST) had a positive influence on abundance of the 
ovenbird, and a negative influence on the Carolina wren, eastern towhee, and hooded warbler. When distance to nearest patch of young forest decreased by $337.3 \mathrm{~m}$ (a one standard deviation), abundances of Carolina wren, eastern towhee, and hooded warbler increased by $69.0 \%, 32.8 \%$, and $50.1 \%$, respectively, and decreased in ovenbirds by $50.5 \%$. The size of the nearest young forest/shrubland patch (SIZE) had a positive influence on common yellowthroat abundance and a negative influence on black-and-white warbler and indigo bunting abundances. Common yellowthroat abundance increased by $218.7 \%$, and black-and-warbler and indigo bunting decreased by $53.6 \%$ and $55.4 \%$, respectively, when SIZE increased.

\section{Discussion}

The proliferation of linear energy infrastructure in West Virginia and the central Appalachian region provides an opportunity for land managers to incorporate these man-made features into their management plans in an effort to manage the young forest songbird community. However, little information is available regarding the effects of habitat variables across multiple spatial scales on the young forest community in order to successfully promote ROW areas. In Chapter 2, we provided evidence that cut-back borders can increase habitat suitability along ROW and wildlife opening areas for young forest avifauna without compromising abundance of forest interior avifauna. In order to expand on these findings and continue developing wildlife management guidelines for these areas, here we have assessed the effects of habitat variables at the local- and landscape-level on songbirds in cut-back borders to determine their relative importance for managing avifauna in these landscapes. This information will provide guidance to managers on where in the landscape to place cut-back borders to optimize efforts that improve habitat suitability of cut-back border for the songbird community.

The landscape-level variable $Y F 500$ had a strong, positive influence on forest gap (cerulean warbler and hooded warbler) and forest interior (black-and-white warbler) species as well as the species of conservation priority guild which includes four forest gap and nine forest interior species (out of 27 total species). Despite YF500 only accounting for 3.8\% of landcover on average (3.0 of $78.5 \mathrm{ha}$ ), an increase of 2.7 ha of young forest/shrubland increased abundances of black-and-white warbler, cerulean warbler, and hooded warbler and richness of species of conservation priority. The strong relationship to YF500 by mature forest-associated species likely indicates that within these mature forest-dominated landscapes, small increases in

young forest/shrubland area increases the habitat suitability of cut-back borders for these species. 
Greater forest age heterogeneity likely benefits mature forest species because young forest/shrubland areas provide resources not provided in mature forests. Forest gap species use edges of small young forest/shrubland patches within contiguous mature forests for foraging, perching, and preening activities due to the increased vertical vegetation diversity provided in these areas (Weakland and Wood 2005, Bakermans and Rodewald 2009, Wood and Perkins 2012). Young forest/shrubland patches are also frequently used by mature forest-associated species during the post-breeding period due to the abundance of food resources and vegetative cover (Vitz and Rodewald 2006, McDermott and Wood 2010, Chandler et al. 2012). Therefore, breeding mature forest adult songbirds likely locate nests within $500 \mathrm{~m}$ of young forest/shrubland patches where fledging birds can access young forest/shrubland patches during the post-breeding period (White and Faaborg 2008, Delancey and Islam 2019). Thus, cut-back borders located in areas with greater amounts of young forest/shrubland increase a juvenile's access to these areas and possibly increase their survival. Surprisingly, no young forest species responded to increased total amount of young forest/shrubland at the landscape scale. Shoe (2018) reported that young forest species occurrence was positively associated with shrubland habitat within a 500-m buffer surrounding point counts in human-modified landscapes (e.g., sand and gravel mines, transmission line rights-of-way), however, Askins et al. (2007) reported surrounding landscape composition was not an important predictor of abundance of young forest species in wildlife openings. Although, our results indicate that YF500 does not appear to be an important driver of abundance or richness of young forest avifauna in cut-back borders, they did respond to distance or size of nearest young forest/shrubland patch.

Abundances of Carolina wren and eastern towhee in cut-back borders was greater when cut-back borders were placed closer to existing young forest/shrubland areas. Within these mature forest-dominated landscapes, cut-back borders were on average $245 \mathrm{~m}$ (15-2214 m) from the closest young forest/shrubland patch. The close proximity to young forest/shrubland habitats likely enhances cut-back borders by providing greater access to resources that young forest species are proficient at exploiting as well as promoting nearby areas through conspecific attraction (Fletcher Jr. 2007). Further, close proximity to young forest/shrubland areas provides a source population of young forest species that can more quickly colonize cut-back border harvests (Schlossberg 2009). Thus, isolation of cut-back borders from existing young forest/shrubland patches may reduce the effectiveness of cut-back borders for young forest 
wildlife management. Buffum and McKinney (2014) and Roberts and King (2017) both reported that young forest species occurred at greater rates in shrublands or wildlife openings when located closer to large young forest/shrubland patches. However, in our study, only the common yellowthroat was positively influenced by the size of the nearest young forest/shrubland patch while the indigo bunting was negatively influenced by $S I Z E$, which is consistent with previous studies on patch size relationships for these species (Rodewald and Vitz 2005, Lehnen and Rodewald 2009). Young forest species are capable of occupying small patches (as small as 0.23 ha) of young forest/shrubland habitats within predominately forested landscapes, but these relationships are often species-specific (Shake et al. 2012, George et al. 2019). Nearby young forest/shrubland patches in our study ranged $0.45-15.24$ ha in size ( $37 \%$ of all patches were $\leq 1$ ha). Species in cut-back borders may not be responding as strongly to the size of nearby young forest/shrubland patches within these landscapes because all our patches were above the minimum 0.23 ha size reported by previous studies. These results suggest that DIST has a more consistent influence on young forest species presence because cut-back borders are less isolated when located closer to other young forest/shrubland patches, while the influence of SIZE on young forest species is likely species-specific.

We observed varied and generally weak effects of $C C$ (a surrogate of cut-back border harvest intensity), MTN100, YF100, and YF500 on young forest species with the exception of species of conservation priority, which included seven young forest species (out of 27 species). Surprisingly, we did not observe a strong response to YF100 by young forest species. Past research has shown that young forest species in ROWs and wildlife openings are likely limited by the amount of surrounding early-successional habitat (Rodewald and Vitz 2005, Schlossberg and King 2008), and therefore we would expect this variable to strongly influence species in these areas. Higher levels of early-successional habitat surrounding wildlife openings increase local young forest species abundances (Askins et al. 2007, Roberts and King 2017, George et al. 2019). This trend is similar for ROW landscapes, as Farwell et al. (2016) reported earlysuccessional species were strongly influenced by edge density within 100-m (a variable that had a strong, positive correlation with YF100 in our study and thus not included in analysis). Additionally, we did not include a landscape-level metric that accounted for patchiness of the landscape (because of the high collinearity with $C F$ ).

\section{Management Implications}


The footprint of linear energy infrastructure within predominantly forested landscapes and its implications on the wildlife community continues to be an important topic with broad reaching consequences for the central Appalachian region. In this study, we found evidence to indicate that the young forest songbird community responded to landscape-level variables that potentially improve habitat suitability in cut-back borders along ROWs and wildlife openings. Placement of cut-back borders closer to pre-existing patches of young forest/shrubland habitat appears to improve habitat suitability for young forest songbirds. Size of nearest young forest/shrubland patch and total amount seem to not be as strong of a factor as distance in determining young forest responses to cut-back borders, possibly due to species-specific variation in area-sensitivity thresholds. Thus, managers can optimize placement of cut-back borders to benefit young forest species by choosing locations within $\sim 300 \mathrm{~m}$ of pre-existing young forest/shrubland patches (Figure 4-1).

The presence of young forest at the landscape-level was the most important habitat variable assessed in this study for mature forest and species of conservation priority species. Thus, within forest-dominated landscapes, a small amount of pre-existing young forest/shrubland habitat ( 10\%; Figure 4-1) is beneficial for the management and conservation of the mature forest songbird community. It should be noted that this study was conducted within a predominantly mature forested landscape. Within this context, young forest/shrubland at relatively low levels appear to benefit mature forest interior species. However, as mature forest levels decrease below certain thresholds, the relationship we observed between mature forest interior species and young forest/shrubland area may change (Becker et al. 2015, Farwell et al. 2020).

Before this study, limited information existed about how best to manage the forest bird community using ROW or wildlife opening areas within the context of the surrounding landscape. This research helps fill a vital knowledge gap on what variables and at what spatial scales are important for the management and conservation of forest songbirds. Our results indicated that across all species, landscape-level variables were the most influential to species abundance and richness in cut-back borders. However, for young forest species, presence of local-level habitat manipulation like cut-back borders likely promotes these areas. Without cutback borders at the local-level, landscape-level variables my not be as influential as we report. Prior to implementing local habitat measures, managers need to be aware of how surrounding 
habitats across multiple spatial scales may affect their management decisions. Future research on thresholds of local- and landscape-level habitats for young forest and mature forest songbirds in cut-back borders will help inform managers about the surrounding limitations of habitats related to cut-back borders in forest-dominated landscapes. Additionally, longer-term monitoring in order to fully evaluate spatio-temporal effects of local- and landscape-level habitats on songbirds will be valuable for developing long-term management plans. 


\section{Literature Cited}

Adams, B.T., and S.N. Matthews. 2019. Diverse temperate forest bird assemblages demonstrate closer correspondence to plant species composition than vegetation structure. Ecography 42 (10): 1752-1764. http://doi.org/10.1111/ecog.04487

Askins, R.A. 1994. Open corridors in a heavily forested landscape: impact on shrubland and forest-interior birds. Wildlife Society Bulletin 22: 339-347.

Askins, R.A., C.M. Folsom-O'Keefe, and M.C. Hardy. 2012. Effects of vegetation, corridor width and regional land use on early successional birds on powerline corridors. PLoS ONE 7 (2): e31520. http://doi.org/10.1371/journal.pone.0031520

Askins, R.A., B. Zuckerberg, and L. Novak. 2007. Do the size and landscape context of forest openings influence the abundance and breeding success of shrubland songbirds in southern New England? Forest Ecology and Management 250: 137-147. http://doi.org/10.1016/j.foreco.2007.05.009

Bakermans, M.H., and A.D. Rodewald. 2009. Think globally, manage locally: The importance of steady-state forest features for a declining songbird. Forest Ecology and Management 258: 224-232. http://doi.org/10.1016/j.foreco.2009.04.010

Bayne, E.M., S.L. Van Wilgenburg, S. Boutin, and K.A. Hobson. 2005. Modeling and fieldtesting of ovenbird (Seiurus aurocapillus) responses to boreal forest dissection by energy sector development at multiple spatial scales. Landscape Ecology 20: 203-216. http://doi.org/10.1007/s10980-004-2265-9

Becker, D.A., P.B. Wood, M.P. Strager, and C. Mazzarella. 2015. Impacts of mountaintop mining on terrestrial ecosystem integrity: identifying landscape thresholds for avian species in the central Appalachians, United States. Landscape Ecology 30: 339-356. http://doi.org/10.1007/s10980-014-0134-8

Bibby, C.J., N.D. Burgess, D.A. Hill, and S.H. Mustoe. 2002. Bird Census Techniques, $2^{\text {nd }}$ edition. Academic Press, London, UK. 302 p.

Brooks, S.P., and A. Gelman. 1998. General methods of monitoring convergence of iterative simulations. Journal of Computational and Graphical Statistics 7 (4): 434-455.

Buffum, B., and R.A. McKinney. 2014. Does proximity to wetland shrubland increase the habitat value for shrubland birds of small patches of upland shrubland in the northeastern United States? International Journal of Forestry Research 329836. http://doi.org/10.1155/2014/329836 
Chandler, C.C., D.I. King, and R.B. Chandler. 2012. Do mature forest birds prefer earlysuccessional habitat during the post-fledging period? Forest Ecology and Management 264: 1-9. http://doi.org/10.1016/j.foreco.2011.09.018

Delancey, C.D., and K. Islam. 2019. Post-fledging habitat use in a declining songbird. PeerJ. http://doi.org/10.7717/peerj.7358

Desrochers, A., C. Renaud, W.M. Hochachka, and M. Cadman. 2010. Area-sensitivity by forest songbirds: theoretical and practical implications of scale-dependency. Ecography 33 (5): 921-931. http://doi.org/10.1111/j.1600-0587.2009.06061.x

Dettmers, R. 2003. Status and conservation of shrubland birds in the northeastern US. Forest Ecology and Management 185: 81-93. http://doi.org/10.1016/S0378-1127(03)00248-2

Didham, R.K., and J.H. Lawton. 1999. Edge structure determines the magnitude of changes in microclimate and vegetation structure in tropical forest fragments. Biotropica 31 (1): 1730.

EIA (Energy Information Administration). 2020. Natural Gas Overview and Summary. U.S. Department of Energy, Washington, D.C. https://www.eia.gov/naturalgas/

ESRI. 2014. ArcGIS Desktop: Release 10.3. Redlands, CA: Environmental Systems Research Institute.

Farwell, L.S., P.B. Wood, R. Dettmers, and M. Brittingham. 2020. Threshold responses of songbirds to forest loss and fragmentation across the Marcellus-Utica shale gas region of central Appalachia, USA. Landscape Ecology 35: 1353-1370. http://doi.org/10.1007/s10980-020-01019-3

Farwell, L.S., P.B. Wood, J. Sheehan, and G.A. George. 2016. Shale gas development effects on the songbird community in a central Appalachian forest. Biological Conservation 201: 78-91. http://doi.org/10.1016/j.biocon.2016.06.019

Fletcher Jr., R.J. 2007. Species interactions and population density mediate the use of social cues for habitat selection. Journal of Animal Ecology 76 (3): 598-606. http://doi.org/10.1111/j.1365-2656.2007.01230.x

Frantz, M.W., K.R. Aldinger, P.B. Wood, J. Duchamp, T. Nuttle, A. Vitz, and J.L. Larkin. 2016. Space and habitat use of breeding Golden-winged Warblers in the central Appalchian Mountains. In Golden-winged Warbler Ecology, Conservation, and Habitat Management (H.M. Streby, D.E. Andersen, and D.A. Buehler, eds.). Studies in Avian Biology 49: 8194.

Gelman, A., J.B. Carlin, H.S. Stern, D.B. Dunson, A. Vehtari, and D.B. Rubin. 2014. Bayesian data analysis. Third edition. CRC Press, Boca Raton, Florida, USA, 661 p. 
George, A.D., P.A. Porneluzi, J.M. Haslerig, and J. Faaborg. 2019. Response of shrubland birds to regenerating clearcut area and shape. The Journal of Wildlife Management 83 (7): 1508-1514. http://doi.org/10.1002/jwmg.21733

Grinde, A.R., G.J. Niemi, B.R. Sturtevant, H. Panci, W. Thogmartin, and P. Wolter. 2017. Importance of scale, land cover, and weather on the abundance of bird species in a managed forest. Forest Ecology and Management 405: 295-308. http://doi.org/10.1016/j.foreco.2017.09.057

Hachè, S., T. Pètry, and M.-A. Villard. 2013. Numerical response of breeding birds following experimental selection harvesting in northern hardwood forests. Avian Conservation and Ecology 8 (1): 4. http://doi.org/10.5751/ACE-00584-080104

HIFLD (Homeland Infrastructure Foundation-Level Data). 2019. Electric Power Transmission Lines. https://hifld-geoplatform.opendata.arcgis.com/datasets/electric-power$\underline{\text { transmission-lines }}$

Hofmeister, J., J. Hošek, M. Brabec, R. Střalková, P. Mỳlová, M. Bouda, J.L. Pettit, M. Rydval, and M. Svoboda. 2019. Microclimate edge effect in small fragments of temperate forests in the context of climate change. Forest Ecology and Management 448: 48-56. http://doi.org/10.1016/j.foreco.2019.05.069

Kellner, K.F. 2015. jagsUI: a wrapper around rjags to streamline JAGS analyses. R package version 1.4.1.

Kéry, M., and J.A. Royle. 2016. Applied Hierarchical Modeling in Ecology: Analysis of distribution, abundance and species richness in R and BUGS, Volume 1. Academic Press. 783 pp.

Lehnen, S.E., and A.D. Rodewald. 2009. Investigating area-sensitivity in shrubland birds: Responses to patch size in a forested landscape. Forest Ecology and Management 257: 2308-2316. http://doi.org/10.1016/j.foreco.2009.03.008

McDermott, M.E., and P.B. Wood. 2010. Influence of cover and food resource variation on postbreeding bird use of timber harvests with residual canopy trees. The Wilson Journal of Ornithology 122 (3): 545-555. http://doi.org/10.1676/09-050.1

McDermott, M.E., P.B. Wood, G.W. Miller, and B.T. Simpson. 2011. Predicting breeding bird occurrence by stand- and microhabitat-scale features in even-aged stands in the Central Appalachians. Forest Ecology and Management 261: 373-380. http://doi.org/10.1016/j.foreco.2010.10.020

McGarigal, K., S.A. Cushman, and E. Ene. 2012. FRAGSTATS v4: Spatial Pattern Analysis Program for Categorical and Continuous Maps. University of Massachusetts, Amherst. 
Mutter, M., D.C. Pavlacky, Jr., N.J. Van Lanen, and R. Grenyer. 2015. Evaluating the impact of gas extraction infrastructure on the occupancy of sagebrush-obligate songbirds.

Ecological Applications 25 (5): 1175-1186.

NOAA (National Oceanic and Atmospheric Administration). 2019. National Weather Service Forecast Office, Charleston, WV. https://w2.weather.gov/climate/xmacis.php?wfo=rlx

Pardieck, K.L., D.J. Ziolkowski, M. Lutmerding, V. Aponte, and M-A.R. Hudson. 2019. North American Breeding Bird Survey Dataset 1966-2018, version 2018.0. U.S. Geological Survey, Patuxent Wildlife Research Center. http://doi.org/10.5066/P9HE8XYJ

Parker, A.J. 1982. The topographic relative moisture index: An approach to soil-moisture assessment in mountain terrain. Physical Geography 3 (2): 160-168.

Plummer, M. 2017. JAGS Version 4.3.0 user manual.

R Core Team. 2020. R: A language and environment for statistical computing. R Foundation for Statistical Computing, Vienna, Austria. https://www.R-project.org/

Roberts, H.P., and D.I. King. 2017. Area requirements and landscape-level factors influencing shrubland birds. The Journal of Wildlife Management 81 (7): 1298-1307. http://doi.org/10.1002/jwmg.21286

Rodewald, A.D., and A.C. Vitz. 2005. Edge- and area-sensitivity of shrubland birds. The Journal of Wildlife Management 69 (2): 681-688. http://doi.org/10.2193/0022541X(2005)069[0681:EAAOSB]2.0.CO;2

Schieck, J. 1997. Biased detection of bird vocalizations affects comparisons of bird abundance among forested habitats. The Condor 99 (1): 179-190.

Schlossberg, S. 2009. Site fidelity of shrubland and forest birds. The Condor 111 (2): 238-2469. http://doi.org/10.1525/cond.2009.080087

Schlossberg, S., and D.I. King. 2008. Are shrubland birds edge specialists? Ecological Applications 18 (6): 1325-1330.

Schlossberg, S., D.I. King, R.B Chandler, and B.A. Mazzei. 2010. Regional synthesis of habitat relationships in shrubland birds. Journal of Wildlife Management 74 (7): 1513-1522. http://doi.org/10.2193/2008-601

Shake, C.S., C.E. Moorman, J.D. Riddle, and M.R. Burchell II. 2012. Influence of patch size and shape on occupancy by shrubland birds. The Condor 114 (2): 268-278. http://doi.org/10.1525/cond.2012.110107 
Sheehan, J., P.B. Wood, D.A. Buehler, P.D. Keyser, J.L. Larkin, A.D. Rodewald, T.B. Wigley, T.J. Boves, G.A. George, M.H. Bakermans, T.A. Beachy, A. Evans, M.E. McDermott, F.L. Newell, K.A. Perkins, and M. White. 2014. Avian response to timber harvesting applied experimentally to manage Cerulean Warbler breeding populations. Forest Ecology and Management 321: 5-18. http://doi.org/10.1016/j.foreco.2013.07.037

Shoe, R. 2018. Site-specific and landscape features associated with shrubland bird occurrence in anthropogenic shrublands in the northeastern United States. Thesis. University of New Hampshire, Durham, New Hampshire, USA.

Smith, A.C., L. Fahrig, and C.M. Francis. 2011. Landscape size affects the relative importance of habitat amount, habitat fragmentation, and matrix quality on forest birds. Ecography 34 (1): 103-113. http://doi.org/10.1111/j.1600-0587.2010.06201.x

Springborn, E.G., and J.M. Meyers. 2005. Home range and survival of breeding painted buntings on Sapelo Island, Georgia. Wildlife Society Bulletin 33 (4): 1432-1439.

Stober, J.M., and D.G. Krementz. 2006. Variation in Bachman's sparrow home-range size at the Savannah river site, South Carolina. The Wilson Journal of Ornithology 118 (2): 138144. http://doi.org/10.1676/04-128.1

Trani, M.K., R.T. Brooks, T.L. Schmidt, V.A. Rudis, and C.M. Gabbard. 2001. Patterns and trends of early successional forests in the eastern United States. Wildlife Society Bulletin 29 (2): 413-424.

Vitz, A.C., and A.D. Rodewald. 2006. Can regenerating clearcuts benefit mature-forest songbirds? An examination of post-breeding ecology. Biological Conservation 127 (4): 477-486. http://doi.org/10.1016/j.biocon.2005.09.011

Weakland, C.A., and P.B. Wood. 2005. Cerulean warbler (Dendroica cerulea) microhabitat and landscape-level habitat characteristics in southern West Virginia. The Auk 122 (2): 497 508. http://doi.org/10.1093/auk/122.2.497

White, J.D., and J. Faaborg. 2008. Post-fledging movement and spatial habitat-use patterns of juvenile Swainson's thrushes. The Wilson Journal of Ornithology 120 (1): 62-73. http://doi.org/10.1676/06-142.1

Wood, P.B., and K.A. Perkins. 2012. Behavioral activities of male Cerulean Warblers in relation to habitat characteristics. The Wilson Journal of Ornithology 124 (3): 497-505. http://doi.org/10.1676/11-147.1

WVGIS (West Virginia GIS Technical Center). 2020. WV State GIS Data Clearinghouse. http://wvgis.wvu.edu/about/about.phpYip, D.A., E.M. Bayne, P. Sólymos, J. Campbell, and D. Proppe. 2017. Sound attenuation in forest and roadside environments: 
Implications for avian point-count surveys. The Condor 119 (1): 73-84. http://doi.org/10.1650/CONDOR-16-93.1 


\section{Tables}

Table 4-1. Percent cover and range (minimum and maximum) of local-level (100-m radius) and landscape-level (500-m radius) land cover variables surrounding each point count station at each Wildlife Management Area. Variable abbreviations include, MTN100 = proportion of maintained habitat (grassland, hay field, agriculture, row crop) within 100-m surrounding the point count, YF100 = proportion of young forest/shrubland within 100-m surrounding the point count, YF500 = proportion of young forest/shrubland within $500-\mathrm{m}$ surrounding the point count, $\mathrm{CF}=$ core forest within $500-\mathrm{m}$ surrounding the point count, and $\mathrm{MF}=$ proportion of mature forest within 500-m surrounding the point count.

\begin{tabular}{|c|c|c|c|c|c|}
\hline \multirow[b]{2}{*}{$\begin{array}{l}\text { Wildlife } \\
\text { Management Area }\end{array}$} & \multicolumn{2}{|c|}{ Local-level } & \multicolumn{3}{|c|}{ Landscape-level } \\
\hline & MTN100 & YF100 & YF500 & $\mathrm{CF}$ & MF \\
\hline Allegheny & $10.4(0.0,25.0)$ & $16.6(0.0,29.0)$ & $1.3(0.0,6.8)$ & $30.9(14.0,39.5)$ & $92.2(64.2,97.2)$ \\
\hline Beury Mountain & $0.0(0.0,0.0)$ & $34.5(15.9,56.2)$ & $6.7(3.3,20.6)$ & $29.1(6.8,42.7)$ & $91.7(76.7,96.5)$ \\
\hline Bluestone & $29.7(16.4,42.3)$ & $17.3(0.0,29.0)$ & $1.2(0.0,3.4)$ & $15.5(7.0,24.7)$ & $72.0(60.0,84.9)$ \\
\hline Burnsville Lake & $5.6(3.7,12.1)$ & $16.6(0.0,29.0)$ & $1.8(0.4,6.6)$ & $22.1(13.4,36.5)$ & $87.7(74.7,96.9)$ \\
\hline Lewis Wetzel & $11.8(0.0,31.4)$ & $19.2(0.0,46.1)$ & $2.4(0.0,8.5)$ & $27.7(12.5,42.0)$ & $87.2(73.4,97.2)$ \\
\hline Little Canaan & $0.0(0.0,0.0)$ & $31.8(12.3,46.9)$ & $5.9(3.1,13.0)$ & $30.7(16.9,39.9)$ & $91.9(80.2,96.7)$ \\
\hline Sleepy Creek & $15.6(10.6,21.0)$ & $16.6(0.0,29.0)$ & $0.7(0.0,1.2)$ & $41.4(31.5,55.8)$ & $96.5(94.8,98.2)$ \\
\hline Stonewall Jackson & $36.3(20.8,58.1)$ & $17.2(0.0,37.7)$ & $4.2(0.4,19.2)$ & $8.8(0.0,24.6)$ & $60.2(42.4,77.5)$ \\
\hline Mean & 11.0 & 23.2 & 3.5 & 26.7 & 86.4 \\
\hline
\end{tabular}


Table 4-2. Model posterior predictive check for each species and guild used in analysis. Bayesian $p$-value was the probability to obtain a Chi-square test statistic that is at least as extreme as the observed Chi-square test statistic. We assumed reasonable model fit if the Bayesian $p$-value of $>0.1$ and $<0.9$.

\begin{tabular}{llr}
\hline Common name & Scientific name & Bayesian $\boldsymbol{p}$-value \\
\hline American goldfinch & Spinus tristis & 0.188 \\
Black-and-white warbler & Mniotilta varia & 0.335 \\
Carolina wren & Thryothorus ludovicianus & 0.193 \\
Cerulean warbler & Setophaga cerulea & 0.337 \\
Common yellowthroat & Geothlypis trichas & 0.313 \\
Eastern towhee & Pipilo erythrophthalmus & 0.303 \\
Eastern wood-pewee & Contopus virens & 0.363 \\
Hooded warbler & Setophaga citrina & 0.390 \\
Indigo bunting & Passerina cyanea & 0.603 \\
Ovenbird & Seiurus aurocapilla & 0.437 \\
Wood thrush & Hylocichla mustelina & 0.235 \\
\hline Avian Guilds & & 0.623 \\
\hline Young forest habitat & & 0.552 \\
Forest gap specialist & & 0.353 \\
Forest interior habitat & & 0.682 \\
Species of conservation priority & \\
\hline
\end{tabular}


Table 4-3. Mean effect size (on the response scale) of local- and landscape-level variables on species abundance and guild richness. Table values indicate the percent change in species-specific abundance or guild-specific species richness when local-and landscapelevel variables increase by one standard deviation ("Variable Increase" in table). Numbers in bold indicate 95\% credible interval of mean effect size did not overlap 0. Variable abbreviations include, MTN100 = proportion of maintained habitat within 100-m surrounding the point count, YF100 = proportion of young forest/shrubland within $100-\mathrm{m}$ surrounding the point count, $\mathrm{CC}=$ percent canopy cover at the point count, WID = width of right-of-way or wildlife opening, YF500 = proportion of young forest/shrubland within 500-m surrounding the point count, $\mathrm{CF}=$ core forest within 500-m surrounding the point count, $\mathrm{MF}=$ proportion of mature forest within 500-m surrounding the point count, DIST $=$ distance to nearest young forest/shrubland patch, and SIZE $=$ size of nearest young forest/shrubland patch.

\begin{tabular}{|c|c|c|c|c|c|c|c|c|c|}
\hline & \multicolumn{4}{|c|}{ Local-level } & \multicolumn{5}{|c|}{ Landscape-level } \\
\hline & MTN100 & YF100 & $\mathbf{C C}$ & WID & YF500 & $\mathbf{C F}$ & MF & DIST & SIZE \\
\hline Variable Increase & $13.3 \%$ & $13.3 \%$ & $35.1 \%$ & $34.1 \%$ & $3.8 \%$ & $11.0 \%$ & $11.8 \%$ & $337.3 \mathrm{~m}$ & $4.3 \mathrm{ha}$ \\
\hline \multicolumn{10}{|l|}{ Individual Species } \\
\hline \multicolumn{10}{|l|}{ Young Forest Guild } \\
\hline American goldfinch & 38.4 & 13.5 & -7.1 & 3.0 & -2.8 & -24.3 & -3.7 & -2.4 & -1.5 \\
\hline Carolina wren & -41.2 & -9.8 & 81.1 & 15.7 & -42.0 & 48.0 & -59.8 & -69.0 & -55.6 \\
\hline Common yellowthroat & -56.9 & -28.9 & -6.3 & 20.9 & -11.0 & 92.9 & -58.9 & -12.8 & 218.7 \\
\hline Eastern towhee & 41.6 & 6.2 & -17.1 & 8.9 & 11.1 & 14.6 & 16.5 & -32.8 & 12.7 \\
\hline Indigo bunting & 14.1 & 19.5 & -4.1 & 1.2 & 12.7 & 19.5 & -23.0 & 7.8 & -55.4 \\
\hline \multicolumn{10}{|l|}{ Forest Interior Guild } \\
\hline Black-and-white warbler & 9.3 & 0.7 & 13.0 & -13.5 & 100.6 & 28.8 & 108.7 & -19.8 & -53.6 \\
\hline Ovenbird & -48.9 & 4.1 & 18.1 & 13.8 & -13.3 & 7.8 & 50.5 & 50.5 & 14.1 \\
\hline Wood thrush & -59.4 & 2.9 & 17.4 & -14.8 & -19.5 & 35.4 & -29.7 & 30.5 & -16.7 \\
\hline \multicolumn{10}{|l|}{ Species of Conservation Priority } \\
\hline Cerulean warbler & -3.2 & -0.5 & -2.6 & 26.5 & 111.9 & -72.7 & 155.5 & -30.6 & 28.9 \\
\hline Eastern wood-pewee & 22.8 & 3.6 & -13.4 & -21.1 & 26.6 & 3.6 & 123.4 & 36.6 & -8.1 \\
\hline Hooded warbler & 33.6 & -12.4 & 15.4 & -32.6 & 79.1 & -12.0 & 104.0 & -50.1 & -16.8 \\
\hline \multicolumn{10}{|l|}{ Avian Guilds } \\
\hline Young forest habitat & 13.3 & 0.7 & -5.8 & 2.8 & 7.4 & 19.1 & -20.6 & -6.9 & 8.4 \\
\hline Forest gap specialist & -13.7 & -10.2 & 2.5 & -4.8 & 18.2 & -14.1 & 9.1 & -14.0 & -8.6 \\
\hline Forest interior habitat & -5.3 & 3.0 & 16.3 & 3.0 & 14.8 & 9.6 & 21.4 & 11.2 & -20.1 \\
\hline Species of conservation priority & 0.6 & -0.4 & 4.7 & -5.3 & 21.5 & 4.7 & 3.7 & -0.2 & -8.6 \\
\hline
\end{tabular}




\section{Figures}
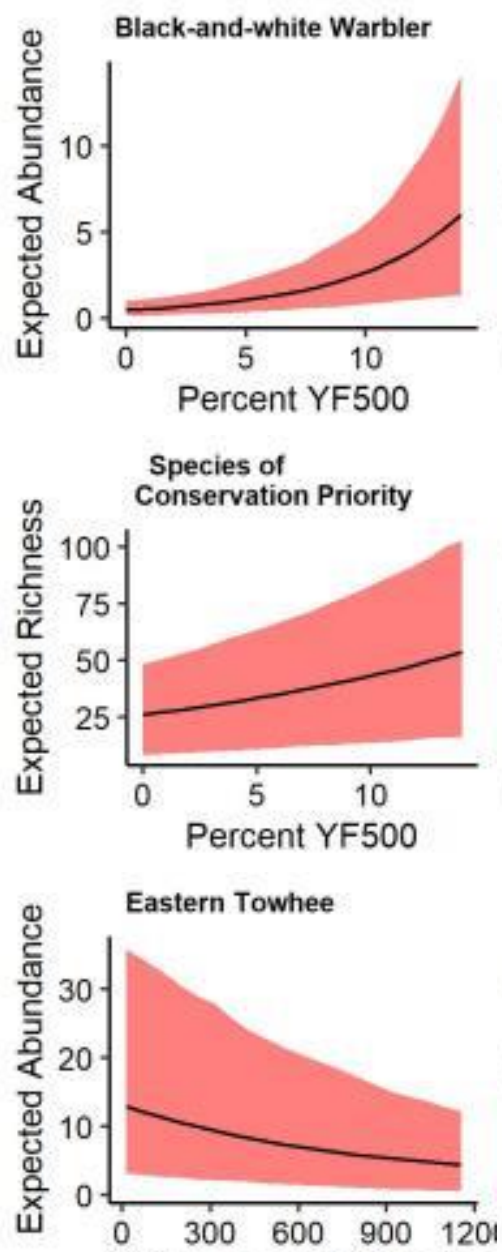

Dist. to nearest YF patch
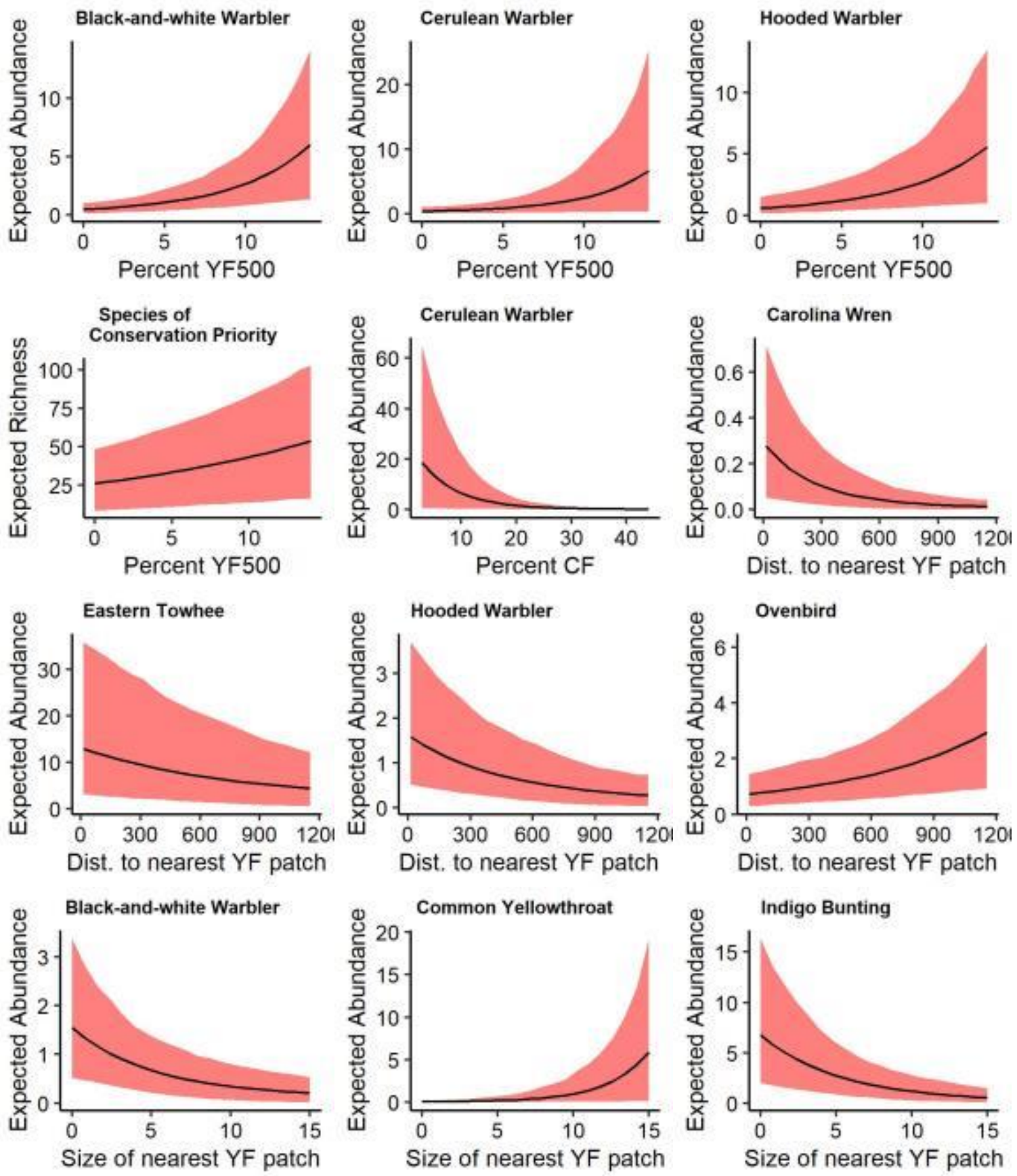

Figure 4-1. Expected point-level mean species abundance or guild richness and $85 \%$ confidence intervals as a function of local- and landscape-level variables surrounding point counts in cutback borders. Data on x-axis for variables includes the $95 \%$ quantile to reduce inflation of estimates near data outliers. 


\section{Appendices}

Appendix 4-A. Coordinates of treatment plot corners for cut-back borders. All coordinates are in NAD83, UTM Zone 17. Control plots have two corners indicating the location of their plot location along the forest edge.

\begin{tabular}{lcc|lcc}
\hline Study Site: Allegheny WMA & & Study Site: Bluestone WMA & \\
\hline Treatment & Easting & Northing & Treatment & Easting & Northing \\
\hline Control & 668713 & 4364639 & Control & 513258 & 4143520 \\
& 669010 & 4364630 & & 513393 & 4143772 \\
\hline $15 \mathrm{~m}, 4.5 \mathrm{~m}^{2} / \mathrm{ha}$ & 668414 & 4364648 & $15 \mathrm{~m}, 4.5 \mathrm{~m}^{2} / \mathrm{ha}$ & 512085 & 4147258 \\
& 668354 & 4364354 & & 512072 & 4147251 \\
& 668339 & 4364357 & & 511882 & 4147567 \\
& 668400 & 4364651 & & 511877 & 4147543 \\
\hline $15 \mathrm{~m}, 14 \mathrm{~m}^{2} / \mathrm{ha}$ & 663400 & 4358311 & $15 \mathrm{~m}, 14 \mathrm{~m}^{2} / \mathrm{ha}$ & 511292 & 4147067 \\
& 663672 & 4358184 & & 511278 & 4147073 \\
& 663678 & 4358197 & & 511185 & 4146795 \\
& 663406 & 4358325 & & 511196 & 4146784 \\
\hline $30 \mathrm{~m}, 4.5 \mathrm{~m}^{2} / \mathrm{ha}$ & 668431 & 4364840 & $30 \mathrm{~m}, 4.5 \mathrm{~m}^{2} / \mathrm{ha}$ & 513013 & 4143204 \\
& 668261 & 4365089 & & 513022 & 4143176 \\
& 668284 & 4365108 & & 512938 & 4142946 \\
& 668457 & 4364855 & & 512909 & 4142953 \\
\hline $30 \mathrm{~m}, 14 \mathrm{~m}^{2} / \mathrm{ha}$ & 667908 & 4363299 & $30 \mathrm{~m}, 14 \mathrm{~m}^{2} / \mathrm{ha}$ & 512774 & 4142804 \\
& 668021 & 4363572 & & 512799 & 4142821 \\
& 667994 & 4363586 & & 512674 & 4142537 \\
& 667938 & 4363293 & & 512694 & 4142514 \\
\hline $45 \mathrm{~m}, 4.5 \mathrm{~m}^{2} / \mathrm{ha}$ & 668107 & 4363752 & $45 \mathrm{~m}, 4.5 \mathrm{~m}^{2} / \mathrm{ha}$ & 512905 & 4145444 \\
& 668211 & 4364017 & & 512887 & 4145402 \\
& 668167 & 4364027 & & 513157 & 4145272 \\
& 668066 & 4363770 & & 513177 & 4145312 \\
\hline $45 \mathrm{~m}, 14 \mathrm{~m}^{2} / \mathrm{ha}$ & 662945 & 4358519 & $45 \mathrm{~m}, 14 \mathrm{~m}^{2} / \mathrm{ha}$ & 512724 & 4145521 \\
& 663218 & 4358395 & & 512705 & 4145480 \\
& 663237 & 4358436 & & 512394 & 4145601 \\
& 662964 & 4358560 & & 512424 & 4145567 \\
\hline
\end{tabular}


Appendix 4-A continued.

\begin{tabular}{lcc|lcc}
\hline \multicolumn{2}{l}{ Study Site: Beury Mountain WMA Block 1 } & \multicolumn{2}{l}{ Study Site: Beury Mountain WMA Block 2 } \\
\hline Treatment & Easting & Northing & Treatment & Easting & Northing \\
\hline Control & 499078 & 4199170 & Control & 500366 & 4198119 \\
& 499078 & 4198883 & & 500638 & 4197993 \\
\hline $15 \mathrm{~m}, 4.5 \mathrm{~m}^{2} / \mathrm{ha}$ & 500096 & 4199967 & $15 \mathrm{~m}, 4.5 \mathrm{~m}^{2} / \mathrm{ha}$ & 501276 & 4197705 \\
& 500091 & 4199981 & & 501282 & 4197719 \\
& 500379 & 4200064 & & 501556 & 4197595 \\
& 500383 & 4200050 & & 501549 & 4197581 \\
\hline $15 \mathrm{~m}, 14 \mathrm{~m}^{2} / \mathrm{ha}$ & 500578 & 4200120 & $15 \mathrm{~m}, 14 \mathrm{~m}^{2} / \mathrm{ha}$ & 498362 & 4199001 \\
& 500574 & 4200106 & & 498368 & 4199015 \\
& 500863 & 4200030 & & 498641 & 4198891 \\
& 500868 & 4200044 & & 498635 & 4198878 \\
\hline $30 \mathrm{~m}, 4.5 \mathrm{~m}^{2} / \mathrm{ha}$ & 501740 & 4199800 & $30 \mathrm{~m}, 4.5 \mathrm{~m}^{2} / \mathrm{ha}$ & 499151 & 4198708 \\
& 501743 & 4199831 & & 499140 & 4198680 \\
& 502044 & 4199752 & & 499415 & 4198561 \\
& 502037 & 4199723 & & 499427 & 4198588 \\
\hline $30 \mathrm{~m}, 14 \mathrm{~m}^{2} / \mathrm{ha}$ & 498268 & 4198747 & $30 \mathrm{~m}, 14 \mathrm{~m}^{2} / \mathrm{ha}$ & 497901 & 4199198 \\
& 498274 & 4198718 & & 497914 & 4199225 \\
& 498569 & 4198766 & & 498186 & 4199098 \\
& 498565 & 4198796 & & 498173 & 4199071 \\
\hline $45 \mathrm{~m}, 4.5 \mathrm{~m}^{2} / \mathrm{ha}$ & 501059 & 4199983 & $45 \mathrm{~m}, 4.5 \mathrm{~m}^{2} / \mathrm{ha}$ & 499894 & 4198313 \\
& 501066 & 4200025 & & 499875 & 4198272 \\
& 501376 & 4199951 & & 500149 & 4198149 \\
& 501367 & 4199908 & & 500168 & 4198191 \\
\hline $45 \mathrm{~m}, 14 \mathrm{~m}^{2} / \mathrm{ha}$ & 499615 & 4199831 & $45 \mathrm{~m}, 14 \mathrm{~m}^{2} / \mathrm{ha}$ & 500820 & 4197910 \\
& 499603 & 4199873 & & 500838 & 4197950 \\
& 499890 & 4199960 & & 501112 & 4197828 \\
& 499902 & 4199917 & & 501093 & 4197786 \\
\hline
\end{tabular}


Appendix 4-A continued.

\begin{tabular}{lcc|lcc}
\hline \multicolumn{3}{l}{ Study Site: Burnsville Lake WMA } & \multicolumn{3}{l}{ Study Site: Sleepy Creek WMA } \\
\hline Treatment & Easting & Northing & Treatment & Easting & Northing \\
\hline Control & 533878 & 4295283 & Control & 745621 & 4380729 \\
& 533967 & 4295539 & & 745616 & 4380732 \\
\hline $15 \mathrm{~m}, 4.5 \mathrm{~m}^{2} / \mathrm{ha}$ & 533056 & 4295470 & $15 \mathrm{~m}, 4.5 \mathrm{~m}^{2} / \mathrm{ha}$ & 740296 & 4364980 \\
& 533057 & 4295484 & & 740310 & 4364976 \\
& 532770 & 4295541 & & 740297 & 4364983 \\
& 532782 & 4295549 & & 740310 & 4364976 \\
\hline $15 \mathrm{~m}, 14 \mathrm{~m}^{2} / \mathrm{ha}$ & 533669 & 4294470 & $15 \mathrm{~m}, 14 \mathrm{~m}^{2} / \mathrm{ha}$ & 740553 & 4365139 \\
& 533683 & 4294465 & & 740544 & 4365151 \\
& 533802 & 4294739 & & 740522 & 4365135 \\
& 533815 & 4294730 & & 740533 & 4365124 \\
\hline $30 \mathrm{~m}, 4.5 \mathrm{~m}^{2} / \mathrm{ha}$ & 532567 & 4295880 & $30 \mathrm{~m}, 4.5 \mathrm{~m}^{2} / \mathrm{ha}$ & 740608 & 4366814 \\
& 532269 & 4295897 & & 740603 & 4366813 \\
& 532266 & 4295867 & & 740594 & 4366842 \\
& 532565 & 4295851 & & 740598 & 4366843 \\
\hline $30 \mathrm{~m}, 14 \mathrm{~m}^{2} / \mathrm{ha}$ & 533721 & 4295116 & $30 \mathrm{~m}, 14 \mathrm{~m}^{2} / \mathrm{ha}$ & 740281 & 4365261 \\
& 533711 & 4295088 & & 740281 & 4365231 \\
& 533819 & 4294854 & & 740253 & 4365411 \\
& 533789 & 4294851 & & 740223 & 4365407 \\
\hline $45 \mathrm{~m}, 4.5 \mathrm{~m}^{2} / \mathrm{ha}$ & 532059 & 4296240 & $45 \mathrm{~m}, 4.5 \mathrm{~m}^{2} / \mathrm{ha}$ & 740439 & 4366331 \\
& 532172 & 4295973 & & 740393 & 4366342 \\
& 532209 & 4295996 & & 740439 & 4366331 \\
& 532106 & 4296239 & & 740393 & 4366342 \\
\hline $45 \mathrm{~m}, 14 \mathrm{~m}^{2} / \mathrm{ha}$ & 533569 & 4295242 & $45 \mathrm{~m}, 14 \mathrm{~m}^{2} / \mathrm{ha}$ & 745261 & 4383007 \\
& 533597 & 4295277 & & 745291 & 4383041 \\
& 533362 & 4295440 & & 745230 & 4383019 \\
& 533370 & 4295484 & & 745225 & 4383064 \\
\hline
\end{tabular}


Appendix 4-A continued.

\begin{tabular}{lcc|lcc}
\hline \multicolumn{3}{l}{ Study Site: Lewis Wetzel WMA Block 1 } & \multicolumn{3}{l}{ Study Site: Lewis Wetzel WMA Block 2 } \\
\hline Treatment & Easting & Northing & Treatment & Easting & Northing \\
\hline Control & 529391 & 4374319 & Control & 529157 & 4372088 \\
& 529562 & 4374084 & & 529216 & 4371776 \\
\hline $15 \mathrm{~m}, 4.5 \mathrm{~m}^{2} / \mathrm{ha}$ & 528184 & 4373598 & $15 \mathrm{~m}, 4.5 \mathrm{~m}^{2} / \mathrm{ha}$ & 529624 & 4373163 \\
& 528170 & 4373604 & & 529633 & 4373150 \\
& 528156 & 4373876 & & 529859 & 4373347 \\
& 528168 & 4373885 & & 529845 & 4373353 \\
\hline $15 \mathrm{~m}, 14 \mathrm{~m}^{2} / \mathrm{ha}$ & 529641 & 4373917 & $15 \mathrm{~m}, 14 \mathrm{~m}^{2} / \mathrm{ha}$ & 529913 & 4373535 \\
& 529656 & 4373916 & & 529924 & 4373525 \\
& 529774 & 4373699 & & 530203 & 4373567 \\
& 529770 & 4373684 & & 530204 & 4373582 \\
\hline $30 \mathrm{~m}, 4.5 \mathrm{~m}^{2} / \mathrm{ha}$ & 528982 & 4373290 & $30 \mathrm{~m}, 4.5 \mathrm{~m}^{2} / \mathrm{ha}$ & 528369 & 4373306 \\
& 528952 & 4373288 & & 528341 & 4373296 \\
& 529035 & 4373572 & & 528508 & 4373048 \\
& 529065 & 4373574 & & 528532 & 4373066 \\
\hline $30 \mathrm{~m}, 14 \mathrm{~m}^{2} / \mathrm{ha}$ & 530917 & 4372626 & $30 \mathrm{~m}, 14 \mathrm{~m}^{2} / \mathrm{ha}$ & 529238 & 4372724 \\
& 530887 & 4372625 & & 529268 & 4372732 \\
& 530884 & 4372354 & & 529318 & 4372417 \\
& 530915 & 4372353 & & 529290 & 4372421 \\
\hline $45 \mathrm{~m}, 4.5 \mathrm{~m}^{2} / \mathrm{ha}$ & 528895 & 4374812 & $45 \mathrm{~m}, 4.5 \mathrm{~m}^{2} / \mathrm{ha}$ & 528660 & 4372884 \\
& 528848 & 4374813 & & 528655 & 4372839 \\
& 528999 & 4374544 & & 528931 & 4372823 \\
& 528964 & 4374517 & & 528962 & 4372856 \\
\hline $45 \mathrm{~m}, 14 \mathrm{~m}^{2} / \mathrm{ha}$ & 529035 & 4374076 & $45 \mathrm{~m}, 14 \mathrm{~m}^{2} / \mathrm{ha}$ & 530417 & 4373548 \\
& 528992 & 4374064 & & 530402 & 4373506 \\
& 529005 & 4373786 & & 530632 & 4373344 \\
& 529049 & 4373780 & & 530666 & 4373373 \\
\hline
\end{tabular}


Appendix 4-A continued.

\begin{tabular}{lcc|lcc}
\hline \multicolumn{3}{l}{ Study Site: Little Canaan WMA Block 1 } & \multicolumn{3}{l}{ Study Site: Little Canaan WMA Block 2 } \\
\hline Treatment & Easting & Northing & Treatment & Easting & Northing \\
\hline Control & 635245 & 4332188 & Control & 633883 & 4331349 \\
& 635364 & 4331917 & & 634090 & 4331138 \\
\hline $15 \mathrm{~m}, 4.5 \mathrm{~m}^{2} / \mathrm{ha}$ & 635063 & 4332645 & $15 \mathrm{~m}, 4.5 \mathrm{~m}^{2} / \mathrm{ha}$ & 634846 & 4330419 \\
& 635049 & 4332639 & & 634862 & 4330438 \\
& 635179 & 4332379 & & 635069 & 4330230 \\
& 635165 & 4332373 & & 635056 & 4330216 \\
\hline $15 \mathrm{~m}, 14 \mathrm{~m}^{2} / \mathrm{ha}$ & 635143 & 4332338 & $15 \mathrm{~m}, 14 \mathrm{~m}^{2} / \mathrm{ha}$ & 634150 & 4331140 \\
& 635128 & 4332332 & & 634137 & 4331127 \\
& 635013 & 4332603 & & 634354 & 4330939 \\
& 635028 & 4332609 & & 634338 & 4330923 \\
\hline $30 \mathrm{~m}, 4.5 \mathrm{~m}^{2} / \mathrm{ha}$ & 635973 & 4330518 & $30 \mathrm{~m}, 4.5 \mathrm{~m}^{2} / \mathrm{ha}$ & 634485 & 4330784 \\
& 636000 & 4330530 & & 634507 & 4330804 \\
& 636117 & 4330256 & & 634712 & 4330594 \\
& 636090 & 4330244 & & 634691 & 4330574 \\
\hline $30 \mathrm{~m}, 14 \mathrm{~m}^{2} / \mathrm{ha}$ & 635562 & 4331539 & $30 \mathrm{~m}, 14 \mathrm{~m}^{2} / \mathrm{ha}$ & 633812 & 4331504 \\
& 635533 & 4331527 & & 633788 & 4331480 \\
& 635679 & 4331271 & & 633991 & 4331271 \\
& 635651 & 4331259 & & 634015 & 4331295 \\
\hline $45 \mathrm{~m}, 4.5 \mathrm{~m}^{2} / \mathrm{ha}$ & 636027 & 4330306 & $45 \mathrm{~m}, 4.5 \mathrm{~m}^{2} / \mathrm{ha}$ & 635039 & 4330200 \\
& 635983 & 4330286 & & 635007 & 4330167 \\
& 636148 & 4330039 & & 634829 & 4330404 \\
& 636104 & 4330018 & & 634797 & 4330372 \\
\hline $45 \mathrm{~m}, 14 \mathrm{~m}^{2} / \mathrm{ha}$ & 635409 & 4331734 & $45 \mathrm{~m}, 14 \mathrm{~m}^{2} / \mathrm{ha}$ & 634248 & 4330990 \\
& 635368 & 4331716 & & 634212 & 4330955 \\
& 635291 & 4332003 & & 634455 & 4330776 \\
& 635249 & 4331985 & & 634420 & 4330741 \\
\hline
\end{tabular}


Appendix 4-A continued.

\begin{tabular}{lcc|lcc}
\hline \multicolumn{2}{l}{ Study Site: Stonewall Jackson WMA } & \multicolumn{3}{l}{ Study Site: Nathaniel Mountain WMA } \\
\hline Treatment & Easting & Northing & Treatment & Easting & Northing \\
\hline Control & 549134 & 4312357 & Control & 688368 & 4336922 \\
& 549417 & 4312269 & & 688664 & 4336868 \\
\hline $15 \mathrm{~m}, 4.5 \mathrm{~m}^{2} / \mathrm{ha}$ & 549243 & 4310959 & $15 \mathrm{~m}, 4.5 \mathrm{~m}^{2} / \mathrm{ha}$ & 687513 & 4335997 \\
& 549012 & 4310904 & & 687810 & 4335955 \\
& 549026 & 4310893 & & 687812 & 4335970 \\
& 549231 & 4310944 & & 687515 & 4336012 \\
\hline $15 \mathrm{~m}, 14 \mathrm{~m}^{2} / \mathrm{ha}$ & 549146 & 4311067 & $15 \mathrm{~m}, 14 \mathrm{~m}^{2} / \mathrm{ha}$ & 688008 & 4335928 \\
& 549157 & 4311081 & & 688306 & 4335891 \\
& 548970 & 4310891 & & 688308 & 4335906 \\
& 548954 & 4310898 & & 688010 & 4335943 \\
\hline $30 \mathrm{~m}, 4.5 \mathrm{~m}^{2} / \mathrm{ha}$ & 543305 & 4307028 & $30 \mathrm{~m}, 4.5 \mathrm{~m}^{2} / \mathrm{ha}$ & 687874 & 4336998 \\
& 543336 & 4307022 & & 688171 & 4336952 \\
& 543398 & 4306859 & & 688175 & 4336982 \\
& 543430 & 4306861 & & 687879 & 4337028 \\
\hline $30 \mathrm{~m}, 14 \mathrm{~m}^{2} / \mathrm{ha}$ & 543673 & 4306116 & $30 \mathrm{~m}, 14 \mathrm{~m}^{2} / \mathrm{ha}$ & 689145 & 4336746 \\
& 543703 & 4306101 & & 688849 & 4336791 \\
& 543715 & 4306316 & & 688844 & 4336762 \\
& 543738 & 4306333 & & 689141 & 4336716 \\
\hline $45 \mathrm{~m}, 4.5 \mathrm{~m}^{2} / \mathrm{ha}$ & 544844 & 4306494 & $45 \mathrm{~m}, 4.5 \mathrm{~m}^{2} / \mathrm{ha}$ & 687425 & 4335897 \\
& 544864 & 4306541 & & 687128 & 4335936 \\
& 544726 & 4306662 & & 687122 & 4335891 \\
& 544770 & 4306655 & & 687419 & 4335853 \\
\hline $45 \mathrm{~m}, 14 \mathrm{~m}^{2} / \mathrm{ha}$ & 544256 & 4308041 & $45 \mathrm{~m}, 14 \mathrm{~m}^{2} / \mathrm{ha}$ & 687623 & 4335868 \\
& 544263 & 4308092 & & 687920 & 4335824 \\
& 543970 & 4308186 & & 687913 & 4335780 \\
& 543930 & 4308155 & & 687616 & 4335823 \\
\hline
\end{tabular}


Appendix 4-B. Coordinates of treatment plot corners for regeneration stands. All coordinates are in NAD83, UTM Zone 17.

\begin{tabular}{|c|c|c|c|c|c|}
\hline \multicolumn{3}{|c|}{ Study Site: Beury Mountain WMA Block 1} & \multicolumn{3}{|c|}{ Study Site: Beury Mountain WMA Block 2} \\
\hline Treatment & Easting & Northing & Treatment & Easting & Northing \\
\hline \multirow[t]{4}{*}{ Control } & 500716 & 4199554 & \multirow[t]{4}{*}{ Control } & 501218 & 4198793 \\
\hline & 500882 & 4199552 & & 501378 & 4198792 \\
\hline & 500884 & 4199301 & & 501381 & 4198543 \\
\hline & 500718 & 4199301 & & 501216 & 4198543 \\
\hline \multirow{4}{*}{$\begin{array}{l}\text { Clearcut-and- } \\
\text { leave }\end{array}$} & 501050 & 4199552 & \multirow{4}{*}{$\begin{array}{l}\text { Clearcut-and- } \\
\text { leave }\end{array}$} & 501882 & 4199301 \\
\hline & 501217 & 4199554 & & 502048 & 4199301 \\
\hline & 500217 & 4199303 & & 502045 & 4199047 \\
\hline & 501050 & 4199303 & & 501883 & 4199047 \\
\hline \multirow{4}{*}{$\begin{array}{l}\text { Clearcut-and- } \\
\text { windrow }\end{array}$} & 500383 & 4199555 & \multirow{4}{*}{$\begin{array}{l}\text { Clearcut-and- } \\
\text { windrow }\end{array}$} & 502049 & 4198792 \\
\hline & 500548 & 4199554 & & 502216 & 4198793 \\
\hline & 500548 & 4199303 & & 502215 & 4198540 \\
\hline & 500383 & 4199303 & & 502049 & 4198541 \\
\hline \multirow[t]{4}{*}{ Hack-and-spray } & 499552 & 4200315 & \multirow[t]{4}{*}{ Hack-and-spray } & 501548 & 4198538 \\
\hline & 499716 & 4200315 & & 501717 & 4198538 \\
\hline & 499716 & 4200062 & & 501715 & 4198288 \\
\hline & 499550 & 4200062 & & 501547 & 4198287 \\
\hline \multicolumn{3}{|c|}{ Study Site: Beury Mountain WMA Block 3} & \multicolumn{3}{|c|}{ Study Site: Beury Mountain WMA Block 4} \\
\hline Treatment & Easting & Northing & Treatment & Easting & Northing \\
\hline \multirow[t]{4}{*}{ Control } & 497553 & 4198032 & \multirow[t]{4}{*}{ Control } & 496879 & 4197785 \\
\hline & 497720 & 4198031 & & 497048 & 4197784 \\
\hline & 497719 & 4197779 & & 497048 & 4197531 \\
\hline & 497552 & 4197778 & & 496880 & 4197530 \\
\hline \multirow{4}{*}{$\begin{array}{l}\text { Clearcut-and- } \\
\text { leave }\end{array}$} & 497216 & 4197786 & \multirow{4}{*}{$\begin{array}{l}\text { Clearcut-and- } \\
\text { leave }\end{array}$} & 496886 & 4199047 \\
\hline & 497384 & 4197785 & & 497052 & 4199047 \\
\hline & 497383 & 4197532 & & 497053 & 4198795 \\
\hline & 497215 & 4197532 & & 496886 & 4198794 \\
\hline \multirow{4}{*}{$\begin{array}{l}\text { Clearcut-and- } \\
\text { windrow }\end{array}$} & 497549 & 4197270 & \multirow{4}{*}{$\begin{array}{l}\text { Clearcut-and- } \\
\text { windrow }\end{array}$} & 497215 & 4198293 \\
\hline & 497720 & 4197271 & & 497384 & 4198293 \\
\hline & 497719 & 4197015 & & 497382 & 4198038 \\
\hline & 497551 & 4197016 & & 497215 & 4198037 \\
\hline \multirow[t]{4}{*}{ Hack-and-spray } & 498381 & 4197529 & \multirow[t]{4}{*}{ Hack-and-spray } & 496881 & 4198292 \\
\hline & 498549 & 4197528 & & 497048 & 4198294 \\
\hline & 498548 & 4197275 & & 497048 & 4198037 \\
\hline & 498383 & 4197275 & & 496881 & 4198038 \\
\hline
\end{tabular}


Appendix 4-B continued.

\begin{tabular}{lcc|lcc}
\hline Study Site: Beury Mountain WMA Block 5 & \multicolumn{2}{l}{ Study Site: Center Branch WMA Block 1 } \\
\hline Treatment & Easting & Northing & Treatment & Easting & Northing \\
\hline Control & 503714 & 4199301 & Control & 556514 & 4344259 \\
& 503879 & 4199302 & & 556684 & 4344151 \\
& 503881 & 4199049 & & 556572 & 4343982 \\
& 503714 & 4199049 & & 556405 & 4344092 \\
\hline Clearcut-and- & 503048 & 4199046 & Clearcut-and- & 556222 & 4343818 \\
leave & 503214 & 4199046 & leave & 556392 & 4343706 \\
& 503212 & 4198793 & & 556279 & 4343541 \\
& 503049 & 4198795 & & 556111 & 4343650 \\
\hline Clearcut-and- & 503380 & 4199300 & Clearcut-and- & 556848 & 4344037 \\
windrow & 503547 & 4199301 & windrow & 557019 & 4343928 \\
& 503547 & 4199045 & & 556906 & 4343761 \\
& 503382 & 4199047 & & 556740 & 4343870 \\
\hline Hack-and-spray & 503714 & 4199809 & Hack-and-spray & \multirow{2}{*}{ No hack-and-spray treatments } \\
& 503883 & 4199806 & & were treated at Center Branch \\
& 503879 & 4199556 & & \multicolumn{2}{c}{ WMA } \\
\hline
\end{tabular}

\begin{tabular}{|c|c|c|c|c|c|}
\hline \multicolumn{3}{|c|}{ Study Site: Center Branch WMA Block 2} & \multicolumn{3}{|c|}{ Study Site: Center Branch WMA Block 3} \\
\hline Treatment & Easting & Northing & Treatment & Easting & Northing \\
\hline \multirow[t]{4}{*}{ Control } & 558083 & 4342986 & \multirow[t]{4}{*}{ Control } & 558017 & 4344714 \\
\hline & 557972 & 4342818 & & 558185 & 4344604 \\
\hline & 558139 & 4342706 & & 558075 & 4344434 \\
\hline & 558250 & 4342875 & & 557906 & 4344546 \\
\hline \multirow{4}{*}{$\begin{array}{l}\text { Clearcut-and- } \\
\text { leave }\end{array}$} & 557747 & 4343207 & \multirow{4}{*}{$\begin{array}{l}\text { Clearcut-and- } \\
\text { leave }\end{array}$} & 557444 & 4343645 \\
\hline & 557915 & 4343097 & & 557612 & 4343535 \\
\hline & 557804 & 4342929 & & 557721 & 4343701 \\
\hline & 557636 & 4343040 & & 557554 & 4343811 \\
\hline \multirow{4}{*}{$\begin{array}{l}\text { Clearcut-and- } \\
\text { windrow }\end{array}$} & 557278 & 4342699 & \multirow{4}{*}{$\begin{array}{l}\text { Clearcut-and- } \\
\text { windrow }\end{array}$} & 557379 & 4343443 \\
\hline & 557445 & 4342588 & & 557546 & 4343333 \\
\hline & 557168 & 4342530 & & 557269 & 4343275 \\
\hline & 557338 & 4342419 & & 557437 & 4343165 \\
\hline Hack-and-spray & $\begin{array}{l}\text { No hack-an } \\
\text { were treatec }\end{array}$ & $\begin{array}{l}\text { ay treatments } \\
\text { enter Branch } \\
\text { A }\end{array}$ & Hack-and-spray & $\begin{array}{l}\text { No hack-an } \\
\text { were treatec }\end{array}$ & $\begin{array}{l}\text { y treatments } \\
\text { enter Branch } \\
\text { A }\end{array}$ \\
\hline
\end{tabular}


Appendix 4-B continued.

\begin{tabular}{|c|c|c|c|c|c|}
\hline \multicolumn{3}{|c|}{ Study Site: Little Canaan WMA Block 1} & \multicolumn{3}{|c|}{ Study Site: Little Canaan WMA Block 2} \\
\hline Treatment & Easting & Northing & Treatment & Easting & Northing \\
\hline \multirow[t]{4}{*}{ Control } & 635221 & 4330721 & \multirow[t]{4}{*}{ Control } & 635426 & 4330944 \\
\hline & 635069 & 4330592 & & 635227 & 4330949 \\
\hline & 635198 & 4330441 & & 635232 & 4331148 \\
\hline & 635351 & 4330567 & & 635431 & 4331144 \\
\hline \multirow{4}{*}{$\begin{array}{l}\text { Clearcut-and- } \\
\text { leave }\end{array}$} & 635663 & 4330205 & \multirow{4}{*}{$\begin{array}{l}\text { Clearcut-and- } \\
\text { leave }\end{array}$} & 635787 & 4331931 \\
\hline & 635514 & 4330073 & & 635922 & 4331781 \\
\hline & 635381 & 4330221 & & 635771 & 4331649 \\
\hline & 635529 & 4330356 & & 635638 & 4331797 \\
\hline \multirow{4}{*}{$\begin{array}{l}\text { Clearcut-and- } \\
\text { windrow }\end{array}$} & 634689 & 4331236 & \multirow{4}{*}{$\begin{array}{l}\text { Clearcut-and- } \\
\text { windrow }\end{array}$} & 635741 & 4332407 \\
\hline & 634536 & 4331108 & & 635874 & 4332258 \\
\hline & 634407 & 4331261 & & 635725 & 4332125 \\
\hline & 634560 & 4331389 & & 635592 & 4332272 \\
\hline \multirow[t]{4}{*}{ Hack-and-spray } & 634236 & 4331707 & \multirow[t]{4}{*}{ Hack-and-spray } & 634911 & 4332276 \\
\hline & 634084 & 4331578 & & 635045 & 4332127 \\
\hline & 634213 & 4331425 & & 634895 & 4331994 \\
\hline & 634366 & 4331553 & & 634761 & 4332143 \\
\hline \multicolumn{3}{|c|}{ Study Site: Little Canaan WMA Block 3} & \multicolumn{3}{|c|}{ Study Site: Little Canaan WMA Block 4} \\
\hline Treatment & Easting & Northing & Treatment & Easting & Northing \\
\hline \multirow[t]{4}{*}{ Control } & 636214 & 4333378 & \multirow[t]{4}{*}{ Control } & 637476 & 4332400 \\
\hline & 636372 & 4333255 & & 637319 & 4332523 \\
\hline & 636249 & 4333097 & & 637442 & 4332680 \\
\hline & 636091 & 4333220 & & 637598 & 4332557 \\
\hline \multirow{4}{*}{$\begin{array}{l}\text { Clearcut-and- } \\
\text { leave }\end{array}$} & 636534 & 4332596 & \multirow{4}{*}{$\begin{array}{l}\text { Clearcut-and- } \\
\text { leave }\end{array}$} & 636721 & 4333198 \\
\hline & 636691 & 4332473 & & 636878 & 4333077 \\
\hline & 636569 & 4332315 & & 636756 & 4332918 \\
\hline & 636411 & 4332438 & & 636598 & 4333041 \\
\hline \multirow{4}{*}{$\begin{array}{l}\text { Clearcut-and- } \\
\text { windrow }\end{array}$} & 635506 & 4332884 & \multirow{4}{*}{$\begin{array}{l}\text { Clearcut-and- } \\
\text { windrow }\end{array}$} & 637087 & 4332946 \\
\hline & 635663 & 4332761 & & 637245 & 4332823 \\
\hline & 635540 & 4332603 & & 637122 & 4332665 \\
\hline & 635382 & 4332725 & & 636964 & 4332788 \\
\hline \multirow[t]{4}{*}{ Hack-and-spray } & 636104 & 4332892 & \multirow[t]{4}{*}{ Hack-and-spray } & 636218 & 4331866 \\
\hline & 636260 & 4332770 & & 636375 & 4331743 \\
\hline & 636138 & 4332612 & & 636253 & 4331585 \\
\hline & 635981 & 4332735 & & 636095 & 4331709 \\
\hline
\end{tabular}


Appendix 4-B continued.

\begin{tabular}{|c|c|c|c|c|c|}
\hline \multicolumn{3}{|c|}{ Study Site: Moncove Lake WMA Block 1} & \multicolumn{3}{|c|}{ Study Site: Moncove Lake WMA Block 2} \\
\hline Treatment & Easting & Northing & Treatment & Easting & Northing \\
\hline \multirow[t]{4}{*}{ Control } & 557975 & 4164284 & \multirow[t]{4}{*}{ Control } & 557515 & 4162908 \\
\hline & 558099 & 4164125 & & 557639 & 4162749 \\
\hline & 558257 & 4164251 & & 557480 & 4162625 \\
\hline & 558134 & 4164407 & & 557356 & 4162783 \\
\hline \multirow{4}{*}{$\begin{array}{l}\text { Clearcut-and- } \\
\text { leave }\end{array}$} & 558698 & 4164340 & \multirow{4}{*}{$\begin{array}{l}\text { Clearcut-and- } \\
\text { leave }\end{array}$} & 557993 & 4163280 \\
\hline & 558822 & 4164183 & & 557833 & 4163154 \\
\hline & 558663 & 4164059 & & 557957 & 4162998 \\
\hline & 558540 & 4164214 & & 558115 & 4163120 \\
\hline \multirow{4}{*}{$\begin{array}{l}\text { Clearcut-and- } \\
\text { windrow }\end{array}$} & 558063 & 4163844 & \multirow{4}{*}{$\begin{array}{l}\text { Clearcut-and- } \\
\text { windrow }\end{array}$} & 558432 & 4163371 \\
\hline & 558187 & 4163687 & & 558309 & 4163528 \\
\hline & 558028 & 4163560 & & 558151 & 4163405 \\
\hline & 557905 & 4163718 & & 558274 & 4163245 \\
\hline \multirow[t]{4}{*}{ Hack-and-spray } & 558382 & 4164092 & \multirow[t]{4}{*}{ Hack-and-spray } & 557586 & 4163472 \\
\hline & 558503 & 4163935 & & 557711 & 4163313 \\
\hline & 558345 & 4163809 & & 557868 & 4163437 \\
\hline & 558221 & 4163968 & & 557745 & 4163595 \\
\hline \multicolumn{3}{|c|}{ Study Site: Nathaniel Mountain WMA } & \multicolumn{3}{|c|}{ Study Site: Sleepy Creek WMA } \\
\hline Treatment & Easting & Northing & Treatment & Easting & Northing \\
\hline \multirow[t]{4}{*}{ Control } & 687232 & 4335221 & \multirow[t]{4}{*}{ Control } & 740909 & 4366056 \\
\hline & 687379 & 4335085 & & 740715 & 4366105 \\
\hline & 687243 & 4334939 & & 740957 & 4366250 \\
\hline & 687096 & 4335075 & & 740764 & 4366299 \\
\hline \multirow{4}{*}{$\begin{array}{l}\text { Clearcut-and- } \\
\text { leave }\end{array}$} & 688208 & 4336413 & \multirow{4}{*}{$\begin{array}{l}\text { Clearcut-and- } \\
\text { leave }\end{array}$} & 741193 & 4367554 \\
\hline & 688374 & 4336302 & & 740998 & 4367600 \\
\hline & 688264 & 4336136 & & 741043 & 4367794 \\
\hline & 688097 & 4336246 & & 741238 & 4367749 \\
\hline \multirow{4}{*}{$\begin{array}{l}\text { Clearcut-and- } \\
\text { windrow }\end{array}$} & 687504 & 4335514 & \multirow{4}{*}{$\begin{array}{l}\text { Clearcut-and- } \\
\text { windrow }\end{array}$} & 741107 & 4366669 \\
\hline & 687650 & 4335377 & & 740914 & 4366720 \\
\hline & 687513 & 4335232 & & 741158 & 4366863 \\
\hline & 687367 & 4335369 & & 740965 & 4366914 \\
\hline \multirow[t]{4}{*}{ Hack-and-spray } & 687843 & 4336591 & \multirow[t]{4}{*}{ Hack-and-spray } & 741209 & 4367082 \\
\hline & 688010 & 4336481 & & 741015 & 4367129 \\
\hline & 687901 & 4336314 & & 741256 & 4367276 \\
\hline & 687733 & 4336424 & & 741062 & 4367323 \\
\hline
\end{tabular}


Appendix 4-B continued.

\begin{tabular}{lcc}
\hline Study Site: Short Mountain WMA & \\
\hline Treatment & Easting & Northing \\
\hline Control & 701648 & 4341012 \\
& 701866 & 4340910 \\
& 701744 & 4340735 \\
& 701592 & 4340842 \\
\hline Clearcut-and- & 701244 & 4339947 \\
leave & 701328 & 4340128 \\
& 701509 & 4340052 \\
& 701429 & 4339864 \\
\hline Clearcut-and- & 701140 & 4339751 \\
windrow & 701326 & 4339680 \\
& 701258 & 4339496 \\
& 701057 & 4339569 \\
\hline Hack-and-spray & 701445 & 4340659 \\
& 701329 & 4340501 \\
& 701492 & 4340386 \\
& 701616 & 4340541 \\
\hline
\end{tabular}


Appendix 4-C. Avian point count coordinates in cut-back borders. All coordinates are in NAD83, UTM Zone 17.

\begin{tabular}{|c|c|c|c|c|c|c|c|}
\hline \multicolumn{4}{|c|}{ Study Site: Allegheny WMA } & \multicolumn{4}{|c|}{ Study Site: Bluestone WMA } \\
\hline Treatment & Point & Easting & Northing & Treatment & Point & Easting & Northing \\
\hline \multirow[t]{2}{*}{ Control } & $\mathrm{A}$ & 668793 & 4364637 & Control & $\mathrm{A}$ & 513389 & 4143707 \\
\hline & $\mathrm{B}$ & 668937 & 4364652 & & B & 513311 & 4143549 \\
\hline \multirow[t]{2}{*}{$15 \mathrm{~m}, 4.5 \mathrm{~m}^{2} / \mathrm{ha}$} & $\mathrm{A}$ & 668385 & 4364578 & $15 \mathrm{~m}, 4.5 \mathrm{~m}^{2} / \mathrm{ha}$ & A & 512050 & 4147324 \\
\hline & $\mathrm{B}$ & 668355 & 4364431 & & $\mathrm{~B}$ & 511950 & 4147447 \\
\hline \multirow[t]{2}{*}{$15 \mathrm{~m}, 14 \mathrm{~m}^{2} / \mathrm{ha}$} & A & 663611 & 4358230 & $15 \mathrm{~m}, 14 \mathrm{~m}^{2} / \mathrm{ha}$ & A & 511265 & 4146997 \\
\hline & $\mathrm{B}$ & 663475 & 4358293 & & $\mathrm{~B}$ & 511229 & 4146851 \\
\hline \multirow[t]{2}{*}{$30 \mathrm{~m}, 4.5 \mathrm{~m}^{2} / \mathrm{ha}$} & A & 668324 & 4365044 & $30 \mathrm{~m}, 4.5 \mathrm{~m}^{2} / \mathrm{ha}$ & A & 512963 & 4143145 \\
\hline & $\mathrm{B}$ & 668410 & 4364914 & & $\mathrm{~B}$ & 512923 & 4143025 \\
\hline \multirow[t]{2}{*}{$30 \mathrm{~m}, 14 \mathrm{~m}^{2} / \mathrm{ha}$} & $\mathrm{A}$ & 668042 & 4363651 & $30 \mathrm{~m}, 14 \mathrm{~m}^{2} / \mathrm{ha}$ & $\mathrm{A}$ & 512798 & 4142740 \\
\hline & $\mathrm{B}$ & 667976 & 4363516 & & B & 512726 & 4142586 \\
\hline \multirow[t]{2}{*}{$45 \mathrm{~m}, 4.5 \mathrm{~m}^{2} / \mathrm{ha}$} & $\mathrm{A}$ & 668227 & 4364110 & $45 \mathrm{~m}, 4.5 \mathrm{~m}^{2} / \mathrm{ha}$ & $\mathrm{A}$ & 512962 & 4145385 \\
\hline & $\mathrm{B}$ & 668186 & 4363966 & & $\mathrm{~B}$ & 513096 & 4145320 \\
\hline \multirow[t]{2}{*}{$45 \mathrm{~m}, 14 \mathrm{~m}^{2} / \mathrm{ha}$} & $\mathrm{A}$ & 663157 & 4358440 & $45 \mathrm{~m}, 14 \mathrm{~m}^{2} / \mathrm{ha}$ & $\mathrm{A}$ & 512485 & 4145579 \\
\hline & $\mathrm{B}$ & 663020 & 4358502 & & $\mathrm{~B}$ & 512641 & 4145524 \\
\hline
\end{tabular}

\begin{tabular}{|c|c|c|c|c|c|c|c|}
\hline \multicolumn{4}{|c|}{ Study Site: Beury Mountain WMA Block 1} & \multicolumn{4}{|c|}{ Study Site: Beury Mountain WMA Block 2} \\
\hline Treatment & Point & Easting & Northing & Treatment & Point & Easting & Northing \\
\hline \multirow[t]{2}{*}{ Control } & $\mathrm{A}$ & 499094 & 4199109 & Control & $\mathrm{A}$ & 500441 & 4198102 \\
\hline & B & 499094 & 4198959 & & B & 500577 & 4198038 \\
\hline \multirow{2}{*}{$15 \mathrm{~m}, 4.5 \mathrm{~m}^{2} / \mathrm{ha}$} & A & 500163 & 4200002 & $15 \mathrm{~m}, 4.5 \mathrm{~m}^{2} / \mathrm{ha}$ & A & 501351 & 4197689 \\
\hline & $\mathrm{B}$ & 500307 & 4200044 & & $\mathrm{~B}$ & 501488 & 4197626 \\
\hline \multirow[t]{2}{*}{$15 \mathrm{~m}, 14 \mathrm{~m}^{2} / \mathrm{ha}$} & A & 500651 & 4200102 & $15 \mathrm{~m}, 14 \mathrm{~m}^{2} / \mathrm{ha}$ & A & 498431 & 4198971 \\
\hline & B & 500796 & 4200064 & & B & 498567 & 4198909 \\
\hline \multirow[t]{2}{*}{$30 \mathrm{~m}, 4.5 \mathrm{~m}^{2} / \mathrm{ha}$} & $\mathrm{A}$ & 501823 & 4199794 & $30 \mathrm{~m}, 4.5 \mathrm{~m}^{2} / \mathrm{ha}$ & A & 499215 & 4198665 \\
\hline & B & 501968 & 4199756 & & $\mathrm{~B}$ & 499353 & 4198605 \\
\hline \multirow[t]{2}{*}{$30 \mathrm{~m}, 14 \mathrm{~m}^{2} / \mathrm{ha}$} & $\mathrm{A}$ & 498494 & 4198769 & $30 \mathrm{~m}, 14 \mathrm{~m}^{2} / \mathrm{ha}$ & A & 497976 & 4199180 \\
\hline & B & 498346 & 4198745 & & B & 498112 & 4199117 \\
\hline \multirow[t]{2}{*}{$45 \mathrm{~m}, 4.5 \mathrm{~m}^{2} / \mathrm{ha}$} & $\mathrm{A}$ & 501152 & 4199976 & $45 \mathrm{~m}, 4.5 \mathrm{~m}^{2} / \mathrm{ha}$ & $\mathrm{A}$ & 499956 & 4198269 \\
\hline & B & 501297 & 4199941 & & $\mathrm{~B}$ & 500093 & 4198208 \\
\hline \multirow[t]{2}{*}{$45 \mathrm{~m}, 14 \mathrm{~m}^{2} / \mathrm{ha}$} & A & 499683 & 4199867 & $45 \mathrm{~m}, 14 \mathrm{~m}^{2} / \mathrm{ha}$ & A & 500895 & 4197893 \\
\hline & B & 499827 & 4199910 & & $\mathrm{~B}$ & 501032 & 4197831 \\
\hline
\end{tabular}


Appendix 4-C continued.

\begin{tabular}{|c|c|c|c|c|c|c|c|}
\hline \multicolumn{4}{|c|}{ Study Site: Burnsville Lake WMA } & \multicolumn{4}{|c|}{ Study Site: Lewis Wetzel WMA Block 1} \\
\hline Treatment & Point & Easting & Northing & Treatment & Point & Easting & Northing \\
\hline \multirow[t]{2}{*}{ Control } & $\mathrm{A}$ & 532145 & 4296042 & Control & $\mathrm{A}$ & 529448 & 4374272 \\
\hline & $\mathrm{B}$ & 532071 & 4296167 & & $\mathrm{~B}$ & 529524 & 4374151 \\
\hline \multirow[t]{2}{*}{$15 \mathrm{~m}, 4.5 \mathrm{~m}^{2} / \mathrm{ha}$} & $\mathrm{A}$ & 532982 & 4295491 & $15 \mathrm{~m}, 4.5 \mathrm{~m}^{2} / \mathrm{ha}$ & $\mathrm{A}$ & 528185 & 4373809 \\
\hline & $\mathrm{B}$ & 532844 & 4295512 & & $\mathrm{~B}$ & 528195 & 4373675 \\
\hline \multirow[t]{2}{*}{$15 \mathrm{~m}, 14 \mathrm{~m}^{2} / \mathrm{ha}$} & $\mathrm{A}$ & 533711 & 4294536 & $15 \mathrm{~m}, 14 \mathrm{~m}^{2} / \mathrm{ha}$ & $\mathrm{A}$ & 529653 & 4373846 \\
\hline & $\mathrm{B}$ & 533773 & 4294665 & & $\mathrm{~B}$ & 529718 & 4373742 \\
\hline \multirow[t]{2}{*}{$30 \mathrm{~m}, 4.5 \mathrm{~m}^{2} / \mathrm{ha}$} & $\mathrm{A}$ & 532491 & 4295866 & $30 \mathrm{~m}, 4.5 \mathrm{~m}^{2} / \mathrm{ha}$ & $\mathrm{A}$ & 529051 & 4373500 \\
\hline & B & 532343 & 4295880 & & $\mathrm{~B}$ & 528978 & 4373363 \\
\hline \multirow[t]{2}{*}{$30 \mathrm{~m}, 14 \mathrm{~m}^{2} / \mathrm{ha}$} & $\mathrm{A}$ & 533802 & 4294930 & $30 \mathrm{~m}, 14 \mathrm{~m}^{2} / \mathrm{ha}$ & $\mathrm{A}$ & 530932 & 4372554 \\
\hline & $\mathrm{B}$ & 533773 & 4295056 & & $\mathrm{~B}$ & 530927 & 4372425 \\
\hline \multirow[t]{2}{*}{$45 \mathrm{~m}, 4.5 \mathrm{~m}^{2} / \mathrm{ha}$} & $\mathrm{A}$ & 533526 & 4295874 & $45 \mathrm{~m}, 4.5 \mathrm{~m}^{2} / \mathrm{ha}$ & $\mathrm{A}$ & 528944 & 4374597 \\
\hline & $\mathrm{B}$ & 533554 & 4295956 & & $\mathrm{~B}$ & 528884 & 4374737 \\
\hline \multirow[t]{2}{*}{$45 \mathrm{~m}, 14 \mathrm{~m}^{2} / \mathrm{ha}$} & $\mathrm{A}$ & 533521 & 4295301 & $45 \mathrm{~m}, 14 \mathrm{~m}^{2} / \mathrm{ha}$ & $\mathrm{A}$ & 529035 & 4374001 \\
\hline & $\mathrm{B}$ & 533436 & 4295436 & & $\mathrm{~B}$ & 529045 & 4373859 \\
\hline \multicolumn{4}{|c|}{ Study Site: Lewis Wetzel WMA Block 2} & \multicolumn{4}{|c|}{ Study Site: Little Canaan WMA Block 1} \\
\hline Treatment & Point & Easting & Northing & Treatment & Point & Easting & Northing \\
\hline \multirow[t]{2}{*}{ Control } & $\mathrm{A}$ & 529136 & 4372017 & Control & $\mathrm{A}$ & 635349 & 4331992 \\
\hline & $\mathrm{B}$ & 529164 & 4371834 & & $\mathrm{~B}$ & 635289 & 4332126 \\
\hline \multirow[t]{2}{*}{$15 \mathrm{~m}, 4.5 \mathrm{~m}^{2} / \mathrm{ha}$} & A & 529694 & 4373195 & $15 \mathrm{~m}, 4.5 \mathrm{~m}^{2} / \mathrm{ha}$ & A & 635149 & 4332448 \\
\hline & $\mathrm{B}$ & 529812 & 4373288 & & $\mathrm{~B}$ & 635092 & 4332576 \\
\hline \multirow[t]{2}{*}{$15 \mathrm{~m}, 14 \mathrm{~m}^{2} / \mathrm{ha}$} & A & 529994 & 4373542 & $15 \mathrm{~m}, 14 \mathrm{~m}^{2} / \mathrm{ha}$ & $\mathrm{A}$ & 635099 & 4332401 \\
\hline & $\mathrm{B}$ & 530125 & 4373569 & & $\mathrm{~B}$ & 635043 & 4332534 \\
\hline \multirow[t]{2}{*}{$30 \mathrm{~m}, 4.5 \mathrm{~m}^{2} / \mathrm{ha}$} & $\mathrm{A}$ & 528380 & 4373229 & $30 \mathrm{~m}, 4.5 \mathrm{~m}^{2} / \mathrm{ha}$ & $\mathrm{A}$ & 636075 & 4330319 \\
\hline & $\mathrm{B}$ & 528468 & 4373113 & & $\mathrm{~B}$ & 636016 & 4330455 \\
\hline \multirow[t]{2}{*}{$30 \mathrm{~m}, 14 \mathrm{~m}^{2} / \mathrm{ha}$} & $\mathrm{A}$ & 529275 & 4372655 & $30 \mathrm{~m}, 14 \mathrm{~m}^{2} / \mathrm{ha}$ & $\mathrm{A}$ & 635634 & 4331332 \\
\hline & $\mathrm{B}$ & 529308 & 4372493 & & $\mathrm{~B}$ & 635577 & 4331463 \\
\hline \multirow[t]{2}{*}{$45 \mathrm{~m}, 4.5 \mathrm{~m}^{2} / \mathrm{ha}$} & $\mathrm{A}$ & 528734 & 4372872 & $45 \mathrm{~m}, 4.5 \mathrm{~m}^{2} / \mathrm{ha}$ & $\mathrm{A}$ & 636104 & 4330100 \\
\hline & B & 528889 & 4372883 & & $\mathrm{~B}$ & 636045 & 4330231 \\
\hline \multirow[t]{2}{*}{$45 \mathrm{~m}, 14 \mathrm{~m}^{2} / \mathrm{ha}$} & $\mathrm{A}$ & 530479 & 4373497 & $45 \mathrm{~m}, 14 \mathrm{~m}^{2} / \mathrm{ha}$ & $\mathrm{A}$ & 635366 & 4331797 \\
\hline & $\mathrm{B}$ & 530603 & 4373414 & & B & 635308 & 4331929 \\
\hline
\end{tabular}


Appendix 4-C continued.

\begin{tabular}{|c|c|c|c|c|c|c|c|}
\hline \multicolumn{4}{|c|}{ Study Site: Little Canaan WMA Block 2} & \multicolumn{4}{|c|}{ Study Site: Nathaniel Mountain WMA } \\
\hline Treatment & Point & Easting & Northing & Treatment & Point & Easting & Northing \\
\hline \multirow{2}{*}{ Control } & A & 634027 & 4331180 & Control & $\mathrm{A}$ & 688416 & 4336844 \\
\hline & B & 633924 & 4331285 & & B & 688561 & 4336821 \\
\hline \multirow[t]{2}{*}{$15 \mathrm{~m}, 4.5 \mathrm{~m}^{2} / \mathrm{ha}$} & A & 635021 & 4330279 & $15 \mathrm{~m}, 4.5 \mathrm{~m}^{2} / \mathrm{ha}$ & A & 687590 & 4336002 \\
\hline & B & 634915 & 4330385 & & B & 687739 & 4335981 \\
\hline \multirow{2}{*}{$15 \mathrm{~m}, 14 \mathrm{~m}^{2} / \mathrm{ha}$} & A & 634311 & 4330982 & $15 \mathrm{~m}, 14 \mathrm{~m}^{2} / \mathrm{ha}$ & A & 688085 & 4335934 \\
\hline & B & 634204 & 4331088 & & $\mathrm{~B}$ & 688234 & 4335916 \\
\hline \multirow[t]{2}{*}{$30 \mathrm{~m}, 4.5 \mathrm{~m}^{2} / \mathrm{ha}$} & A & 634654 & 4330634 & $30 \mathrm{~m}, 4.5 \mathrm{~m}^{2} / \mathrm{ha}$ & A & 687951 & 4337002 \\
\hline & B & 634549 & 4330741 & & B & 688099 & 4336979 \\
\hline \multirow[t]{2}{*}{$30 \mathrm{~m}, 14 \mathrm{~m}^{2} / \mathrm{ha}$} & $\mathrm{A}$ & 633957 & 4331330 & $30 \mathrm{~m}, 14 \mathrm{~m}^{2} / \mathrm{ha}$ & $\mathrm{A}$ & 688921 & 4336766 \\
\hline & B & 633851 & 4331437 & & B & 689069 & 4336743 \\
\hline \multirow[t]{2}{*}{$45 \mathrm{~m}, 4.5 \mathrm{~m}^{2} / \mathrm{ha}$} & $\mathrm{A}$ & 634975 & 4330241 & $45 \mathrm{~m}, 4.5 \mathrm{~m}^{2} / \mathrm{ha}$ & $\mathrm{A}$ & 687201 & 4335912 \\
\hline & B & 634871 & 4330341 & & B & 687349 & 4335893 \\
\hline \multirow[t]{2}{*}{$45 \mathrm{~m}, 14 \mathrm{~m}^{2} / \mathrm{ha}$} & A & 634393 & 4330819 & $45 \mathrm{~m}, 14 \mathrm{~m}^{2} / \mathrm{ha}$ & $\mathrm{A}$ & 687696 & 4335843 \\
\hline & $\mathrm{B}$ & 634290 & 4330925 & & $\mathrm{~B}$ & 687844 & 4335821 \\
\hline \multicolumn{4}{|c|}{ Study Site: Sleepy Creek WMA } & \multicolumn{4}{|c|}{ Study Site: Stonewall Jackson WMA } \\
\hline Treatment & Point & Easting & Northing & Treatment & Point & Easting & Northing \\
\hline \multirow[t]{2}{*}{ Control } & $\mathrm{A}$ & 745686 & 4380700 & Control & $\mathrm{A}$ & 549340 & 4312258 \\
\hline & $\mathrm{B}$ & 745573 & 4380716 & & B & 549208 & 4312319 \\
\hline \multirow[t]{2}{*}{$15 \mathrm{~m}, 4.5 \mathrm{~m}^{2} / \mathrm{ha}$} & A & 740358 & 4365007 & $15 \mathrm{~m}, 4.5 \mathrm{~m}^{2} / \mathrm{ha}$ & A & 549177 & 4310983 \\
\hline & $\mathrm{B}$ & 740316 & 4364911 & & $\mathrm{~B}$ & 549054 & 4310957 \\
\hline \multirow[t]{2}{*}{$15 \mathrm{~m}, 14 \mathrm{~m}^{2} / \mathrm{ha}$} & A & 740606 & 4365155 & $15 \mathrm{~m}, 14 \mathrm{~m}^{2} / \mathrm{ha}$ & A & 549088 & 4311083 \\
\hline & $\mathrm{B}$ & 740500 & 4365068 & & B & 548984 & 4310966 \\
\hline \multirow[t]{2}{*}{$30 \mathrm{~m}, 4.5 \mathrm{~m}^{2} / \mathrm{ha}$} & $\mathrm{A}$ & 740666 & 4366816 & $30 \mathrm{~m}, 4.5 \mathrm{~m}^{2} / \mathrm{ha}$ & A & 543417 & 4306933 \\
\hline & $\mathrm{B}$ & 740534 & 4366798 & & B & 543306 & 4306962 \\
\hline \multirow[t]{2}{*}{$30 \mathrm{~m}, 14 \mathrm{~m}^{2} / \mathrm{ha}$} & $\mathrm{A}$ & 740271 & 4365468 & $30 \mathrm{~m}, 14 \mathrm{~m}^{2} / \mathrm{ha}$ & $\mathrm{A}$ & 543729 & 4306170 \\
\hline & $\mathrm{B}$ & 740327 & 4365298 & & $\mathrm{~B}$ & 543790 & 4306300 \\
\hline \multirow[t]{2}{*}{$45 \mathrm{~m}, 4.5 \mathrm{~m}^{2} / \mathrm{ha}$} & $\mathrm{A}$ & 740437 & 4366396 & $45 \mathrm{~m}, 4.5 \mathrm{~m}^{2} / \mathrm{ha}$ & $\mathrm{A}$ & 544187 & 4308099 \\
\hline & $\mathrm{B}$ & 740427 & 4366276 & & $\mathrm{~B}$ & 544021 & 4308138 \\
\hline \multirow[t]{2}{*}{$45 \mathrm{~m}, 14 \mathrm{~m}^{2} / \mathrm{ha}$} & $\mathrm{A}$ & 745311 & 4382968 & $45 \mathrm{~m}, 14 \mathrm{~m}^{2} / \mathrm{ha}$ & $\mathrm{A}$ & 544710 & 4306595 \\
\hline & B & 745189 & 4382979 & & B & 544778 & 4306521 \\
\hline
\end{tabular}


Appendix 4-D. Avian point count coordinates in regeneration stands. All coordinates are in NAD83, UTM Zone 17.

\begin{tabular}{|c|c|c|c|c|c|}
\hline \multicolumn{3}{|c|}{ Study Site: Beury Mountain WMA Block 1} & \multicolumn{3}{|c|}{ Study Site: Beury Mountain WMA Block 2} \\
\hline Treatment & Easting & Northing & Treatment & Easting & Northing \\
\hline Control & 500800 & 4199428 & Control & 501298 & 4198670 \\
\hline Clearcut-and-leave & 501133 & 4199427 & Clearcut-and-leave & 501965 & 4199173 \\
\hline Clearcut-windrow & 500466 & 4199429 & Clearcut-windrow & 502132 & 4198667 \\
\hline Hack-and-spray & 499633 & 4200189 & Hack-and-spray & 501633 & 4198412 \\
\hline \multicolumn{3}{|c|}{ Study Site: Beury Mountain WMA Block 3} & \multicolumn{3}{|c|}{ Study Site: Beury Mountain WMA Block 4} \\
\hline Treatment & Easting & Northing & Treatment & Easting & Northing \\
\hline Control & 497636 & 4197906 & Control & 496965 & 4197657 \\
\hline Clearcut-and-leave & 497299 & 4197659 & Clearcut-and-leave & 496970 & 4198921 \\
\hline Clearcut-windrow & 497635 & 4197143 & Clearcut-windrow & 497299 & 4198165 \\
\hline Hack-and-spray & 498466 & 4197401 & Hack-and-spray & 496964 & 4198166 \\
\hline \multicolumn{3}{|c|}{ Study Site: Beury Mountain WMA Block 5} & \multicolumn{3}{|c|}{ Study Site: Center Branch WMA Block 1} \\
\hline Treatment & Easting & Northing & Treatment & Easting & Northing \\
\hline Control & 503797 & 4199177 & Control & 556543 & 4344121 \\
\hline Clearcut-and-leave & 503131 & 4198920 & Clearcut-and-leave & 556252 & 4343678 \\
\hline Clearcut-windrow & 503464 & 4199173 & Clearcut-windrow & 556877 & 4343899 \\
\hline Hack-and-spray & 503798 & 4199681 & Hack-and-spray & & \\
\hline \multicolumn{3}{|c|}{ Study Site: Center Branch WMA Block 2} & \multicolumn{3}{|c|}{ Study Site: Center Branch WMA Block 3} \\
\hline Treatment & Easting & Northing & Treatment & Easting & Northing \\
\hline Control & 558111 & 4342846 & Control & 558046 & 4344574 \\
\hline Clearcut-and-leave & 557775 & 4343067 & Clearcut-and-leave & 557583 & 4343672 \\
\hline Clearcut-windrow & 557308 & 4342560 & Clearcut-windrow & 557408 & 4343304 \\
\hline Hack-and-spray & \multicolumn{2}{|c|}{ NA } & Hack-and-spray & \multicolumn{2}{|c|}{ NA } \\
\hline \multicolumn{3}{|c|}{ Study Site: Little Canaan WMA Block 1} & \multicolumn{3}{|c|}{ Study Site: Little Canaan WMA Block 2} \\
\hline Treatment & Easting & Northing & Treatment & Easting & Northing \\
\hline Control & 635210 & 4330580 & Control & 635330 & 4331047 \\
\hline Clearcut-and-leave & 635515 & 4330229 & Clearcut-and-leave & 635780 & 4331790 \\
\hline Clearcut-windrow & 634549 & 4331248 & Clearcut-windrow & 635734 & 4332266 \\
\hline Hack-and-spray & 634225 & 4331566 & Hack-and-spray & 634904 & 4332136 \\
\hline \multicolumn{3}{|c|}{ Study Site: Little Canaan WMA Block 3} & \multicolumn{3}{|c|}{ Study Site: Little Canaan WMA Block 4} \\
\hline Treatment & Easting & Northing & Treatment & Easting & Northing \\
\hline Control & 636233 & 4333237 & Control & 637458 & 4332539 \\
\hline Clearcut-and-leave & 636551 & 4332456 & Clearcut-and-leave & 636738 & 4333059 \\
\hline Clearcut-windrow & 635523 & 4332744 & Clearcut-windrow & 637104 & 4332805 \\
\hline Hack-and-spray & 636120 & 4332752 & Hack-and-spray & 636272 & 4331673 \\
\hline
\end{tabular}

Appendix 4-D continued. 


\begin{tabular}{lcc|lcc}
\hline \multicolumn{5}{l}{ Study Site: Moncove Lake WMA Block 1 } & \multicolumn{4}{l}{ Study Site: Moncove Lake WMA Block 2 } \\
\hline Treatment & Easting & Northing & Treatment & Easting & Northing \\
\hline Control & 558117 & 4164267 & Control & 557497 & 4162767 \\
\hline Clearcut-and-leave & 558681 & 4164199 & Clearcut-and-leave & 557975 & 4163137 \\
\hline Clearcut-windrow & 558046 & 4163703 & Clearcut-windrow & 558293 & 4163388 \\
\hline Hack-and-spray & 558364 & 4163952 & Hack-and-spray & 557728 & 4163455 \\
\hline \multicolumn{7}{c}{} \\
\hline \multicolumn{7}{l}{ Study Site: Nathaniel } & Mountain WMA & \multicolumn{4}{l}{ Study Site: Sleepy Creek WMA } \\
\hline \multicolumn{7}{l}{ Treatment } & Easting & Northing & Treatment & Easting & Northing \\
\hline Control & 4335080 & 687238 & Control & 4366178 & 740837 \\
\hline Clearcut-and-leave & 4336274 & 688236 & Clearcut-and-leave & 4367675 & 741118 \\
\hline Clearcut-windrow & 4335374 & 687509 & Clearcut-windrow & 4366792 & 741037 \\
\hline Hack-and-spray & 4336453 & 687873 & Hack-and-spray & 4367203 & 741136 \\
\hline
\end{tabular}

\begin{tabular}{lcc}
\hline Study Site: Short Mountain WMA & \\
\hline Treatment & Easting & Northing \\
\hline Control & 4340869 & 701698 \\
\hline Clearcut-and-leave & 4340000 & 701378 \\
\hline Clearcut-windrow & 4339628 & 701198 \\
\hline Hack-and-spray & 4340521 & 701469 \\
\hline
\end{tabular}


Appendix 4-E. Salamander coverboard coordinates in cut-back borders. All coordinates are in NAD83, UTM Zone 17.

\begin{tabular}{|c|c|c|c|c|c|c|c|}
\hline \multicolumn{4}{|c|}{ Study Site: Beury Mountain WMA Block 1} & \multicolumn{4}{|c|}{ Study Site: Beury Mountain WMA Block 2} \\
\hline Treatment & Point & Easting & Northing & Treatment & Point & Easting & Northing \\
\hline \multirow[t]{4}{*}{ Control } & $\mathrm{A}$ & 499094 & 4199146 & Control & $\mathrm{A}$ & 500406 & 4198117 \\
\hline & B & 499094 & 4199071 & & B & 500474 & 4198085 \\
\hline & $\mathrm{C}$ & 499094 & 4198996 & & $\mathrm{C}$ & 500542 & 4198054 \\
\hline & $\mathrm{D}$ & 499094 & 4198921 & & $\mathrm{D}$ & 500610 & 4198022 \\
\hline \multirow[t]{4}{*}{$30 \mathrm{~m}, 4.5 \mathrm{~m}^{2} / \mathrm{ha}$} & A & 501786 & 4199803 & $30 \mathrm{~m}, 4.5 \mathrm{~m}^{2} / \mathrm{ha}$ & $\mathrm{A}$ & 499180 & 4198679 \\
\hline & B & 501859 & 4199784 & & B & 499249 & 4198649 \\
\hline & $\mathrm{C}$ & 501932 & 4199765 & & $\mathrm{C}$ & 499318 & 4198619 \\
\hline & $\mathrm{D}$ & 502004 & 4199746 & & $\mathrm{D}$ & 499387 & 4198589 \\
\hline \multirow[t]{4}{*}{$30 \mathrm{~m}, 14 \mathrm{~m}^{2} / \mathrm{ha}$} & $\mathrm{A}$ & 498530 & 4198775 & $30 \mathrm{~m}, 14 \mathrm{~m}^{2} / \mathrm{ha}$ & $\mathrm{A}$ & 497942 & 4199195 \\
\hline & B & 498456 & 4198763 & & B & 498010 & 4199164 \\
\hline & $\mathrm{C}$ & 498382 & 4198750 & & $\mathrm{C}$ & 498078 & 4199132 \\
\hline & $\mathrm{D}$ & 498308 & 4198738 & & $\mathrm{D}$ & 498146 & 4199100 \\
\hline \multirow[t]{4}{*}{$45 \mathrm{~m}, 4.5 \mathrm{~m}^{2} / \mathrm{ha}$} & $\mathrm{A}$ & 501115 & 4199985 & $45 \mathrm{~m}, 4.5 \mathrm{~m}^{2} / \mathrm{ha}$ & A & 499922 & 4198284 \\
\hline & B & 501188 & 4199967 & & B & 499990 & 4198253 \\
\hline & $\mathrm{C}$ & 501260 & 4199949 & & $\mathrm{C}$ & 500059 & 4198223 \\
\hline & $\mathrm{D}$ & 501333 & 4199932 & & $\mathrm{D}$ & 500127 & 4198192 \\
\hline \multirow[t]{4}{*}{$45 \mathrm{~m}, 14 \mathrm{~m}^{2} / \mathrm{ha}$} & $\mathrm{A}$ & 499647 & 4199855 & $45 \mathrm{~m}, 14 \mathrm{~m}^{2} / \mathrm{ha}$ & A & 500860 & 4197908 \\
\hline & B & 499718 & 4199877 & & B & 500929 & 4197877 \\
\hline & $\mathrm{C}$ & 499790 & 4199899 & & $\mathrm{C}$ & 500997 & 4197846 \\
\hline & $\mathrm{D}$ & 499862 & 4199920 & & $\mathrm{D}$ & 501065 & 4197815 \\
\hline \multicolumn{4}{|c|}{ Study Site: Lewis Wetzel WMA Block 1} & \multicolumn{4}{|c|}{ Study Site: Lewis Wetzel WMA Block 2} \\
\hline Treatment & Point & Easting & Northing & Treatment & Point & Easting & Northing \\
\hline \multirow[t]{4}{*}{ Control } & $\mathrm{A}$ & 529428 & 4374304 & Control & $\mathrm{A}$ & 529166 & 4372206 \\
\hline & $\mathrm{B}$ & 529460 & 4374237 & & $\mathrm{~B}$ & 529146 & 4372131 \\
\hline & $\mathrm{C}$ & 529493 & 4374175 & & $\mathrm{C}$ & 529140 & 4372053 \\
\hline & $\mathrm{D}$ & 529543 & 4374120 & & $\mathrm{D}$ & 529136 & 4371976 \\
\hline \multirow[t]{4}{*}{$30 \mathrm{~m}, 4.5 \mathrm{~m}^{2} / \mathrm{ha}$} & $\mathrm{A}$ & 529053 & 4373535 & $30 \mathrm{~m}, 4.5 \mathrm{~m}^{2} / \mathrm{ha}$ & A & 528369 & 4373265 \\
\hline & B & 529029 & 4373468 & & B & 528388 & 4373193 \\
\hline & $\mathrm{C}$ & 528991 & 4373397 & & $\mathrm{C}$ & 528435 & 4373126 \\
\hline & $\mathrm{D}$ & 528967 & 4373327 & & D & 528496 & 4373086 \\
\hline \multirow[t]{4}{*}{$30 \mathrm{~m}, 14 \mathrm{~m}^{2} / \mathrm{ha}$} & $\mathrm{A}$ & 530911 & 4372590 & $30 \mathrm{~m}, 14 \mathrm{~m}^{2} / \mathrm{ha}$ & $\mathrm{A}$ & 529264 & 4372692 \\
\hline & B & 530944 & 4372524 & & B & 529282 & 4372620 \\
\hline & $\mathrm{C}$ & 530950 & 4372453 & & $\mathrm{C}$ & 529300 & 4372531 \\
\hline & $\mathrm{D}$ & 530909 & 4372391 & & $\mathrm{D}$ & 529311 & 4372457 \\
\hline \multirow[t]{4}{*}{$45 \mathrm{~m}, 4.5 \mathrm{~m}^{2} / \mathrm{ha}$} & $\mathrm{A}$ & 528965 & 4374564 & $45 \mathrm{~m}, 4.5 \mathrm{~m}^{2} / \mathrm{ha}$ & A & 528697 & 4372867 \\
\hline & $\mathrm{B}$ & 528924 & 4374628 & & B & 528771 & 4372883 \\
\hline & $\mathrm{C}$ & 528889 & 4374701 & & $\mathrm{C}$ & 528852 & 4372884 \\
\hline & $\mathrm{D}$ & 528879 & 4374775 & & $\mathrm{D}$ & 528925 & 4372871 \\
\hline \multirow[t]{4}{*}{$45 \mathrm{~m}, 14 \mathrm{~m}^{2} / \mathrm{ha}$} & $\mathrm{A}$ & 529030 & 4374038 & $45 \mathrm{~m}, 14 \mathrm{~m}^{2} / \mathrm{ha}$ & $\mathrm{A}$ & 530446 & 4373521 \\
\hline & B & 529038 & 4373962 & & $\mathrm{~B}$ & 530506 & 4373474 \\
\hline & $\mathrm{C}$ & 529042 & 4373895 & & $\mathrm{C}$ & 530575 & 4373432 \\
\hline & $\mathrm{D}$ & 529039 & 4373820 & & $\mathrm{D}$ & 530631 & 4373390 \\
\hline
\end{tabular}


Appendix 4-E continued. 


\begin{tabular}{lccc|lccc}
\hline Treatment & Point & Easting & Northing & Treatment & Point & Easting & Northing \\
\hline Control & A & 635364 & 4331957 & Control & A & 634053 & 4331154 \\
& B & 635334 & 4332026 & & B & 634000 & 4331208 \\
& C & 635304 & 4332092 & & C & 633951 & 4331258 \\
& D & 635274 & 4332160 & & D & 633898 & 4331312 \\
\hline $30 \mathrm{~m}, 4.5 \mathrm{~m}^{2} / \mathrm{ha}$ & A & 636090 & 4330284 & $30 \mathrm{~m}, 4.5 \mathrm{~m}^{2} / \mathrm{ha}$ & $\mathrm{A}$ & 634680 & 4330606 \\
& B & 636060 & 4330353 & & $\mathrm{~B}$ & 634627 & 4330660 \\
& C & 636031 & 4330420 & & $\mathrm{C}$ & 634575 & 4330714 \\
& D & 636002 & 4330489 & & $\mathrm{D}$ & 634523 & 4330768 \\
\hline $30 \mathrm{~m}, 14 \mathrm{~m}^{2} / \mathrm{ha}$ & A & 635649 & 4331298 & $30 \mathrm{~m}, 14 \mathrm{~m}^{2} / \mathrm{ha}$ & $\mathrm{A}$ & 633983 & 4331303 \\
& B & 635620 & 4331366 & & $\mathrm{~B}$ & 633930 & 4331356 \\
& C & 635592 & 4331430 & & $\mathrm{C}$ & 633877 & 4331410 \\
& D & 635561 & 4331498 & & $\mathrm{D}$ & 633825 & 4331463 \\
\hline $45 \mathrm{~m}, 4.5 \mathrm{~m}^{2} / \mathrm{ha}$ & A & 636119 & 4330067 & $45 \mathrm{~m}, 4.5 \mathrm{~m}^{2} / \mathrm{ha}$ & $\mathrm{A}$ & 635001 & 4330215 \\
& B & 636088 & 4330134 & & $\mathrm{~B}$ & 634948 & 4330267 \\
& C & 636059 & 4330198 & & $\mathrm{C}$ & 634898 & 4330315 \\
& D & 636029 & 4330266 & & $\mathrm{D}$ & 634844 & 4330367 \\
\hline $45 \mathrm{~m}, 14 \mathrm{~m}^{2} / \mathrm{ha}$ & A & 635381 & 4331762 & $45 \mathrm{~m}, 14 \mathrm{~m}^{2} / \mathrm{ha}$ & $\mathrm{A}$ & 634419 & 4330792 \\
& B & 635352 & 4331830 & & $\mathrm{~B}$ & 634367 & 4330845 \\
& C & 635323 & 4331894 & & $\mathrm{C}$ & 634315 & 4330899 \\
& D & 635292 & 4331963 & & $\mathrm{D}$ & 634264 & 4330953 \\
\hline
\end{tabular}

\begin{tabular}{lccc}
\hline \multicolumn{4}{l}{ Study Site: Stonewall Jackson WMA } \\
\hline Treatment & Point & Easting & Northing \\
\hline Control & A & 549376 & 4312277 \\
& B & 549307 & 4312265 \\
& C & 549237 & 4312301 \\
& D & 549174 & 4312341 \\
\hline $30 \mathrm{~m}, 4.5 \mathrm{~m}^{2} / \mathrm{ha}$ & A & 543414 & 4306896 \\
& B & 543401 & 4306962 \\
& C & 543335 & 4306940 \\
& D & 543307 & 4306993 \\
\hline $30 \mathrm{~m}, 14 \mathrm{~m}^{2} / \mathrm{ha}$ & A & 543703 & 4306143 \\
& B & 543754 & 4306195 \\
& C & 543814 & 4306280 \\
& D & 543754 & 4306303 \\
\hline $45 \mathrm{~m}, 4.5 \mathrm{~m}^{2} / \mathrm{ha}$ & A & 544223 & 4308086 \\
& B & 544147 & 4308108 \\
& C & 544059 & 4308133 \\
& D & 543984 & 4308149 \\
\hline $45 \mathrm{~m}, 14 \mathrm{~m}^{2} / \mathrm{ha}$ & A & 544725 & 4306627 \\
& B & 544698 & 4306569 \\
& C & 544745 & 4306540 \\
& D & 544813 & 4306510 \\
\hline
\end{tabular}


Appendix 4-F. Salamander coverboard coordinates in regeneration stands. All coordinates are in NAD83, UTM Zone 17.

\begin{tabular}{lccc|lccc}
\hline \multicolumn{3}{l}{ Study Site: } & Beury Mountain WMA Block 1 & \multicolumn{4}{l}{ Study Site: } \\
\hline Treatment & Point & Easting & Northing & Treatment & Point & Easting & Northing \\
\hline Control & A & 500758 & 4199491 & Control & A & 501259 & 4198730 \\
& B & 500841 & 4199489 & & B & 501338 & 4198730 \\
& C & 500842 & 4199364 & & C & 501340 & 4198605 \\
& D & 500759 & 4199364 & & D & 501257 & 4198605 \\
\hline Hack-and- & A & 499592 & 4200252 & Hack-and- & A & 501590 & 4198476 \\
Spray & B & 499675 & 4200252 & Spray & B & 501675 & 4198476 \\
& C & 499675 & 4200125 & & C & 501673 & 4198351 \\
& D & 499591 & 4200125 & & D & 501590 & 4198349 \\
\hline
\end{tabular}

\begin{tabular}{|c|c|c|c|c|c|c|c|}
\hline \multicolumn{4}{|c|}{ Study Site: Beury Mountain WMA Block 3} & \multicolumn{4}{|c|}{ Study Site: Beury Mountain WMA Block 4} \\
\hline Treatment & Point & Easting & Northing & Treatment & Point & Easting & Northing \\
\hline \multirow[t]{4}{*}{ Control } & $\mathrm{A}$ & 497594 & 4197970 & \multirow[t]{4}{*}{ Control } & A & 496921 & 4197723 \\
\hline & B & 497678 & 4197969 & & B & 497007 & 4197721 \\
\hline & $\mathrm{C}$ & 497678 & 4197842 & & $\mathrm{C}$ & 497007 & 4197593 \\
\hline & $\mathrm{D}$ & 497593 & 4197841 & & $\mathrm{D}$ & 496922 & 4197593 \\
\hline \multirow{4}{*}{$\begin{array}{l}\text { Hack-and- } \\
\text { Spray }\end{array}$} & A & 498422 & 4197467 & \multirow{4}{*}{$\begin{array}{l}\text { Hack-and- } \\
\text { Spray }\end{array}$} & A & 496922 & 4198230 \\
\hline & B & 498508 & 4197464 & & B & 497007 & 4198230 \\
\hline & $\mathrm{C}$ & 498507 & 4197338 & & $\mathrm{C}$ & 497007 & 4198100 \\
\hline & D & 498424 & 4197337 & & D & 496922 & 4198101 \\
\hline
\end{tabular}

\begin{tabular}{lccc}
\hline \multicolumn{3}{c}{ Study Site: } & \multicolumn{3}{c}{ Beury Mountain WMA Block 5 } \\
\hline Treatment & Point & Easting & Northing \\
\hline Control & A & 503755 & 4199239 \\
& B & 503838 & 4199239 \\
& C & 503839 & 4199112 \\
& D & 503755 & 4199112 \\
\hline Hack-and- & A & 503755 & 4199747 \\
Spray & B & 503840 & 4199744 \\
& C & 503838 & 4199618 \\
& D & 503754 & 4199616 \\
\hline
\end{tabular}

